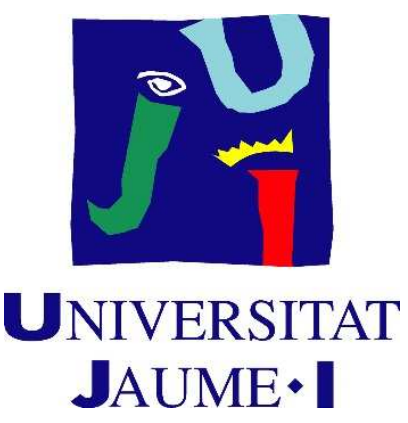

UNIVERSITAT JAUME I DE CASTELLÓ

ESCUELA SUPERIOR DE TECNOLOGÍA Y CIENCIAS EXPERIMENTALES

Departamento de Ingeniería Química

Programa de doctorado en Tecnologías Industriales, Materiales y Edificación

\title{
ANÁLISIS DE LA INFLUENCIA DE LAS CARACTERÍSTICAS DE LOS MATERIALES PULVERULENTOS SOBRE SU PODER DE EMISIÓN DE POLVO
}

\author{
MEMORIA \\ que para optar al grado de \\ Doctora en Ingeniería Química presenta \\ ANA LÓPEZ LILAO
}

Castellón, Junio 2017 

Eliseo Monfort Gimeno, Catedrático de Ingeniería Química de la Universitat JaUME I Y JOSÉ GUSTAVO MaLlol Gasch, DOCTOR EN CIENCIAS QUÍMICAS DE LA UNIVERSITAT JAUME I.

CERTIFICAN: Que Dña. Ana López Lilao ha realizado bajo su dirección, en los laboratorios del Instituto de Tecnología Cerámica, dentro del programa de doctorado en Tecnologías Industriales, Materiales y Edificación de la Universitat Jaume I de Castellón, el trabajo que bajo el título "Análisis de la influencia de las características de los materiales pulverulentos sobre su poder de emisión de polvo" presenta en esta Memoria y que constituye su tesis para optar al grado de Doctora en Ingeniería Química.

Y para que conste a los efectos oportunos, firman el presente certificado en Castellón, a 15 de junio 2017.

Eliseo Monfort Gimeno

Catedrático de Ingeniería Química
José Gustavo Mallol Gasch

Doctor en Ciencias Químicas 

Este estudio ha sido financiado por el Ministerio de Ciencia e Innovación, el Ministerio de Economía y Competitividad y el Fondo Europeo de desarrollo Regional a través de dos proyectos de Investigación: 1) Cuantificación y caracterización de emisiones difusas de partículas en la gestión y transporte de materiales pulverulentos (CGL2009-14680-C02) y 2) Predicción de emisiones y exposición a partículas micro y nanométricas en ambientes industriales (CGL2015-66777-C2).

Durante el desarrollo de la tesis, la doctoranda ha disfrutado de una beca predoctoral (ACIF/2012/111) otorgada por la Generalitat Valenciana en el marco del Programa VALi+d para investigadores en formación. 

A mis padres y a Jordi 

AGRADECIMIENTOS 

El presente trabajo se ha desarrollado en los laboratorios del Instituto de Tecnología Cerámica fruto del concierto entre la Universitat Jaume I de Castellón y la Asociación de Investigación de las Industrias Cerámicas, por lo que deseo hacer patente mi agradecimiento a ambas instituciones por poner a mi disposición los medios humanos y materiales necesarios para su realización.

Por otro lado, me gustaría mostrar mi agradecimiento a todas aquellas personas que han colaborado directa o indirectamente en la realización del presente trabajo.

En primer lugar, quiero agradecer a mis directores, el Prof. Eliseo Monfort y el Dr. José Gustavo Mallol la confianza depositada en este proyecto y en mí desde el inicio de la tesis doctoral. Al Prof. Eliseo Monfort por creer en mí, por apoyar mis ideas, por saber siempre cuál era el camino a seguir y por estar siempre allanando el camino con sus conocimientos, en definitiva, por permitir que la realización de este trabajo haya sido posible. Al Dr. José Gustavo Mallol porque no dudó en escucharme y en interesarse por este proyecto, por sus siempre acertadas aportaciones y por, al igual que Eliseo, confiar en este proyecto y en mi capacidad para llevarlo a cabo.

A mis compañeros de unidad, Raúl Moliner, Teresa Ros y Salvador Gomar por estar siempre dispuestos a ayudar y por preguntar siempre cómo va, a Tica Sanfelix por enseñarme tanto sobre emisiones difusas, a Fabiola Rueda por enseñarme a manejar los equipos y a Alberto Escrig por dedicar siempre el tiempo necesario a escuchar mis dudas y ayudarme a resolverlas con esa facilidad que le hace único.

A Irina Celades por su apoyo en el inicio de esta aventura y por responder siempre a cualquier duda.

A Salva Ferrer, Ana Mezquita y Sara Estupiñá por crear un buen ambiente de trabajo, por ayudarme con los temas de formato y por apoyarme siempre.

A Mํㅡㄹ Jesús lbáñez por introducirme en el mundo de la salud laboral y por estar siempre dispuesta a ayudar.

A Ma José Orts y Ana Gozalbo por su trabajo con el microscopio, por estar siempre dispuestas a ayudar y por preocuparse siempre por cómo lo llevo.

A Marta Lavall, Marine Bruzi, Remy Bolle y Manon Juárez por colaborar en las tareas de caracterización de los materiales pulverulentos.

A Carmen Segarra por ayudarme siempre que ha sido necesario en planta piloto.

A Javier Montolio y a Lilian Foucard por estar siempre dispuestos a ayudar cuando algo decide que no quiere funcionar.

A Miguel Aguilella por enseñarme los ensayos de fluidez y hacerlo siempre con una sonrisa. 
A Paqui Quereda, Ma José Vicente, Rosa Pérez y Carmen Moreda por ayudarme con la obtención y preparación de los materiales. A Pilar Gómez, Jessica Gilabert, Julia Toledo y Eulalia Zumaquero por la colaboración en la caracterización de muestras y la obtención y tratamiento de las isotermas.

A David Lores por ayudarme con la maquetación de la tesis y solucionar los mil y un problemas informáticos que he tenido durante todo este tiempo.

Al instituto IGF (Alemania) y concretamente a Dirk Dahman por colaborar en la puesta a punto y la intercomparación de equipos.

Tampoco puedo olvidarme de aquellas personas que, aunque no han colaborado en los aspectos técnicos me han apoyado, soportado y animado durante todo este tiempo.

A Pablo Carpio, Sonia Sales, Eugeni Cañas y Victor Carnicer por su amistad y por esas conversaciones durante las comidas que te permiten desahogarte y afrontar la tarde con una sonrisa.

A Susana Pallares, aunque no ha estado durante la realización de la tesis, estuvo durante sus primeros pasos y creyó en este proyecto desde el primer momento. Por su amistad, por hacer el trabajo tan agradable y por preguntarme cada dos por tres cómo lo llevo aun en la distancia.

A mis amigos, especialmente a $\mathrm{M}^{\mathrm{a}}$ José y Lorena por ser como son, por entenderme y apoyarme como nadie, por confiar en mi desde hace muchos años y repetirme mil y una veces que yo llegaría tan lejos como quisiera.

A Isabel y Vicente por quererme, por valorar mi trabajo y por apoyarme siempre. A Jordi por su comprensión, por realizar la portada de la presente tesis, pero sobre todo por soportarme, entenderme y escucharme durante todo este tiempo, incluso cuando mi único tema de conversación era la formación de capas monomoleculares de agua sobre la superficie de arcillas. Gracias por quererme tanto.

Gracias a mi hermano y mi cuñada por preocuparse siempre por cómo lo llevo y por apoyarme en todo. A mi sobrino que, aun sin ser consciente de ello, con sus tia has acabat ja? véns a jugar? y sobre todo con sus risas y abrazos me ha ayudado a desconectar y me ha dado fuerzas en momentos de debilidad.

Finalmente, gracias a mis padres por permitir que tuviera una educación y enseñarme a valorar lo que de verdad importa, por quererme, por mostrar su orgullo por mí y por no permitir que me hundiera en los malos momentos, por valorar siempre mi esfuerzo y mis resultados, por hacerme sentir que era capaz de llevar a cabo este proyecto y por quererme como nadie.

Quiero disculparme y mostrar mi agradecimiento a aquellas personas que hayan colaborado en la realización del presente trabajo y que haya olvidado nombrar.

A todos, mi más sincero agradecimiento. 
$\overline{\text { ÍNDICE }}$ 

ÍNDICE

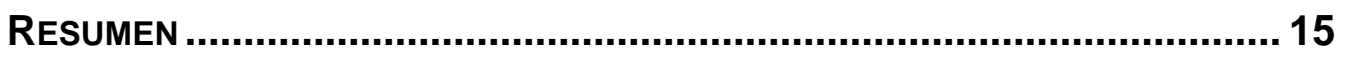

ABSTRACT

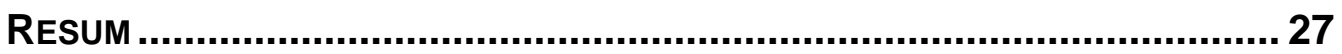

BLOQUE I: INTRODUCCIÓN, OBJETIVOS Y ESTRUCTURA ............ 33

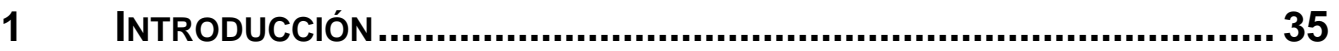

$1.1 \quad$ Material particulado atmosférico (PM) …..................................37

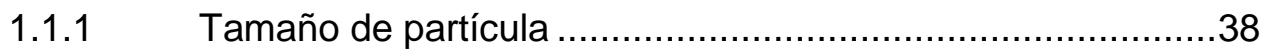

1.1.2 Morfología de las partículas ...............................................44

1.1.3 Composición química del PM ..........................................45

$1.2 \quad$ Emisiones industriales de PM .................................................49

1.2.1 Emisiones difusas de PM .............................................51

1.2.2 Medidas preventivas y/o correctoras ..................................53

1.2.3 Control industrial de las emisiones difusas de PM ...............59

1.3 Efectos del PM sobre la salud ..............................................63

1.3.1 Contaminación atmosférica...............................................63

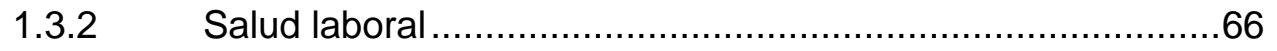

$1.4 \quad$ Legislación en materia de PM ……...................................... 70

1.4.1 Contaminación atmosférica................................................70

1.4.1.1 Introducción al marco normativo .............................................. 70

1.4.1.2 Normativa de calidad de aire en referencia al PM ...................... 71

1.4.2 Emisiones industriales de PM .......................................74

1.4.2.1 Introducción al marco normativo .................................................... 74

1.4.2.2 Normativa en emisiones difusas de PM....................................... 75

1.4.3 Riegos laborales ....................................................... 77

1.4.3.1 Introducción al marco normativo general ................................... 77

1.4.3.2 Marco normativo en materia de exposición laboral a PM .............. 78

$1.5 \quad$ Poder de emisión de polvo .......................................................79

1.5.1 Equipos para la medición del poder de emisión de polvo de los materiales pulverulentos .............................................................

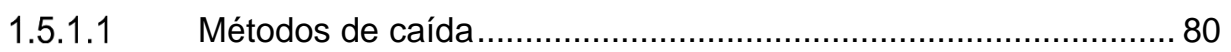

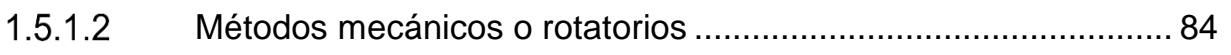

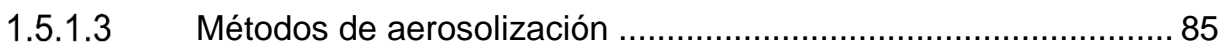




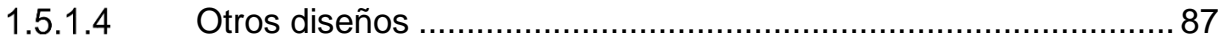

1.5.2 Parámetros que influyen sobre la capacidad de generación de

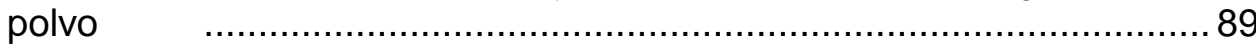

1.5.2.1 Distribución de tamaño de partícula..........................................91

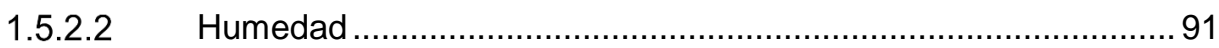

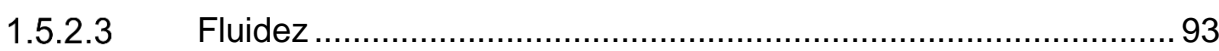

1.5.2.4 Forma y superficie especifica .................................................. 93

1.5.3 Revisión de modelos de predicción del poder de emisión de

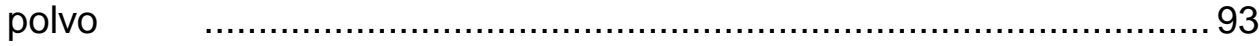

1.5.4 Modelo propuesto para la predicción del poder de emisión de polvo

1.5.5 Poder de emisión de polvo y prevención de riesgos laborales .......................................................................................97

2 OBJETIVOS Y ESTRUCTURA ..................................................... 103

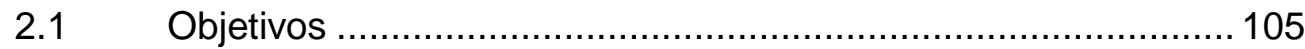

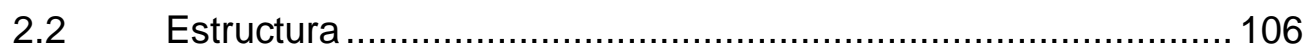

BLOQUE II: MATERIALES Y METODOLOGÍA ...............................109

3 MATERIALES Y METOdOLOGÍA .................................................111

3.1 Selección de materias primas ............................................. 113

3.2 Muestras objeto de estudio ................................................. 114

3.2.1 Obtención de fracciones granulométricas .......................... 114

3.2.1.1 Método de separación vía seca ………................................... 114

3.2.1.2 Métodos de separación vía húmeda.........................................115

3.2.2 Obtención de muestras a distintas humedades .................. 117

3.3 Caracterización de los materiales............................................ 117

3.3.1 Fluidez................................................................... 117

3.3.2 Humedad............................................................. 119

3.3.3 Densidad real del sólido .............................................. 120

3.3.4 Distribución de tamaño de partícula y/o aglomerado .......... 121

3.3.5 Difracción láser vía húmeda .......................................... 121

3.3.6 Sedimentación gravitacional .......................................... 123

3.3.7 Determinación de la superficie especifica......................... 126

3.3.8 Forma de las partículas ................................................ 127

3.3.8.1 Determinación del "Aspect ratio" (AR) .................................... 127

3.3.8.2 Obtención de imágenes MEB...................................................... 129

3.3.9 Determinación del poder de emisión de polvo .................... 130 
4 Resultados y discusión.

4.1 Evaluación preliminar de la influencia de las variables del material sobre su poder de emisión de polvo.....

4.2 Evaluación de la influencia del tamaño medio de partícula sobre el poder de emisión de polvo

4.3 Evaluación de la influencia de la humedad sobre el poder de emisión de polvo

4.4 Modelo de predicción del poder de emisión de polvo de materiales pulverulentos.

4.5 Medidas de reducción del poder de emisión de polvo de los materiales pulverulentos

BLOQUE IV: CONCLUSIONES, LÍNEAS FUTURAS Y DIFUSIÓN DE

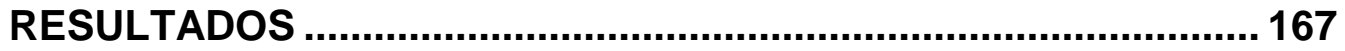

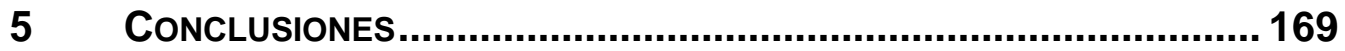

$6 \quad$ LíNEAS FUTURAS ..................................................................... 177

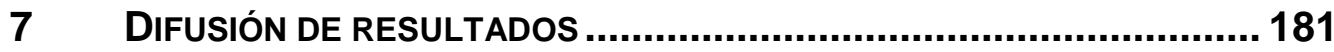

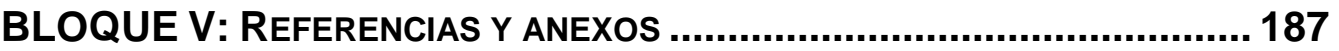

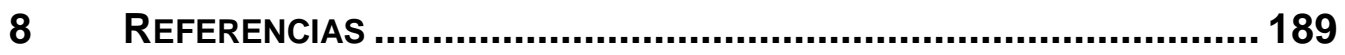

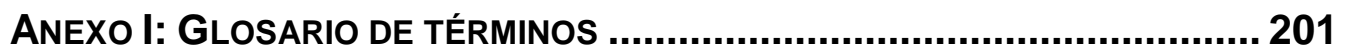

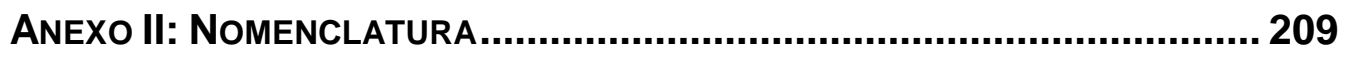

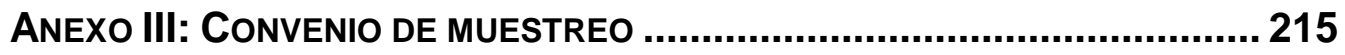

ANEXo IV: CaRACTERIZACIÓN FísICA DE LOS MATERIALES....................... 219

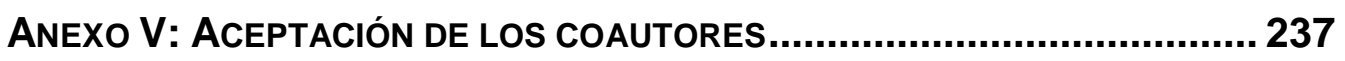




A nivel nacional, tal y como se indica en el Plan Nacional de Mejora de la Calidad de Aire (en adelante PNMCA), ciertas zonas de España presentan una problemática asociada a superaciones de los valores límite de material particulado (en adelante PM). Estas superaciones de los valores límite, dan lugar a que sea necesario un control y reducción de las emisiones de PM para evitar o reducir los efectos nocivos que puede tener sobre la salud, el clima, los ecosistemas, etc. En este sentido, entre las fuentes de PM identificadas como mayoritarias, una de las más significativas es la industria. De hecho, las emisiones al aire constituyen uno de los mayores impactos medioambientales de muchas actividades industriales, tanto por focos canalizados como difusos, siendo en procesos industriales, que llevan asociadas actividades de manipulación de materiales pulverulentos a granel, las partículas sólidas emitidas los contaminantes atmosféricos más significativos.

Cabe destacar que, en cualquier actividad industrial en la que se genere PM, adicionalmente a la problemática asociada a la emisión del mismo, existe un riesgo por exposición a PM en los ambientes laborales. Por este motivo, la legislación sobre salud laboral incide en la necesidad de limitar los riesgos inherentes a la exposición a PM, principalmente por inhalación, de los trabajadores en los ambientes laborales.

En este sentido, para establecer medidas preventivas que permitan reducir el impacto asociado a la generación de emisiones de PM, se considera fundamental conocer los mecanismos de generación de PM cuando se procesan materiales pulverulentos. No obstante, en la bibliografía consultada, se ha observado que las principales debilidades en los estudios referentes a la tendencia de los materiales pulverulentos a generar polvo cuando son manipulados (poder de emisión de polvo) son: 1) la falta de coherencia, entre los resultados y 2) los modelos de predicción del poder de emisión de polvo son mayoritariamente modelos estadísticos que dependen de multitud de variables del material y, por tanto, su uso implica la realización de ensayos adicionales que pueden suponer incluso más tiempo que la determinación del poder de emisión de polvo en sí mismo.

Por ello, en la primera parte del trabajo, se ha llevado a cabo una evaluación preliminar de la influencia de variables de más de 30 materiales pulverulentos empleados en la industria cerámica e industrias afines sobre su poder de emisión de polvo. Este estudio muestra que la distribución de tamaño de partícula, la fluidez, la superficie específica y la humedad son parámetros clave en el estudio del poder de emisión de polvo.

Estos resultados fueron la base para llevar a cabo una segunda fase en la que se realizó un estudio específico sobre el efecto del tamaño, fluidez y superficie específica sobre el poder de emisión de polvo de muestras de caolín y cuarzo. En este sentido, con la finalidad de cubrir un amplio rango de tamaño de partícula, se emplearon tanto muestras comerciales como muestras preparadas a escala de laboratorio mediante distintas técnicas de separación granulométrica (hidrociclones, tamizado vía húmeda, etc.). A partir de una 
exhaustiva caracterización de las muestras, se ha observado que la influencia de las variables del material sobre su poder de emisión de polvo depende del rango de tamaño evaluado. Concretamente, en las muestras objeto de estudio, se ha observado que, para tamaños inferiores a 25 micrómetros, incrementos en la fluidez y tamaño, así como descensos en la superficie especifica suponen un incremento en el poder de emisión de polvo mientras que para tamaños superiores se observa el efecto contrario. Esto podría ser debido al predominio de las fuerzas superficiales en el primer caso (tamaños inferiores a 25 micrómetros) mientras que para tamaños superiores predominan las fuerzas volumétricas. Por tanto, en contra de lo que cabría esperar, las muestras más finas no han resultado ser las que presentan un mayor poder de emisión de polvo. De hecho, el poder de emisión de polvo presenta un máximo a contenidos intermedios de partículas finas.

En una tercera fase, se evaluó el efecto de la humedad sobre el poder de emisión de polvo de materiales higroscópicos (arcillas y caolines). Este estudio ha mostrado que el efecto de la humedad sobre el poder de emisión de polvo es de elevada complejidad ya que el efecto producido depende de si el agua actúa como ligante o como lubricante. En este sentido, un estudio conjunto de los mecanismos de hidratación, la fluidez del lecho y el grado de saturación de la muestra ha permitido observar que: 1) durante la adsorción de una película de agua fuertemente atraída a la superficie de la partícula (2-3 capas monomoleculares), se incrementan las fuerzas de unión entre partículas (incrementa la cohesión) y, por tanto, disminuye el poder de emisión de polvo, 2) una vez se han adsorbido las capas de agua fuertemente atraídas por la partícula, continua la adsorción de capas de agua. No obstante, la atracción entre partículas y la atracción partícula-agua es débil y, por tanto, el agua actúa como lubricante, 3) Sin embargo, cuando deja de existir una fuerza de atracción partícula-agua, el agua no tiene una posición preferente (no es atraída por la superficie de la partícula). Por este motivo, actúa como ligante entre grupos de partículas (aumentando la cohesión y, por tanto, disminuyendo el poder de emisión de polvo), 4) Posteriormente, a medida que se incrementa el contenido en humedad, se favorece la granulación de la muestra y, por tanto, se produce un nuevo incremento de la fluidez que pude suponer un incremento en el poder de emisión de polvo si existen partículas susceptibles de generar polvo (presencia de finos) o si el granulo es susceptible de desmenuzarse durante la manipulación (gránulos friables), 5) Finalmente, mayores contenidos en agua producen una disminución en el poder de emisión de polvo hasta el límite plástico, contenido en humedad en el que el poder de emisión de polvo puede considerarse despreciable.

Atendiendo a estos mecanismos, se ha desarrollado una metodología que permite estimar los puntos críticos (en referencia al poder de emisión de polvo) en base a la determinación del grado de saturación de la muestra y de su isoterma de adsorción de agua.

En una cuarta fase del estudio, atendiendo a los resultados descritos previamente, se desarrolló un modelo de predicción del poder de emisión de 
polvo que se fundamenta en la hipótesis de que el poder de emisión de polvo o emisión absoluta (ratio entre la masa de polvo generado de tamaño i y la masa de material ensayado) depende fundamentalmente de dos factores: el contenido en finos del material y la facilidad para liberar esos finos o emisión relativa (ratio entre la masa de polvo generado de tamaño i y la masa de partículas de tamaño i en el material ensayado). En este sentido, a partir de un análisis detallado de la influencia de las variables del material sobre su facilidad de liberación de polvo, se ha observado que, a mayor tamaño medio de partícula, mayor es la facilidad de liberación de polvo (mayor emisión relativa). Por tanto, un material grueso presentará mayor facilidad de liberación de polvo que un material compuesto en su totalidad por partículas finas. No obstante, esto no necesariamente implica que su poder de emisión de polvo sea mayor ya que eso va a depender también del contenido en finos del material. El modelo desarrollado proporciona muy buenos resultados para materiales secos y aproximadamente esféricos. Además, cabe destacar que el modelo desarrollado se basa sólo en datos de la distribución de tamaño de partícula y, por tanto, no requiere ensayos adicionales para la estimación del poder de emisión de polvo.

En la última fase del estudio, se evaluó el poder de emisión de polvo de cinco muestras procedentes de las distintas etapas del proceso de preparación y acondicionado de materias primas para la fabricación de los soportes de las baldosas cerámicas. Este proceso consta de las siguientes etapas: mezclado de las materias primas, homogeneización y dosificación de las mismas, trituración (muestra 1), molienda vía seca (muestra 2) o vía húmeda y acondicionado de la muestra, en referencia a su granulometría y humedad (5.5$6.5 \%$ ) para la operación de prensado. Este acondicionado puede realizarse por humectación de la mezcla molida vía seca (muestra 3), granulación de la misma (muestra 4) o atomización de la muestra molida vía húmeda (muestra 5).

En base a los resultados obtenidos, se ha observado que la muestra procedente de la molienda vía seca (muestra 2) es el caso más desfavorable (desde el punto de vista de la generación de emisiones difusas de PM). Por otro lado, la humectación de la muestra (muestra 3, humedad: 6.5\%) y la granulación de la misma (muestra 4) suponen una reducción del poder de emisión de polvo de más de un $75 \%$. Finalmente, el secado por atomización genera un material granulado (muestra 5) que da lugar a una reducción del poder de emisión de polvo superior al 95\%. Por este motivo, tanto la humectación como la granulación, y sobre todo el secado por atomización pueden ser consideradas como medidas eficaces para la reducción del poder de emisión de polvo.

Finalmente, de forma general, los resultados obtenidos y el modelo desarrollado, en base a un exhaustivo estudio de la influencia de las variables de los materiales pulverulentos sobre su poder de emisión de polvo, resultan ser muy novedosos y de gran interés por la aplicabilidad de los resultados obtenidos en ámbitos muy diferentes. A continuación, se destacan algunos de estos aspectos, sin pretender realizar un listado exhaustivo: 
- Científico-técnico: se ha avanzado en el conocimiento de los mecanismos de generación de PM mediante un estudio exhaustivo de la influencia de las variables de los materiales pulverulentos sobre su poder de emisión de polvo. Por otro lado, se ha desarrollado un modelo que permite estimar el poder de emisión de polvo de los materiales pulverulentos, en base a información relativa a su distribución de tamaño de partícula. Además, este modelo permite justificar la falta de uniformidad detectada en estudios previos sobre el poder de emisión de polvo ya que, tal y como se ha observado, al aumentar el tamaño y la fluidez, así como al disminuir la superficie específica aumenta la facilidad de liberación de polvo, pero eso no necesariamente implica un incremento del poder de emisión de polvo.

- Administraciones Públicas: los resultados pueden ser de gran utilidad para desarrollar una normativa futura teniendo en cuenta las condiciones óptimas de presentación de las distintas materias primas. Por otro lado, en vista a los resultados obtenidos, se podría proponer una metodología de control basada en la determinación periódica del poder de emisión de polvo de los materiales procesados.

- Industrial: el estudio del poder de emisión de polvo de las materias primas y de la influencia que presentan sus propiedades sobre el mismo, así como el modelo desarrollado permiten obtener información referente al riesgo potencial asociado a la manipulación de los distintos materiales pulverulentos y, por tanto, aplicar criterios para la selección de materias primas, implantación de medidas específicas, etiquetado de productos, etc. 
ABSTRACT 

At country level, as indicated in the Air quality improvement national plan (hereafter PNMCA), certain areas in Spain suffer a problem associated with surpassing the limit values to particulate matter (hereafter PM). This limit value surpassing, makes necessary to control and reduce the PM emissions to avoid or reduce the hazardous effects on human health, climate, ecosystems, etc. In this regard, between the identified main sources of PM, one of the main contributors is the industry. In fact, the emissions to the air are one of the main impacts to environment from the industrial activities, not only from channelled emissions but also from diffuse emissions, being the solid particles emitted in the industrial processes that involve the manipulation of dusty bulk materials, the most important atmospheric pollutants.

It should be noted that, in any industrial activity where PM is generated, additionally to the problem associated with its emission, exists a risk due to the exposition to PM at workplace. For this reason, the legislation about occupational hygiene falls on the necessity to limit the risks inherent to the exposure to PM, mainly by inhalation, by the workers at their workplace.

For this reason, to establish preventive measures that allow reducing the impact associated to the generation of PM emissions, may be deemed essential to know the PM generation mechanisms when powdered materials are handled. However, in the reviewed literature, the main observed faults in the studies, regarding the dustiness of bulk materials when handled, where: 1) lack of coherence, due to apparently contradictory results, and 2) the prediction models for dustiness are mainly statistic and they depend upon a multitude of material parameters that can even require larger time than the dustiness determination test itself.

In this regard, the first part of this study, has been a preliminary assessment of the influence of the material parameters, from more than 30 powdered materials used in the ceramic and related industries, on their dustiness. This study shows that the particle size distribution, specific surface area and moisture are key factors to the study of the bulk material dustiness.

These results are the basics for a second stage where a specific study about the effect of the size, flowability and specific surface area on the dustiness of kaolin and quarts samples. In this regard, in order to encompass a wide range of particle size, both commercial samples, as well as, laboratory prepared samples with different granulometric separation techniques (hydrocyclone, wet or dry sieving, etc.) were used. After an in-depth characterisation of the samples, it has been observed that the influence of the parameters on its dustiness depends on the size range evaluated. Specifically, the samples studied that had sizes smaller than 25 micrometres showed that rises in flowability and size, or reductions in specific surface area, entail an increase in the material dustiness, while for higher sizes the opposite effect is observed. This may be due to the dominance of the surface forces for the smaller sizes while with the higher sizes the volumetric forces dominate. Therefore, the finest 
samples do not present the highest dustiness. In fact, a maximum is observed at intermediate sizes.

In a third stage, the effect of moisture on the dustiness of hygroscopic bulk materials was evaluated. This study showed that the effect of moisture on the dustiness of a sample is quite complex due to the different effects produced depending on the water acting as glue or lubricant. In this sense, a combined study of the hydration mechanisms, flowability, and the saturation degree of the sample has allowed to observe that 1) during the adsorption of a film of water strongly attracted by the surface of the particle (2-3 monomolecular layers), the union forces between particles increase (increased cohesion) and therefore dustiness decreases. 2) Once the strongly attracted layers have been adsorbed, the adsorption of water continues. However, the attraction between particles and between particles and water is weak, and therefore water acts as a lubricant 3) When the attraction forces between water and particles disappear, water does not have a predisposed position (it is not attracted by the surface). Due to this, water acts as a glue between groups of particles (increasing cohesion and therefore decreasing dustiness). 4) Afterwards, as the water content increased, the granulation is favoured and therefore an increase on flowability is produced again that can increment dustiness if there are particles susceptible to generate dust (fine presence) or if the grain is susceptible to be crumbled during the handling. 5) Finally, at higher water contents produce a reduction of the dustiness up to the plastic limit, where the dustiness can be considered negligible.

Taking into account these mechanisms, a methodology has been developed that allows estimating the critic points (in accordance to the dustiness), based on the saturation degree of the sample and the water adsorption isotherm.

In a fourth stage of the study, attending to the results described previously, a dustiness prediction model was developed which is founded on the hypothesis that the dustiness or absolute emission (ratio between generated dust mass from a size i and the tested material mass) depends mainly on two factors: the fine content and the easiness to release these fine particles or relative emission (ratio between the mass of dust with size $i$ and the mass of particles of size $i$ in the material tested). In this sense, from the detailed analysis of the influence of the material variables on the easiness to release dust, it has been observed that as medium particle size increases, higher is the easiness to release dust (higher relative emission). Therefore, a coarse material will have a higher easiness to release dust than a material composed on its totality of fine particles. However, this does not necessarily mean that its dustiness will be higher due to the fact that it will also depend on the fine content of the material. The developed model returns very good results for dry materials and approximately spherical. Additionally, it should be highlighted that the developed model only relies in a few data of the particle size distribution and therefore does not require additional test to estimate the material dustiness. 
At the last stage of the study, the dustiness of five samples from the different stages of the manufacturing process of ceramic body tiles. This process consists of the following stages: raw material mixing, homogenization and dosage, grinding (sample 1), dry milling (sample 2) or wet milling and the conditioning of the samples, its granulometry and moisture (5.5-6.5\%), for the pressing operation. This conditioning can take place by wetting of the mix from a dry milling process (sample 3 ), or by granulation from the dry milling sample (sample 4) or by the spray-drying from a wet milling process sample (sample 5).

Based on the obtained results, has been observed that the sample from the dry milling process (sample 2) is the worst case (from the generation of diffuse emissions point of view). On the other hand, the wetting of the sample (sample 3 , moisture: $6.5 \%$ ) and the granulation (sample 4) of the same dry sample, entail a reduction of the dustiness over a $75 \%$. Finally, the spray-drying process generates a granulated material (sample 5) that gives birth to a reduction in the dustiness over a $95 \%$. In this regard, the wetting, granulation and especially spray drying of the samples can be considered as efficient preventive measures to reduce dustiness.

To sum up, the obtained results and the developed model, based on an exhaustive study about the influence of the raw material parameters on its dustiness, are very interesting and innovative due to its applicability in different ambits. Next there are some of the outstanding aspects, but without doing an exhaustive list:

- Scientific-technical: A progress in the knowledge of the mechanisms of PM generation, through an exhaustive study of the influence of the material parameters on their dustiness, has been achieved. On the other hand, a model to predict the dustiness of bulk materials has been developed based on the information from the particle size distribution. Additionally, the model allows justifying the lack of uniformity found in the previous studies about the dustiness, as observed, when increasing size and flowability, or decrease the specific surface, the easiness to release dust increases but does not necessarily mean an increase in the dustiness.

- Public administrations: The results may be very helpful to develop future legislation considering the optimum presentation form of the different bulk materials. On the other hand, based on the results, it could be proposed a control methodology based on the periodic determination of the processed materials dustiness.

- Industrial: The study raw materials dustiness and the influence of their properties on dustiness, as the developed model allow to obtain information in reference with the potential risk associated with the manipulation of the different powdered materials, and therefore, apply selection criteria for the raw materials, the application of specific measures, the labelling of products, etc. 

RESUM 

A nivell nacional, tal i com s'indica en el Pla Nacional de millora de la qualitat del aire (en endavant PNMCA), certes zones d'Espanya presenten una problemàtica associada a superacions dels valors límit de material particulat (en endavant PM). Aquestes superacions dels valors límit, donen lloc a que sigui necessari un control i reducció de les emissions de PM per a evitar o reduir els efectes nocius que poden tenir sobre la salut, el clima, els ecosistemes, etc. En aquest sentit, entre les fonts de PM identificades com a majoritàries, una de les més significatives es l'industria. De fet, les emissions al aire constitueixen un dels majors impactes mediambientals de moltes activitats industrials, tant per focus canalitzats com difusos, sent en processos industrials, que porten associades activitats de manipulació de materials pulverulents a granel, les partícules sòlides emeses els contaminants atmosfèrics més significatius.

Cal destacar que, en qualsevol activitat industrial en la que es generi PM, addicionalment a la problemàtica associada a l'emissió del mateix, existeix un risc per exposició a PM en els ambients laborals. Per aquest motiu, la legislació sobre la salut laboral incideix en la necessitat de limitar els riscos inherents a la exposició a PM, principalment per inhalació dels treballadors en els ambients laborals.

Per aquest motiu, per establir mesures preventives que permetin reduir el impacte associat a la generació de emissions de PM, es considera essencial conèixer els mecanismes de generació de PM quan es processen materials pulverulents. No obstant, en la bibliografia consultada, s'ha observat que les principals debilitats en els estudis referents al poder d'emissió de pols dels materials pulverulents (tendència dels materials de generar pols quan son manipulats) son : 1) la falta de coherència, resultats aparentment contradictoris i 2) els models de predicció del poder d'emissió de pols son majoritàriament models estadístics que depenen de multitud de variables del material, i per tant, el seu us implica la realització de assajos addicionals que poden suposar inclús més temps que la determinació del poder d'emissió de pols en sí mateix.

Per això, en la primera part del treball, s'ha dut a terme una avaluació preliminar de la influencia de variables de més de 30 materials pulverulents empleats en la industria ceràmica i afins sobre el seu poder d'emissió de pols. Aquest estudi mostra que la distribució de la mida de partícula, la fluïdesa, la superfície específica i la humitat son paràmetres clau en el estudi del poder d'emissió de pols.

Aquest resultats van ser la base per dur a terme una segona fase en la que es va realitzar un estudi específic sobre el efecte de la mida, fluïdesa i superfície específica sobre el poder d'emissió de pols de mostres de caolí i quars. En aquest sentit, amb la finalitat de cobrir un ampli rang de mides de partícula, es van utilitzar tant mostres comercials com mostres preparades a escala de laboratori mitjançant diferents tècniques de separació granulomètrica (hidrociclons, tamisat via humida, etc.) A partir d'una exhaustiva caracterització de les mostres, s'ha observat que la influencia de les variables del material sobre el seu poder d'emissió de pols depèn del rang de mida avaluat. 
Concretament, en les mostres objecte d'estudi, s'ha observat que, per a mides inferiors a 25 micrómetres, increments en la fluïdesa i la mida, així com reduccions en la superfície específica suposen un increment en el poder d'emissió de pols, mentre que per a mides superiors s'observa el efecte contrari. Això podria ser degut al predomini de les forces superficials en el primer cas (mides inferiors a 25 micròmetres) mentre que per a mides superiors predominen les forces volumètriques. Per tant, en contra del que caldria esperar, les mostres més fines no han resultat ser les que presenten un major poder d'emissió de pols. De fet, el poder d'emissió de pols presenta un màxim a continguts mitjans de partícules fines.

En una tercera fase, es va avaluar el efecte de la humitat sobre el poder d'emissió de pols de materials higroscòpics (argiles i caolins). Aquest estudi ha mostrat que el efecte de la humitat sobre el poder d'emissió de pols es d'elevada complexitat ja que el efecte produït depèn de si el aigua actua com a aglutinant o com a lubricant. En aquest sentit, un estudi conjunt dels mecanismes d'hidratació, la fluïdesa del jaç de material i del grau de saturació de la mostra, ha permès observar que: 1) durant la adsorció de una pel-lícula d'aigua fortament atreta a la superfície de la partícula (2-3 capes monomoleculars), s'incrementen les forces d'unió entre partícules (incrementa la cohesió) i, per tant, disminueix el poder d'emissió de pols, 2) una vegada s'han absorbit les capes d'aigua fortament atretes per la partícula, continua la absorció de capes d'aigua. No obstant, l'atracció entre partícules i l'atracció partícula-aigua es dèbil i per tant, el aigua actua com a lubricant. 3) En canvi, quan deixa d'existir una força d'atracció partícula-aigua, l'aigua no té una posició preferent (no es atreta per la superfície de la partícula). Per aquest motiu, actua com a aglutinant entre grups de partícules (augmentat la cohesió i, per tant, disminuint el poder d'emissió de pols). 4) Posteriorment, a mesura que s'incrementa el contingut en humitat, s'afavoreix la granulació de la mostra i, per tant, es produeix un nou increment de la fluïdesa que pot suposar un increment en el poder d'emissió de pols si existeixen partícules susceptibles de generar pols (presencia de partícules fines) o si el grànul es susceptible de esmicolar-se durant la manipulació (grànuls friables).5) Finalment, majors continguts en aigua produeixen una disminució en el poder d'emissió de pols fins al límit plàstic, contingut en humitat en el que el poder d'emissió de pols es pot considerar menyspreable.

Atenent a aquest mecanismes, s'ha desenvolupat una metodologia que permet estimar els punts crítics (en referencia al poder d'emissió de pols) en base a la determinació del grau de saturació de la mostra i de la seva isoterma de adsorció d'aigua.

En una quarta fase de l'estudi, atenent als resultats descrits prèviament, es va desenvolupar un model de predicció del poder d'emissió de pols que es fonamenta en la hipòtesi de que el poder d'emissió de pols o emissió absoluta (rati entre la massa de pols generat de mida "i" i la massa de material assajat) depèn fonamentalment de dos factors: el contingut en fins del material i la facilitat per a lliurar aquests fins o emissió relativa (rati entre la massa de pols 
generat de mida "i" i la massa de partícules de mida i en el material assajat). En aquest sentit, a partir de un anàlisis detallat de la influència de les variables del material sobre la seva facilitat de alliberar el pols, s'ha observat que, a major mida mitja de partícula, major es la facilitat de alliberar el pols (major emissió relativa). Per tant un material gros, presentarà major facilitat per alliberar el pols que un material compost en la seva totalitat per partícules fines. No obstant, això no necessàriament implica que el seu poder d'emissió de pols sigui major, ja que això dependrà també del contingut en fins del material. El model desenvolupat proporciona molt bons resultats per a materials secs i aproximadament esfèrics. A més, cal destacar que el model desenvolupat es basa només en dades extretes de la distribució de mida de partícula i, per tant, no requereix d'assajos addicionals per a la estimació del poder d'emissió de pols.

En una ultima fase del estudi, es va avaluar el poder d'emissió de pols de cinc mostres procedents de les diferents etapes del procés de preparació i acondicionat de matèries primeres per a la fabricació dels suports de rajoles ceràmiques. Aquest procés consta de les següents etapes: mescla, homogeneïtzació i dosificació de les matèries primeres, trituració (mostra 1), mòlta via seca (mostra 2) o via humida i condicionat de la mostra, en referencia a la seva granulometria i humitat $(5.5-6.5 \%)$ per a la operació de premsat. Aquest condicionat es pot dur a terme per humectació de la mescla mòlta via seca (mostra 3), granulació de la mateixa (mostra 4) o la atomització de la mostra mòlta via humida (mostra 5).

En base als resultats obtinguts, s'ha observat que la mostra procedent de la mòlta via seca (mostra 2) es el cas més desfavorable (des de el punt de vista de generació de emissions difuses de PM). Per altre banda, la humectació de la mostra (mostra 3, humitat 6.5\%) i la granulació (mostra 4) de la mateixa suposen una reducció del poder d'emissió de pols de més de un $75 \%$. Finalment, el assecat per atomització genera un material granulat (mostra 5) que dona lloc a una reducció del poder d'emissió de pols superior al 95\%. Per aquest motiu, tant la humectació com la granulació, i sobre tot el assecat per atomització, poden ser considerades com a mesures eficaces per a la reducció del poder emissió de pols.

Finalment, de forma general, els resultats obtinguts i el model desenvolupat, en base a un exhaustiu estudi de la influencia de les variables dels materials pulverulents sobre el seu poder d'emissió de pols, resulten innovadors i de gran interès per la aplicabilitat dels resultats obtinguts en àmbits molt diferents. $A$ continuació, es destaquen alguns d'aquests aspectes, sense pretendre realitzar un llistat exhaustiu:

- Cientificotècnic: s'ha avançat en el coneixement dels mecanismes de generació de PM mitjançant un estudi exhaustiu de la influencia de les variables dels materials pulverulents sobre el seu poder d'emissió de pols. Per un altre banda, s'ha desenvolupat un model que permet estimar el poder d'emissió de pols dels materials pulverulents, en base 
a informació relativa a la seva distribució de mida de partícula. A més aquest model permet justificar la falta d'uniformitat detectada en estudis previs sobre el poder d'emissió de pols ja que, tal i com s'ha observat, al augmentar la mida i la fluïdesa, així com al disminuir la superfície augmenta la facilitat d'alliberar el pols, però això no necessàriament implica un increment en el poder d'emissió de pols.

- Administracions Publiques: Els resultats poden ser de gran utilitat per desenvolupar una normativa futura tenint en compte les condicions òptimes de presentació de les diferents matèries primeres. Per altre banda, en vista dels resultats obtinguts, es podria proposar una metodologia de control basada en la determinació periòdica del poder d'emissió de pols dels materials processats.

- Industrial: el estudi del poder d'emissió de pols de les matèries primeres i de la influencia que presenten les seves propietats sobre el mateix, així com el model desenvolupat permeten obtindré informació referent al risc potencial associat a la manipulació dels diferents materials pulverulents i, per tant, aplicar criteris per a la selecció de matèries primeres, implantació de mesures específiques, etiquetat de productes, etc. 


\section{BLOQUE I: INTRODUCCIÓN, OBJETIVOS Y ESTRUCTURA}

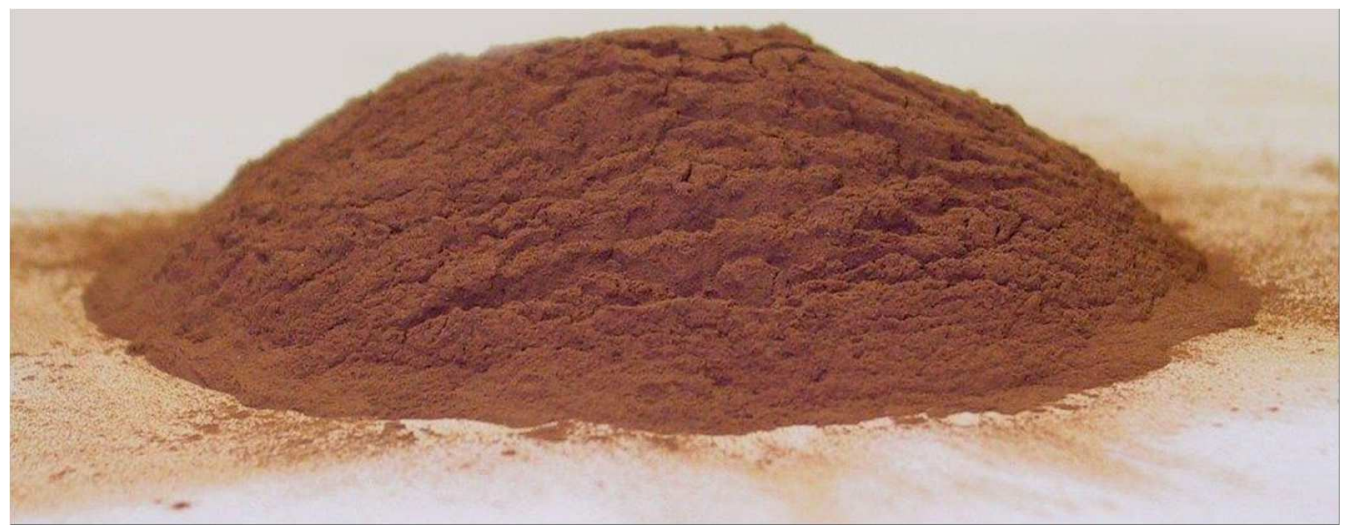



1 INTRODUCCIÓN 



\subsection{Material particulado atmosférico (PM)}

El material particulado atmosférico (PM, del inglés particulate matter) se define como un conjunto de partículas sólidas y/o líquidas, a excepción del agua pura, presentes en suspensión en la atmósfera (Mészáros 1999). Generalmente, el término aerosol atmosférico se utiliza como sinónimo de partículas atmosféricas, aunque los dos términos no sean estrictamente equivalentes, ya que el primero incluye las partículas (sólidas y/o líquidas) y el gas sobre el que éstas se encuentran suspendidas (Putaud et al. 2004). Es necesario considerar que el término PM es un concepto amplio que engloba tanto las partículas en suspensión como las partículas sedimentables (>20 $\mu \mathrm{m})$, caracterizadas por un corto tiempo de residencia en la atmósfera (varias horas).

La presencia de este PM en la atmósfera que altera su composición natural, bien sea por aportes naturales o antropogénicos, se denomina contaminación atmosférica por material particulado.

Con objeto de minimizar el impacto ambiental y el efecto sobre la salud, producido por dicha contaminación, es necesario poner en funcionamiento estrategias de control y reducción de las emisiones de PM.

En este sentido, las partículas en suspensión en el aire ambiente pueden ser de diferentes tipos y orígenes: partículas procedentes de procesos de resuspensión, procedentes de centrales térmicas, partículas formadas a partir de precursores gaseosos, aerosol marino, partículas de hielo, entre otros. Asimismo, la afección de las mismas sobre el entorno es también muy variable, no afectando sólo a la visibilidad y al clima, sino también a la calidad del aire que nos rodea, $y$, por consiguiente, a la salud humana.

El PM puede clasificarse en diversos tipos atendiendo a varios criterios (Celades 2013; Amato 2010; Minguillón 2007):

- Granulometría: el PM se separa, principalmente, en partículas ultrafinas, finas y gruesas.

- Tiempo de residencia en la atmósfera: dependiendo fundamentalmente de su diámetro, su composición química y sus propiedades termodinámicas, el PM permanece mayor o menor tiempo en suspensión en la atmósfera.

- Mecanismos de formación: las partículas pueden ser emitidas como tales a la atmósfera (primarias) o bien ser generadas por reacciones químicas (partículas secundarias). Dichas reacciones químicas pueden consistir en la interacción entre gases precursores en la atmósfera para formar una nueva partícula por condensación, o entre un gas y una partícula atmosférica para dar lugar a un nuevo aerosol por adsorción o coagulación.

- Naturaleza o composición: dependiendo de la fuente de procedencia, el PM puede estar formado por distintos compuestos químicos. 
- Origen: el PM puede ser de origen natural o antropogénico (Bozlaker et al. 2013; Wagstrom \& Pandis 2011; Gieré \& Querol 2010); naturales son aquellas que la propia naturaleza hace que se encuentren en la atmósfera (resuspensión natural de los suelos áridos o zonas desérticas, de las olas marinas, los volcanes, incendios forestales, etc.), mientras que las antrópicas se encuentran en la atmósfera debido a actividades humanas (Karagulian et al. 2015; Streets et al. 2011). Las principales fuentes antrópicas de PM se encuentran en zonas urbanas e industriales; destacan el tráfico, las emisiones tanto canalizadas como difusas (Figura 1.1) derivadas de la actividad industrial (transporte, minería, cerámica, manipulación de material pulverulento al aire libre, sector energético, etc.), emisiones generadas en actividades de construcción 0 en algunas actividades agrícolas (quema de biomasa, arado, etc.) y emisiones procedentes del sector residencial y servicios.

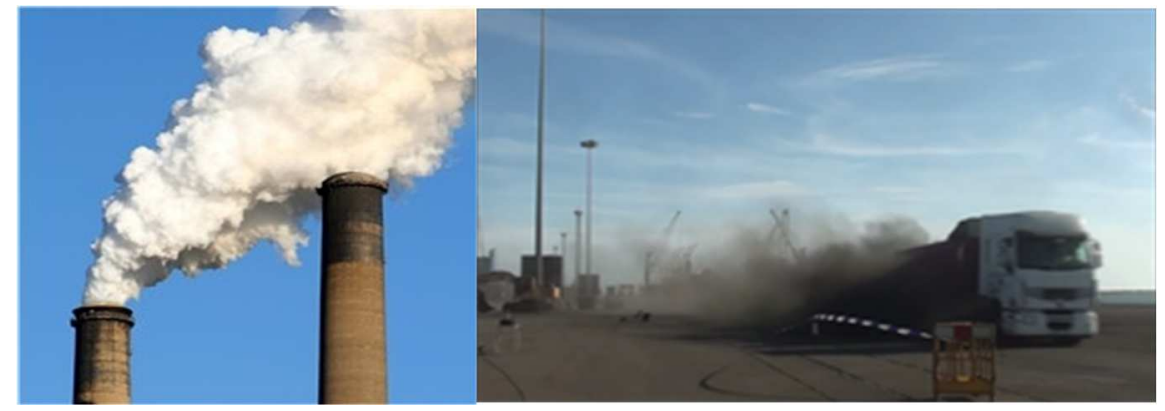

Figura 1.1 Fuentes industriales de PM: canalizadas (izq.) y difusas (dcha.)

Como resultado de esta variabilidad de fuentes y transformaciones, el PM atmosférico consiste en una mezcla compleja de compuestos de naturaleza orgánica e inorgánica con diferentes distribuciones granulométricas y composición química, ambas condicionadas por la composición de los gases que las rodean (Querol et al. 2008).

Los niveles de PM atmosférico se suelen expresar en forma de masa por unidad de volumen de aire $\left(\mu \mathrm{g} / \mathrm{m}^{3}\right)$ o para partículas submicrónicas de menor masa (por ejemplo, nanopartículas) como número de partículas por unidad de volumen de aire (normalmente representado como número de partículas $\left.(\#) / \mathrm{cm}^{3}\right)$.

Las características del PM que más definen los posibles impactos de la contaminación atmosférica sobre el medio son: el tamaño de sus partículas, la morfología y la composición química (Celades 2013; McKenna et al. 2008; Baron \& Willeke 2001; Hinds 1999).

\subsubsection{Tamaño de partícula}

El tamaño de las partículas es el parámetro más importante para caracterizar el comportamiento de las mismas y su afección sobre la salud humana, así como su impacto sobre el medio ambiente. La gran mayoría de las propiedades de las partículas van a depender de su tamaño, éste puede oscilar entre nanómetros $(<0.1 \mu \mathrm{m})$ hasta tamaños superiores a $100 \mu \mathrm{m}$. 
Cuando se hace referencia al tamaño de partículas atmosféricas en aire ambiente, su clasificación resulta muy compleja debido a la presencia de partículas de diferentes orígenes, cuyo tamaño puede ir variando como consecuencia de mecanismos de reacción secundarios o por su propia eliminación. La forma más habitual de presentar los distintos rangos de tamaños de partículas es en términos de "modas", estando relacionadas, en su mayoría, con el mecanismo de formación. Estas modas son: nucleación o fracción ultrafina $(<60 \mathrm{~nm})$, Aitken $(0.06-0.1 \mu \mathrm{m})$, acumulación $(0.1-1 \mu \mathrm{m})$ y la moda gruesa (>1 $\mu \mathrm{m}$ ) (Seinfeld et al. 1998; EPA 1996; Warneck 1988). (Véase Figura 1.2).

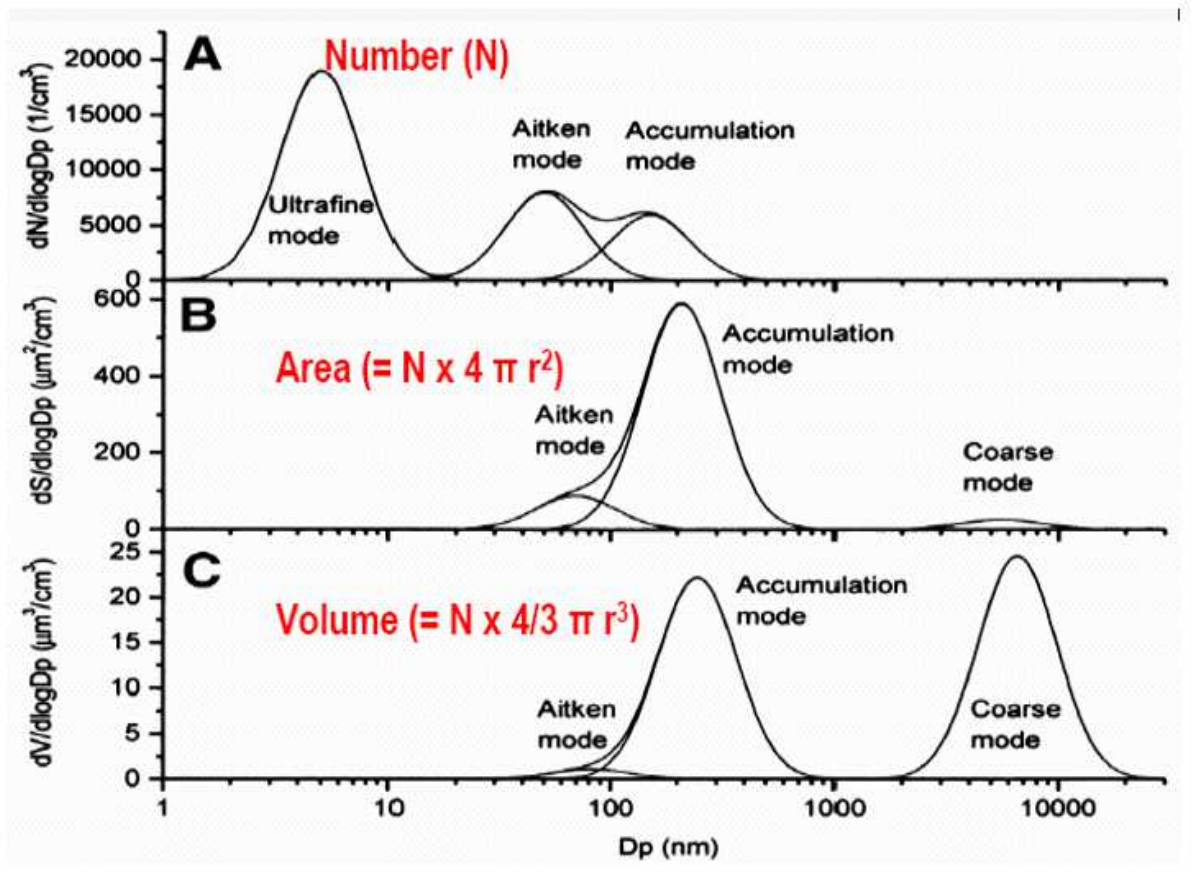

Figura 1.2 Distribución del número, superficie y volumen de las partículas en función del diámetro (fuente: Brice Temime, Department of Chemistry, University College Cork)

La transferencia de las partículas entre las diferentes modas se encuentra con un límite situado alrededor de $1 \mu \mathrm{m}$, debido a que el crecimiento de las partículas de tamaño $<1 \mu \mathrm{m}$ no suele dar lugar a partículas de tamaño $>1 \mu \mathrm{m}$, y a que los procesos mecánicos que generan partículas primarias no producen normalmente partículas de diámetro $<1 \mu \mathrm{m}$, debido a limitaciones energéticas. Por este motivo, se suelen distinguir dos grandes grupos de partículas: fracción fina $(<1 \mu \mathrm{m})$ y fracción gruesa $(>1 \mu \mathrm{m})$.

La fracción fina de las partículas (Hinds 1999), también referenciada como PM1, está constituida por las modas de Nucleación, Aitken y acumulación.

- Las partículas de tamaño inferior a $0.1 \mu \mathrm{m}$ ("nucleación+Aitken" o ultrafinas), son partículas de origen primario naturales o procedentes de procesos de combustión, así como partículas de origen secundario, 
formadas por procesos denominados de nucleación o condensación por vía homogénea o heterogénea (Kerminen et al. 2007; Lingard et al. 2006; Rodríguez et al. 2005; Charron \& Harrison 2003; Wehner et al. 2002; Zhu et al. 2002).

- Las partículas de tamaños comprendidos entre 0.1 y $1 \mu \mathrm{m}$, pertenecientes a la moda de acumulación, se forman a partir de la moda Aitken (Zhang \& Wexler 2002), que crecen como consecuencia de procesos de aglomeración, condensación y de reacciones en fase líquida. Aunque estas partículas pueden ser eliminadas por la lluvia (Hinds 1999), el proceso de coagulación es tan lento que no se llega a alcanzar la moda gruesa, sin embargo, estas partículas tienen una extensa vida en la atmósfera, ya que las ultrafinas tienden a aglomerarse entre ellas y desaparecer como partículas individuales, para hacer crecer el modo acumulación. Por otra parte, las gruesas tienden a depositarse gravitacionalmente.

Las partículas de tamaño comprendido entre 1 y $10 \mu \mathrm{m}$ pertenecen a la moda gruesa.

- Las partículas pertenecientes a la moda gruesa $(>1 \mu \mathrm{m})$ de origen primario tienen su origen en procesos mecánicos. Así, pueden proceder de emisiones biogénicas, de la erosión de la superficie terrestre (materia mineral o crustal) o de otros materiales, o de las superficies de mares y océanos (aerosol marino). Las partículas de origen secundario presentes en esta moda se forman por reacciones químicas entre las partículas primarias de origen crustal y marino y gases presentes en la atmósfera. La concentración de partículas gruesas es muy reducida o despreciable, si se considera el número de partículas, mientras que es muy elevada si el parámetro considerado es la masa.

Como se observa en la definición de los distintos rangos de tamaños de partículas, el parámetro básico es el diámetro geométrico. No obstante, para el estudio de partículas de densidad y tamaño arbitrario se propone el uso de un diámetro equivalente. En este sentido, la bibliografía consultada propone distintos parámetros para caracterizar el diámetro de partícula: diámetro aerodinámico, diámetro de Stokes, diámetro difuso, diámetro óptico, etc. La selección de un tipo de diámetro u otro va a depender principalmente del tipo de medida realizada.

Los diámetros más utilizados en estudios de contaminación atmosférica en el rango micrométrico $(>0.5 \mu \mathrm{m})$, donde los efectos inerciales son significativos, son: el diámetro de Stokes y el diámetro aerodinámico (Celades 2013; McKenna et al. 2008; Ehrlich et al. 2007; Baron \& Willeke 2001; Hinds 1999; WHO/SDE/OEH/99.14 1999). Por debajo de ese tamaño, tienen mucha importancia la difusión browniana de las partículas y, el diámetro utilizado es el diámetro difusivo.

Para mejorar la comprensión de estos conceptos, en la Figura 1.3, se compara una partícula irregular y sus equivalentes esferas aerodinámicas y de Stokes, cada una de ellas tiene la misma velocidad de sedimentación, pero con una 
densidad y una forma diferente. Tanto el diámetro aerodinámico como el diámetro de Stokes, se definen en base al comportamiento aerodinámico de la partícula sin considerar su geometría.

Partícula irregular

$\mathrm{d}_{\mathrm{A}}=5.0 \mu \mathrm{m}$

$\rho_{\mathrm{T}}=4 \mathrm{~g} / \mathrm{cm}^{3}$

$\mathrm{d}_{\mathrm{A}}$

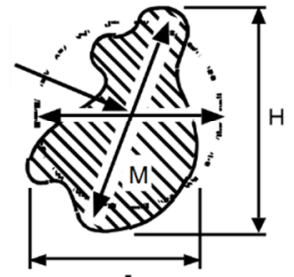

W
Diámetro equivalente de stokes

$\mathrm{d}_{\mathrm{s}}=4.3 \mu \mathrm{m}$

$\rho_{\mathrm{T}}=4 \mathrm{~g} / \mathrm{cm}^{3}$

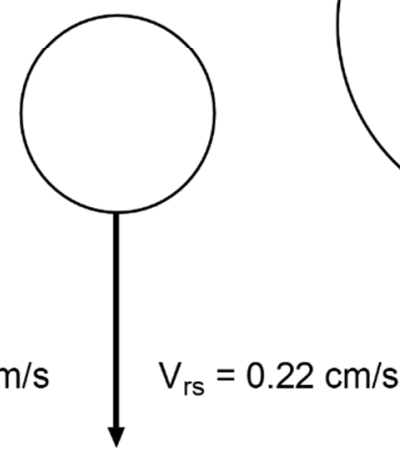

$\mathrm{d}_{\mathrm{a}}=8.6 \mu \mathrm{m}$

$\rho_{\mathrm{T}}=1 \mathrm{~g} / \mathrm{cm}^{3}$

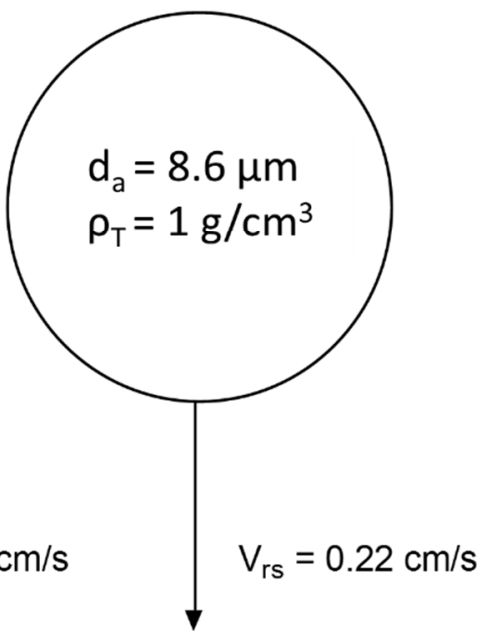

Figura 1.3 Comparación de diferentes tipos de diámetros considerados. $d_{A}, d_{s}, d_{a}$ : diámetro de una esfera con la misma área proyectada que la partícula (orientación aleatoria), diámetro de Stokes, y diámetro aerodinámico, respectivamente (Hinds 1999).

En este sentido, el diámetro aerodinámico se define como el diámetro de una partícula ficticia esférica de densidad $1 \mathrm{~g} / \mathrm{cm}^{3}$ que tiene el mismo comportamiento aerodinámico (misma velocidad terminal en régimen estacionario en el aire) que la partícula real. Por otro lado, el diámetro de Stokes se define como el diámetro de una partícula ficticia esférica de igual densidad que la partícula real que tiene la misma velocidad terminal en régimen estacionario en el aire que la partícula real. En la Ecuación 1.1 se muestra la relación entre estos diámetros.

$$
\mathrm{d}_{\text {Stokes }}=\frac{\mathrm{d}_{\text {aerodinámico }}}{\sqrt{\rho_{\mathrm{t}}}}
$$

Ecuación 1.1

dStokes: diámetro de Stokes $(\mu \mathrm{m})$; daerodinámico: diámetro aerodinámico $(\mu \mathrm{m})$;

$\rho_{\mathrm{t}}$ : densidad real $\left(\mathrm{g} / \mathrm{cm}^{3}\right)$

Aunque el parámetro "diámetro de partícula", es genérico para todos los ámbitos, la denominación de las partículas incluidas en determinados rangos granulométricos varía en función del ámbito de estudio. A continuación, se identifica la nomenclatura seguida en tres de los ámbitos más conocidos: calidad del aire, emisiones industriales y salud laboral. 


\section{Calidad de aire (inmisión o aire ambiente)}

En el caso de estudios de calidad de aire se ha desarrollado toda una normativa que tiene por objeto limitar los niveles de contaminantes en aire ambiente, con el fin de evitar o reducir los efectos nocivos del PM sobre la salud humana y el medio ambiente en su conjunto. Las fracciones granulométricas consideradas son PST, $\mathrm{PM}_{10}$ y $\mathrm{PM}_{2.5}$. Asimismo, también son objeto de estudio intervalos aplicables a las fracciones anteriormente nombradas.

El término PST se refiere a partículas en suspensión totales, mientras que $\mathrm{PMx}$ $\left(\mathrm{PM}_{10}\right.$ y $\left.\mathrm{PM}_{2.5}\right)$ se define como la materia particulada en suspensión en el aire que es suficientemente pequeña para pasar a través de un cabezal de tamaño selectivo con una eficiencia de corte del $50 \%$ para un diámetro aerodinámico de $x \mu \mathrm{m}$ (UNE EN 123412015$)$.

\section{Emisiones industriales}

Para el estudio de las emisiones de PM emitido a partir de focos canalizados de origen industrial, las fracciones de mayor interés ambiental por su impacto sobre los niveles de calidad de aire son: PST, $\mathrm{PM}_{10}$ y $\mathrm{PM}_{2.5}$. En el caso de emisiones industriales procedentes de focos difusos se consideran también las partículas sedimentables (PSD). La relación entre las distintas fracciones granulométricas va a depender del tipo de proceso que dé origen a las emisiones industriales, así como del tipo de contaminantes y otras características que definan la emisión generada.

\section{Salud laboral}

En el estudio de ambientes de trabajo, en higiene o salud laboral, se utiliza una nomenclatura diferente (UNE EN 481 1995), con respecto a la utilizada en contaminación atmosférica (aire ambiente y emisión), aun así, se puede crear un paralelismo en cuanto a dicha nomenclatura para los diferentes tamaños de partículas sólidas y la normativa habitual en contaminación atmosférica, tal y como se detalla a continuación:

- Fracción inhalable: fracción másica de partículas que es inhalada a través de la nariz y la boca. En términos de contaminación atmosférica se puede asemejar a un $\mathrm{PM}_{100}$, equivalente aproximadamente a PST.

- Fracción torácica: fracción másica de partículas inhaladas que penetra más allá de la laringe. En términos de contaminación atmosférica se puede asemejar a un $\mathrm{PM}_{10}$.

- Fracción respirable: fracción másica de partículas inhaladas que penetra en las vías respiratorias no ciliadas. En términos de contaminación atmosférica se puede asemejar a un $\mathrm{PM}_{4}$.

En la Tabla 1.1, a modo de resumen, se detalla la nomenclatura y tamaños de partícula considerados en calidad de aire, emisiones industriales y salud laboral. 
Tabla 1.1 Clasificación de las partículas en función de su granulometría

\begin{tabular}{|c|c|c|c|}
\hline \multicolumn{2}{|r|}{ Calidad de aire/Emisiones industriales } & \multicolumn{2}{|r|}{ Salud laboral } \\
\hline Fracción & Definición & Fracción & Definición \\
\hline PST & $\begin{array}{l}\text { Partículas en suspensión totales } \\
\text { Orden de } 10 \text { de agosto de } 1976\end{array}$ & $\begin{array}{l}\text { Fracción } \\
\text { inhalable }\end{array}$ & $\begin{array}{l}\text { Fracción de partículas } \\
\text { suspendidas en el aire } \\
\text { que es inhalada a través } \\
\text { de la nariz y la boca } \\
\text { UNE EN 481:1995 }\end{array}$ \\
\hline $\mathbf{P M}_{10}$ & $\begin{array}{l}\text { Material particulado en suspensión que } \\
\text { atraviesa un cabezal de tamaño selectivo } \\
\text { para un diámetro aerodinámico de } 10 \mu \mathrm{m} \\
\text { con una eficiencia de corte del } 50 \% \\
\text { UNE EN 12341:2015 } \\
\text { Directiva 1999/30/CE }\end{array}$ & $\begin{array}{l}\text { Fracción } \\
\text { torácica }\end{array}$ & $\begin{array}{c}\text { Fracción másica de las } \\
\text { partículas inhaladas que } \\
\text { penetra más allá de la } \\
\text { laringe } \\
\text { UNE EN 481:1995 }\end{array}$ \\
\hline $\mathrm{PM}_{4}$ & n.a. & $\begin{array}{l}\text { Fracción } \\
\text { respirable }\end{array}$ & $\begin{array}{l}\text { Fracción másica de } \\
\text { partículas inhaladas que } \\
\text { penetra en las vías } \\
\text { respiratorias no ciliadas } \\
\text { UNE EN 481:1995 }\end{array}$ \\
\hline $\mathrm{PM}_{2.5}$ & $\begin{array}{l}\text { Material particulado en suspensión que } \\
\text { atraviesa un cabezal de tamaño selectivo } \\
\text { para un diámetro aerodinámico de } 2.5 \mu \mathrm{m} \\
\text { con una eficiencia de corte del } 50 \% \\
\text { UNE EN 12341:2015 } \\
\text { Directiva 1999/30/CE }\end{array}$ & n.a. & - \\
\hline $\mathbf{P M}_{1}$ & $\begin{array}{c}\text { Material particulado en suspensión que } \\
\text { atraviesa un cabezal de tamaño selectivo } \\
\text { para un diámetro aerodinámico de } 1 \mu \mathrm{m} \text { con } \\
\text { una eficiencia de corte del } 50 \%\end{array}$ & n.a. & - \\
\hline PSD & $\begin{array}{l}\text { Partículas sedimentables } \\
\text { Decreto 833/1975 } \\
\text { Orden de } 10 \text { de agosto de } 1976\end{array}$ & n.a. & - \\
\hline
\end{tabular}

n.a.: no aplica

Por otro lado, en los últimos años, se ha producido un crecimiento notable en el campo de la nanotecnología, como consecuencia de sus múltiples aplicaciones en un gran número de sectores industriales. Cabe comentar que se entiende por nanopartícula, la partícula que cuenta con una o más dimensiones en el rango de 0.1 milésimas de milímetro (100 nanómetros) o menos.

En este sentido, las nanopartículas suelen ser más reactivas que partículas de la misma naturaleza de mayor tamaño y, por tanto, el efecto producido sobre la salud puede ser distinto. No obstante, la rápida aplicación de la nanotecnología ha ocasionado que se extienda su uso cuando aún se tiene un conocimiento incompleto con respecto a los daños para la salud que pueda suponer la 
exposición a estos materiales. De hecho, no se conocen valores límite para nanopartículas, excepto es casos específicos como el dióxido de titanio.

Por este motivo, como consecuencia del potencial riesgo por exposición a nanopartículas, en los últimos años se ha potenciado el estudio de dicha fracción (Figura 1.4, (Godinho da Fonseca 2016)) en los tres ámbitos mencionados: calidad de aire, emisiones industriales y salud laboral.

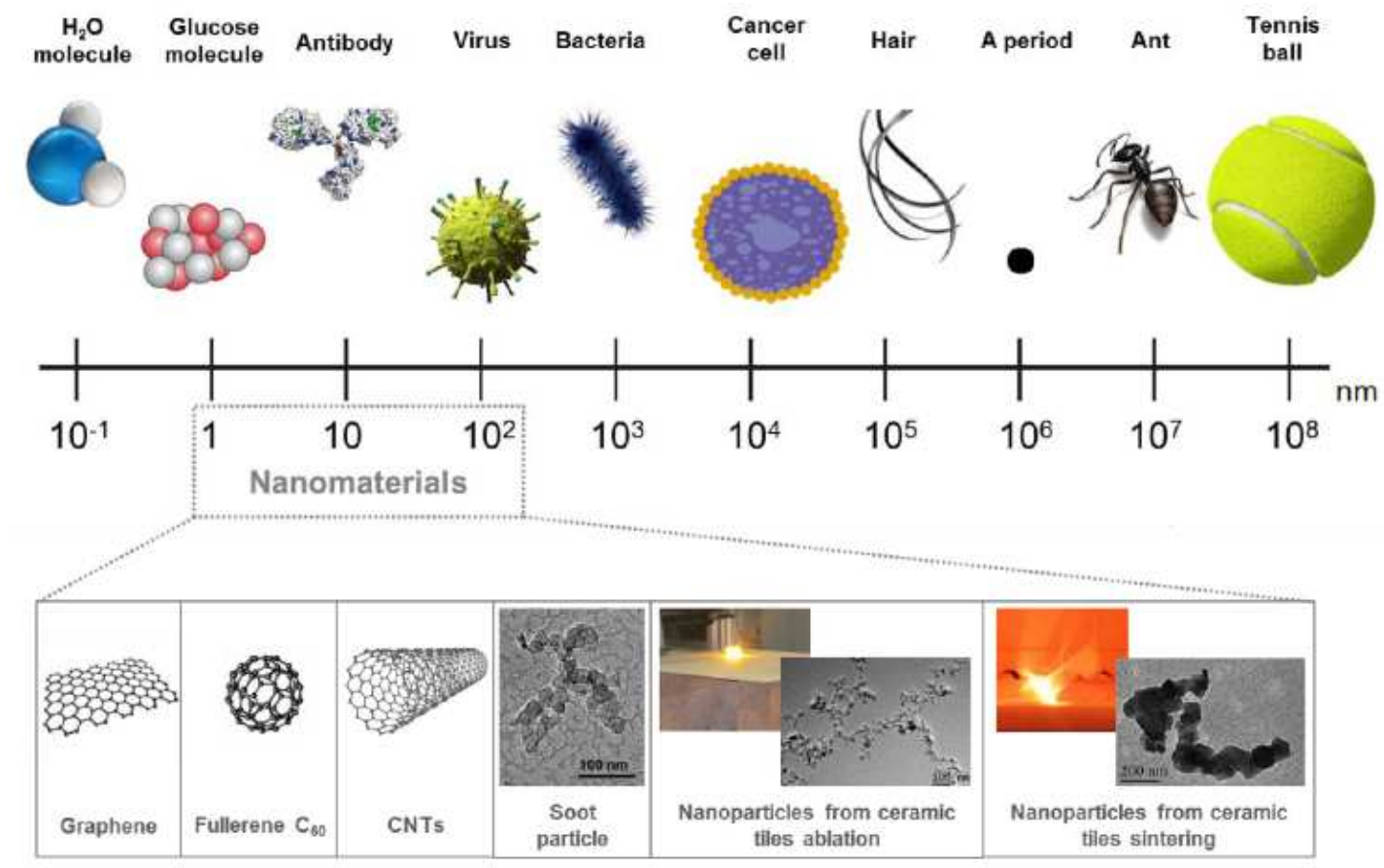

Figura 1.4 Rango granulométrico nanomateriales (Godinho da Fonseca 2016)

\subsubsection{Morfología de las partículas}

La morfología de las partículas incluye la forma de la partícula y las características de su superficie. El diámetro aerodinámico equivalente, que permite establecer las características dimensionales de las partículas, no tiene en cuenta la forma, porosidad o rugosidad de las partículas. Estas propiedades tienen gran importancia en los efectos de las partículas sobre la salud o en su comportamiento en las reacciones atmosféricas.

La forma y la densidad, determinan la relación entre la masa y el volumen. El área eficaz de reacción incluye la superficie específica de los eventuales poros, determinando la capacidad de las partículas para adsorber gases o cargas eléctricas. El estudio de la morfología de las partículas permite establecer las características de su superficie como rasgo diferenciador incluso entre partículas de tamaños similares emitidas a partir de un mismo foco emisor, además de servir para identificar posibles orígenes y mecanismos de formación: procesos térmicos (evaporación-condensación) y mecánicos, principalmente. 


\subsubsection{Composición química del PM}

La composición química de las partículas es una materia de estudio de enorme interés. También lo es la identificación de las especies químicas en las que se presentan los diferentes elementos en las partículas, de cara a conocer el impacto de las mismas sobre el medio y los seres vivos.

Dependiendo fundamentalmente de su origen, la composición química varía mucho de unas partículas a otras. De forma general, respecto a los compuestos exclusivamente de origen antropogénico, se observa una variación espacial en su concentración de PM relacionada con el tipo de actividad antropogénica dominante y su importancia relativa, así como con las características climáticas. En este sentido, determinadas zonas con influencia de emisiones industriales específicas pueden presentar niveles y características de PM diferentes, influenciadas por el tipo de industria. En este caso, el perfil químico de la emisión va a depender del proceso productivo, es decir, de la naturaleza y flujo de las materias primas y combustibles, de las condiciones de operación y de la presencia de otras partículas secundarias.

Además, las partículas primarias una vez emitidas a la atmósfera pueden estar sometidas a procesos de reacción química dando lugar a partículas secundarias, todas estas transformaciones van a depender, a su vez, de las condiciones meteorológicas y otros factores ambientales.

En función de su composición el material particulado se puede clasificar en: materia mineral, aerosol marino, compuestos de azufre, compuestos de nitrógeno y compuestos de carbono (Putaud et al. 2010).

\section{Materia mineral}

El material particulado mineral de origen natural constituye la fracción mayoritaria en cuanto a masa del aerosol atmosférico, 44\% de las emisiones a nivel terrestre (IPCC 1996; Duce 1995). La formación de partículas minerales se origina por medio de la acción de los vientos sobre la superficie terrestre en forma de emisiones fugitivas.

La emisión de las partículas de origen mineral depende de la velocidad del viento, de la superficie del suelo, de la humedad y de la cobertura vegetal, entre otros factores (Marticorena et al. 1997).

La composición química y mineralógica de estas partículas, de forma general, está constituida por calcita $\left(\mathrm{CaCO}_{3}\right)$, cuarzo $\left(\mathrm{SiO}_{2}\right)$, dolomita $\left[\mathrm{CaMg}\left(\mathrm{CO}_{3}\right)_{2}\right]$, arcillas [sobre todo caolinita $\mathrm{Al}_{2} \mathrm{Si}_{2} \mathrm{O}_{5}(\mathrm{OH})_{4}$, e illita $\mathrm{K}(\mathrm{Al}, \mathrm{Mg})_{3} \mathrm{SiAl}_{10}(\mathrm{OH})$ ], feldespatos $\left[\mathrm{KAISi}_{3} \mathrm{O}_{8}\right.$ y $(\mathrm{Na}, \mathrm{Ca})(\mathrm{AISi})_{4} \mathrm{O}_{8}$ ] y cantidades inferiores de sulfato cálcico $\left(\mathrm{CaSO}_{4} .2 \mathrm{H}_{2} \mathrm{O}\right)$ y óxidos de hierro $\left(\mathrm{Fe}_{2} \mathrm{O}_{3}\right)$, entre otros (Caquineau et al. 1998; Avila et al. 1997; Adedokun et al. 1989; Schütz \& Sebert 1987; Glaccum \& Prospero 1980).

A pesar de que la mayor parte de las emisiones de materia mineral es de origen natural, es necesario considerar la existencia de un número limitado de fuentes 
de PM mineral de origen antropogénico. Así, actividades como la construcción, la minería o la fabricación de cerámicas o cementos generan partículas minerales, ya sea a través de la propia actividad o durante los procesos de manipulación y transporte de materias primas (emisiones difusas de PM). El tráfico puede constituir también una fuente de partículas minerales, a través de la erosión del firme de rodadura y/o procesos de resuspensión de polvo (Escrig et al. 2011).

\section{Aerosol marino}

El aerosol marino es el segundo tipo de partícula con mayor importancia en cuanto al volumen total de emisiones a escala global, $38 \%$ de las emisiones globales a nivel terrestre (IPCC 2001). Al igual que el PM mineral, las partículas de aerosol marino son en su mayoría origen natural y son emitidas directamente a la atmosfera (partículas primarias).

La composición química del aerosol marino deriva de su fuente de origen: el agua de los mares y océanos, así la fracción primaria del aerosol marino está principalmente compuesta por cloruro sódico $(\mathrm{NaCl})$ aunque otras formas de cloruros y sulfatos pueden estar también presentes (ej. $\mathrm{MgSO}_{4} \circ \mathrm{K}_{2} \mathrm{SO}_{4}$ ).

\section{Compuestos de azufre}

Los sulfatos presentes en la atmósfera son generalmente partículas de origen secundario, ya que no son emitidos directamente a la atmósfera, sino que se generan mayoritariamente como resultado de la oxidación de precursores gaseosos (principalmente $\mathrm{SO}_{2}$ ). Los compuestos de azufre representan aproximadamente entre el $7-10 \%$ de las emisiones globales a nivel terrestre (IPCC 2001; IPCC 1996).

Los sulfatos de origen no natural constituyen la fracción principal del PM atmosférico antropogénico, y las emisiones antropogénicas son responsables de entre el $60-80 \%$ del azufre en la atmósfera a escala global (Chuang et al. 1997).

La producción antropogénica de gases precursores de los sulfatos de origen secundario se centra esencialmente en procesos de combustión de combustibles fósiles con alto contenido en azufre, mayoritariamente carbón y fuel-oil en centrales térmicas y complejos industriales (la combustión de carbón supone el $60 \%$ de las emisiones de sulfato antropogénico, el petróleo supone el $28 \%$, según (Warneck 1988)).

\section{Compuestos de nitrógeno}

Los compuestos de nitrógeno en la atmósfera (principalmente $\mathrm{NO}_{3}^{-}$y $\mathrm{NH}_{4}{ }^{+}$), al igual que los sulfatos, son de origen mayoritariamente secundario y provienen de la reacción de precursores gaseosos naturales y antropogénicos. Estos compuestos representan aproximadamente el $2-5 \%$ de las emisiones globales a nivel terrestre (IPCC 1996). 
En cuanto a los precursores gaseosos de los nitratos de origen antropogénico, en la actualidad se conocen numerosas fuentes emisoras entre las cuales destacan la producción eléctrica (combustión de gas, fuel-oil y carbón) y otros procesos de combustión a temperaturas elevadas (capaces de oxidar el $\mathrm{N}_{2}$ atmosférico) tales como los que ocurren en los motores de los vehículos y la quema de biomasa.

Los principales gases emitidos por fuentes naturales y antropogénicas son así $\mathrm{NO}, \mathrm{NO}_{2}, \mathrm{~N}_{2} \mathrm{O}$ y $\mathrm{NH}_{3}$, cuya oxidación en la atmósfera tiene como resultado más frecuente la formación de ácido nítrico $\left(\mathrm{HNO}_{3}\right)$ (Mészáros 1999; Warneck 1988) y amonio $\left(\mathrm{NH}_{4}^{+}\right)$.

\section{Compuestos de carbono}

Los compuestos carbonosos comprenden una amplia variedad de especies naturales y antropogénicas de composición y estructura diversa, cuya característica común es la presencia de carbono en su composición. Los compuestos carbonosos representan aproximadamente el $2-5 \%$ de las emisiones globales a nivel terrestre (IPCC 2007).

EI PM carbonoso primario de origen antropogénico tiene su principal fuente en la atmósfera en la generación eléctrica (procesos de combustión). Sin embargo, es necesario considerar también la contribución de otras fuentes de origen industrial como los aportes de tráfico.

En la Tabla 1.2 se resumen las características de los distintos tipos de PM en función de su composición: 
Tabla 1.2 Características del material particulado atmosférico en función de la composición (Celades 2013; Minguillón 2007)

\begin{tabular}{|c|c|c|c|c|}
\hline Composición & $\begin{array}{l}\text { Compuestos } \\
\text { mayoritarios }\end{array}$ & Granulometría & Tipo partículas & $\begin{array}{c}\text { Gases } \\
\text { precursores }\end{array}$ \\
\hline \multirow{2}{*}{$\begin{array}{l}\text { Materia } \\
\text { mineral }\end{array}$} & $\begin{array}{c}\text { Mayoritariamente: } \\
\text { calcita, cuarzo, arcillas }\end{array}$ & \multirow{2}{*}{$\begin{array}{c}\text { Gruesa: } 5-25 \mu \mathrm{m} \\
\text { Modas: } 1.5,6.7 \mathrm{y} \\
14.2\end{array}$} & \multirow[b]{2}{*}{ Primarias } & \multirow[b]{2}{*}{-} \\
\hline & $\begin{array}{c}\text { En menor medida: } \\
\text { feldespatos, dolomita, } \\
\text { talco }\end{array}$ & & & \\
\hline \multirow{2}{*}{$\begin{array}{l}\text { Aerosol } \\
\text { marino }\end{array}$} & $\begin{array}{l}\text { Mayoritariamente: } \\
\qquad \mathrm{NaCl}\end{array}$ & \multirow{2}{*}{$\begin{array}{l}\text { Moda principal: } \\
1-5 \mu \mathrm{m} \\
\text { Moda inferior: } \\
5-10 \mu \mathrm{m}\end{array}$} & \multirow{2}{*}{ Primarias } & \multirow{2}{*}{-} \\
\hline & $\begin{array}{l}\text { En menor medida: } \\
\qquad \mathrm{MgCl}_{2}, \mathrm{MgSO}_{4}\end{array}$ & & & \\
\hline \multirow{2}{*}{$\begin{array}{l}\text { Compuestos } \\
\text { de azufre }\end{array}$} & $\begin{array}{c}\text { Mayoritariamente: } \\
\mathrm{NH}_{4} \mathrm{HSO}_{4},\left(\mathrm{NH}_{4}\right)_{2} \mathrm{SO}_{4}\end{array}$ & $<1 \mu \mathrm{m}$ & \multirow[t]{2}{*}{$\begin{array}{c}\text { Mayoritariamente } \\
\text { secundarias }\end{array}$} & \multirow{2}{*}{$\mathrm{SO}_{2}$} \\
\hline & $\begin{array}{l}\text { En menor medida: } \\
\mathrm{CaSO}_{4}, \mathrm{Na}_{2} \mathrm{SO}_{4}\end{array}$ & $>1 \mu \mathrm{m},<10 \mu \mathrm{m}$ & & \\
\hline \multirow{2}{*}{$\begin{array}{l}\text { Compuestos } \\
\text { de nitrógeno }\end{array}$} & $\begin{array}{c}\mathrm{NH}_{4} \mathrm{NO}_{3} \text { (inestable a } \\
\mathrm{T}>25^{\circ} \mathrm{C} \text { ) }\end{array}$ & $<1 \mu \mathrm{m}$ & \multirow{2}{*}{$\begin{array}{c}\text { Mayoritariamente } \\
\text { secundarias }\end{array}$} & \multirow{2}{*}{$\begin{array}{c}\mathrm{NO}, \mathrm{NO}_{2}, \mathrm{~N}_{2} \mathrm{O} \\
\mathrm{NH}_{3}, \mathrm{~N}_{2}\end{array}$} \\
\hline & $\mathrm{NaNO}_{3}, \mathrm{Ca}\left(\mathrm{NO}_{3}\right)_{2}$ & $>1 \mu \mathrm{m},<10 \mu \mathrm{m}$ & & \\
\hline \multirow{3}{*}{$\begin{array}{l}\text { Compuestos } \\
\text { de carbono }\end{array}$} & Carbono elemental & \multirow[b]{2}{*}{$\begin{array}{c}\text { Moda: } 1 \mu \mathrm{m} \\
\text { (aunque el } 85 \% \text { en } \\
\text { número es }<0.1 \\
\mu \mathrm{m})\end{array}$} & $\begin{array}{c}\text { Primarias } \\
\text { mayoritariamente }\end{array}$ & - \\
\hline & Carbono orgánico & & $\begin{array}{l}\text { Primarias y } \\
\text { secundarias }\end{array}$ & $\begin{array}{c}\text { a COVs } \\
\text { (isopropeno, } \\
\text { monoterpenos), } \\
{ }^{\text {bDMS }}\end{array}$ \\
\hline & $\begin{array}{c}\text { Carbono total } \\
\text { (elemental+orgánico) }\end{array}$ & $\begin{array}{c}\text { Bimodal: }<2.5 \mu \mathrm{m} \\
\text { (partículas } \\
\text { orgánicas y } \\
\text { antrópicas) y }>10 \\
\mu \mathrm{m} \text { (carbonatos } \\
\text { minerales) }\end{array}$ & - & - \\
\hline
\end{tabular}

a COVs: Compuestos orgánicos volátiles

${ }^{b}$ DMS: Dimetil-sulfuro 


\subsection{Emisiones industriales de PM}

A nivel nacional, tal y como se indica en el Plan Nacional de Mejora de la Calidad de Aire (PNMCA 2013), ciertas zonas de España presentan una problemática asociada a superaciones de los valores límite de PM. Estas superaciones de los valores límite, dan lugar a que sea necesario un control y reducción de las emisiones de PM para evitar o reducir los efectos nocivos que puede tener sobre la salud, el clima, los ecosistemas, etc.

Existen una gran cantidad de fuentes de PM, que pueden ser tanto de origen natural como antropogénico, por lo que resulta de gran complejidad identificar las causas de superación de $\mathrm{PM}_{10}$. En base a la información publicada en el Registro Estatal de Emisiones y Fuentes Contaminantes (PRTR-España, http://www.prtr-es.es/), en diversos estudios (PNMCA 2013; Querol et al. 2012) se indica que las principales fuentes de PM de origen antropogénico, en orden decreciente, son: el tráfico, la industria local, la proximidad a carreteras, la calefacción doméstica, las canteras y minas y los accidentes industriales (Figura 1.5).
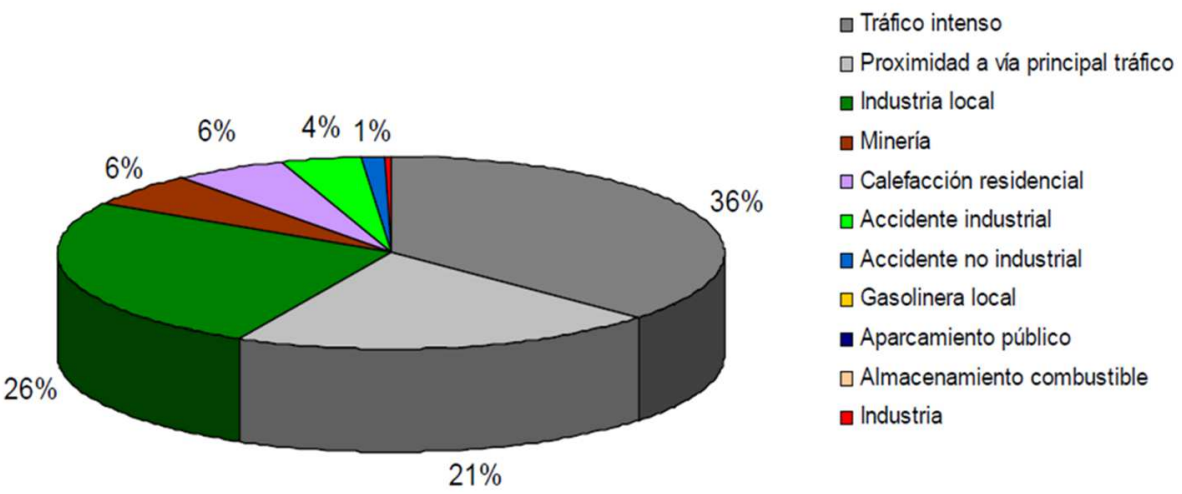

Figura 1.5 Causas antropogénicas de superación del VLA de PM10: promedio 2001-2009 (PNMCA 2013)

Entre las fuentes antropogénicas de PM identificadas como mayoritarias, una de las más significativas es la industria (26\%). De hecho, las emisiones al aire constituyen uno de los mayores impactos medioambientales de muchas actividades industriales, tanto por focos canalizados como difusos, siendo en procesos industriales que llevan asociadas actividades de manipulación de materiales pulverulentos a granel, las partículas sólidas emitidas los contaminantes atmosféricos más significativos. Cabe especificar que las emisiones difusas engloban toda descarga de partículas y/o gases a la atmósfera, no realizada a través de focos canalizados, ya sea continua 0 discontinua. Quedan incluidas las emisiones no capturadas liberadas al ambiente exterior por ventanas, puertas, respiraderos y aberturas similares, 0 directamente generadas en exteriores (BOPV 23/01/2012; Decreto 278/2011).

En este sentido, el elevado grado de implantación de medidas correctoras en focos canalizados, debido a la existencia de valores límite de emisión legislados para partículas en suspensión totales (PST), ha puesto de manifiesto el impacto 
de las emisiones difusas de PM en la calidad del aire en zonas con elevada actividad industrial. En este sentido, cabe comentar que, en determinadas actividades industriales, las emisiones difusas de PM pueden tener una importancia cuantitativa y ambiental similar e incluso mayor que las emisiones canalizadas. Por ejemplo, en la fabricación de cemento las emisiones difusas de PM pueden representar un $25 \%$ de las emisiones globales de PM a la atmosfera (PMCA-AL 2010). Del mismo modo, estudios de emisiones de partículas en procesos de fabricación de productos cerámicos indican que la emisión de PM por focos difusos, dependiendo del proceso de fabricación, puede tener una importancia similar a las emisiones por fuentes canalizadas, pudiendo llegar a representar incluso un $80 \%$ de las emisiones globales de PM (PMCA-AL 2010; Minguillón et al. 2009; Monfort et al. 2009; PMCA-CS 2008).

Dada la importancia relativa que este tipo de emisiones está adquiriendo en algunas actividades industriales, actualmente se les está prestando una mayor atención, tanto desde un punto de vista normativo como técnico, estableciéndose requisitos específicos para su control en las Autorizaciones Ambientales Integradas (AAls), así como la introducción de la necesidad de cuantificar dichas emisiones en las declaraciones de emisiones requeridas por la Unión Europea (PRTR). Sin embargo, sigue existiendo un gran desconocimiento, a la vez que un vacío normativo importante en lo referente a emisiones difusas, y dado que en muchos casos contribuyen significativamente a las superaciones registradas en calidad de aire, se considera necesario prestarles una mayor atención. En este sentido, los estudios de carácter técnico se consideran de extremada relevancia para la determinación de requisitos específicos para el control y el establecimiento de obligaciones tecnológicas y ambientales.

La problemática ambiental de las emisiones difusas de PM, objeto de estudio de la presente tesis doctoral, viene asociada mayoritariamente a actividades relacionadas con la gestión de materiales de naturaleza pulverulenta (Figura 1.6). Estas actividades se localizan principalmente en entornos industriales relacionados con la extracción de minerales a cielo abierto, acondicionamiento de materiales minerales para su posterior uso (lavado de caolines, plantas de áridos, etc.) y todas aquellas actividades que consisten en la elaboración de productos o materiales que utilizan como materias primas, minerales 0 materiales pulverulentos a granel (cerámica, fabricantes de cal, acerías, cementeras, etc.).

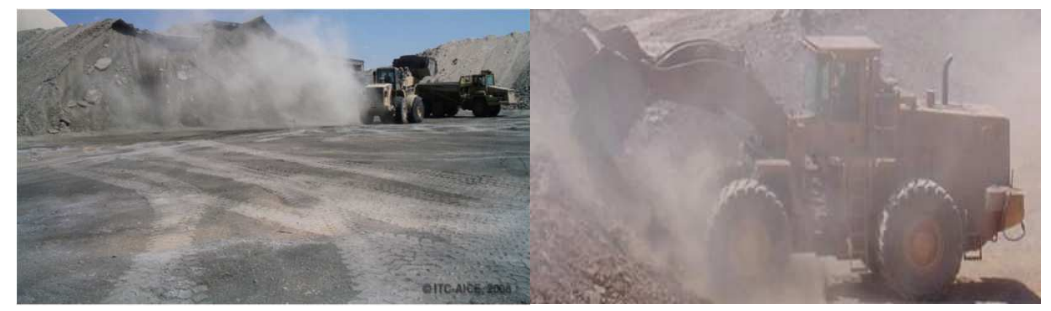

Figura 1.6 Emisiones difusas de PM generadas en operaciones de manipulación de sólidos pulverulentos 


\subsubsection{Emisiones difusas de PM}

Existen multitud de actividades industriales susceptibles de generar emisiones difusas de PM, incluyendo: sector cerámico, sector cementero, fabricación de cal, fundiciones, canteras, procesos de refino de petróleo, plantas de hormigón, coquerías, puertos, etc. (Guía aireaAIRE 2012). No obstante, a pesar de la diversidad sectorial afectada por esta problemática, se pueden identificar una serie de actividades genéricas, comunes a todos estos procesos industriales, susceptibles de generar emisiones difusas de PM: extracción de materias primas, transporte, gestión, tratamiento y almacenamiento de materiales pulverulentos (Tabla 1.3).

Tabla 1.3 Operaciones genéricas susceptibles de generar emisiones difusas de PM

\begin{tabular}{|c|c|c|}
\hline Actividad & Subactividad & Operación \\
\hline \multirow{5}{*}{ Extracción de materias primas } & Extracción & Voladura, perforación, etc. \\
\hline & Cargas/Descargas & Manipulación \\
\hline & Tratamiento & Trituración, cribado, etc. \\
\hline & \multirow{2}{*}{ Transporte interno } & Transferencia (cintas) \\
\hline & & $\begin{array}{c}\text { Transporte por zona asfaltada } \\
\text { y/o zona no asfaltada }\end{array}$ \\
\hline \multirow[t]{4}{*}{ Recepción de materias primas } & \multirow{2}{*}{$\begin{array}{c}\text { Transporte externo } \\
\text { hasta la planta } \\
\text { industrial }\end{array}$} & \multirow{2}{*}{$\begin{array}{l}\text { Transporte por carretera, } \\
\text { marítimo o ferroviario }\end{array}$} \\
\hline & & \\
\hline & Descarga & Manipulación \\
\hline & $\begin{array}{l}\text { Apilamiento con } \\
\text { máquina pala }\end{array}$ & Manipulación \\
\hline \multirow[t]{2}{*}{ Almacenamiento de materias prim } & \multirow[b]{2}{*}{$\begin{array}{l}\text { Almacenamiento } \\
\text { a cielo abierto }\end{array}$} & \multirow[b]{2}{*}{ Erosión eólica } \\
\hline & & \\
\hline \multirow{4}{*}{$\begin{array}{l}\text { Gestión y } \\
\text { tratamiento de materias primas }\end{array}$} & \multirow{2}{*}{ Transporte interno } & Transferencia (cintas) \\
\hline & & $\begin{array}{l}\text { Transporte por zona } \\
\text { asfaltada/zona no asfaltada }\end{array}$ \\
\hline & Cargas/descargas & Manipulación \\
\hline & $\begin{array}{l}\text { Tratamiento y/o } \\
\text { procesado }\end{array}$ & $\begin{array}{l}\text { Trituración, molienda, } \\
\text { tamizado, mezclado, etc. }\end{array}$ \\
\hline \multirow[t]{2}{*}{ Expedición del producto } & $\begin{array}{c}\text { Carga de } \\
\text { camiones/barcos }\end{array}$ & Manipulación \\
\hline & $\begin{array}{l}\text { Expedición del } \\
\text { producto }\end{array}$ & $\begin{array}{l}\text { Transporte por carretera, } \\
\text { marítimo o ferroviario }\end{array}$ \\
\hline
\end{tabular}


En este sentido, las emisiones difusas de PM, generadas en la extracción, manipulación y almacenamiento al aire libre de las materias primas, son partículas primarias de composición similar al material procesado (Monfort et al. 2009; Monfort et al. 2004). La cantidad emitida y su granulometría depende de muchos factores, incluyendo: características del material procesado (humedad, granulometría, etc.), condiciones meteorológicas (velocidad y dirección del viento, humedad ambiental, etc.), proceso, etc.

En el caso del transporte de materiales pulverulentos, se generan emisiones de partículas por cuatro mecanismos (Figura 1.7):

- $\quad$ Pérdidas de la carga del camión por reboses o cierres deficientes. Las emisiones de estas pérdidas dependen del tipo de camión (camiones cisterna o volquete), de las condiciones del transporte y de las prácticas de carga, descarga y transporte (buen estado de la puerta trasera de la bañera o volquete que garantice un cierre adecuado, cobertura total de la carga con toldos, grado de llenado pare evitar reboses superiores, grado de limpieza de ruedas y bajos del camión, entre otros factores).

- Resuspensión de material depositado en el firme. La pérdida y deposición sobre la calzada de material pulverulento durante el transporte de las materias primas o bien el depósito atmosférico de las emisiones canalizadas provocan unas emisiones muy importantes por la continua resuspensión del citado material por el tráfico rodado. Una limpieza periódica de los firmes de rodadura garantizaría una reducción considerable de estas emisiones.

- Emisiones de los motores diésel de los vehículos pesados cuya composición se caracteriza por la presencia de $\mathrm{NO}_{x}, \mathrm{CO}, \mathrm{CO}_{2}$ y COVNM (compuestos orgánicos volátiles no metánicos). Cabe destacar la emisión de partículas ultrafinas o nanopartículas en el rango de tamaño 20-130 nm (Kittelson 1998; Morawska et al. 1998).

- Desgaste de frenos, neumáticos y firme de rodadura que da lugar a partículas minerales, partículas carbonosas, así como metales pesados como $\mathrm{Fe}, \mathrm{Cu}, \mathrm{Ba}, \mathrm{Cr}, \mathrm{Sn}, \mathrm{Sb}$ (Amato 2010).

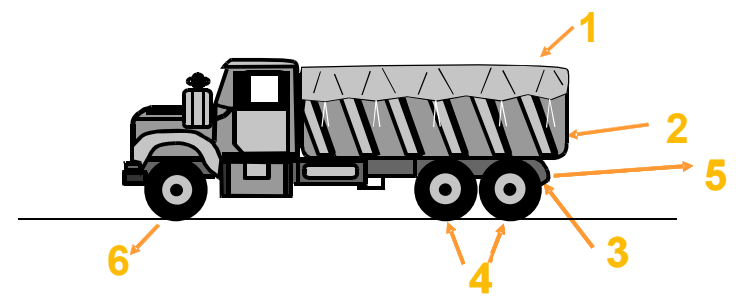

Figura 1.7 Emisiones en el transporte de materiales pulverulentos (camiones volquete). 1. Reboses o pérdidas de material (con o sin carga), 2. Vertido de materiales a la calzada por cierre deficiente, 3. Pérdidas de material adherido a las ruedas y bajos del camión, 4. Resuspensión de polvo (sobre todo en vías no asfaltadas), 5 . Emisiones de los gases de escape del vehículo, 6. Desgaste de frenos, neumáticos y firme de rodadura. 


\subsubsection{Medidas preventivas y/o correctoras}

A continuación, se presentan las medidas para la reducción de las emisiones difusas de PM, obtenidas de la revisión de los documentos BREFs (IPTS 2013; IPTS 2007; IPTS 2006), Planes de Mejora de la Calidad del Aire (PNMCA 2013; PMCA-AL 2010; PMCA-CS 2008) y guías para la prevención de emisiones difusas de PM (Monfort et al. 2014; Guía aireaAIRE 2012). En estos documentos se indican las Mejores Técnicas Disponibles (MTDs) para reducir las emisiones de PM generadas en la manipulación, transporte y almacenamiento de materiales pulverulentos (Tabla 1.4):

- Almacenamiento cerrado de materias primas con sistema de manipulación automático. Los silos y los almacenamientos cerrados con manipulación automática de los materiales pulverulentos se consideran la solución más efectiva para el problema de las emisiones de polvo generadas por los acopios de gran volumen. Estos almacenamientos deben estar equipados con sistemas de aspiración y posterior depuración del aire aspirado mediante filtros de mangas.

- Protección contra el viento en las pilas a la intemperie de materias primas. Cuando existen almacenamientos de materiales a la intemperie es posible reducir las emisiones difusas empleando barreras contra el viento diseñadas para ese fin. En ciertos casos, este tipo de pantallas pueden ser empleadas tanto para minimizar las emisiones por erosión eólica, como la dispersión del material particulado generado en la manipulación de materiales pulverulentos. Las pantallas pueden ser opacas o porosas.

- Riego por aspersión con agua y/o con aditivos. En las zonas u operaciones susceptibles de emitir emisiones difusas de partículas, se puede utilizar la pulverización de agua para reducir las emisiones difusas. Es importante considerar que la eficacia no sólo depende de la cantidad de agua aplicada, sino de que se realice de forma adecuada: correcta pulverización, frecuencia de riego, etc. Se pueden utilizar también una amplia variedad de agentes químicos tensoactivos que se añaden al agua para mejorar la eficacia de este sistema.

- Transferencia de materiales en sistemas cerrados dotados de aspiración y filtración posterior del aire aspirado. Siempre que sea posible, los materiales que precisen manipulación deben ser transportados a través de sistemas cerrados mantenidos en depresión. El aire de aspiración de este sistema tiene que ser posteriormente depurado en un filtro de mangas antes de ser emitido a la atmósfera.

- Pavimentación y limpieza de viales. Los viales de circulación interna de camiones deben pavimentarse y mantenerse limpios mediante barrido y/o riego, en la medida en que sea posible. Si no es posible su 
pavimentación, algunas alternativas son el riego por aspersión o depositar una capa de materiales de granulometría gruesa.

Tabla 1.4 Ejemplos de medidas correctoras para la reducción de emisiones generadas durante la gestión de materiales pulverulentos

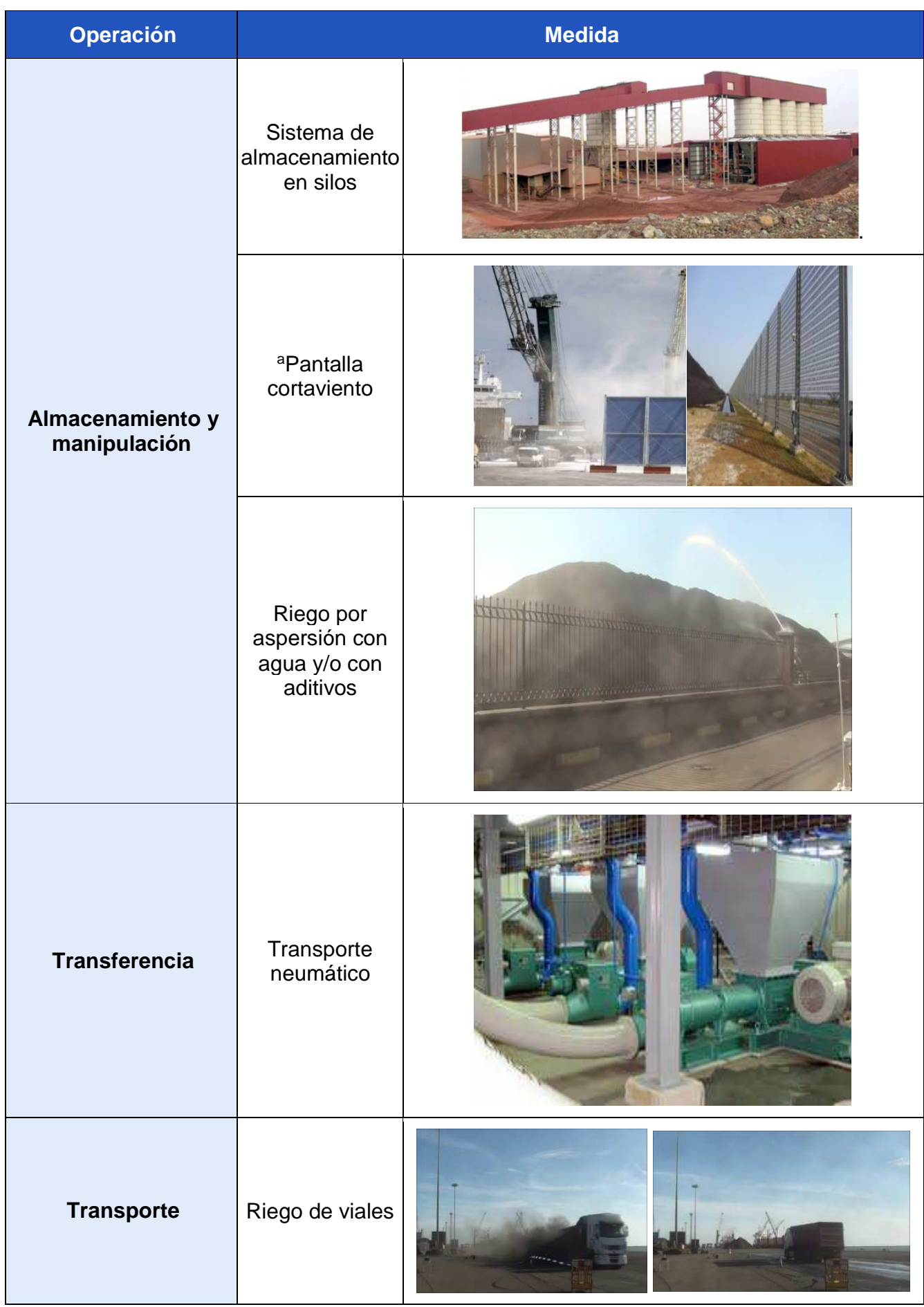

${ }^{a}$ http://www.laverdad.es/alicante/ciudad-alicante/201602/11/puerto-preve-triplicar-superficie20160211015759-v.html y http://www.steelwindbreak.es/1-3-wind-fence.html 
Por otro lado, los camiones más habituales para el transporte de materiales pulverulentos son los camiones tipo volquete porque presentan muy pocas limitaciones técnicas en cuanto a la tipología de materiales a transportar. Por este motivo, para minimizar las consecuencias del transporte de material pulverulento se ha considerado oportuno establecer unas recomendaciones tanto aplicables al vehículo como a las empresas usuarias de este medio de transporte (Tabla 1.5). Además, el transporte de materiales pulverulentos a granel puede realizarse con otros tipos de camiones o sistemas que garantizan un mejor confinamiento de los materiales que los camiones volquete, aunque todos ellos presentan limitaciones en su aplicación. En la Tabla 1.6 se detallan tres de estos sistemas de transporte alternativos, así como un resumen de sus ventajas y desventajas.

Tabla 1.5 Métodos y técnicas para reducir las emisiones de polvo generadas por el transporte mediante camiones volquete

\begin{tabular}{|c|c|}
\hline Aplicación & Medida \\
\hline \multirow[t]{3}{*}{ Aplicables al vehículo (camión volquete) } & $\begin{array}{l}\text { Cubrir la bañera o volquete con un } \\
\text { toldo siempre (con o sin carga) }\end{array}$ \\
\hline & $\begin{array}{l}\text { Asegurar un buen sellado de la } \\
\text { puerta trasera }\end{array}$ \\
\hline & $\begin{array}{c}\text { Moderar la velocidad } \\
\text { principalmente en vías no } \\
\text { asfaltadas }\end{array}$ \\
\hline \multirow[t]{2}{*}{$\begin{array}{c}\text { Aplicables a las empresas (proveedores materias } \\
\text { primas, minas, receptores, etc.) }\end{array}$} & $\begin{array}{l}\text { Sistemas de llenado que eviten } \\
\text { sobrecargas }\end{array}$ \\
\hline & $\begin{array}{c}\text { Evitar ensuciar las vías públicas } \\
\text { (emisiones difusas y seguridad } \\
\text { vial): } \\
\text { Zonas de circulación } \\
\text { pavimentadas y limpias } \\
\text { Disponer de sistemas de limpieza } \\
\text { de ruedas y bajos de vehículos }\end{array}$ \\
\hline
\end{tabular}


Tabla 1.6 Sistemas de transporte de alta eficacia

\begin{tabular}{|c|c|c|c|}
\hline Sistema de transporte & Ventajas & Desventajas & Aplicación general \\
\hline CAMIONES CIST & Muy eficiente & $\begin{array}{c}\text { Necesita } \\
\text { infraestructuras } \\
\text { adecuadas en carga y } \\
\text { descarga }\end{array}$ & $\begin{array}{c}\text { Aplicable a materiales } \\
\text { de alto valor o elevada } \\
\text { toxicidad } \\
\text { Ejemplos: } \mathrm{ZnO}, \\
\text { silicatos de circonio, } \\
\text { nitratos, óxidos de } \\
\text { plomo y cemento }\end{array}$ \\
\hline $\begin{array}{c}\text { SILOS } \\
\text { TRANSPORTABLE } \\
\text { (1) }\end{array}$ & $\begin{array}{l}\text { Muy eficiente } \\
\text { ambientalmente } \\
\text { Gran flexibilidad }\end{array}$ & $\begin{array}{c}\text { Sólo para materiales } \\
\text { con buena fluidez } \\
\text { Necesita: } \\
\text { infraestructura de silos, } \\
\text { camiones especiales, } \\
\text { etc. } \\
\text { Distancias cortas }\end{array}$ & $\begin{array}{c}\text { Aplicable a materiales } \\
\text { de alto valor y consumo } \\
\text { moderado } \\
\text { Ejemplo: granulado } \\
\text { coloreado en cerámica } \\
\text { y piensos }\end{array}$ \\
\hline SACOS O BIG-BAGS & Muy eficiente & $\begin{array}{c}\text { Cantidades moderadas } \\
\text { Gestión de los residuos } \\
\text { de envase }\end{array}$ & $\begin{array}{l}\text { Aplicable a materiales } \\
\text { procesados } \\
\text { Ejemplos: cementos, } \\
\text { fertilizantes, piensos y } \\
\text { fritas }\end{array}$ \\
\hline
\end{tabular}

La aplicación de las medidas preventivas y/o correctoras previamente descritas supone una reducción de las emisiones difusas de PM que puede ser estimada en base al rendimiento de las MTDs implantadas (Tabla 1.7). 
Tabla 1.7 Rendimientos asociados a algunas de las principales medidas correctoras implantadas para la reducción de emisiones difusas de PM

\begin{tabular}{|c|c|c|}
\hline Operación & Medida correctora implantada & Rendimiento (\%) \\
\hline \multirow{4}{*}{$\begin{array}{c}\text { Transporte zona no } \\
\text { asfaltada }\end{array}$} & Riego (>2 litros $\left./ \mathrm{m}^{2} / \mathrm{h}\right)$ & 75 \\
\hline & Pavimentado & 90 \\
\hline & Pavimentado + barrido & 97 \\
\hline & $\begin{array}{c}\text { Pavimentado }+ \text { Barrido }+ \text { Riego con } \\
\text { agua }\end{array}$ & 99 \\
\hline \multirow{3}{*}{ Transporte zona asfaltada } & Barrido & 70 \\
\hline & Riego con agua & 80 \\
\hline & Barrido + Riego con agua & 94 \\
\hline \multirow{4}{*}{ Manipulación } & Riego por aspersión de los montones & 50 \\
\hline & Cabina de cerramiento & 70 \\
\hline & $\begin{array}{l}\text { Cabina de cerramiento parcial + } \\
\text { Instalación filtros de mangas }\end{array}$ & 83 \\
\hline & $\begin{array}{l}\text { Cabina de cerramiento total }+ \\
\text { Instalación filtros mangas }\end{array}$ & 99 \\
\hline \multirow{3}{*}{ Trituración } & Cabina de cerramiento & 70 \\
\hline & $\begin{array}{l}\text { Cabina de cerramiento parcial + } \\
\text { Instalación filtros de mangas }\end{array}$ & 83 \\
\hline & $\begin{array}{l}\text { Cabina de cerramiento total }+ \\
\text { Instalación filtros mangas }\end{array}$ & 99 \\
\hline \multirow{2}{*}{ Erosión } & Vallas perimetrales & 30 \\
\hline & Riego por aspersión de los montones & 50 \\
\hline
\end{tabular}

Fuentes: (Environmental Australia 2012; Generalitat de Catalunya. Direcció General de Qualitat Ambiental 2004)

En este sentido, en función del grado de cerramiento se pueden distinguir tres tipos de instalaciones (Monfort et al. 2011; PMCA-CS 2008):

- Instalaciones cerradas: se incluye el almacenamiento en silos de los materiales pulverulentos, con sistemas de carga y descarga del silo completamente cerrados y dotados de sistemas de aspiración en los puntos en los que pueda generarse polvo; o alternativamente realizar todas las operaciones de almacenamiento y manipulación en naves cerradas y en depresión con filtración posterior del aire evacuado de estos locales.

- Instalaciones semicerradas: zonas de almacenamiento y manipulación de materias primas semicerradas, y cerramiento completo de las zonas en las que se llevan a cabo las operaciones más susceptibles de generar polvo como la molienda. 
- Instalaciones abiertas o al aire libre: la zona de almacenamiento de materias primas se encuentra al aire libre. En ese caso, con el fin de minimizar al máximo la posible resuspensión del material existente en los acopios de material, es necesario implantar medidas preventivas y/o correctoras. Entre ellas destacan el almacenamiento en compartimentos o celdas formadas por muros de contención. Otras medidas a adoptar son principalmente limitar la altura de montones, orientar los montones adecuadamente con respecto a la dirección del viento, mantener siempre humedecidos los materiales al menos superficialmente, disponer de vallas perimetrales con una altura superior a los acopios, cubrir la superficie de los acopios con lonas y evitar trabajos en días de viento intenso.

Además, en función del tipo de cerramiento y el grado de implantación de MTDs, se pueden distinguir cuatro escenarios tecnológicos (Monfort et al. 2011):

- Escenario I: Instalación cerrada. Instalaciones en las que el transporte se realiza por vías pavimentadas y la totalidad de las actividades de manipulación de materiales pulverulentos se realiza en recintos cerrados con aspiración y posterior filtración del aire evacuado.

- Escenario II: Instalación semicerrada. Instalaciones en las que el transporte se realiza por vías pavimentadas y las operaciones de manipulación de materiales pulverulentos se encuentran parcialmente cerradas.

- Escenario III: Instalaciones abiertas con alto grado de implantación de medidas preventivas y/o correctoras. Instalaciones en las que la zona de almacenamiento de materias primas se encuentra al aire libre, el transporte se realiza mayoritariamente por vías pavimentadas y operaciones como la trituración se encuentran cerradas. Disponen de pantallas cortavientos en el perímetro.

- Escenario IV: Instalaciones abiertas con bajo grado de implantación de medidas preventivas y/o correctoras. Instalaciones en las que la zona de almacenamiento de materias primas se encuentra al aire libre, el transporte se realiza mayoritariamente por vías no pavimentadas y disponen de escasas medidas para la reducción de las emisiones generadas en operaciones de manipulación y/o tratamiento de los materiales pulverulentos.

A modo de ejemplo, en la Tabla 1.8, se muestran los resultados obtenidos en un estudio de emisiones difusas de PM realizado en el sector cerámico (Monfort et al. 2011), en el cual, en base a los criterios antes mencionados, las instalaciones en las que se llevan a cabo operaciones susceptibles de generar emisiones difusas de PM fueron divididas en los grupos antes mencionados. 
Tabla 1.8 Rendimientos globales en función del tipo de instalación en industrias de fabricación de productos cerámicos (Adaptado de Monfort et al., 2011)

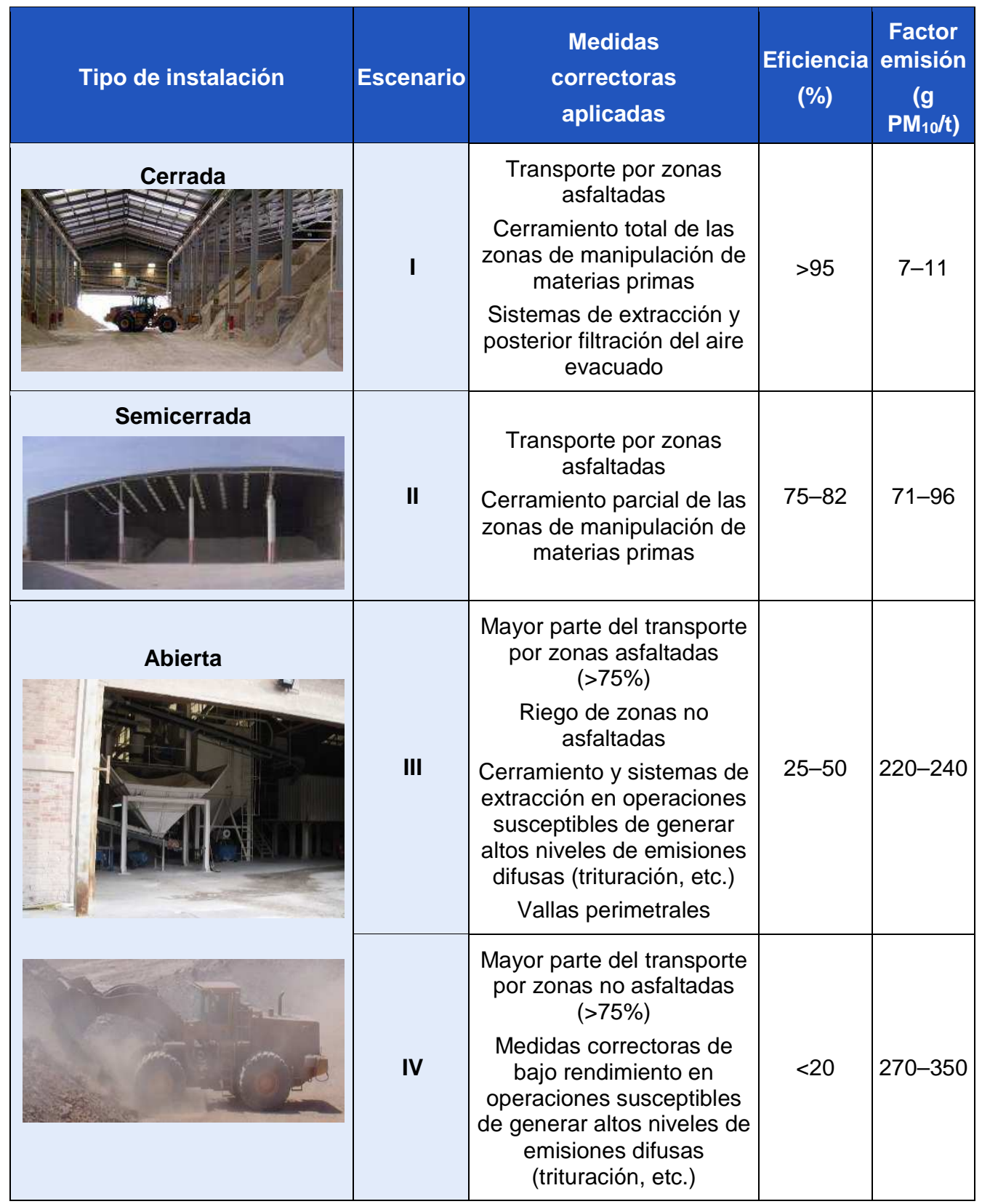

\subsubsection{Control industrial de las emisiones difusas de PM}

Como consecuencia de que las emisiones difusas son vertidas a la atmósfera principalmente desde un área o volumen, y no a través de una conducción, como es el caso de las emisiones canalizadas, no es posible aplicar los métodos de control habituales aplicados para las emisiones canalizadas, basados en la extracción de una muestra representativa e integrada de un volumen conocido de esta corriente y conocido el caudal de la misma, estimar el flujo másico. 
Por tanto, las principales dificultades que se plantean en el control de las emisiones difusas son la cuantificación de las mismas y la evaluación de la eficacia de las medidas correctoras implantadas, debido a la dificultad intrínseca que conlleva su medida en instalaciones complejas, con muchas actividades potencialmente generadoras de emisiones difusas y ubicadas en zonas de elevada concentración industrial. Este hecho, ocasiona que en muchas ocasiones no sea posible asociar valores medidos a una actividad concreta, por lo que se considera necesario conocer los perfiles químicos de diferentes tipos de fuentes y del aire ambiente para poder realizar una estimación de contribución de fuentes (Watson et al. 2002; Watson, Chow \& Houck 2001; Watson, Chow \& Fujita 2001).

Asimismo, cabe destacar que la elevada complejidad que presenta el estudio de las emisiones difusas de PM radica principalmente en que además de factores de ingeniería de proceso o tecnológicos como el tipo de pretratamiento del material y de las medidas correctoras implantadas (cobertura parcial de los montones de material, riego por aspersión con agua y/o con agentes tensoactivos, vallas cortavientos perimetrales, etc.), influyen en gran medida las condiciones meteorológicas tales como velocidad y dirección predominante del viento, precipitaciones, estabilidad atmosférica, etc. Estas condiciones meteorológicas a su vez inciden de forma conjunta tanto en la generación de partículas en las emisiones difusas, como en la posterior dispersión de las mismas a la atmósfera. Estos factores físicos, técnicos y meteorológicos pueden variar ampliamente en función del proceso y de la zona geográfica en la que se ubique la instalación.

Por otro lado, las características del material procesado (naturaleza, granulometría, etc.) pueden tener un efecto significativo sobre su poder de emisión de polvo, es decir, sobre su tendencia a generar polvo cuando es sometido a una manipulación.

Otro problema asociado al estudio de este tipo de emisiones es la identificación en una zona determinada de todas las actividades generadoras de emisiones difusas, ya que existen pequeñas empresas o actividades, pero en gran número, que pueden emitir cantidades significativas, y cuantificar todas estas fuentes presenta una gran complejidad. Este hecho se refleja en los inventarios de emisiones que se realizan para modelizar la calidad de aire a nivel local, nacional, etc., ya que se observa una subestimación de los niveles obtenidos al no disponer de información real de las fuentes emisoras.

Esta situación conlleva una elevada complejidad en la cuantificación de emisiones difusas de PM de forma experimental por lo que para el control industrial se recurre a metodologías más sencillas de aplicar. Uno de los métodos más extendidos para el control de las emisiones difusas de PM es la medida de la concentración de PM en el perímetro de la instalación. Esta metodología es sencilla y posibilita la comparación directa con los valores límite establecidos para partículas en suspensión totales, $\mathrm{PM}_{10}$ y partículas sedimentables (ver capítulo 1.4) pero no permite cuantificar el flujo másico 
emitido. Además, requiere una evaluación exhaustiva para localizar los puntos adecuados de muestreo; la ubicación de los equipos debe realizarse en puntos en los que no se produzcan o sean mínimas las interferencias con focos de emisión distintos del foco objeto de estudio. Además, los puntos de muestreo pueden requerir disponer de suministro eléctrico y ser zonas seguras en cuanto a robos, manipulación de equipos, etc.

Por este motivo, una de las metodologías más extendidas para la cuantificación de las emisiones difusas de PM es el uso de factores de emisión teóricos o de ecuaciones semiempíricas cuya aplicación es sencilla y requiere el conocimiento de pocos parámetros experimentales. No obstante, el uso de este tipo de factores, conlleva en ocasiones el establecimiento de escenarios medioambientales basados en información estimada o en la aplicación de factores de emisión que no son representativos de una muestra determinada. Por tanto, los resultados obtenidos mediante esta metodología pueden presentar elevadas incertidumbres y/o no ser representativos de la situación real o de la zona de estudio considerada.

En este sentido, con la finalidad de obtener factores de emisión que permitan realizar inventarios de emisiones más precisos, se pueden emplear dos metodologías experimentales: métodos basados en balances de materia en instalaciones cerradas, denominados en la bibliografía "Roof monitor" (Monfort et al. 2009; Enviroment Australia 1999) y modelos de dispersión inversa.

La metodología "Roof Monitor" puede emplearse para la estimación de emisiones asociadas a actividades que se desarrollan íntegramente en instalaciones completamente cerradas. Este método se basa en calcular el flujo de materia en las principales aberturas. Para aplicar este método, se mide la concentración de $\mathrm{PM}_{10}\left(\mathrm{C}_{\mathrm{i}}\right)$ y la velocidad del viento $\left(\mathrm{V}_{\mathrm{i}}\right)$ en cada una de las aberturas principales de la instalación. La emisión total (E, Ecuación 1.2), será la suma de todas las emisiones individuales, en cada una de las aberturas.

$$
E=\sum_{i=1}^{n} v_{i} \cdot C_{i} \cdot A \cdot 10^{-6}
$$

Ecuación 1.2

E: Emisión global de las $n$ aberturas ( $\mathrm{g} / \mathrm{s})$; $\mathrm{V}_{\mathrm{i}}$ : Velocidad media del viento en la abertura $\mathrm{i}$ $(\mathrm{m} / \mathrm{s})$; $\mathrm{C}_{\mathrm{i}}$ : Concentración de $\mathrm{PM}_{10}$ en la abertura i $\left(\mu \mathrm{g} \mathrm{PM} 10 / \mathrm{m}^{3}\right)$, A: Área de la abertura i $\left(\mathrm{m}^{2}\right)$

Por otro lado, los modelos de dispersión de contaminantes se basan en estimar la concentración conociendo la emisión de contaminantes. Si el dato conocido es la concentración, se pueden emplear para estimar la emisión. En este caso se suelen denominar modelos de dispersión inversa (MDI). La aplicación de esta metodología implica la realización de campañas de medida en las que se registran en continuo las concentraciones de material particulado, así como aquellos parámetros meteorológicos y de posicionamiento que posibiliten la simulación de la dispersión de contaminantes. En algunos casos, en función 
del modelo empleado, se requiere el registro de otros parámetros (registro de actividad, altura de la fuente, recorrido de fuentes móviles, etc.).

En la Tabla 1.9 se muestra un resumen referente a las distintas metodologías empleadas para la estimación y control de las emisiones difusas de PM, sus ventajas y desventajas y el ámbito de aplicación de las mismas.

Tabla 1.9 Metodología para la estimación de emisiones difusas de PM

\begin{tabular}{|c|c|c|c|c|c|}
\hline \multicolumn{3}{|c|}{ Métodos } & Ventajas & Desventajas & Aplicación \\
\hline \multicolumn{3}{|c|}{$\begin{array}{c}\text { Concentraciones } \\
\text { perimetrales }\end{array}$} & $\begin{array}{l}\text { Valores directos, } \\
\text { no requiere } \\
\text { cálculos } \\
\text { Sencillez en la } \\
\text { interpretación }\end{array}$ & $\begin{array}{c}\text { No cuantifica el flujo } \\
\text { másico } \\
\text { Ubicación adecuada } \\
\text { de los puntos de } \\
\text { muestreo }\end{array}$ & $\begin{array}{l}\text { Control de } \\
\text { instalaciones }\end{array}$ \\
\hline \multirow{3}{*}{$\begin{array}{l}\text { Flujo } \\
\text { másico }\end{array}$} & \multicolumn{2}{|c|}{$\begin{array}{c}\text { Ecuaciones } \\
\text { semiempíricas y } \\
\text { factores de emisión }\end{array}$} & $\begin{array}{l}\text { Muy útiles para } \\
\text { estimar } \\
\text { emisiones sobre } \\
\text { proyectos } \\
\text { Requieren pocos } \\
\text { parámetros } \\
\text { experimentales }\end{array}$ & $\begin{array}{l}\text { Pueden presentar } \\
\text { incertidumbres } \\
\text { elevadas si los } \\
\text { factores de emisión } \\
\text { y/o ecuaciones } \\
\text { semiempíricas no } \\
\text { son representativos } \\
\text { de las condiciones } \\
\text { reales de la } \\
\text { instalación }\end{array}$ & $\begin{array}{l}\text { Inventarios de } \\
\text { emisiones } \\
\text { Declaraciones } \\
\text { anuales } \\
\text { Control de } \\
\text { rendimientos }\end{array}$ \\
\hline & \multirow[b]{2}{*}{ Experimentales } & $\begin{array}{c}\text { Roof } \\
\text { Monitor }\end{array}$ & $\begin{array}{l}\text { Se basa en los } \\
\text { valores } \\
\text { experimentales } \\
\text { de la instalación, } \\
\text { mayor precisión } \\
\text { Cálculo } \\
\text { matemático } \\
\text { sencillo }\end{array}$ & $\begin{array}{l}\text { Sólo aplicable a } \\
\text { recintos cerrados }\end{array}$ & \multirow{2}{*}{$\begin{array}{l}\text { Obtención de } \\
\text { factores de } \\
\text { emisión que } \\
\text { permitan realizar } \\
\text { inventarios de } \\
\text { emisiones más } \\
\text { precisos } \\
\text { (Escenarios } \\
\text { complejos o no } \\
\text { estudiados. } \\
\text { Investigación) }\end{array}$} \\
\hline & & aMDI & $\begin{array}{c}\text { Se basa en } \\
\text { datos } \\
\text { experimentales } \\
\text { de la instalación, } \\
\text { mayor precisión } \\
\text { Al usar modelos } \\
\text { permite simular } \\
\text { distintas } \\
\text { situaciones }\end{array}$ & $\begin{array}{l}\text { Tratamiento } \\
\text { matemático } \\
\text { complejo }\end{array}$ & \\
\hline
\end{tabular}

a MDI (RDM): Modelos de dispersión inversa (Reverse dispersion model) 


\subsection{Efectos del PM sobre la salud}

Cuando se hace referencia a la concentración de PM en el aire y sus efectos sobre la salud, es importante matizar la diferencia del concepto concentración de partículas en las siguientes situaciones:

- Concentración de partículas en el aire ambiente (calidad del aire), que es el aire que respira la población en general, incluidos la población más sensible (niños, ancianos y personas con afecciones respiratorias).

- Concentración de partículas en el aire ambiente de trabajo (higiene industrial), que es el aire que respira un trabajador sano, durante periodos de exposición relativamente reducidos (alrededor de 40 horas semanales).

\subsubsection{Contaminación atmosférica}

La relación existente entre elevados niveles de contaminación atmosférica y efectos adversos en la salud es conocida desde la antigüedad y cobró importancia a partir de la primera mitad del siglo XX cuando en los países industrializados se produjo un incremento en la mortalidad y morbilidad que evidenció que los niveles altos de contaminación atmosférica se asociaban causalmente con un incremento en las muertes tempranas (Querol et al. 2012).

En referencia al PM, numerosos estudios afirman que existe una correlación significativa entre la exposición a PM y diversos efectos adversos sobre la salud (WHO 2005; Wichmann \& Peters 2000; Künzli et al. 2000; Künzli et al. 1997; Brunekreef 1997; Brunekreef, B. et al. 1997; Dockery \& Pope 1996; Bascom 1996; Schwartz 1996; Schwartz et al. 1996; Schwartz et al. 1994; J. Schwartz 1994; J Schwartz 1994; Dockery et al. 1993). Los efectos del PM dependen fundamentalmente de los siguientes factores: granulometría, composición y tiempo de exposición a un ambiente con altos niveles de PM.

En referencia a la granulometría, las partículas de $\mathrm{PM}_{10}$ son capaces de penetrar en la región tetrabronquial, se denominan partículas torácicas y son eliminadas por acción ciliar. La fracción respirable (equivalente aproximadamente a $\mathrm{PM}_{4}$ ) se corresponde con la fracción másica de las partículas inhaladas que penetra en las vías respiratorias no ciliadas. Las partículas de diámetro entre 0.1 y $2.5 \mu \mathrm{m}$ pueden alcanzar la cavidad alveolar, son denominadas partículas alveolares, llegan a los bronquios y no son eliminadas, quedando retinadas de forma crónica (Leopold \& Gough 1957). Las partículas de diámetro inferior a $0.1 \mu \mathrm{m}$ son demasiado pequeñas para sedimentar durante la respiración, no obstante, se depositan en las paredes alveolares por difusión o bien se expulsan con la misma respiración, se eliminan rápidamente y no son retenidas en cantidad en el parénquima pulmonar (Brauer, Avila-Casado, et al. 2001; Brauer, Ebelt, et al. 2001; Churg \& Brauer 1997). En la Figura 1.8 y Figura 1.9 se muestran un esquema de la penetración de material particulado y la deposición fraccional del mismo en el tracto respiratorio (Koivisto 2013), respectivamente. 


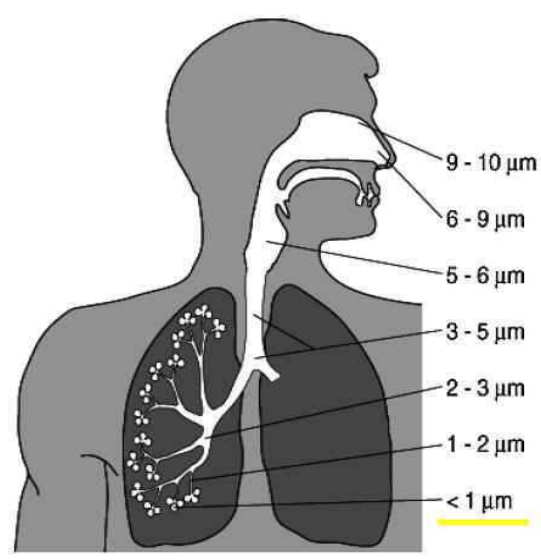

Figura 1.8 Penetración del material particulado en el aparato respiratorio (fuente: http://www.cleanairhouston.com/test-page.htm)

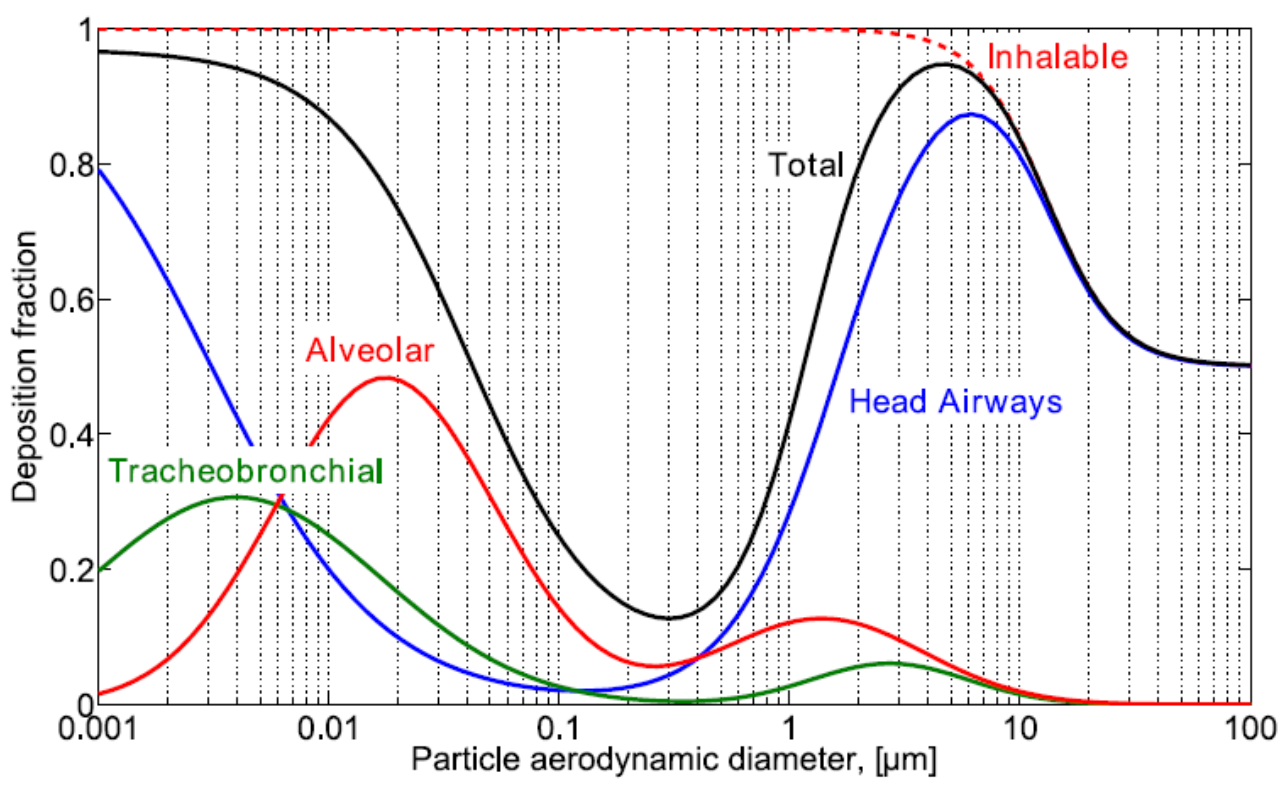

Figura 1.9 Depósito fraccional en cada región del tracto respiratorio bajo condiciones de reposo o ejercicio ligero (respiración por la nariz) de acuerdo al modelo ICRP. Fuente: (Koivisto, 2013)

Para llevar a cabo la interpretación de los efectos que produce la contaminación atmosférica en la salud, se pueden realizar dos clases de estudios: los toxicológicos y los epidemiológicos.

- Estudios toxicológicos: se basan en exponer al hombre o animales a la sustancia contaminante cuyos efectos se desean evaluar. En estos estudios, la concentración, duración y condiciones de la exposición son controladas por el investigador. 
- Estudios epidemiológicos: se basan en la observación de los sucesos que se desarrollan en las poblaciones humanas bajo condiciones naturales. Como medida de la exposición a la contaminación atmosférica muchos estudios han utilizado los datos de las redes de vigilancia de la contaminación atmosférica, pero también se utilizan otros tipos de aproximaciones a la medida de la exposición.

Las partículas en suspensión son el contaminante más comúnmente utilizado como indicador de contaminación, especialmente las $\mathrm{PM}_{10}$, para efectos a corto plazo, y las $\mathrm{PM}_{2.5}$ o partículas finas como indicadores de la exposición a largo plazo. Como resultado de los centenares de estudios epidemiológicos que evalúan los efectos de la contaminación atmosférica en la salud se dispone de una serie de estimaciones sobre la asociación entre las exposiciones a contaminantes y diferentes efectos en salud (Querol et al. 2012). En la Tabla 1.10 se resumen los resultados de estudios internacionales respecto a los efectos de la exposición, aguda y crónica, a las partículas en suspensión.

Tabla 1.10 Resumen de los efectos de la exposición a partículas en suspensión (adaptado de Querol et al. 2012)

\begin{tabular}{|c|c|c|c|}
\hline \multirow{2}{*}{\multicolumn{2}{|c|}{ Efectos en salud }} & \multicolumn{2}{|c|}{$\begin{array}{l}\text { Cambio porcentual en el indicador de } \\
\qquad \text { la salud }\end{array}$} \\
\hline & & $\begin{array}{c}\text { Incremento de } 10 \\
\mu \mathrm{g} / \mathrm{m}^{3} \text { en } \mathrm{PM}_{10}\end{array}$ & $\begin{array}{l}\text { Incremento de } 5 \\
\mathrm{ug} / \mathrm{m}^{3} \text { en } \mathrm{PM}_{2.5}\end{array}$ \\
\hline \multirow{4}{*}{$\begin{array}{l}\text { Incremento } \\
\text { Mortalidad }\end{array}$} & $\begin{array}{l}\text { Todas las causas } \\
\text { menos las externas }\end{array}$ & $0.2-1.0$ & $2-3$ \\
\hline & Cardiovascular & $0.7-1.4$ & $3-6$ \\
\hline & Respiratoria & $1.3-3.4$ & - \\
\hline & Cáncer de pulmón & - & 4 \\
\hline \multirow{4}{*}{$\begin{array}{l}\text { Incremento } \\
\text { Ingresos } \\
\text { hospitalarios }\end{array}$} & $\begin{array}{l}\text { Enfermedades } \\
\text { respiratorias }\end{array}$ & $0.8-2.4$ & - \\
\hline & $\begin{array}{l}\text { Enfermedad pulmonar } \\
\text { obstructiva crónica }\end{array}$ & $1.0-2.5$ & - \\
\hline & Asma & $1.1-1.9$ & - \\
\hline & $\begin{array}{l}\text { Enfermedades } \\
\text { cardiovasculares }\end{array}$ & $0.5-1.2$ & - \\
\hline Enfermedades & Bronquitis & - & 7 \\
\hline \multirow{2}{*}{$\begin{array}{l}\text { Disminución de la } \\
\text { función pulmonar }\end{array}$} & Niños & 0.15 & 1 \\
\hline & Adultos & 0.08 & 1.5 \\
\hline
\end{tabular}


En base a los resultados obtenidos en dichos estudios epidemiológicos (Samoli et al. 2008; Pope \& Dockery 2006; Stieb et al. 2002; Pope et al. 2002; Tertre et al. 2002; Dominici et al. 2002; Katsouyanni et al. 2001; Biggeri et al. 2001; Atkinson et al. 2001; Samet et al. 2000), puede observarse:

- En referencia a exposiciones agudas: a incrementos diarios de $10 \mu \mathrm{g} / \mathrm{m}^{3}$ en los niveles de $\mathrm{PM}_{10}$ le sigue un aumento en el número de defunciones diarias de entre el 0.2 y el $1 \%$. La magnitud de dicha relación es mayor para causas cardiovasculares y respiratorias. Para los ingresos hospitalarios por causas respiratorias los resultados indican un incremento de entre el 0.8 y el $2.4 \%$. Finalmente, en referencia a la disminución de la función pulmonar se observa un incremento del 0.15 y $0.08 \%$ para niños y adultos, respectivamente.

- En referencia a exposiciones crónicas: A incrementos de $5 \mu \mathrm{g} / \mathrm{m}^{3}$ en los niveles de $\mathrm{PM}_{2.5}$, le sigue un aumento en el número de defunciones de entre el 2 y el $3 \%$. La magnitud de dicha relación es mayor para causas cardiovasculares. En el caso de la bronquitis los resultados indican un incremento del $7 \%$. Finalmente, en referencia a la disminución de la función pulmonar, se observa un incremento del 1 y $1.5 \%$ para niños y adultos, respectivamente.

\subsubsection{Salud laboral}

En cualquier actividad industrial en la que se genere PM, adicionalmente a la problemática asociada a la emisión al ambiente externo, existe un riesgo interno por exposición laboral a PM en los ambientes laborales.

En este sentido, existen multitud de estudios sobre la problemática asociada a la exposición a PM en ambientes laborales (Gautam et al. 2016; Moran et al. 2014; Hashim 2014; Healy et al. 2013; Radnoff \& Kutz 2013; Fang et al. 2010; Monfort et al. 2008). Los resultados obtenidos en estos estudios, así como los listados de enfermedades profesionales causadas por inhalación de polvo en España ((CEPROSS 2015),(Tabla 1.11), denotan la necesidad de controlar y minimizar los niveles de exposición a PM en ambientes laborales. Cabe destacar que se entiende por enfermedad profesional el deterioro lento y paulatino de la salud del trabajador, producido por una exposición crónica a situaciones adversas, sean éstas producidas por el ambiente en el que se desarrolla el trabajo o por la forma en que éste está organizado (INSHT n.d.). 
Tabla 1.11 Partes comunicados por enfermedades profesionales causadas por inhalación de sustancias (Fuente: CEPROSS - Seguridad Social, 2015)

\begin{tabular}{|c|c|c|c|}
\hline Agente & $\begin{array}{c}\text { Con } \\
\text { baja }\end{array}$ & $\begin{array}{c}\text { Sin } \\
\text { baja }\end{array}$ & Total \\
\hline $\begin{array}{c}\text { Sustancias de alto peso molecular (sustancias de origen } \\
\text { vegetal, animal, microorganismos, y sustancias enzimáticas } \\
\text { de origen vegetal, animal y/o de microorganismos) }\end{array}$ & 159 & 128 & 287 \\
\hline Polvo de sílice libre & 101 & 141 & 242 \\
\hline $\begin{array}{c}\text { Sustancias de bajo peso molecular (metales y sus sales, } \\
\text { polvos de maderas, productos farmacéuticos, sustancias } \\
\text { químico plásticas, aditivos, etc.) }\end{array}$ & 80 & 73 & 153 \\
\hline Polvos de amianto (asbesto) & 11 & 43 & 54 \\
\hline $\begin{array}{c}\text { Otros polvos de minería (Talco, caolín, tierra de batán, } \\
\text { bentonita, sepiolita, mica, otros silicatos naturales) }\end{array}$ & 8 & 13 & 21 \\
\hline $\begin{array}{c}\text { Metales sinterizados, compuestos de carbono metálicos de } \\
\text { alto punto de fusión y metales de ligazón de bajo punto de } \\
\text { fusión }\end{array}$ & 5 & 5 & 10 \\
\hline Polvo de carbón & 2 & 4 & 6 \\
\hline Neumoconiosis por polvo de aluminio & 1 & 2 & 3 \\
\hline Berilio (glucinio) y sus compuestos & 1 & 0 & 1 \\
\hline Total & $\mathbf{3 6 8}$ & $\mathbf{4 0 9}$ & $\mathbf{7 7 7}$ \\
\hline
\end{tabular}

A partir de la Tabla 1.11 se puede observar el significativo número de enfermedades profesionales producidas por exposición a PM. Cabe destacar las causadas por inhalación de sílice (uno de los materiales objeto de la presente tesis doctoral). En Europa existen más de 4 millones de trabajadores expuestos al polvo de la sílice cristalina respirable (European Trade Union Confederation, 2007). En este sentido, los países con un mayor número de trabajadores expuestos a sílice cristalina respirable (SCR) son: Alemania, Reino Unido, España, Italia, Países Bajos, Francia y Austria (Scarselli et al. 2008; Mirabelli \& Kauppinen 2005; Kauppinen et al. 2000) (Figura 1.10).

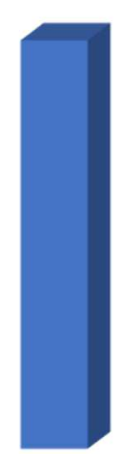

Alemania Reino Unido

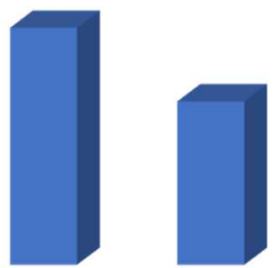

España
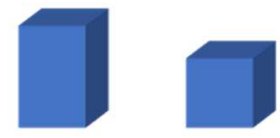

Italia Países Bajos

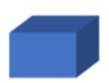

Francia

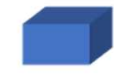

Austria

Figura 1.10 Países europeos con un mayor número de trabajadores expuestos a SCR 
Con respecto a lo antes mencionado, es bien conocido que la exposición prolongada a sílice cristalina respirable (SCR) causa inflamación pulmonar, el desarrollo de granulomas y silicosis (Leung et al. 2012; Monfort et al. 2008; Clouter et al. 2001; Soutar et al. 2000; Donaldson \& Borm 1998; Goldsmith et al. 1997; Castranova et al. 1995), Figura 1.11.

Aparte de estar ligada a una enfermedad profesional propia (silicosis), la Agencia Internacional de Investigación sobre el Cáncer (IARC) ha planteado la posibilidad de que exista un vínculo entre la exposición a SCR y el riesgo de contraer cáncer de pulmón (IARC 1997; IARC 1987). En efecto, este organismo ha clasificado a "la sílice cristalina inhalada en la forma de cuarzo o cristobalita" como carcinógena para los humanos (grupo 1).

En este sentido, en la monografía de la IARC en la que se establecía la citada clasificación (IARC 1997) se puntualizó: "la carcinogénesis no se ha constatado en todas las situaciones industriales estudiadas", lo que no tenía precedentes hasta la fecha. Además, también se indicaba que "la carcinogénesis parece depender de características inherentes a la sílice cristalina o de factores externos que afectan a su actividad biológica".

No obstante, en la monografía publicada en 2012 (IARC 2012),se indicó que "Existen evidencias suficientes de la carcinogénesis de la sílice cristalina respirable en forma de cuarzo o cristobalita. El polvo de sílice cristalina en forma de cuarzo o cristobalita provoca cáncer de pulmón. Hay evidencias suficientes de la carcinogénesis del polvo de cuarzo en experimentos animales. Hay una evidencia limitada en los experimentos animales sobre la carcinogénesis del polvo de tridimita y cristobalita. La sílice cristalina respirable en forma de cuarzo y cristobalita es carcinógena para los humanos (tipo 1)."

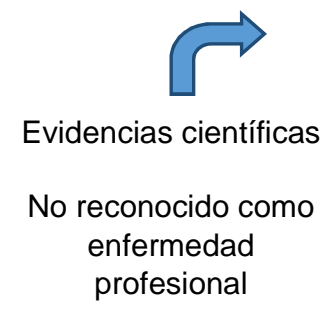

En fase de inclusión en la directiva de agentes cancerígenos

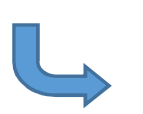

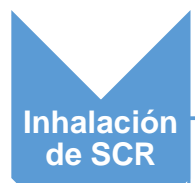

- La inhalación en grandes dosis de SCR produce la enfermedad profesional conocida como silicosis

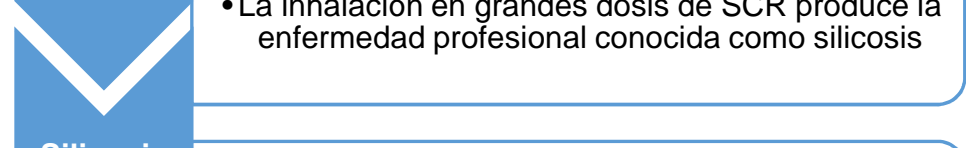

Silicosis

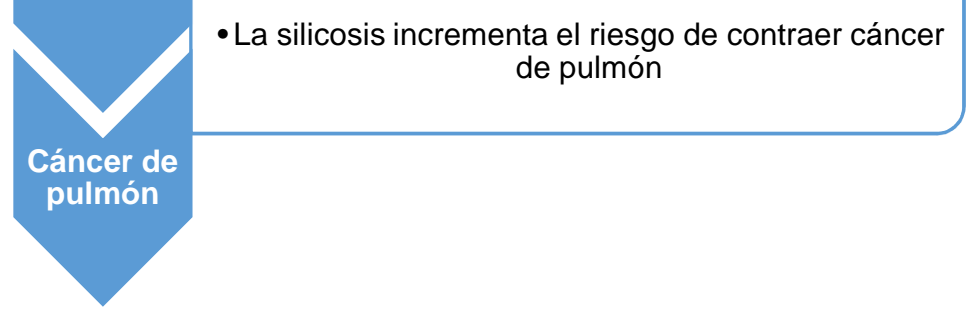

Figura 1.11 Efecto exposición prolongada a SCR 
En este sentido, el Comité Científico para los Límites de Exposición profesional a Agentes Químicos de la Unión Europea (SCOEL/SUM/94 2003) indicó que el valor límite de exposición a SCR debería ser inferior a $0.05 \mathrm{mg} / \mathrm{m}^{3}$. Además, actualmente se encuentra en fase de consulta la inclusión de la SCR en la directiva europea sobre agentes carcinogénicos y mutagénicos ((COM (2016), amending Directive 2004/37/EC). En esta propuesta se establecen las medidas a adoptar en la gestión de este tipo de sustancias y se establece un límite máximo para la SCR de $0.1 \mathrm{mg} / \mathrm{m}^{3}$. Este valor límite de exposición es el actual límite de exposición de muchos países (Figura 1.12). No obstante, otros países deberán implantarlo y/o modificarlo para adecuarse a la nueva legislación (Alemania, Polonia, etc.). Por último, ciertos países, como España, tienen un valor límite de exposición inferior al valor propuesto y, por tanto, debería prevalecer el valor más restrictivo.

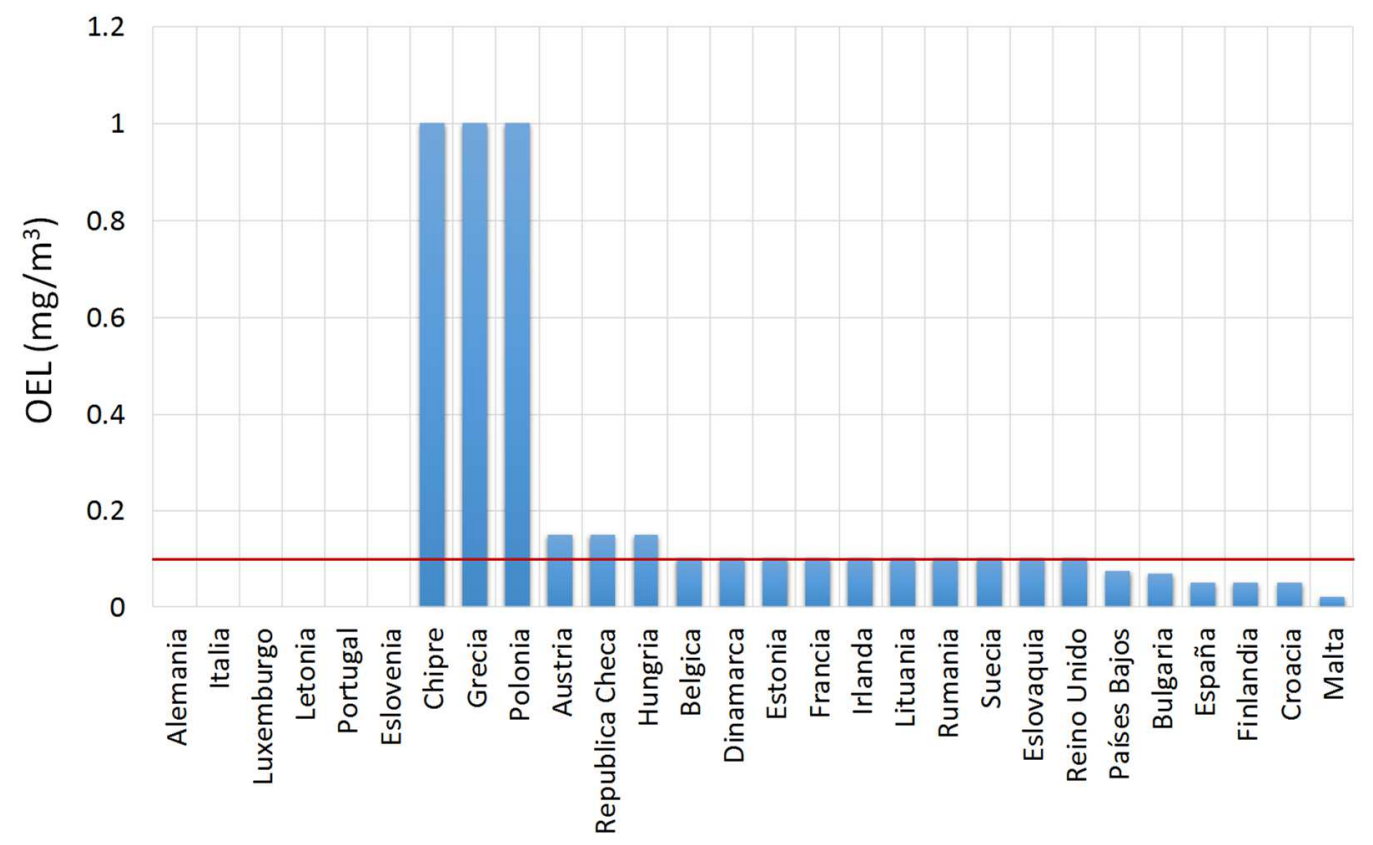

Figura 1.12 SCR: Actual OEL (Occupational Exposure Limit) y límite propuesto por la UE 


\subsection{Legislación en materia de PM}

\subsubsection{Contaminación atmosférica}

\subsubsection{Introducción al marco normativo}

La normativa en materia de contaminación atmosférica tiene como última finalidad establecer los niveles considerados como tolerables para la protección del medio ambiente, y sobre todo la salud de los ciudadanos. Para ello, la normativa se centra por un lado en controlar los niveles de emisión en las fuentes contaminantes (fijas y móviles), y, por otro lado, en la conservación y mejora de los niveles de calidad del aire (relativamente equivalentes a los de exposición de la población).

A partir de los años setenta, en los países de Europa más desarrollados, comenzó a emerger legislación referente a temas ambientales, ligada a un apreciable y creciente proceso de industrialización, desarrollo tecnológico, explotación cada vez más intensiva de los recursos y de urbanización de grandes áreas de territorio. En este sentido, las primeras medidas de niveles de contaminación atmosférica se iniciaron en 1960. Paralelamente se iniciaron las políticas de control ambiental y, como consecuencia de ello, durante las décadas de los 70 y 80 se registró un notable descenso en los niveles de contaminación atmosférica.

En el año 1987 la Organización Mundial de la Salud (OMS) editó la primera edición de sus Guías de calidad del aire para Europa. En estas guías se establecían valores para distintos contaminantes como objetivo a no superar. A partir de ese momento, con el objetivo de proteger a la población y al medio ambiente, se han establecido sucesivos programas europeos en materia de medio ambiente como el: "Programa Aire Puro para Europa (denominado por sus siglas en inglés CAFE: Hacia una estrategia temática en pro de la calidad del aire"), aprobado por la Comisión Europea en el 2001.

Por otro lado, a nivel estatal la conservación del medio ambiente es de tal importancia, que la propia Constitución Española de 1978, norma fundamental de nuestro ordenamiento jurídico, reconoce en su artículo 45 el derecho de todos los españoles a disfrutar de un medio ambiente adecuado para el desarrollo de la persona, de igual forma que establece el deber de conservarlo.

Respecto a los instrumentos normativos que regulan la calidad del aire, merece especial atención, la Directiva 1996/62/CE del Consejo, de 27 de septiembre de 1996, sobre evaluación y control de la calidad del aire ambiente, fue comúnmente denominada "Directiva Marco" o "Directiva Madre" (DM), y tomada como base normativa para el posterior desarrollo de mecanismos de gestión y evaluación de la calidad del aire ambiente.

A partir de ésta, surgen una serie de directivas o "Directivas Hijas" (DHs) que establecen criterios específicos de gestión y evaluación para distintos contaminantes, entre las que destacan: la Directiva 1999/30/CE, relativa al 
dióxido de azufre, óxidos de nitrógeno, partículas y plomo; la Directiva 2000/69/CE, relativa al benceno y el monóxido de carbono; y la Directiva 2002/03/CE, relativa al ozono en el aire ambiente. En fecha 15 de febrero de 2005 entra en vigor la Directiva 2004/107/CE, relativa al arsénico, cadmio, mercurio, níquel y los hidrocarburos aromáticos policíclicos en el aire ambiente. Estas directivas entraron a nuestro ordenamiento jurídico, a partir de la base legal que constituía la Ley 38/1972, de 22 de diciembre, desarrollada por el Decreto 833/1975 mediante los siguientes decretos: R.D. 1073/2002, R.D. 1796/2003 y R.D. 812/2007. Cabe mencionar que la Directiva 2008/50/CE del Parlamento Europeo y del Consejo, relativa a la calidad del aire ambiente y a una atmósfera más limpia en Europa, sustituye a todas las DHs excepto la 2004/107/CE.

A nivel estatal, la Ley 38/1972, de 22 de diciembre, de Protección del Ambiente Atmosférico fue sustituida por la Ley 34/2007, de 15 de noviembre, de calidad del aire y protección de la atmosfera. Para trasponer al derecho español la Directiva 2008/50/CE, desarrollar la ley $34 / 2007$ y simplificar la normativa nacional, el 28 de enero de 2011 se aprobó el R.D. 102/2011 sobre la mejora de la calidad del aire, que sustituye a los siguientes reales decretos: R.D. 1073/2002, R.D. $1796 / 2003$ y R.D. 812/2007.

Recientemente, la Directiva 2015/1480 ha modificado varios anexos de las directivas anteriores (2008/50/CE y 2004/107/CE), en los que se establecen las normas relativas a los métodos de referencia, la validación de datos y la ubicación de los puntos de muestreo para la evaluación de la calidad del aire ambiente. A nivel estatal, para incorporar las novedades de la Directiva 2015/1480, el R.D. $102 / 2011$ ha sido recientemente modificado por el R.D. $39 / 2017$.

\subsubsection{Normativa de calidad de aire en referencia al PM}

En España, hasta el año 2001, el control de los niveles de PM se realizaba a partir de medidas de humos negros $(\mathrm{HN})$ y de partículas totales en suspensión (PST), según el R.D. 1613/1985 y el R.D. 1321/1992, que provienen de la incorporación a la legislación española de las Directivas Europeas 80/779/CEE y 98/427/CEE.

A partir de julio de 2001 entró en vigor la Directiva Europea 1999/30/CE que, como ya se ha mencionado con anterioridad, establece "valores límite $y$, en su caso, umbrales de alerta con respecto a las concentraciones de dióxido de azufre, dióxido de nitrógeno y óxidos de nitrógeno, partículas y plomo en el aire ambiente para evitar, prevenir o reducir los efectos nocivos para la salud humana y para el medio ambiente en su conjunto". Esta nueva Directiva produjo un cambio en los parámetros de medida, pasándose a medir $\mathrm{PM}_{10}$ (definido como la masa de partículas que pasan a través de un cabezal de tamaño selectivo para un diámetro aerodinámico de $10 \mu \mathrm{m}$ con una eficiencia de corte del $50 \%$ ) en vez de HN y PST, y estableciendo una mayor restricción en los valores límite. 
Esta nueva Directiva proponía dos fases. La Fase I hasta el 2005, con un límite anual medio de concentración de partículas de $40 \mu \mathrm{g} / \mathrm{m}^{3}$ y diario de $50 \mu \mathrm{g} / \mathrm{m}^{3}$, donde el número de superaciones anuales permitidas del valor límite diario (VLD) es de 35. La Fase II (2010), con valores indicativos de $20 \mu \mathrm{g} / \mathrm{m}^{3}$ de media anual y $50 \mu \mathrm{g} / \mathrm{m}^{3}$ de media diaria para el percentil 99, lo que corresponde a 7 días de superaciones permitidas en un año.

Sin embargo, la directiva expone que para que la fase de 2010 entrase en vigencia, los valores indicativos fijados para tal fecha tendrían que haberse ratificado como tales en la evaluación de la directiva de 2003. Esta ratificación no se ha producido, dado que los estudios realizados indican que los límites propuestos no eran realistas y, por tanto, no han llegado a entrar en vigor, quedando como valores límite de $\mathrm{PM}_{10}$ los fijados para la primera fase.

En la Directiva también se proponía que a finales de 2003 se evaluara la posibilidad de determinar valores límite para el parámetro $\mathrm{PM}_{2.5}$, dado que estudios epidemiológicos apuntan que las partículas más perjudiciales para la salud son aquellas con un diámetro menor de $2.5 \mu \mathrm{m}$. Este aspecto se contempla en la aprobada, Directiva 2008/50/CE, del Parlamento Europeo y del Consejo, de 21 de mayo de 2008, relativa a la calidad del aire ambiente y a una atmósfera más limpia en Europa, que regula los niveles de $\mathrm{PM}_{10}$, incorporando también nueva regulación para los niveles de concentración de $\mathrm{PM}_{2.5}$. En el caso de $\mathrm{PM}_{10}$, dicha Directiva no ha modificado los límites ya vigentes, y en cuanto a $\mathrm{PM}_{2.5}$, el valor propuesto se establece en $25 \mu \mathrm{g} / \mathrm{m}^{3}$. Dicho valor se fijó como valor objetivo para 2010 y desde 2015 se aplica como valor límite.

Tabla 1.12 Valores límite anuales, diarios y número de superaciones establecidos en España desde 1992 hasta la actualidad

\begin{tabular}{|c|c|c|c|c|}
\hline $\begin{array}{l}\text { Normativa } \\
\text { europea }\end{array}$ & $\begin{array}{l}\text { Directivas } \\
\text { 80/779/CEE y } \\
\text { 98/427/CEE }\end{array}$ & $\begin{array}{c}\text { Directiva } \\
\text { 1999/30/CE }\end{array}$ & \multicolumn{2}{|c|}{ Directiva 2008/50/CE } \\
\hline $\begin{array}{l}\text { Normativa } \\
\text { estatal }\end{array}$ & R. D. $1321 / 1992$ & R.D. $1073 / 2002$ & \multicolumn{2}{|c|}{ R.D. $102 / 2011$} \\
\hline Período & $1992-2001$ & $2001-2010$ & \multicolumn{2}{|c|}{$2011-2015$} \\
\hline Parámetro & PST & $\mathrm{PM}_{10}$ & $\mathrm{PM}_{10}$ & $\mathrm{PM}_{2.5}$ \\
\hline $\begin{array}{c}\text { Valor límite } \\
\text { anual }\left(\mu \mathrm{g} / \mathrm{m}^{3}\right)\end{array}$ & 150 & 40 & 40 & $25(>2015)$ \\
\hline $\begin{array}{l}\text { Valor objetivo } \\
\text { anual }\left(\mu \mathrm{g} / \mathrm{m}^{3}\right)\end{array}$ & - & - & - & $25(<2015)$ \\
\hline $\begin{array}{c}\text { Valor límite } \\
\text { diario }\left(\mu \mathrm{g} / \mathrm{m}^{3}\right)\end{array}$ & 300 & 50 & 50 & - \\
\hline $\begin{array}{c}\text { Número de } \\
\text { superaciones del } \\
\text { valor límite } \\
\text { diario permitidas }\end{array}$ & 18 & 35 & 35 & - \\
\hline
\end{tabular}


Según muestra la Tabla 1.12 la normativa actual es considerablemente más restrictiva que la vigente en España en 1993 cuando entró en vigor el R.D. 1321/1992. En primer lugar, el cambio del parámetro de medida supone un mayor grado de control de las emisiones de tipo antropogénico. En segundo lugar, la disminución del valor límite anual (VLA) es muy acusada, pasando de $150 \mu \mathrm{g} \mathrm{PST} / \mathrm{m}^{3}$ a $40 \mu \mathrm{gPM} 10 / \mathrm{m}^{3}$. Con respecto al VLD, la reducción es considerable, de $300 \mu \mathrm{g} \mathrm{PST} / \mathrm{m}^{3}$ a $50 \mu \mathrm{g} \mathrm{PM} \mathrm{PM}_{10} / \mathrm{m}^{3}$, por lo que, aunque el número de superaciones anuales permitidas es mayor, la nueva legislación se puede considerar más restrictiva también en los valores diarios.

El periodo de transición para cumplir el VLA y diario de $\mathrm{PM}_{10}$ ha estado regulado por la Directiva 1999/30/CE, para los diferentes años desde su publicación hasta el año 2005, en el cual se debían cumplir los límites establecidos.

Según estudios llevados a cabo en España con datos de 2001 (Querol, Alastuey, Rodríguez, et al. 2004), los límites anual y diario establecidos para 2005 por la Directiva 1999/30/CE no son equivalentes, sino que el límite diario es mucho más restrictivo. Así, fijando el límite anual en $40 \mu \mathrm{g} / \mathrm{m}^{3}$ de $\mathrm{PM}_{10}$, el correspondiente número de superaciones anuales del límite diario de $50 \mu \mathrm{g} / \mathrm{m}^{3}$ de $\mathrm{PM}_{10}$ equivalente sería de $80-85$; o bien el VLD correspondiente a 35 superaciones anuales (percentil 90.4) equivaldría a un VLD de $60 \mu \mathrm{g} / \mathrm{m}^{3}$ de $\mathrm{PM}_{10}$. Si se fija el límite diario de $50 \mu \mathrm{g} / \mathrm{m}^{3}$ de $\mathrm{PM}_{10}$ con un máximo de 35 superaciones anuales, el correspondiente límite anual debería ser de $30 \mu \mathrm{g} / \mathrm{m}^{3}$ de $\mathrm{PM}_{10}$ (Tabla 1.13). Ello no significa que los VLD y VLA tengan que ser equivalentes, de ser así con uno de ellos bastaría, el hecho que se quiere resaltar es que el VLD es mucho más restrictivo que el VLA.

Tabla 1.13 Equivalencias de los valores límite fijados por la Directiva 1999/30/CE para 2005, según (Querol, Alastuey, Viana, et al. 2004), en negrita el parámetro que cambia respecto a las Directivas 1999/30/CE y 2008/50/CE. Adaptado de (Minguillón, 2007)

\begin{tabular}{|c|c|c|c|c|}
\hline Directiva/Equivalencia & $\begin{array}{c}\text { VLA } \\
\text { PM10 }\left(\mu \mathrm{g} / \mathrm{m}^{3}\right)\end{array}$ & $\begin{array}{c}\text { VLD } \\
\text { PM10 }\left(\mu \mathrm{g} / \mathrm{m}^{3}\right)\end{array}$ & $\begin{array}{c}\text { Número de } \\
\text { superaciones } \\
\text { anuales del } \\
\text { VLD }\end{array}$ & $\begin{array}{c}\text { Percentil } \\
\text { correspondiente } \\
\text { al número de } \\
\text { superaciones }\end{array}$ \\
\hline $\begin{array}{c}\text { Directiva 1999/30/CE } \\
\text { Directiva 2008/50/CE }\end{array}$ & 40 & 50 & 35 & 90 \\
\hline Equivalencia 1 & 40 & 50 & $\mathbf{8 0 - 8 5}$ & $\mathbf{7 6 - 7 8}$ \\
\hline Equivalencia 2 & 40 & $\mathbf{6 0}$ & 35 & 90 \\
\hline Equivalencia 3 & $\mathbf{3 0}$ & 50 & 35 & 90 \\
\hline
\end{tabular}

Aunque, como se ha dicho antes, la influencia de las emisiones naturales se reduce si se toma como parámetro el $\mathrm{PM}_{10}$ en vez de PST, ciertas regiones europeas están sometidas a grandes influencias de fenómenos naturales que inciden notablemente sobre los niveles de $\mathrm{PM}_{10} \mathrm{y}$, por tanto, pueden dificultar o impedir el cumplimiento de los VLDs y VLAs establecidos por las Directivas 1999/30/CE y 2008/50/CE. 
Atendiendo a estas consideraciones, las superaciones del VLD de $\mathrm{PM}_{10}$ debidas a la presencia de uno de los fenómenos naturales contemplados en la Directiva deberán ser descontadas del cómputo final. En España, el fenómeno natural que incide con mayor frecuencia sobre los niveles de material particulado atmosférico es la intrusión de masas de aire de origen africano, cargadas con partículas procedentes del desierto del Sahara y/o del Sahel. Otro fenómeno natural con influencia en los niveles de material particulado en España es la resuspensión de partículas minerales a escala local en zonas semiáridas.

\subsubsection{Emisiones industriales de PM}

\subsubsection{Introducción al marco normativo}

Para el control y armonización de los valores límite de emisión en la UE, sin duda la Directiva más importante ha sido la Directiva 1996/61/CE, conocida por sus siglas en inglés como Directiva IPPC. Esta Directiva ha supuesto una de las actuaciones más ambiciosas que se han puesto en marcha en el seno de la Unión Europea para la aplicación del principio de prevención de la contaminación y, por lo tanto, ha provocado un cambio notable con respecto a la normativa previa.

La Directiva IPPC establece un nuevo enfoque en el régimen de intervención administrativa, previa a la puesta en marcha de instalaciones industriales y en la consideración de los impactos ambientales asociados a su actividad. Los aspectos más novedosos introducidos por esta normativa se pueden resumir en tres puntos:

- Exige la coordinación administrativa, una especie de "ventanilla única" para tramitar un permiso único considerando el medio ambiente en su conjunto; este permiso se conoce como Autorización Ambiental Integrada (en adelante AAI) y debe renovarse periódicamente (cada 8 años).

- Establece criterios para definir los Valores Límite de Emisión (VLE) basándose en las Mejores Técnicas Disponibles (MTD) o también denominadas Best Available Techniques (BAT), en función de las características propias de la instalación y del lugar donde se ubica.

- Voluntad de transparencia informativa, haciendo pública la información de autorizaciones, inventario de emisiones, etc.

- Las mejores tecnologías disponibles se determinan en documentos específicos para cada actividad, denominados BREF (acrónimo en inglés de Best Available Techniques Reference Document).

Por otro lado, y de acuerdo con el artículo 16 de la Directiva 1996/61/CE y la Decisión 2000/479, se establece la obligación, para los Estados miembros, de informar a la Comisión Europea de las principales emisiones contaminantes a la atmósfera y al agua producidas en su país que hayan superado los valores límite umbrales que se especifican en el Anexo I de la citada decisión. Con 
dicha información, la Comisión Europea elaborará un Inventario Europeo de Emisiones Contaminantes (PRTR, del inglés Pollutant Release and Transfer Register).

A nivel estatal, la Directiva 1996/61/CE fue transpuesta al estado español mediante la ley 16/2002. Por otro lado, en 2007 entró en vigor la Ley 34/2007, esta ley es una normativa de carácter general que aborda aspectos relativos a la protección del ambiente atmosférico entre los que se destacan la evaluación y gestión de la calidad del aire, la prevención y control de emisiones, los instrumentos de fomento de protección de la atmósfera y su planificación y los mecanismos de control inspección y seguimiento de las emisiones, así como el régimen sancionador. La Ley establece para la Prevención y el Control de emisiones dos tipos de medidas principales: el establecimiento de unos valores límites de emisión para los distintos contaminantes y actividades, así como fijar las obligaciones específicas respecto a los distintos procesos que afectan a los productos que pueden generar contaminación. Por último, EL RD 100/2012, actualiza el catálogo de actividades potencialmente contaminadoras de la atmósfera, contenido en el anexo IV de la Ley 34/2007, de 15 de noviembre, de calidad del aire y protección de la atmósfera, y establece determinadas disposiciones básicas para su aplicación y unos mínimos criterios comunes en relación con las medidas para el control de las emisiones que puedan adoptar las comunidades autónomas para las actividades incluidas en dicho catálogo.

La Directiva IPPC se ha actualizado recientemente mediante la publicación de la Directiva de emisiones industriales 2010/75/UE, conocida por sus siglas como Directiva DEI. En esta Directiva se refuerza el papel de los Documentos BREF y de las MTD como base para fijar los Valores Límite de Emisión (VLE) aplicables a las diferentes instalaciones industriales.

A nivel estatal, el proceso de transposición de la Directiva 2010/75/UE ha consistido en la publicación de la Ley $5 / 2013$, de 11 de junio, sobre emisiones industriales que modifica la Ley 16/2002, de 1 de julio, de prevención y control integrados de la contaminación, y del R.D. 815/2013, de 18 de octubre, por el que se aprueba el Reglamento de emisiones industriales que desarrolla la citada Ley 16/2002. Recientemente, mediante el RD 1/2016 se ha integrado en un texto único las sucesivas modificaciones introducidas en la Ley 16/2002, de 1 de julio, a través de las siguientes leyes: Ley 1/2005, de 9 de marzo, Ley $27 / 2006$, la Ley $34 / 2007$, Ley 42/2007, Ley 40/2010, Real Decretoley $8 / 2011$ y Ley $5 / 2013$.

\subsubsection{Normativa en emisiones difusas de $P M$}

En el caso de las emisiones difusas de partículas, originadas como consecuencia del transporte, manipulación y almacenamiento al aire libre de materiales de naturaleza pulverulenta, la actual legislación a nivel nacional establece la necesidad de adoptar medidas preventivas. El R.D. 100/2012 establece que "los titulares de las instalaciones en las que se desarrollen actividades incluidas en el catálogo minimizarán tanto las emisiones 
canalizadas como las difusas de contaminantes a la atmósfera aplicando, en la medida de lo posible, las mejores técnicas disponibles". En este sentido, los BREF identifican el PM asociado a fuentes difusas como un contaminante significativo, por tanto, se han definido en los mismos las MTD para reducir este tipo de emisiones. Además, se ha elaborado un BREF horizontal para emisiones asociadas al almacenamiento (IPTS, 2006).

A nivel estatal, no se concretan valores límites de emisión para las emisiones difusas de PM. No obstante, en ciertas comunidades, se especifican valores límites para este tipo de emisiones. En la Tabla 1.14, a modo de ejemplo, se muestran los criterios establecidos por distintas comunidades autónomas para su control periódico.

Tabla 1.14 VLE de partículas para focos difusos en entornos industriales

\begin{tabular}{|c|c|c|c|c|c|}
\hline \multirow[b]{2}{*}{ CCAA } & \multirow[b]{2}{*}{$\begin{array}{l}\text { Instrumento } \\
\text { normativo }\end{array}$} & \multirow[b]{2}{*}{$\begin{array}{l}\text { Distancia } \\
\text { núcleo } \\
\text { urbano }\end{array}$} & \multirow[b]{2}{*}{$\begin{array}{l}\text { Parámetro } \\
\text { control }\end{array}$} & \multicolumn{2}{|c|}{ VLE } \\
\hline & & & & $\begin{array}{c}\text { Valor medio } \\
\text { valores } \\
\text { diarios }\end{array}$ & $\begin{array}{l}\text { Máximo } \\
\text { valores } \\
\text { diarios }\end{array}$ \\
\hline Andalucía & Decreto & \multirow{6}{*}{$\begin{array}{l}\text { No se } \\
\text { especifica }\end{array}$} & PST & $150 \mu \mathrm{g} / \mathrm{m}^{3}$ & \multirow{6}{*}{$\begin{array}{l}\text { No se } \\
\text { especifica }\end{array}$} \\
\hline Cantabria & Decreto & & PSD & $\begin{array}{c}300 \\
\mathrm{mg} /\left(\mathrm{m}^{2} \mathrm{dí} a\right)\end{array}$ & \\
\hline $\begin{array}{c}\text { Castilla La } \\
\text { Mancha }\end{array}$ & Orden & & PST & $150 \mu \mathrm{g} / \mathrm{m}^{3}$ & \\
\hline Cataluña & $\begin{array}{l}\text { Instrucción } \\
\text { técnica }\end{array}$ & & PSD & $\begin{array}{c}300 \\
\mathrm{mg} /\left(\mathrm{m}^{2} \text { día }\right)\end{array}$ & \\
\hline \multirow{2}{*}{$\begin{array}{l}\text { Comunidad } \\
\text { de Madrid }\end{array}$} & \multirow{2}{*}{ Resolución } & & PSD & $\begin{array}{c}300 \\
\mathrm{mg} /\left(\mathrm{m}^{2} \mathrm{dí} a\right)\end{array}$ & \\
\hline & & & PST & $150 \mu \mathrm{g} / \mathrm{m}^{3}$ & \\
\hline \multirow{3}{*}{$\begin{array}{l}\text { Comunidad } \\
\text { Valenciana }\end{array}$} & \multirow{3}{*}{$\begin{array}{c}\text { Decreto } \\
\text { Plan Mejora } \\
\text { Calidad Aire }\end{array}$} & $\leq 500 \mathrm{~m}$ & PM10 & $40 \mu \mathrm{g} / \mathrm{m}^{3}$ & $50 \mu \mathrm{g} / \mathrm{m}^{3}$ \\
\hline & & \multirow{2}{*}{$>500 \mathrm{~m}$} & PST & $150 \mu \mathrm{g} / \mathrm{m}^{3}$ & $300 \mu \mathrm{g} / \mathrm{m}^{3}$ \\
\hline & & & PSD & $\begin{array}{c}300 \\
\mathrm{mg} /\left(\mathrm{m}^{2} \mathrm{dí} a\right)\end{array}$ & $\begin{array}{c}\text { No se } \\
\text { especifica }\end{array}$ \\
\hline País Vasco & $\begin{array}{l}\text { Orden } \\
\text { Decreto }\end{array}$ & \multicolumn{4}{|c|}{$\begin{array}{l}\text { Definidos en el Plan de Vigilancia Atmosférica } \\
\text { Contaminantes a medir: PSD, } \mathrm{PM}_{10}, \mathrm{PM}_{2.5}\end{array}$} \\
\hline $\begin{array}{l}\text { Región de } \\
\text { Murcia }\end{array}$ & Resolución & $\begin{array}{c}\text { No se } \\
\text { especifica }\end{array}$ & PSD & $\begin{array}{c}300 \\
\mathrm{mg} /\left(\mathrm{m}^{2} \mathrm{dí} a\right)\end{array}$ & $\begin{array}{c}\text { No se } \\
\text { especifica }\end{array}$ \\
\hline
\end{tabular}




\subsubsection{Riegos laborales}

\subsubsection{Introducción al marco normativo general}

Las disposiciones relativas a la evaluación de riesgos de la Ley 31/1995, de Prevención de Riesgos Laborales, y del R.D. 39/1997, por el que se aprueba el Reglamento de los Servicios de Prevención, implican la utilización de valores límite de exposición para poder valorar los riesgos debidos a la exposición profesional a agentes químicos. Por otra parte, el R.D. 374/2001 sobre la protección de la salud y la seguridad de los trabajadores contra los riesgos relacionados con los agentes químicos durante el trabajo, que transpone al ordenamiento jurídico español la Directiva 98/24/CE del Consejo, relativa a la protección de la salud y la seguridad de los trabajadores contra los riesgos relacionados con los agentes químicos durante el trabajo, y la Directiva 2000/39/CE de la Comisión, por la que se establece una primera lista de valores límite de exposición profesional indicativos, en aplicación de la Directiva anterior, deroga el segundo párrafo del artículo 18 y el anexo 2 del Reglamento de Actividades Molestas, Insalubres, Nocivas y Peligrosas (RAMINP) de 1961. En el contexto anterior y dado que los Estados miembros de la UE deben establecer valores límite de exposición profesional nacionales, el R.D. $374 / 2001$ remite a los publicados por el Instituto Nacional de Seguridad e Higiene en el Trabajo (INSHT), como valores de referencia para la evaluación y control de los riesgos originados por la exposición de los trabajadores a agentes químicos. Los conceptos y valores incluidos en este documento son el resultado de una evaluación crítica de los valores límite de exposición establecidos por las entidades más relevantes y prestigiosas en la materia, teniendo en cuenta, fundamentalmente, la fiabilidad de los datos utilizados para el establecimiento de cada uno de ellos, su fecha de actualización y los criterios de la UE para la adopción de los límites de exposición comunitarios. Además, la lista de los valores límite adoptados será ampliada y revisada, al menos anualmente, en función de las necesidades que planteen los cambios en los procesos de producción y la introducción de nuevas sustancias, de los nuevos conocimientos técnicos y científicos, así como de la evolución del marco legal en el que se apliquen (INSHT 2016).

En este sentido, el INSHT publica anualmente dicha lista de valores límite de exposición a agentes químicos. Atendiendo a dichos límites, es necesario esclarecer el significado de los mismos.

- Valor Límite Ambiental-Exposición Diaria (VLA-ED): representan condiciones a las cuales se cree, basándose en los conocimientos actuales, que la mayoría de los trabajadores pueden estar expuestos 8 horas diarias y 40 horas semanales durante toda su vida laboral, sin sufrir efectos adversos para su salud.

- Valor Límite Ambiental-Exposición de Corta Duración (VLA-EC): valor que no debe ser superado por ninguna exposición de corta duración (cualquier periodo de 15 minutos a lo largo de la jornada laboral, excepto para aquellos agentes químicos para los que se 
especifique un periodo de referencia inferior) a lo largo de la jornada laboral.

\subsubsection{Marco normativo en materia de exposición laboral a PM}

El valor límite para la materia particulada no fibrosa se expresa en $\mathrm{mg} / \mathrm{m}^{3}$ o submúltiplos y el de fibras, en fibras $/ \mathrm{m}^{3}$ o fibras $/ \mathrm{cm}^{3}$, en ambos casos para las condiciones reales de temperatura y presión atmosférica del puesto de trabajo. Esto significa que las concentraciones medidas en estas unidades, en cualquiera de las condiciones de presión y temperatura, no requieren ninguna corrección para ser comparadas con los valores límite aplicables. Cabe comentar que en el caso del material particulado los límites establecidos por el INSHT en 2016 (INSHT 2016) son los que se detallan en la Tabla 1.15.

Tabla 1.15 Límites INSHT 2016 para partículas (insolubles o poco solubles) no especificadas de otra forma

Partículas (insolubles o poco solubles) no especificadas de otra forma
VLA-ED $\left(\mathrm{mg} / \mathrm{m}^{3}\right)$

\begin{tabular}{|c|c|}
\hline Fracción inhalable & 10 \\
\hline Fracción respirable & 3 \\
\hline
\end{tabular}

No obstante, cabe comentar que estos valores pueden ser más restrictivos en el caso de determinados contaminantes. Por ejemplo, en el caso de la sílice (uno de los materiales objeto de estudio de la presente tesis doctoral), para la fracción respirable (sílice cristalina respirable, SCR), reconocida como cancerígeno para los humanos por la International Agency for Research on Cancer (IARC 2012; IARC 1997; IARC 1987) e incluida recientemente en la directiva europea (en fase de consulta) sobre agentes carcinogénicos y mutagénicos (COM (2016), amending Directive 2004/37/EC), los valores límite, aplicables en España, son los que se detallan en la Tabla 1.16.

Tabla 1.16 Valores límite para la fracción respirable de la sílice cristalina (LEP 2016, INSHT)

\begin{tabular}{|c|c|}
\hline Sílice cristalina & VLA-ED $\left(\mathrm{mg} / \mathrm{m}^{3}\right)$ \\
\hline Cristobalita (Fracción respirable) & 0.05 \\
\hline Cuarzo (Fracción respirable) & 0.05 \\
\hline
\end{tabular}




\subsection{Poder de emisión de polvo}

Un parámetro de gran interés para evaluar, controlar y minimizar los riesgos asociados a las emisiones difusas y niveles de exposición a PM, generadas durante la manipulación y transporte de materiales pulverulentos, es el poder de emisión de polvo de los materiales. Este parámetro se define como la tendencia de los materiales a producir polvo suspendido en el aire cuando se manipulan (Figura 1.13).

Cabe comentar que el poder de emisión de polvo no es una característica intrínseca de la composición química, sino que depende de las propiedades físicas del material (humedad, tamaño de partícula, etc.), del tipo de ensayo utilizado y de las variables medioambientales (temperatura y humedad del aire).
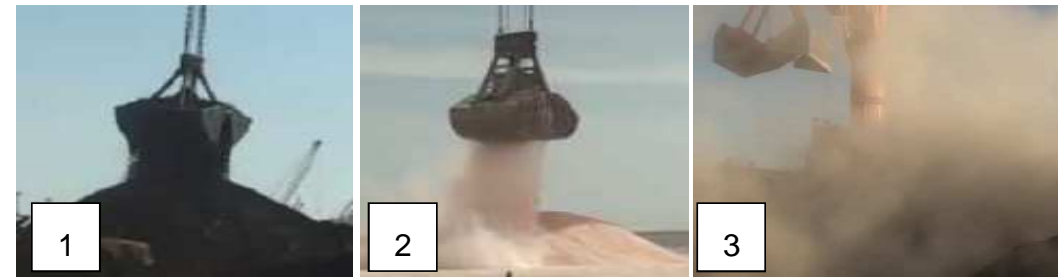

Figura 1.13 Comparativa de la descarga de materiales con poder de emisión de polvo muy bajo (1), bajo (2) y moderado (3)

\subsubsection{Equipos para la medición del poder de emisión de polvo de los materiales pulverulentos}

Tal y como se ha indicado previamente, el poder de emisión de polvo de los materiales pulverulentos depende del tipo de manipulación al que es sometido el material. Por este motivo, con el objetivo de simular distintas operaciones industriales, existen multitud de equipos para determinar el poder de emisión de polvo de los materiales pulverulentos (Hamelmann et al. 2003) y posiblemente ninguno de ellos es capaz de representar la gran diversidad de actividades de gestión y/o manipulación que sufren los materiales pulverulentos durante su procesado industrial. No obstante, a pesar de la gran diversidad de dispositivos, (Hamelmann et al. 2003) propone una clasificación sistemática de los elementos comunes que componen estos equipos (Figura 1.14):

- El sistema de alimentación de material pulverulento

- El sistema de aplicación de energía para generar polvo

- El sistema de muestreo

- El sistema de caracterización del polvo 


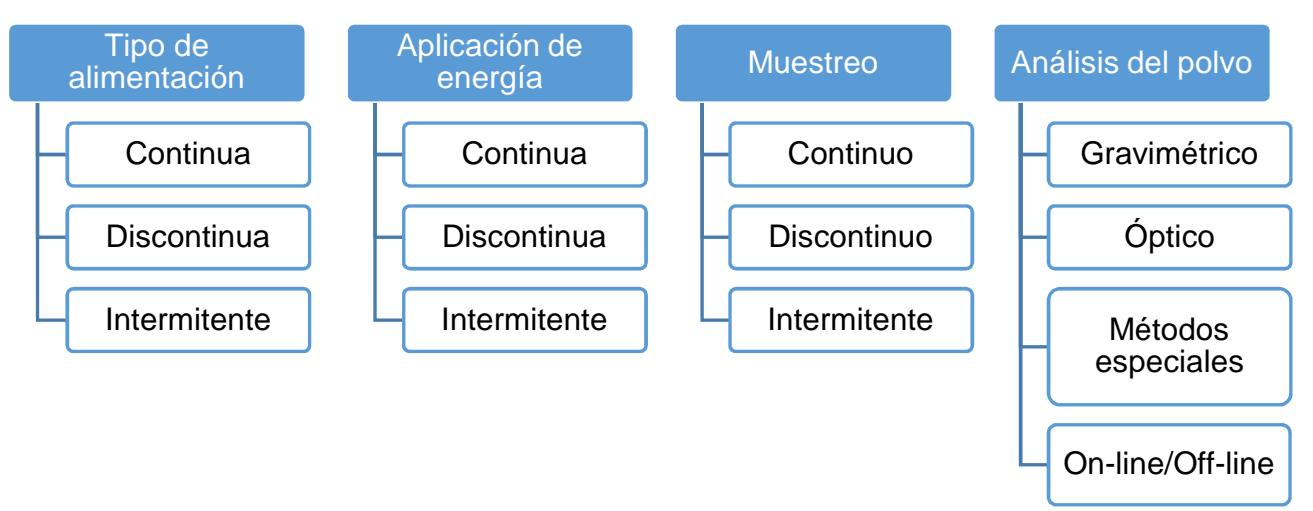

Figura 1.14 Clasificación sistemática de los componentes que forman los dispositivos de determinación del poder de emisión de polvo (Adaptado de Hamelmann et al., 2003)

Por otro lado, en función del tipo de energía aplicada, estos dispositivos se dividen fundamentalmente en cuatro grupos: métodos de caída o gravimétricos, métodos de tambor rotatorio o mecánicos, métodos de aerosolización y diseños especiales. A continuación, se describe brevemente el fundamento de las distintas tipologías de dispositivos empleados para la determinación del poder de emisión de polvo.

\subsubsection{Métodos de caída}

Métodos en los que la generación de polvo se produce por la caída del material ya sea ésta continua o intermitente. Estos dispositivos, en general, constan de un tubo de caída del material y una cámara de generación de polvo. Existen diversas modalidades en las que lo que cambia fundamentalmente es la forma de alimentación (continua o intermitente) y la forma de colectar el polvo (Tabla 1.17).

En los primeros dispositivos (ASTM D547-41 1980; Andreasen et al. 1939) se dejaba caer el material de una sola vez al abrir un obturador y, posteriormente a la caída, se introducían diversas bandejas que permitían realizar una clasificación por tamaños del polvo generado en función de la distinta velocidad de sedimentación que presentan las partículas de diferente tamaño. El equipo diseñado por (Perra 1984) es una modificación de dichos dispositivos. En este sistema, la bandeja colectora se coloca al inicio del ensayo, pero el sistema de alimentación y distribución del material (en forma de cono) impide que el material caiga directamente sobre la bandeja colectora que recogerá únicamente el polvo generado durante la caída del material. El equipo diseñado por (Mikula \& Parsons 1991) y el equipo normalizado (DIN 55992-2 1999), siguen el mismo fundamento que los equipos anteriores pero la medida se realiza mediante un láser y un detector óptico, de forma que la concentración de material particulado se evalúa en base a la atenuación de la intensidad del haz láser producida por la nube de polvo. Por último, en el caso del sistema diseñado por (Wells \& Alexander 1978), el polvo generado pasa por un elutriador horizontal (muestreador Hexhlet) que permite determinar el polvo total o separar la fracción respirable del polvo. 
Tomando como base dichos dispositivos, se llevaron a cabo modificaciones que posibilitan la alimentación continua del material durante la realización del ensayo. El equipo del Midwest Research Institute (Cowherd et al. 1989) emplea un sistema de alimentación que se fundamenta en la rotación y vibración de una "cazoleta". En este sistema, el polvo generado durante la caída es transferido por una corriente de aire a la zona de muestreo donde el polvo puede ser recogido en impactadores, filtros o caracterizado con medidores ópticos. En el caso de los equipos diseñados por (Plinke et al. 1991) y (Cawley \& Leith 1993) destaca la separación de la zona de generación de polvo y la zona de transferencia del polvo generado a la zona de muestreo. Además, cabe destacar que en este dispositivo la alimentación es continua y permite realizar el ensayo con distintas alturas de caída.

Finalmente, en la Norma (UNE EN 15051 2007) y en su actualización (UNE EN 150512014 ) se propone el uso de un método de caída continua. Este equipo de muestreo consiste, básicamente, en una conducción cilíndrica por la que circula un caudal de aire en sentido ascendente. Desde la parte superior de dicha conducción se dosifica el material de ensayo. El polvo se deja caer por un conducto interior, concéntrico al conducto por el que asciende el aire. La longitud de este tubo es menor que la del conducto exterior, de manera que el polvo se libera en el seno del flujo en contracorriente. Ligeramente por encima de la posición de descarga del material se ubican un par de cabezales de muestreo de fracciones granulométricas con relevancia en la salud (inhalable y respirable).

Tabla 1.17 Esquemas de los métodos de caída para la determinación del poder de emisión de polvo

\begin{tabular}{|c|c|c|c|}
\hline $\begin{array}{c}\text { Tipo de } \\
\text { alimentación }\end{array}$ & $\begin{array}{c}\text { Sistema de } \\
\text { colección de } \\
\text { polvo }\end{array}$ & \multicolumn{2}{|c|}{ Ejemplos (Esquema/Imagen) } \\
\hline $\begin{array}{c}\text { Al inicio (el } \\
\text { material cae } \\
\text { de una sola } \\
\text { vez al abrir un } \\
\text { obturador) }\end{array}$ & $\begin{array}{c}\text { Sistema de } \\
\text { colección de } \\
\text { polvo en } \\
\text { bandejas }\end{array}$ & $\begin{array}{c}\text { Cubeta } \\
\text { ANSI/ATSM D547-41,1980 }\end{array}$ \\
\hline
\end{tabular}


Tabla 1.17 Esquemas de los métodos de caída para la determinación del poder de emisión de polvo

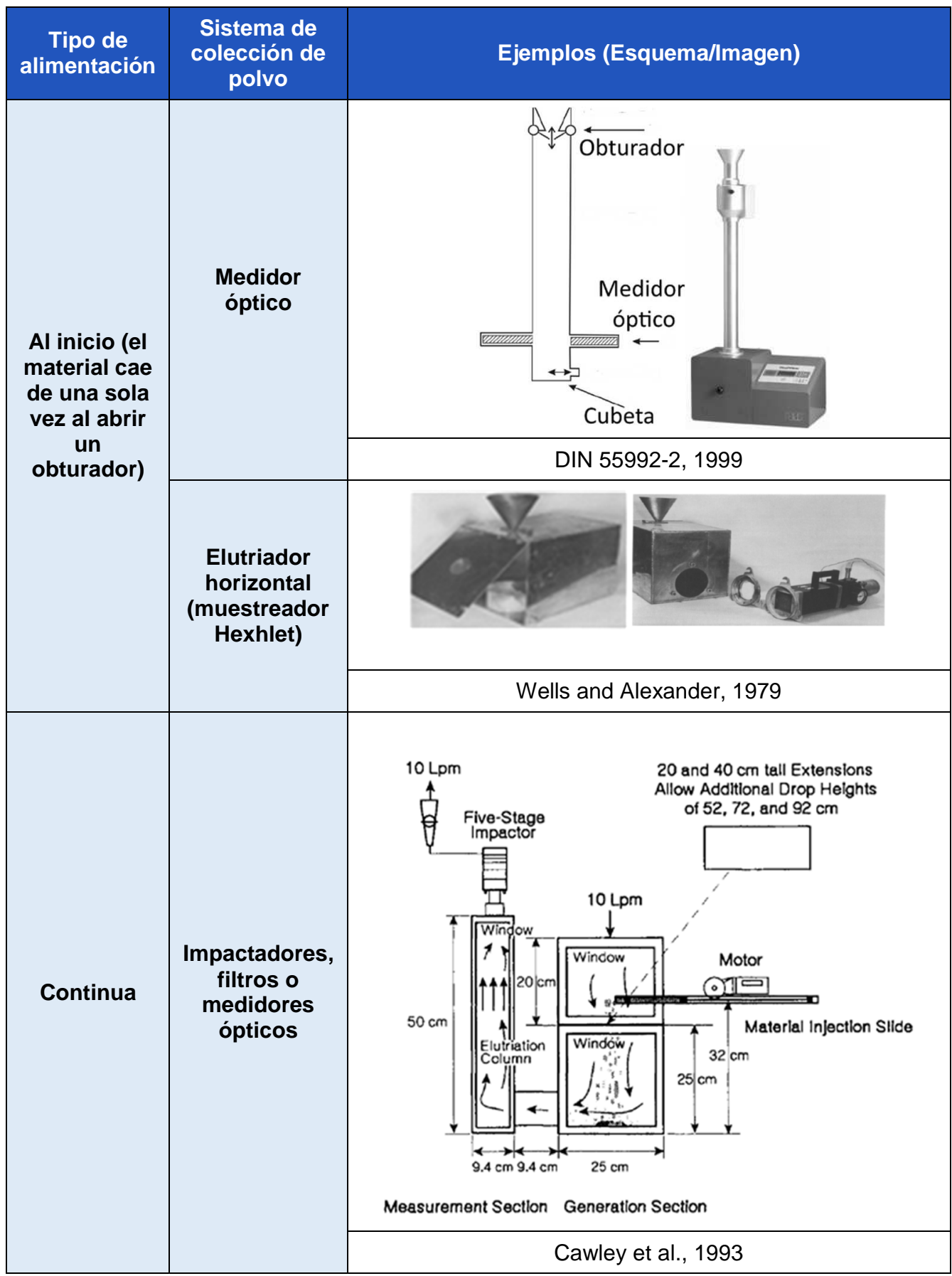




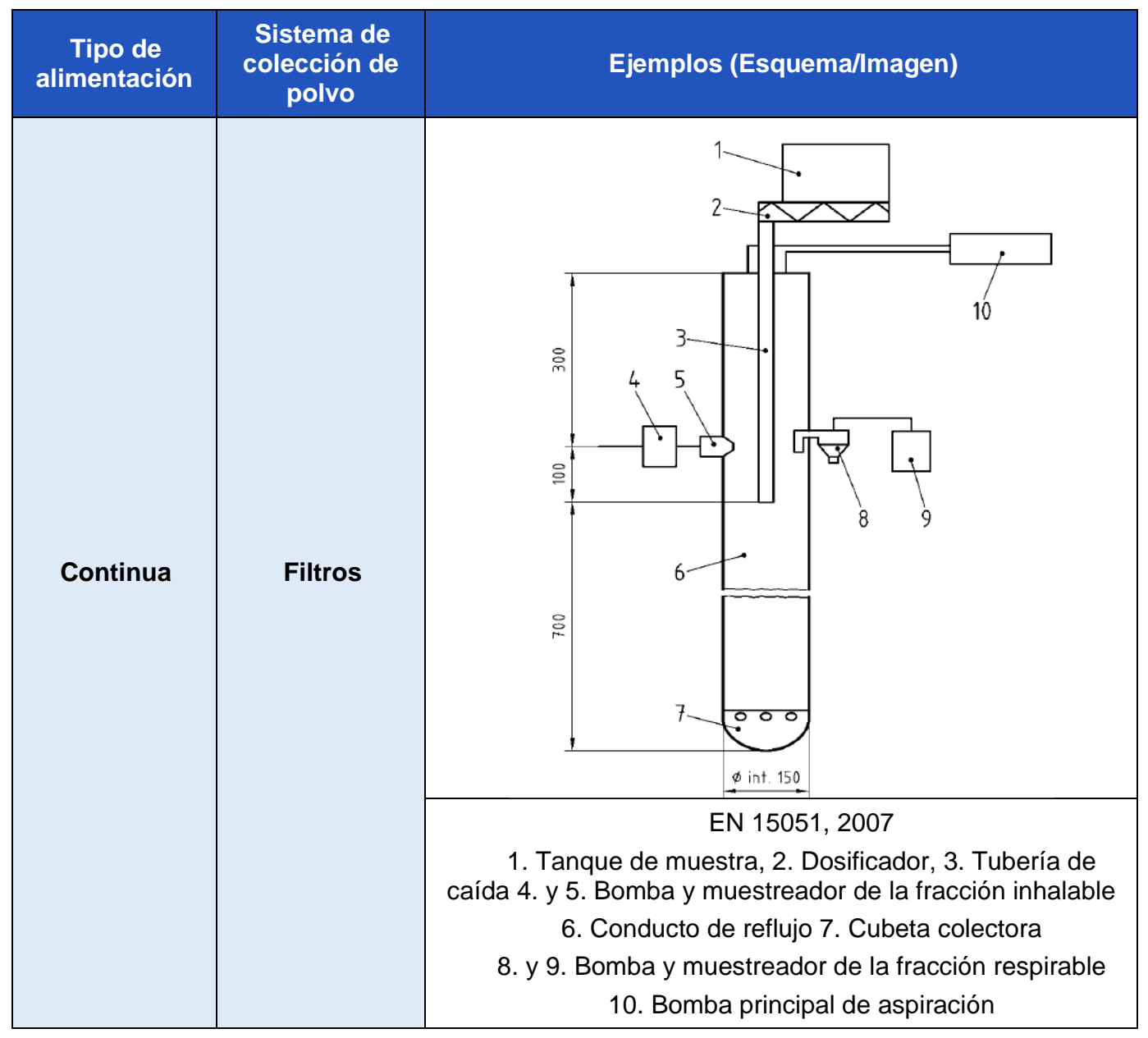




\subsubsection{Métodos mecánicos o rotatorios}

En estos dispositivos el polvo se genera por una acción mecánica sobre el material. Aunque existen diversas variantes, los equipos mayoritariamente empleados han sido aquellos en los que dicha energía se transmite mediante la rotación de un tambor. La muestra es introducida en un tambor rotatorio, el polvo generado durante el ensayo es transferido por una corriente horizontal de aire a la zona de toma de muestras, donde la muestra puede ser recogida en filtros/espumas o impactadores para la posterior determinación gravimétrica del poder de emisión de polvo o analizada directamente mediante contadores ópticos, etc.

Existen diversos equipos (Takai \& Dahl 2008; AS 4156.6 2000; DIN 55992-1 1999; Lyons \& Mark 1992) basados en este esquema (Tabla 1.18), cuyas diferencias radican fundamentalmente en las dimensiones del tambor y condiciones del ensayo (caudal de aire, masa de material empleada, velocidad de rotación, etc.).

Finalmente, en la Norma (UNE EN 150512007 ) y en su actualización (UNE EN 150512014 ) se propone el uso de un método de tambor rotatorio. Este equipo consta de un tambor rotatorio que gira con un volumen conocido de material a granel. El material cae de forma continua repetidas veces sobre una corriente de aire horizontal a baja velocidad. El polvo generado por la caída del material es conducido por el aire a la sección de toma de muestras donde se separan las tres fracciones de tamaño relacionadas con la salud (inhalable, torácica y respirable).

Tabla 1.18 Esquemas de los métodos mecánicos para la determinación del poder de emisión de polvo

\begin{tabular}{|c|c|c|}
\hline $\begin{array}{c}\text { Tipo de } \\
\text { alimentación }\end{array}$ & $\begin{array}{l}\text { Sistema de } \\
\text { colección de } \\
\text { polvo }\end{array}$ & Ejemplos (Esquema/lmagen) \\
\hline \multirow{3}{*}{$\begin{array}{l}\text { Al inicio (el } \\
\text { material se } \\
\text { introduce en } \\
\text { el tambor } \\
\text { previamente } \\
\text { a la } \\
\text { realización } \\
\text { del ensayo) }\end{array}$} & \multirow[t]{3}{*}{$\begin{array}{l}\text { Impactadores, } \\
\text { filtros o } \\
\text { medidores } \\
\text { ópticos }\end{array}$} & $\begin{array}{l}\text { Lyons \& Mark, } 1992 \\
\text { a. Salida b. Unidad de muestreo c. Rotámetro y } \\
\text { controlador de caudal d. Manómetro e. Bomba f. Motor } \\
\text { g. Rodillo accionador h. Entrada de aire i. Tambor }\end{array}$ \\
\hline & & \\
\hline & & Norma AS4156.6, 2000 \\
\hline
\end{tabular}




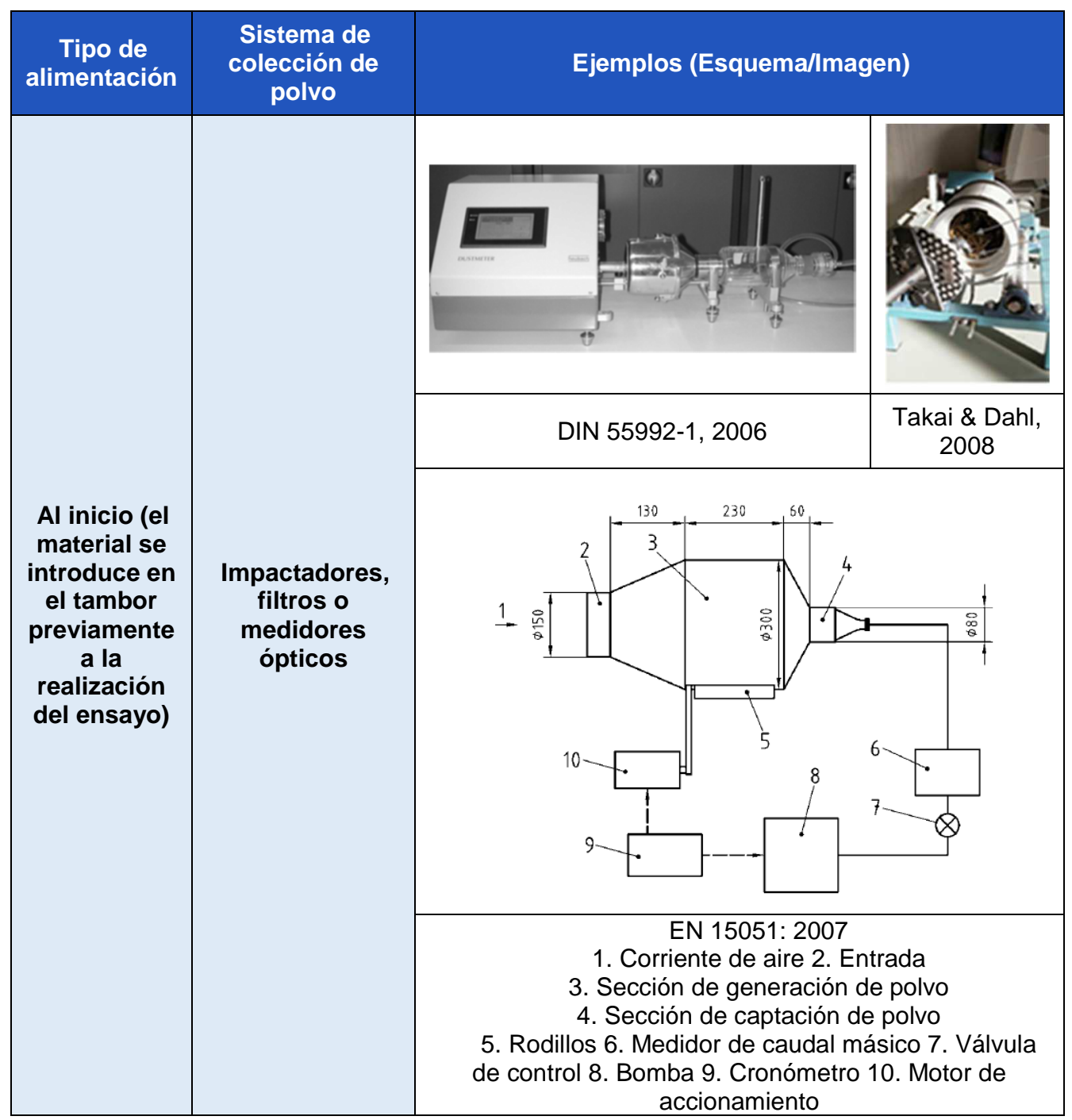

\subsubsection{Métodos de aerosolización}

Estos métodos se basan en aplicar una elevada cantidad de energía al material a ensayar mediante una corriente de aire a elevada velocidad (Tabla 1.19).

En 1991 (Mikula \& Parsons 1991) se desarrolló un montaje simple que consistía en un embudo en el que se colocaba una rejilla y un filtro sobre el que se situaba el material a ensayar, una corriente ascendente de aire atravesaba el material y el polvo generado era arrastrado fuera del embudo. De esta forma, considerando la cantidad de muestra inicial y final se determinaba un indicador del poder de emisión de polvo. Posteriormente, basados en este sistema, se diseñaron dispositivos más complejos (Schofield 1981; Sethi 1997; Sethi \& Schneider 1996) en los que la corriente de aire arrastra las partículas con baja velocidad de sedimentación a la zona de toma de muestras donde son recogidas en un filtro, medidas con contadores ópticos o monitores de balanza oscilante (TEOM). En estos sistemas, debido a la alta energía aplicada al 
material, los aglomerados o pellets pueden ser destruidos. Además, la gran energía aplicada provoca que la representatividad de estos sistemas sea limitada. En 2002, en la norma (DIN 33897 2002) se propuso el uso de un dispositivo que se fundamenta en la aerosolización de material mediante el uso de un compresor y un dispersor. En la cámara en la que se produce la aerosolización se ubican dos cabezales de muestreo (inhalable y respirable). Recientemente, (Boundy et al. 2006) diseñaron un dispositivo para determinar el poder de emisión de polvo empleando muy poca cantidad de material (especialmente diseñado para trabajar con materiales de alto coste como materiales farmacéuticos, nanopartículas, etc.). En este sistema, el material es aerosolizado en un breve espacio de tiempo. Posteriormente a la inyección de material, la corriente de aerosolización se desconecta y se continúa con el muestreo durante varios minutos.

Tabla 1.19 Esquemas de los métodos de aerosolización para la determinación del poder de emisión de polvo

\begin{tabular}{|c|c|c|}
\hline $\begin{array}{c}\text { Tipo de } \\
\text { alimentación }\end{array}$ & $\begin{array}{c}\text { Sistema de } \\
\text { colección de polvo }\end{array}$ & Ejemplos (Esquema/lmagen) \\
\hline \multirow[t]{2}{*}{$\begin{array}{l}\text { El material se } \\
\text { ubica sobre el } \\
\text { sistema } \\
\text { rejilla/filtro al } \\
\text { inicio del ensayo }\end{array}$} & \multirow[t]{2}{*}{ n.a. } & (1) \\
\hline & & Mikula et al., 1991 \\
\hline \multirow[t]{2}{*}{ Continua } & \multirow[t]{2}{*}{$\begin{array}{c}\text { Impactadores, } \\
\text { filtros o medidores } \\
\text { ópticos }\end{array}$} & Partial \\
\hline & & $\begin{array}{l}\text { Sethi, 1996; Sethi and Schneider, } 1997 \\
\text { a. Contador óptico de partículas b. Módulo de } \\
\text { vidrio c. Conectores para la medición de } \\
\text { presión d. TEOM e. Ciclón f. Diluidor }\end{array}$ \\
\hline
\end{tabular}




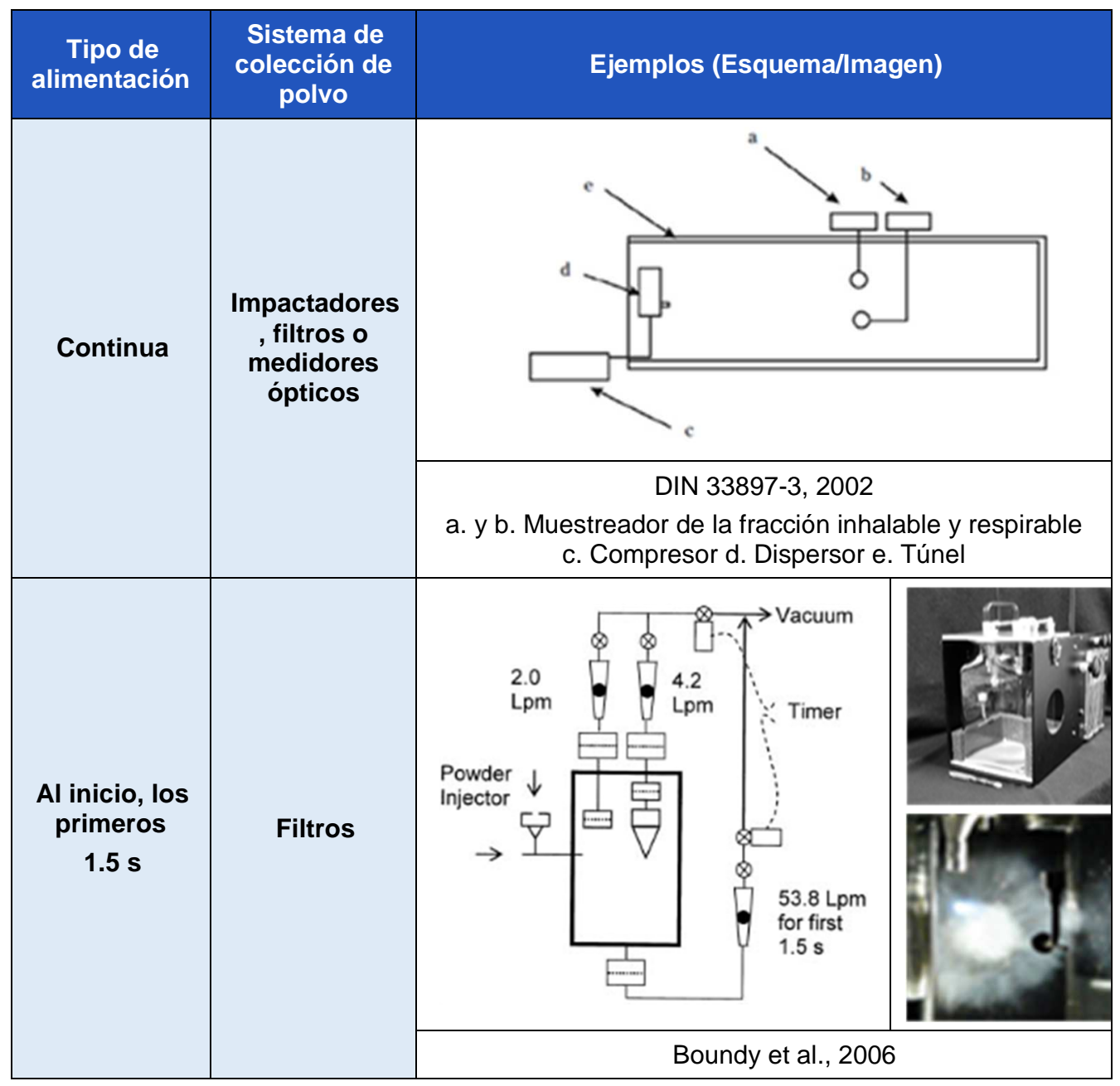

\subsubsection{Otros diseños}

Para determinadas aplicaciones y estudios se ha considerado oportuno el diseño de dispositivos especiales. A modo de ejemplo, en la Tabla 1.20 se detallan las principales características de algunos de ellos, incluyendo: la cámara de resuspensión (Visser \& Cleijne 1994; Visser 1992), el método combinado de caída y tambor rotatorio (Burdett et al. 2000) y el dispositivo diseñado por (Wypych \& Mar 2013).

La cámara de resuspensión (Visser \& Cleijne 1994; Visser 1992) se diseñó para evaluar el efecto de la humedad ambiental y la velocidad del viento sobre el poder de emisión de polvo. En este dispositivo, el material es alimentado en continuo, cae en un túnel de viento (perpendicularmente a la corriente de aire) y es recogido en una cubeta tras pasar por una rejilla que evita la resuspensión del material. El polvo generado durante la caída es transferido por la corriente de aire a la zona de toma de muestras. Por otro lado, en el año 2000 (Burdett et al. 2000), se desarrolló un dispositivo que combina dos métodos (caída y tambor rotatorio). El montaje de este sistema es modular y, por tanto, permite 
que pueda ser empleado como método de caída, de tambor rotatorio o como la combinación de ambos. Las muestras son recogidas sobre sistemas filtrantes (espumas y/o filtros). Por último, en el equipo diseñado por (Wypych \& Mar 2013), una pila de material se introduce en un túnel de viento y se somete a incrementos progresivos en la velocidad del aire. Esto permite determinar cuál es la velocidad requerida para que se inicie la puesta en suspensión del material y la cantidad de polvo emitida (pesada de la pila de material previa y posteriormente a la realización del ensayo), así como evaluar el incremento producido en la emisión al aumentar la velocidad del aire.

Tabla 1.20 Esquemas de los métodos especiales para la determinación del poder de emisión de polvo

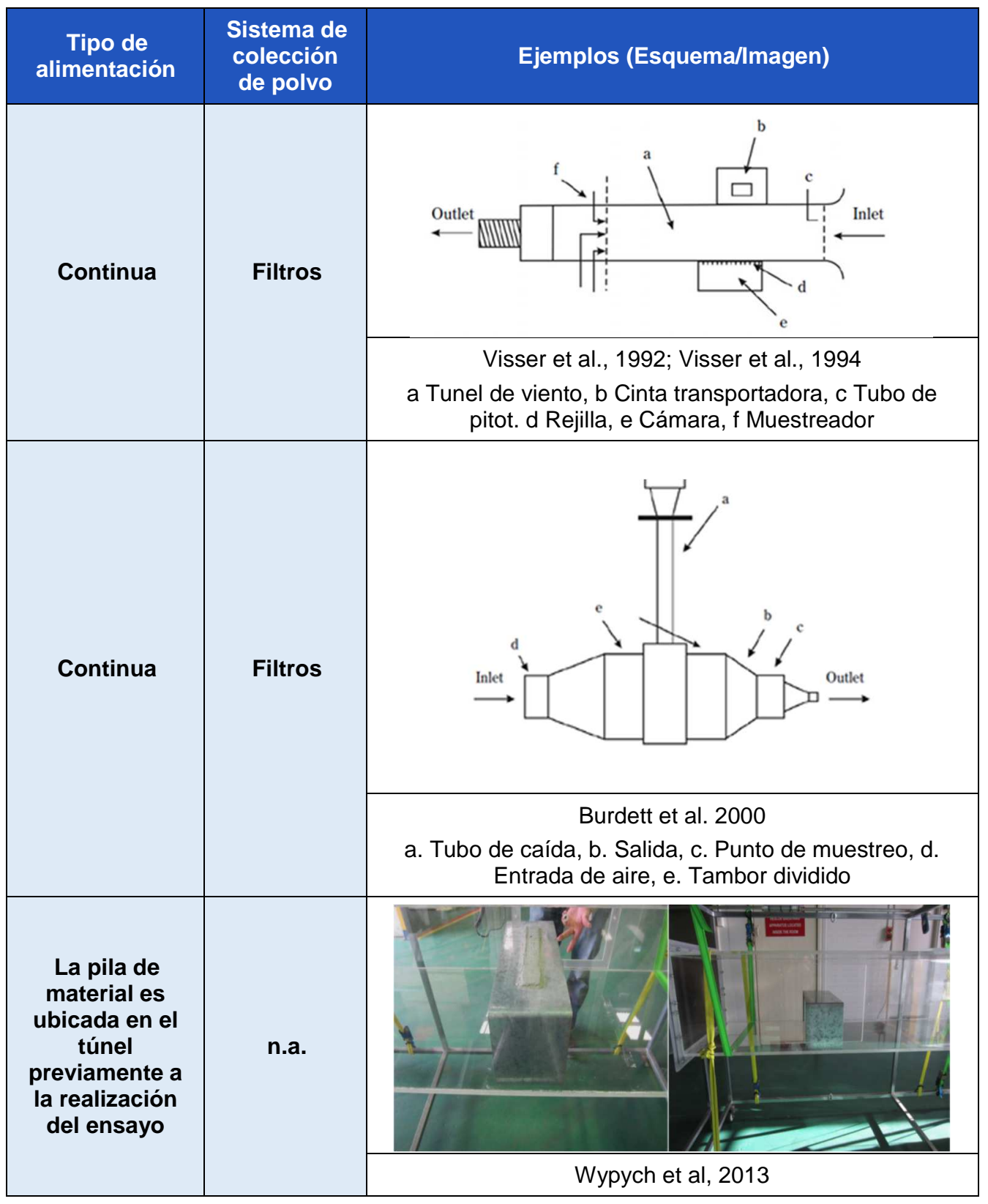




\subsubsection{Parámetros que influyen sobre la capacidad de generación de polvo}

Por analogía con los líquidos, el poder de emisión de polvo para materiales pulverulentos puede considerarse un parámetro equivalente la volatilidad para líquidos (Figura 1.15). Pero mientras que la capacidad de emisión de gases 0 vapores de un líquido de una composición química dada depende básicamente de su temperatura, presión y del área interfacial líquido-gas, el poder de emisión de polvo no es una característica intrínseca de la composición química, sino que depende del ensayo utilizado, de las características físicas del material (humedad, DTP, etc.) y de las variables medioambientales (temperatura y humedad del aire).

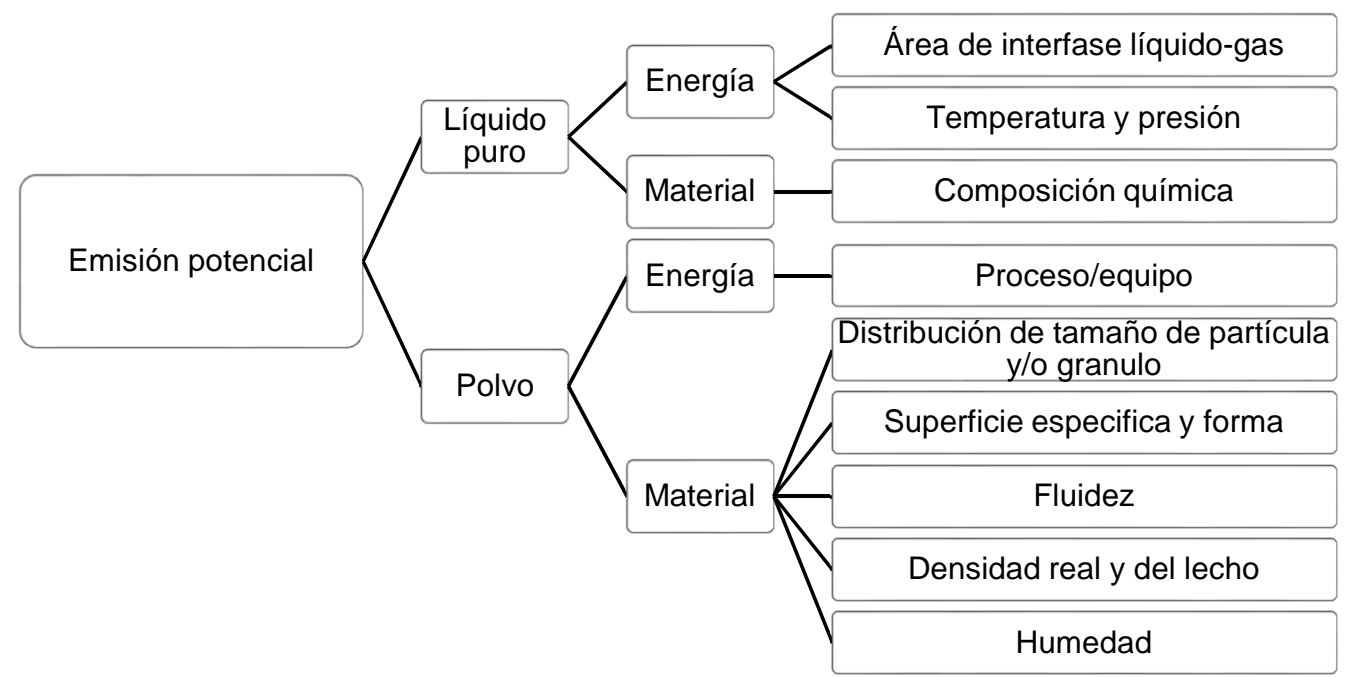

Figura 1.15 Potencial de emisión de líquidos y materiales pulverulentos

A continuación, se describen brevemente los resultados obtenidos en estudios precedentes a la realización del presente trabajo, en referencia al estudio de la influencia de variables de los materiales pulverulentos sobre su poder de emisión de polvo. Dado que el tipo de material y el equipo empleado van a influir marcadamente en los resultados obtenidos y su interpretación, en la Tabla 1.21 se detalla el equipo y materiales empleados por los distintos autores. 
Tabla 1.21 Estudios previos sobre el poder de emisión de polvo (en orden cronológico)

\begin{tabular}{|c|c|c|}
\hline Estudio & Equipo & Materiales \\
\hline Powell et al., 1933 & Caída (Similar ASTM D547) & $\begin{array}{l}\text { Carbón y coke } \\
\text { Aditivos: cloruro cálcico, aceite, etc. }\end{array}$ \\
\hline $\begin{array}{l}\text { Schofield, 1979; } \\
\text { Schofield, } 1981\end{array}$ & $\begin{array}{l}\text { Aerosolización } \\
\text { (Schofield, 1979) }\end{array}$ & - \\
\hline Higman, 1986 & Tambor (WSL) & Coke \\
\hline Hsiesh, 1987 & Caída (Perra, 1987) & $\begin{array}{c}\text { Alúmina } \\
\text { Aditivo: ESP (electro-precipitador) }\end{array}$ \\
\hline $\begin{array}{c}\text { Authier-Martin, } \\
1987\end{array}$ & Caída (Similar Perra, 1987) & Alúmina \\
\hline $\begin{array}{c}\text { Cohwerd et al., } \\
1989\end{array}$ & Caída (MRI) & $\begin{array}{l}\text { Cloruro sódico, cemento, talco, Black } \\
\text { carbón, hidróxido de calcio, carbón } \\
\text { activado, arcillas, cal hidratada, } \\
\text { tripolifosfato de sodio y colorantes }\end{array}$ \\
\hline Farrugia, 1989 & Tambor & Carbón \\
\hline $\begin{array}{l}\text { Wetsborg and } \\
\text { Cortson, } 1990\end{array}$ & Tambor & Carbón \\
\hline Upton, 1990 & Tambor (WSL) & Alúmina, titania y esferas de vidrio \\
\hline Leith, 1991 & Tambor (Heubach) & Carburo de silicio y alúmina \\
\hline Mikula et al., 1991 & $\begin{array}{l}\text { Caída (ASTM D547 y Mikula } \\
\text { et al., 1991) y aerosolización } \\
\text { (Mikula et al., 1991) }\end{array}$ & $\begin{array}{c}\text { Carbón } \\
\text { Aditivo: agua y aceite }\end{array}$ \\
\hline Chambers, 1992 & $\begin{array}{c}\text { Caída (Perra, 1984) y } \\
\text { aerosolización (Chambers, } \\
\text { 1992) }\end{array}$ & $\begin{array}{c}\text { Alúmina } \\
\text { Aditivo: ESP (electro-precipitador) }\end{array}$ \\
\hline Plinke, 1992 & $\begin{array}{l}\text { Caída (MRI) y tambor } \\
\text { (Heubach) }\end{array}$ & Carburo de silicio y alúmina \\
\hline Cawley et al., 1993 & Caída (Cawley et al., 1993) & $\begin{array}{l}\text { Piedra caliza, dióxido de titanio, vidrio y } \\
\text { lactosa }\end{array}$ \\
\hline Plinke, 1995 & Caída (Cawley et al., 1993) & Dióxido de titanio, caliza, vidrio y lactosa \\
\hline Pujara, 1997 & Tambor (Heubach) & Materiales farmacéuticos \\
\hline Pensis et al., 2009 & $\begin{array}{l}\text { Caída (EN15051) y tambor } \\
\text { (EN 15051) }\end{array}$ & $\begin{array}{l}\text { Cuarzo, cristobalita, feldespato, caolín, } \\
\text { chamota, talco, mármol, arcilla caolinifera } \\
\text { plástica o "ball clay" y tiza }\end{array}$ \\
\hline Wypych, 2013 & $\begin{array}{c}\text { Tambor (AS4156.6 y EN } \\
\text { 15051: 2006) y diseño } \\
\text { especial (Wypych et al, 2013) }\end{array}$ & Coke y mena \\
\hline
\end{tabular}


En la bibliografía consultada, los parámetros del material que influyen en mayor medida sobre su poder de emisión de polvo son: distribución de tamaño de partícula, humedad, fluidez, forma y superficie específica.

A continuación, se describen brevemente los resultados obtenidos en trabajos previos publicados acerca de la influencia de estos parámetros sobre el poder de emisión de polvo de los materiales pulverulentos.

\subsubsection{Distribución de tamaño de partícula}

Multitud de estudios han evidenciado que la distribución de tamaño de partícula es un factor clave en el poder de emisión de polvo de materiales pulverulentos. No obstante, los resultados obtenidos hasta el momento parecen contradictorios. En este sentido, diversos autores han observado que, al aumentar el tamaño medio de partícula, disminuye el poder de emisión de polvo (Pujara 1997; Cowherd et al. 1989; Authier-Martin 1987; Schofield et al. 1979), otros estudios muestran el efecto contrario (Pensis et al. 2009; Chambers 1992; Upton et al. 1990) e incluso algunos muestran un máximo en el poder de emisión de polvo a tamaños intermedios (Upton et al. 1990; Chambers 1992). Además, otros autores (Cawley \& Leith 1993; Plinke et al. 1992) han sugerido que las partículas gruesas se liberan más fácilmente que las partículas finas (mayor emisión relativa). Respecto al efecto de la amplitud de la distribución, todos los estudios parecen coincidir en que las distribuciones amplias presentan un mayor poder de emisión que las distribuciones monodispersas (Pensis et al. 2009; Cowherd et al. 1989). De hecho, en numerosos trabajos se ha evaluado la influencia de las mezclas de muestras "finas" y "gruesas" observando en algunos casos que las mezclas pueden ser casi tan pulverulentas como las muestras compuestas en su totalidad por finos (Plinke et al. 1992) y que, por tanto, en contra de lo que cabría esperar, reducir el contenido en finos de un material no reduce proporcionalmente la generación de partículas de ese tamaño (Cawley \& Leith 1993; Plinke et al. 1992) e incluso en algunos casos se ha observado un poder de emisión de polvo máximo a porcentajes relativamente elevados de partículas gruesas (Upton et al. 1990; Hsieh 1987; Higman 1986).

\subsubsection{Humedad}

En general, al aumentar la humedad, aumenta las fuerzas de atracción entre partículas y, por tanto, aumenta la cohesión y disminuye la generación de polvo (WHO/SDE/OEH/99.14). En este sentido, un gran número de trabajos muestran que la adición de agua a una amplia variedad de materiales pulverulentos reduce su poder de emisión de polvo (Wypych \& Mar 2013; Alwis et al. 1999; Teschke et al. 1999; Hjemsted \& Schneider 1996; Plinke et al. 1995; Cawley \& Leith 1993; Plinke et al. 1992; Mikula \& Parsons 1991; Westborg \& Cortson 1990; Cowherd et al. 1989; Farrugia et al. 1989). Además, existen numerosos ejemplos industriales en los que se usa el agua como supresor de polvo: pulverizado de agua sobre la superficie de acopios de material (en puertos, canteras, minas, etc.), procesado en húmedo de materiales y/o el uso de 
suspensiones y materiales húmedos en la industria cerámica (WHO/SDE/OEH/99.14). En general, se puede afirmar que el agua es el supresor de polvo más común a nivel industrial por su bajo coste, disponibilidad y compatibilidad química.

No obstante, cuando se revisan estudios específicos sobre el efecto de la humedad, se observa que pequeños incrementos en la humedad pueden suponer en ocasiones un incremento en el poder de emisión de polvo, mientras que incrementos significativos casi siempre suponen un descenso (Hsieh 1987). Por otro lado, diversos estudios muestran que el efecto de la humedad puede ser incrementar o disminuir el poder de emisión de polvo en función del material (Plinke et al. 1995; Cawley \& Leith 1993; Cowherd et al. 1989).

Por tanto, puede considerarse que el efecto de la humedad es complejo y puede variar entre materiales, dependiendo del contenido de agua que es absorbido internamente o superficialmente (Leith 1991), que a su vez depende de las propiedades superficiales del material y de su higroscopicidad (WHO/SDE/OEH/99.14).

En este sentido, diversos estudios han evaluado el efecto de otros aditivos (aceite, cloruro cálcico, etc.) sobre el poder de emisión de polvo. (Powell \& Russell 1933) observaron que la presencia de algunos aditivos (cloruro cálcico, aceite, etc.) puede reducir significativamente el poder de emisión de polvo (Figura 1.16). Este mismo efecto fue observado por (Mikula \& Parsons 1991). No obstante, los autores indicaron que esta reducción obtenida a escala de laboratorio, no se observaba tan claramente a escala industrial, indicando como posibles causas las diferencias en: altura de caída, eficacia de mezclado, cantidad manipulada, etc.
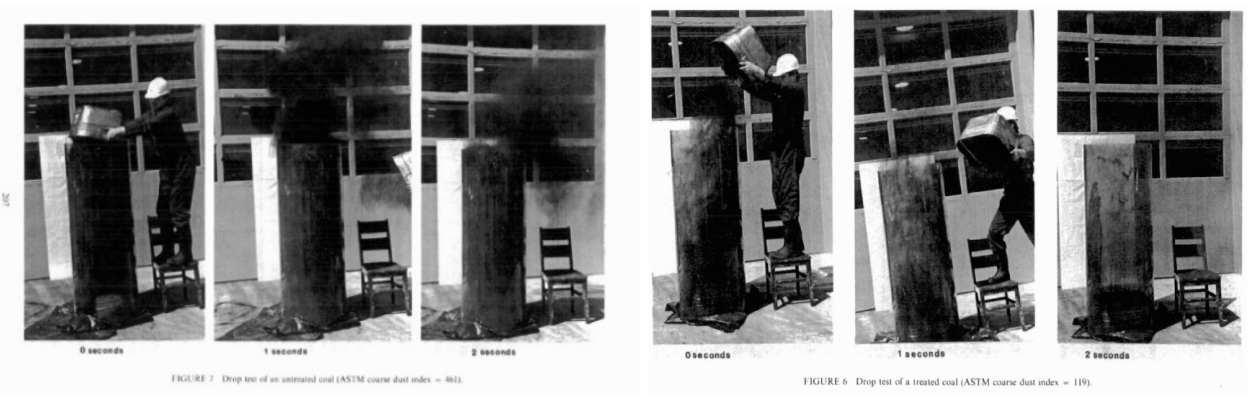

Figura 1.16 Comparativa de las emisiones generadas previa (izq.) y posteriormente (dcha.) al tratamiento del carbón (Mikula \& Parsons 1991) 


\subsubsection{Fluidez}

En general, los resultados obtenidos por diversos autores que han intentado correlacionar el poder de emisión de polvo con la fluidez, indican que, a mayor fluidez, mayor poder de emisión de polvo independientemente del tipo de sistema empleado para la determinación de la fluidez: ángulo de reposo (Figura 1.17, (Cowherd et al. 1989; Hsieh 1987; Authier-Martin 1987)) o célula de Jenike (Plinke et al. 1995; Cawley \& Leith 1993).

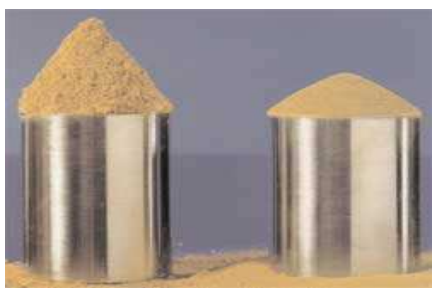

Figura 1.17 Ángulo de reposo (izq.: baja fluidez, dcha.: alta fluidez)

\subsubsection{Forma y superficie especifica}

La tendencia general, en los trabajos encontrados en la bibliografía, es que al aumentar la superficie específica disminuye el poder de emisión de polvo (Pensis et al. 2009; Pujara 1997). En este sentido, adicionalmente a la superficie específica, la forma de la partícula parece ser un factor significativo en referencia al poder de emisión de polvo (Figura 1.18). Diversos autores han observado que los materiales formados por partículas laminares e irregulares se aerosolizan más fácilmente que los que están constituidos por partículas esféricas (Pujara 1997; Hjemsted \& Schneider 1996).
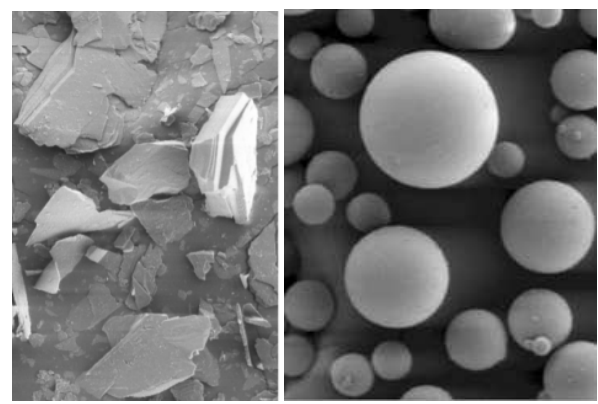

Figura 1.18 Micrografías (izq.: partícula laminar, dcha.: partícula esférica)

\subsubsection{Revisión de modelos de predicción del poder de emisión de polvo}

En la bibliografía consultada se proponen diversos modelos para la predicción del poder de emisión de polvo (Tabla 1.22). No obstante, tal y como se ha indicado anteriormente, algunos conducen a resultados aparentemente contradictorios. Además, requieren en muchas ocasiones llevar a cabo un gran número de ensayos de caracterización que consumen más recursos (tiempo y coste) que el propio ensayo de determinación del poder de emisión de polvo en sí mismo, por lo que son de poca utilidad práctica. 
Tabla 1.22 Modelos propuestos en la literatura para la estimación del poder de emisión de polvo

\begin{tabular}{|c|c|}
\hline Modelo & Referencia \\
\hline $\begin{array}{l}{ }^{\text {a) }} \mathrm{W}_{\mathrm{I}}=16.6 \cdot \mathrm{S}_{\mathrm{g}}^{3.9} \cdot \mathrm{M}^{-0.75} \cdot \rho_{\mathrm{b}}{ }^{-1.2} \cdot \mathrm{d}_{50}-0.45 \\
\mathbf{N}=\mathbf{1 4}\end{array}$ & Cowherd et al., 1989 \\
\hline $\begin{array}{l}\mathrm{RE}_{\mathrm{i}}=80 \cdot \mathrm{S}^{2.5} \cdot \mathrm{M}^{-0.3} \cdot \mathrm{d}_{\mathrm{i}}^{2.2} \cdot \mathrm{X}_{\mathrm{i}}^{-0.6} \\
\mathbf{R}^{\mathbf{2}}=\mathbf{0 . 8 4} \mathbf{N}=\mathbf{1 3}\end{array}$ & Plinke et al., 1992 \\
\hline $\begin{array}{l}\mathrm{RE}_{\mathrm{i}}=\mathrm{e}^{-9.1} \cdot \mathrm{X}_{\mathrm{i}}-0.2 \frac{\text { Impaction }}{1.0} \\
\mathbf{R}^{\mathbf{2}}=\mathbf{0 . 6 5} \mathbf{N}=\mathbf{1 2}\end{array}$ & Plinke et al., 1995 \\
\hline $\begin{array}{l}\mathrm{RE}_{\mathrm{i}}=\text { const } \cdot \mathrm{H}^{\mathrm{a}} \mathrm{X}_{\mathrm{i}}^{\mathrm{b}} \cdot \mathrm{F}^{\mathrm{c}} \cdot \mathrm{M}^{\mathrm{d}} \cdot\left(-\mathrm{d}_{\mathrm{i}} \ln \frac{\mathrm{d}_{\mathrm{i}}}{25}\right)^{g} \\
\mathbf{R}^{2}=\mathbf{0 . 5 3 - 0 . 7 1 \mathrm { N } = 1 7}\end{array}$ & Cawley et al., 1993 \\
\hline 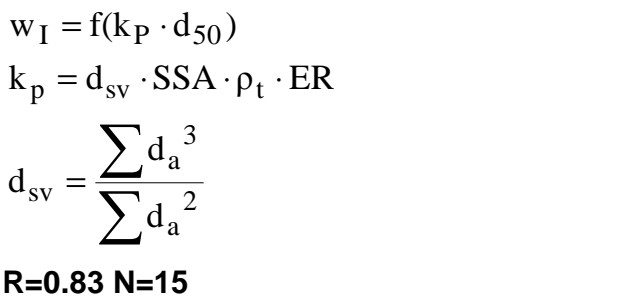 & Pujara et al., 1997 \\
\hline $\begin{array}{l}\text { All samples } \\
\mathrm{w}_{\mathrm{I}}(\text { Drop })=1.335 \cdot \mathrm{BQ}-0.047 \cdot \mathrm{d}_{50} \\
\mathrm{w}_{\mathrm{I}}(\text { Drum })=0.687 \cdot \mathrm{BQ}-0.0512 \cdot \mathrm{d}_{50} \\
\mathrm{w}_{\mathrm{R}}(\text { Drop })=0.689 \cdot \log \frac{\mathrm{d}_{97}}{\mathrm{~d}_{10}}-0.115 \cdot \mathrm{SSA} \\
\mathrm{w}_{\mathrm{R}}(\text { Drum })=0.568 \cdot \log \frac{\mathrm{d}_{97}}{\mathrm{~d}_{10}}+0.0025 \cdot \mathrm{d}_{50}\end{array}$ & \multirow{3}{*}{ Pensis et al., 2009} \\
\hline $\begin{array}{l}\text { Samples with } \mathrm{d}_{50<100} \mu \mathrm{m} \\
\mathrm{w}_{\mathrm{I}}(\text { Drop })=-0.0158 \cdot \mathrm{d}_{50}-0.034 \cdot \mathrm{SSA} \\
\mathrm{w}_{\mathrm{I}}(\text { Drum })=-0.0171 \cdot \mathrm{d}_{50}-0.0412 \cdot \mathrm{SSA} \\
\mathrm{w}_{\mathrm{R}}(\text { Drop })=0.0317 \cdot \mathrm{d}_{50}-0.0827 \cdot \mathrm{SSA} \\
\mathrm{w}_{\mathrm{R}}(\text { Drum })=0.0363 \cdot \mathrm{d}_{50}\end{array}$ & \\
\hline$R^{2}=0.667-0.79 \mathrm{~N}=29-37$ & \\
\hline
\end{tabular}




\section{Variables modelos (Nomenclatura)}

WI, WR: fracción másica de polvo Inhalable y respirable, respectivamente, expresada como el ratio entre la masa de polvo (colectada en los cabezales de muestreo) y la masa de material ensayado $(\mathrm{mg} / \mathrm{kg})$

$\mathrm{S}_{\mathrm{g}}$ : Desviación estándar de la distribución de tamaño de partícula

$\rho_{b}$ : Densidad del lecho $\left(\mathrm{g} / \mathrm{cm}^{3}\right)$

$\mathrm{d}_{50}$ : Tamaño medio de partícula $(\mu \mathrm{m})$

M: Humedad (\%)

$\mathrm{RE}_{\mathrm{i}}$ : Emisión relativa, ratio entre la masa de polvo de tamaño i (colectada en los cabezales de muestreo) y la masa de partículas de ese tamaño en el material $(\mathrm{g} / \mathrm{g})$

S: factor asociado al equipo empleado, $1 \mathrm{MRI}$ y 2 Heubach

di: diámetro medio aerodinámico colectado en cada etapa del impactador $(\mu \mathrm{m})$

$\mathrm{X}_{\mathrm{i}}$ : Fracción másica de partículas (en el material) con tamaño i

$\mathrm{H}$ : Altura de caída $(\mathrm{m})$

F: Flujo másico de material $(\mathrm{kg} / \mathrm{s})$

Const, a, b, c, d and g: constantes que dependen del material

Impaction: Ratio entre la fuerza de impacto y el flujo de material $(\mathrm{m} / \mathrm{s})$

Cohesion: medida con una celula rotacional de Pesch $(\mathrm{kPa})$

$\mathrm{k}_{\mathrm{p}}$ : factor de forma Superficie-Volumen

$\mathrm{d}_{\mathrm{sv}}$ : diámetro medio superficie-volumen, es el tamaño medio basado en la superficie especifica por unidad de volumen $(\mu \mathrm{m})$

$\mathrm{d}_{\mathrm{a}}$ : diámetro de área proyectada, determinado mediante análisis de imagen $(\mu \mathrm{m})$

SSA: superficie especifica $\left(\mathrm{m}^{2} / \mathrm{g}\right)$

$\rho_{\mathrm{t}}$ : densidad real $\left(\mathrm{g} / \mathrm{cm}^{3}\right)$

ER: ratio de elongación, es el ratio entre el máximo diámetro y el mínimo diámetro de la partícula

$\mathrm{d}_{97} / \mathrm{d}_{10}$ : Ratio que representa la amplitud de la distribución de tamaño de partícula

$\mathrm{BQ}$ : Contenido en cuarzo (\%)

$\mathrm{N}$ : Número de muestras

\subsubsection{Modelo propuesto para la predicción del poder de emisión de polvo}

En este sentido, a partir de un análisis detallado de los modelos previos, los parámetros con un efecto significativo sobre el poder de emisión de polvo se pueden agrupar en tres factores:

- Propiedades del material: tamaño medio de partícula, fluidez, superficie específica, humedad, amplitud de la distribución de tamaño, etc.

\section{- Contenido en finos del material o fracción susceptible de emitir}

- Energía aplicada y tipo de manipulación: Este factor depende del equipo empleado (tambor, caída continua, etc.) así como de los parámetros propios del ensayo (altura de caída, velocidad de rotación, etc.)

En base a estos tres factores, en la presente tesis se propone un modelo cuya hipótesis es que el poder de emisión de polvo de un material $\left(w_{i}\right)$ depende de su contenido en finos $\left(X_{i}\right)$ y de la capacidad para liberar dichos finos (Ecuación 1.3). Esta capacidad a su vez depende de las propiedades del material $\left(\mathrm{MF}_{\mathrm{i}}\right)$ y del proceso (cantidad y tipo de energía aplicada, PF). 


$$
w_{i}=X_{i} \cdot M F_{i} \cdot P F
$$

Ecuación 1.3

$\mathrm{W}_{\mathrm{i}}$ : Fracción másica de polvo generado con tamaño i

(mg polvo generado de tamaño i /kg material ensayado)

$\mathrm{X}_{\mathrm{i}}$ : Fracción de partículas en el material susceptibles de ser emitidas

MFi: factor del material, indicador de la facilidad de liberación de polvo de tamaño i

(dependiente de parámetros del material)

PF: Factor de proceso, indicador del tipo y cantidad de energía aplicada

(depende del ensayo)

En este sentido, la capacidad de liberación de polvo o emisión relativa del material puede definirse como el ratio entre la masa de polvo generado de tamaño i y la masa de material ensayado con este tamaño (Ecuación 1.4). Por tanto, atendiendo a dicha definición, si un material liberará toda la fracción susceptible de emitir, el poder de emisión de polvo coincidiría con dicha fracción (poder de emisión de polvo máximo). No obstante, en general factores propios del material y del ensayo limitan el porcentaje de partículas susceptibles de emitir que son puestas en suspensión, es decir, la emisión relativa es inferior al $100 \%$.

$$
R E_{i}=\frac{w_{i}}{X_{i}} \cdot 100
$$

Ecuación 1.4

$\mathrm{w}_{\mathrm{i}}$ : Fracción másica de polvo de tamaño i

( $\mathrm{kg}$ polvo generado de tamaño i /kg material ensayado)

$\mathrm{X}_{\mathrm{i}}$ : Fracción de partículas en el material susceptibles de ser emitidas

$R E_{i}$ : Emisión relativa de polvo de tamaño i (\%)

(kg polvo generado de tamaño i /kg material ensayado con tamaño i) *100

Combinando la Ecuación 1.3 y la Ecuación 1.4 se obtiene la Ecuación 1.5, según la cual la emisión relativa del material depende de la facilidad de liberación del polvo (factor del material) y del tipo y cantidad de energía aplicada (factor de proceso). No obstante, cabe indicar que en el presente estudio se ha empleado el método de caída continua (propuesto en la norma EN 15051) y, por tanto, el factor de proceso se ha mantenido constante (Ecuación 1.6). 


$$
\begin{array}{c|c}
R E_{i}=\frac{W_{i}}{X_{i}} \cdot 100=M F_{i} \cdot P F \cdot 100 & \text { Ecuación 1.5 } \\
R E_{i}=k \cdot M F_{i} & \text { Ecuación 1.6 }
\end{array}
$$

Wi: Fracción másica de polvo de tamaño i $(\mathrm{kg} / \mathrm{kg})$

$X_{i}$ : Fracción de partículas en el material susceptibles de ser emitidas

$R E_{i}$ : Emisión relativa de polvo de tamaño i (\%)

$\mathrm{K}$ : Constante $\mathrm{MF}_{\mathrm{i}}$ : Factor del material PF: Factor del proceso

En este trabajo se ha realizado un análisis exhaustivo de la influencia de las variables del material sobre su poder de emisión de polvo. En dicho análisis se ha evidenciado que la emisión relativa de un material está directamente relacionada con el tamaño medio de partícula $\left(d_{50}\right)$; en esta tesis se propone la siguiente ecuación (Ecuación 1.7) para parametrizar dicha relación.

$$
R E_{i}=A \cdot d_{50}{ }^{m}
$$

Ecuación 1.7

$R E_{i:}$ Emisión relativa de polvo de tamaño i (\%)

$$
\text { A, m: Constantes empíricas }
$$

$\mathrm{d}_{50}$ : tamaño medio de partícula $(\mu \mathrm{m})$

Combinando la Ecuación 1.4 con la Ecuación 1.7, para las fracciones inhalable y respirable, se obtienen la Ecuación 1.8 y la Ecuación 1.9.

$$
\begin{gathered}
w_{l}=X_{I} \cdot A_{1} \cdot d_{50} m_{l} \\
w_{R}=X_{R} \cdot A_{R} \cdot d_{50} m_{R}
\end{gathered}
$$

Ecuación 1.8

Ecuación 1.9

WI, R: Fracción másica de polvo inhalable y respirable, respectivamente $\mathrm{d}_{50}$ : tamaño medio de partícula $(\mu \mathrm{m})$

$A_{l}, A_{R}, m_{l}, m_{R}$ : constantes empíricas

\subsubsection{Poder de emisión de polvo y prevención de riesgos laborales}

El riesgo por exposición a una sustancia química que se presenta como material pulverulento depende de la peligrosidad intrínseca de la sustancia química a manipular (composición química, composición mineralógica, etc.), pero también de los niveles de exposición ambiental a dicha sustancia. Por tanto, el riesgo potencial depende fundamentalmente de la peligrosidad intrínseca de la sustancia procesada, su tendencia a emitir (volatilidad y/o poder de emisión de polvo) y la cantidad manipulada. Este riesgo potencial del material junto con los factores propios del escenario laboral (proceso, periodo de exposición, etc.) determinan el riesgo por exposición (Figura 1.19). 


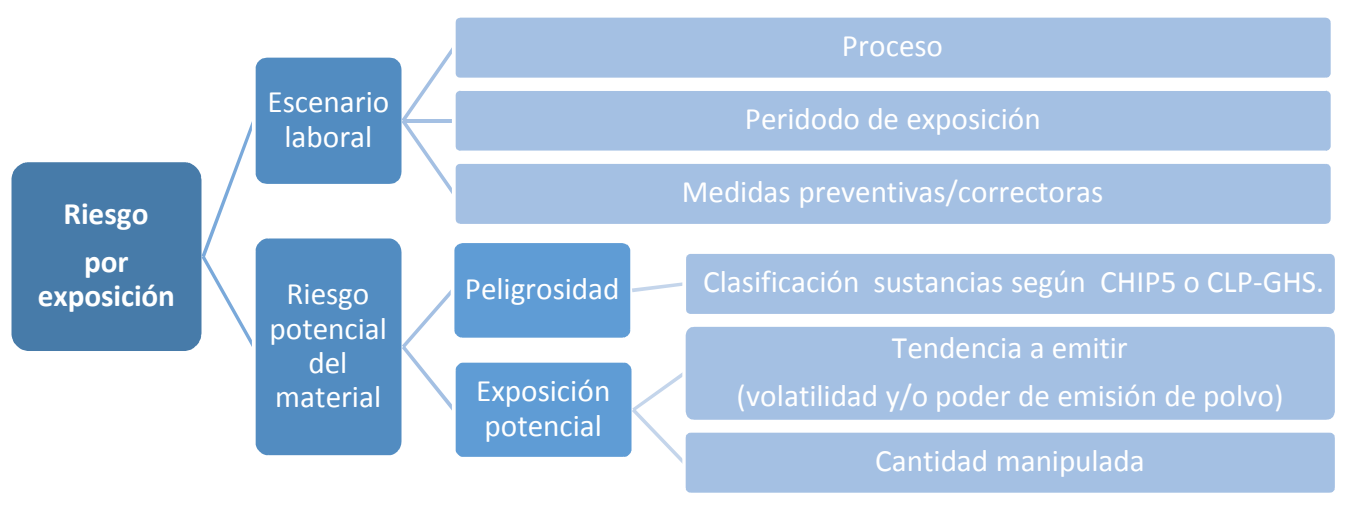

Figura 1.19 Riesgo por exposición a sustancias químicas

En este sentido, existen una serie de modelos que proporcionan asesoramiento sobre las medidas de control adecuadas durante la exposición a agentes químicos, cuya vía de entrada al organismo es la inhalatoria a partir de información cualitativa. Estos modelos permiten obtener una estimación inicial del riesgo potencial de las exposiciones a agentes químicos por inhalación, así como realizar evaluaciones de riesgo en la fase de diseño o discriminar situaciones aceptables de situaciones de riesgo potencial elevado (INSHT 2012). Estos modelos se fundamentan en clasificar el riesgo potencial en diferentes bandas en función del grado de peligrosidad de la sustancia, la cantidad manipulada y la tendencia a emitir del material.

A modo de ejemplo, se describe brevemente el modelo COSHH Essential (metodología de evaluación de riesgos desarrollada por el Health and Safety Executive del Reino Unido). Este modelo se fundamenta en determinar la banda de riesgo potencial en base a 5 grados de menor a mayor peligrosidad (grupo A, B, C, D, E), 3 escalas de manipulación: pequeña $(\mathrm{g})$, mediana $(\mathrm{kg})$ o grande (t) y 3 categorías de pulverulencia: baja (pellets), media (sólidos granulares o cristalinos) y alta (polvos finos y de baja densidad). En la Figura 1.20 se muestra la tabla de determinación del riesgo potencial según el modelo COSHH Essential. 


\begin{tabular}{|c|c|c|c|c|}
\hline $\begin{array}{l}\text { Amount } \\
\text { used }\end{array}$ & $\begin{array}{l}\text { Low volatility } \\
\text { or dustiness }\end{array}$ & $\begin{array}{l}\text { Medium } \\
\text { volatility }\end{array}$ & $\begin{array}{l}\text { Medium } \\
\text { dustiness }\end{array}$ & $\begin{array}{l}\text { High volatility } \\
\text { or dustiness }\end{array}$ \\
\hline & \multicolumn{4}{|c|}{ Hazard Group A substances } \\
\hline Small & 1 & 1 & 1 & 1 \\
\hline Medium & 1 & 1 & 1 & 2 \\
\hline \multirow[t]{2}{*}{ Large } & 1 & 1 & 2 & 2 \\
\hline & \multicolumn{4}{|c|}{ Hazard Group B substances } \\
\hline Small & 1 & 1 & 1 & 1 \\
\hline Medium & 1 & 2 & 2 & 2 \\
\hline \multirow[t]{2}{*}{ Large } & 1 & 2 & 3 & 3 \\
\hline & \multicolumn{4}{|c|}{ Hazard Group C substances } \\
\hline Small & 1 & 2 & 1 & 2 \\
\hline Medium & 2 & 3 & 3 & 3 \\
\hline \multirow[t]{2}{*}{ Large } & 2 & 4 & 4 & 4 \\
\hline & \multicolumn{4}{|c|}{ Hazard Group D substances } \\
\hline Small & 2 & 3 & 2 & 3 \\
\hline Medium & 3 & 4 & 4 & 4 \\
\hline \multirow[t]{2}{*}{ Large } & 3 & 4 & 4 & 4 \\
\hline & \multicolumn{4}{|c|}{ Hazard Group E substances } \\
\hline All amounts & 4 & 4 & 4 & 4 \\
\hline
\end{tabular}

Figura 1.20 Evaluación de riesgos (COSHH ESSENTIAL)

Cabe comentar que existen otros modelos similares (TNO (Fransman et al. 2009), Stofenmanager, etc.) con el mismo fundamento pero que en algunos casos emplean clasificaciones distintas. Por ejemplo, en el caso del poder de emisión de polvo, el modelo COSSHH Essential propone tres categorías de pulverulencia mientras que el TNO propone cinco (Tabla 1.23). En la Tabla 1.24 se muestra la clasificación según algunos de los modelos de control banding más utilizados (TNO, Stofenmanager y COSSHH Essential).

Tabla 1.23 Clasificación propuesta por el TNO

\begin{tabular}{|c|c|c|c|c|c|}
\hline \multirow{2}{*}{ Modelo } & \multicolumn{5}{|c|}{ Categoría } \\
\hline & 1 & 2 & 3 & 4 & 5 \\
\hline \multirow{2}{*}{$\begin{array}{l}\text { TNO, } \\
2009\end{array}$} & $\begin{array}{c}\text { Polvo } \\
\text { extremadamente } \\
\text { fino y ligero }\end{array}$ & Polvo fino & Polvo grueso & $\begin{array}{c}\text { Granulos o } \\
\text { pellets }\end{array}$ & $\begin{array}{c}\text { Pellets } \\
\text { firmes (poco } \\
\text { friables) }\end{array}$ \\
\hline & & & & & \\
\hline
\end{tabular}


Tabla 1.24 Clasificaciones propuestas (modelos control banding)

\begin{tabular}{|c|c|c|c|}
\hline Modelo & Clasificación & $\begin{array}{l}\text { Tipo de } \\
\text { material }\end{array}$ & Descripción \\
\hline \multirow{5}{*}{ TNO, 2009} & 1 & $\begin{array}{l}\text { Extremely } \\
\text { fine } \\
\text { and light } \\
\text { powder }\end{array}$ & $\begin{array}{l}\text { A powdered product containing very fine, free } \\
\text { flowing, light particles. This category may also } \\
\text { contain products with a mixture of very fine particles } \\
\text { and large particles or granules. Handling the } \\
\text { product in its dry form results in a dust cloud that } \\
\text { remains airborne for a long time. The product may } \\
\text { be wind swept: e.g., magnesium stearate. }\end{array}$ \\
\hline & 2 & Fine dust & $\begin{array}{l}\text { A powdered product containing fine particles. This } \\
\text { category may also contain products with a mixture } \\
\text { of fine particles and large particles or granules. } \\
\text { Handling } \\
\text { the product in its dry form results in a dust cloud } \\
\text { that is clearly visible for some time: e.g., carbon } \\
\text { black. }\end{array}$ \\
\hline & 3 & Coarse dust & $\begin{array}{l}\text { A powdered product containing coarse particles. } \\
\text { Handling the product in its dry form results in a dust } \\
\text { cloud that settles quickly due to gravity: e.g. sand. }\end{array}$ \\
\hline & 4 & $\begin{array}{l}\text { Granules, } \\
\text { flakes or } \\
\text { pellets }\end{array}$ & $\begin{array}{l}\text { Granules or flakes may fall apart and crumble, } \\
\text { resulting in only a very limited amount of fine } \\
\text { particles. Handling the product does not result in a } \\
\text { visible dust cloud; e.g., fertilizer, garden peat, } \\
\text { animal pellets. }\end{array}$ \\
\hline & 5 & $\begin{array}{c}\text { Firm } \\
\text { granules, } \\
\text { flakes, pellets } \\
\text { or solid } \\
\text { objects }\end{array}$ & $\begin{array}{l}\text { Product does not result in dust emission without } \\
\text { intentional breakage of products: e.g., firm polymer } \\
\text { granules, granules covered with a layer of wax }\end{array}$ \\
\hline \multirow{3}{*}{$\begin{array}{c}\text { COSHH } \\
\text { Essential, } 1999\end{array}$} & 1 & $\begin{array}{l}\text { Fine solid and } \\
\text { light powder }\end{array}$ & $\begin{array}{l}\text { Fine, light powders. When used dust clouds remain } \\
\text { in air for some time }\end{array}$ \\
\hline & 2 & $\begin{array}{l}\text { Granular or } \\
\text { crystalline }\end{array}$ & $\begin{array}{l}\text { Crystalline, granular solids. When used, dust is } \\
\text { seen but settles out quickly }\end{array}$ \\
\hline & 3 & $\begin{array}{l}\text { Pellet - does } \\
\text { not break up }\end{array}$ & $\begin{array}{l}\text { Pellet-like solids that don't break up. Little dust } \\
\text { visible during use }\end{array}$ \\
\hline \multirow{6}{*}{$\begin{array}{c}\text { Stoffenmanager, } \\
2000\end{array}$} & 1 & $\begin{array}{l}\text { Extremely } \\
\text { dusty } \\
\text { products }\end{array}$ & $\begin{array}{c}\text { For example, firm polymer granules, granules } \\
\text { covered with a layer of wax, bound fibres, such as } \\
\text { in cotton. No dust emission without intentional } \\
\text { breakage of the product }\end{array}$ \\
\hline & 2 & Fine dust & $\begin{array}{l}\text { Granules or flakes that may fall apart and crumble. } \\
\text { For example, washing powder, sugar or fertilizer }\end{array}$ \\
\hline & 3 & Coarse dust & $\begin{array}{l}\text { A dust cloud is formed, but settles quickly due to } \\
\text { gravity. For example, sand or coarse carbon black }\end{array}$ \\
\hline & 4 & $\begin{array}{l}\text { Granules or } \\
\text { flakes }\end{array}$ & $\begin{array}{l}\text { A dust cloud is formed that is clearly visible for } \\
\text { some time. For example, talcum powder, flour }\end{array}$ \\
\hline & 5 & $\begin{array}{c}\text { Firm granules } \\
\text { or flakes }\end{array}$ & A visible dust cloud remains airborne for a long time \\
\hline & 6 & Solid objects & $\begin{array}{l}\text { Solid forms of substances or products, such as } \\
\text { blocks }\end{array}$ \\
\hline
\end{tabular}


Cabe comentar que, independientemente del modelo empleado, el poder de emisión de polvo es un factor clave en la evaluación de riesgos. No obstante, la clasificación de los materiales en función de su pulverulencia se realiza en base a criterios cualitativos de aspecto y de apreciación subjetiva. Esta clasificación presenta la ventaja de su facilidad de uso, pero presenta el inconveniente de la incertidumbre asociada. Adicionalmente, la dificultad intrínseca del poder de emisión de polvo provoca que estas clasificaciones puedan llevar a error ya que tal y como se indica en algunas de ellas, una mezcla de finos y gruesos puede ser tan pulverulenta como un material compuesto en su totalidad por finos. Por tanto, la clasificación errónea de un material puede llevar a una incorrecta evaluación de riesgos. Por este motivo, se considera indispensable disponer de métodos y modelos que posibiliten una estimación sencilla y objetiva de dicho parámetro.

Por último, es necesario mencionar que el poder de emisión de polvo es un parámetro clave en la evaluación preliminar de riesgos que permite evaluar medidas preventivas, comparar materiales, etc. No obstante, de acuerdo con la literatura no hay una relación directa entre el poder de emisión de polvo y los niveles de exposición a escala industrial ya que la exposición depende de factores de proceso, medidas preventivas y/o correctoras, etc. y, por tanto, la relación debe ser evaluada para cada escenario. Por tanto, la determinación del poder de emisión de polvo no puede en ningún caso sustituir a las medidas de exposición laboral a sustancias químicas. No obstante, el poder de emisión de polvo de una sustancia aporta información clave en la evaluación de riesgos, tal como se ha indicado anteriormente, e incluso podría formar parte de la información de las fichas de seguridad de sustancias químicas y/o etiquetado de productos (Figura 1.21).

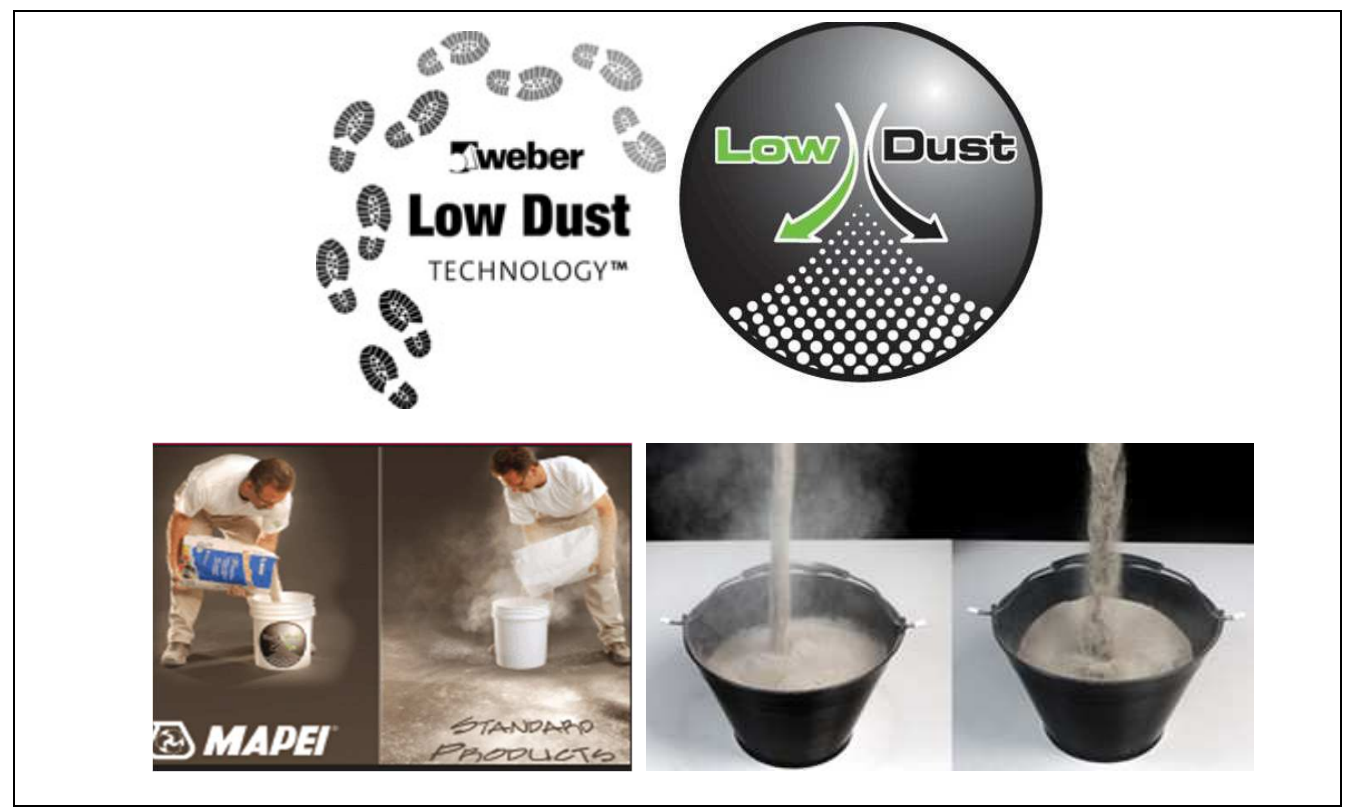

Figura 1.21 Ejemplo de etiquetado low dust (gentileza de MAPEI y Weber) 



\section{OBJETIVOS Y ESTRUCTURA}





\subsection{Objetivos}

A la vista del análisis de la bibliografía consultada y de las deficiencias encontradas, se ha planteado este estudio que tiene como objetivo general avanzar en el conocimiento de los mecanismos de generación de polvo mediante el análisis de la influencia de las variables de los materiales pulverulentos sobre su tendencia a generar polvo. Para ello, se abordará el desarrollo de un modelo empírico que permita estimar el poder de emisión de polvo, así como establecer las condiciones óptimas de manipulación de los materiales pulverulentos.

Para conseguir dichos objetivos generales, se deben alcanzar los siguientes objetivos específicos:

1. Seleccionar las materias primas objeto de estudio y llevar a cabo la preparación de muestras.

2. Realizar una exhaustiva caracterización de las materias primas, incluyendo todos aquellos parámetros que pueden tener una influencia significativa sobre su poder de emisión de polvo (humedad, granulometría, fluidez, forma, densidad, etc.).

3. Obtener una base de datos de poder de emisión de polvo, incluyendo la fracción másica inhalable y la respirable.

4. Analizar exhaustiva y sistemáticamente la influencia de las distintas variables sobre el poder de emisión de polvo de los materiales pulverulentos.

5. Desarrollar un modelo empírico de predicción del poder de emisión de polvo de los materiales pulverulentos.

6. Evaluar la forma de presentación óptima que minimice el impacto asociado a la manipulación, almacenamiento y transporte de materiales pulverulentos. 


\subsection{Estructura}

El presente trabajo se estructura en cinco bloques principales. El primer bloque engloba una introducción general y los objetivos propuestos. El segundo bloque engloba los materiales estudiados y la metodología empleada. En el tercer bloque se exponen los resultados obtenidos, la discusión y evaluación de los mismos. En el cuarto bloque se muestran las conclusiones, futuras líneas de investigación y publicaciones derivadas del presente trabajo. Finalmente, el quinto bloque incluye las referencias bibliográficas y los anexos.

\section{Bloque I: Introducción, objetivos y estructura}

\section{Capítulo 1: Introducción}

Se explican las generalidades correspondientes a la contaminación atmosférica por material particulado, se identifica la problemática asociada a las emisiones y exposición a material particulado en ambientes industriales y se realiza un repaso al marco normativo en materia de calidad de aire, emisiones industriales y salud laboral. Por otro lado, se describen las metodologías para determinar el poder de emisión de polvo de materiales pulverulentos, parámetro considerado de gran utilidad para el control de las emisiones generadas en la gestión de materiales pulverulentos y se describe, en base a la revisión bibliográfica realizada, el efecto de determinados parámetros de los materiales sobre su capacidad de dispersión. Por último, se describe el modelo propuesto en la presente tesis para la predicción del poder de emisión de polvo, así como su utilidad en protocolos de prevención de riesgos laborales.

\section{Capítulo 2: Objetivos y estructura}

Se describen brevemente los objetivos a alcanzar y la estructura de la memoria presentada.

\section{Bloque II: Materiales y metodología}

\section{Capítulo 3: Materiales y metodología}

Se especifican los materiales seleccionados para el presente estudio y se detallan las técnicas experimentales empleadas para la preparación y caracterización de las muestras, así como para la determinación de su poder de emisión de polvo.

\section{Bloque III: Resultados y discusión}

\section{Capítulo 4: Resultados}

Los resultados obtenidos en la presente tesis, así como la discusión de los mismos, se han desarrollado en 6 publicaciones científicas. Los resultados publicados serán expuestos de la siguiente forma: 
Capítulo 4.1: Evaluación preliminar de la influencia de las variables del material sobre su poder de emisión de polvo.

Capítulo 4.2: Evaluación de la influencia del tamaño medio de partícula sobre el poder de emisión de polvo.

Capítulo 4.3: Evaluación de la influencia de la humedad sobre el poder de emisión de polvo.

Capítulo 4.4: Modelo de predicción del poder de emisión de polvo de los materiales pulverulentos.

Capítulo 4.5: Medidas de reducción del poder de emisión de polvo de los materiales pulverulentos.

Bloque IV: Conclusiones, líneas futuras de investigación, difusión de resultados

\section{Capítulo 5: Conclusiones}

Se resumen las principales conclusiones a las que se ha llegado tras la realización del presente estudio.

\section{Capítulo 6: Líneas futuras de investigación}

Se plantean las principales líneas de investigación como continuación del presente trabajo.

\section{Capítulo 7: Difusión de resultados}

Se enumeran las publicaciones y comunicaciones, adicionales a las presentadas en el capítulo 4, en las que se ha llevado a cabo la difusión de los resultados obtenidos en la presente tesis doctoral.

\section{Bloque V: Referencias y Anexos}

\section{Capítulo 8: Referencias}

Se recoge la bibliografía utilizada en el desarrollo de la presente tesis.

\section{Anexos}

Por último, con el fin de simplificar la lectura de la memoria de la tesis, se ha creído conveniente añadir cuatro anexos dedicados a glosario de términos, nomenclatura, convenio de muestreo de las fracciones inhalable, torácica y respirable y caracterización física de los materiales, respectivamente. Por último, en el quinto anexo se incluye la autorización de los coautores para presentar la presente tesis por compendio de artículos. 



\section{BLOQUE II: MATERIALES Y METODOLOGÍA}



3 MATERIALES Y METOdOLOGÍA 



\subsection{Selección de materias primas}

Se han seleccionado una gran variedad de materias primas de uso mayoritario en España en los sectores de cerámica y vidrio (baldosas, esmaltes, ladrillos y tejas, refractarios, sanitarios y vajilla). En la Tabla 3.1 se detallan las materias primas consideradas, su consumo y el número de muestras objeto de estudio, tanto comerciales, como preparadas a escala de laboratorio.

Tabla 3.1 Materias primas y muestras objeto de estudio y consumo de las mismas en los sectores de fabricación de cerámica y vidrio en España

\begin{tabular}{|c|c|c|c|c|c|}
\hline \multirow{2}{*}{ Materia prima } & \multirow{2}{*}{ Sectores } & \multirow{2}{*}{ a Consumo (kt) } & \multicolumn{3}{|c|}{ Muestras } \\
\hline & & & Industriales & b Laboratorio & Totales \\
\hline Arcilla roja & $\begin{array}{c}\text { Baldosas, Esmaltes, } \\
\text { ladrillos y tejas }\end{array}$ & 44550 & 2 & 14 & 16 \\
\hline Cuarzo & $\begin{array}{c}\text { Baldosas, esmaltes, } \\
\text { vidrio, sanitarios y } \\
\text { vajillas }\end{array}$ & 2811 & 12 & 6 & 18 \\
\hline Arcilla blanca & $\begin{array}{c}\text { Baldosas, esmaltes, } \\
\text { sanitarios y vajillas }\end{array}$ & 1858 & 1 & 8 & 9 \\
\hline $\begin{array}{l}\text { Feldespatos, } \\
\text { feldespatoides y } \\
\text { arenas } \\
\text { feldespáticas }\end{array}$ & $\begin{array}{c}\text { Baldosas, esmaltes, } \\
\text { vidrio, sanitarios y } \\
\text { vajillas }\end{array}$ & 1613 & 5 & - & 5 \\
\hline Dolomita & $\begin{array}{l}\text { Esmaltes, vidrio y } \\
\text { refractarios }\end{array}$ & 630 & 1 & - & 1 \\
\hline Caolín & $\begin{array}{c}\text { Baldosas, esmaltes, } \\
\text { sanitarios y vajillas }\end{array}$ & 319 & 2 & 12 & 14 \\
\hline $\begin{array}{l}\text { Carbonato } \\
\text { cálcico }\end{array}$ & $\begin{array}{c}\text { Baldosas, esmaltes } \\
\text { y vidrio }\end{array}$ & 260 & 1 & - & 1 \\
\hline $\begin{array}{l}\text { Silicato de } \\
\text { circonio }\end{array}$ & $\begin{array}{c}\text { Baldosas, esmaltes } \\
\text { y refractarios }\end{array}$ & 145 & 2 & - & 2 \\
\hline Alúmina & $\begin{array}{l}\text { Esmaltes y } \\
\text { refractarios }\end{array}$ & 79 & 1 & - & 1 \\
\hline $\begin{array}{l}\text { Composición de } \\
\text { materias primas } \\
\text { del soporte }\end{array}$ & Baldosas & ${ }^{c}$ n.a. & 4 & 7 & 11 \\
\hline Total & & d 52265 & 51 & 56 & 78 \\
\hline
\end{tabular}

a) Consumo de materias primas empleadas en los sectores de cerámica y vidrio en 2004. b) Muestras preparadas a escala de laboratorio con la finalidad de evaluar de forma sistemática la influencia de las distintas variables del material sobre su poder de emisión de polvo. c) Las composiciones de materias primas del soporte están formuladas por las distintas materias primas consideradas. d) Este consumo representa el $97 \%$ del total de materias primas empeladas en los sectores de fabricación de cerámica y vidrio (53760 kt). 


\subsection{Muestras objeto de estudio}

Las muestras industriales se han obtenido directamente de las diferentes etapas de los procesos de manipulación de materiales pulverulentos considerados en este trabajo.

Por otro lado, para evaluar de forma sistemática la influencia de las principales variables del material (tamaño y humedad) sobre su poder de emisión de polvo, se ha llevado a cabo la preparación adicional de muestras a escala de laboratorio.

Para evaluar el efecto del tamaño, con la finalidad de obtener distintas fracciones granulométricas de las muestras industriales, se han empleado diferentes metodologías: tamizado vía seca y vía húmeda y separación mediante el uso de hidrociclones.

Así mismo, para evaluar el efecto de la humedad, a partir de muestras industriales, se han preparado muestras con diferentes contenidos en humedad.

\subsubsection{Obtención de fracciones granulométricas}

La metodología de obtención de las distintas fracciones granulométricas va a depender del estado de aglomeración de la muestra inicial. En efecto, si el polvo inicial de partida está compuesto por aglomerados el método de obtención de las distintas fracciones granulométricas será el tamizado vía seca. Por el contario, si las partículas son finas y se encuentran individualizadas en la muestra industrial, se utilizarán métodos de separación vía húmeda. En este caso, si se pretenden obtener partículas muy finas $\left(d_{50}<10 \mu \mathrm{m}\right)$ se utilizarán sistemas de hidrociclones. Sin embargo, si el tamaño de las partículas es mayor $\left(d_{50}>25 \mu \mathrm{m}\right)$ se utilizará el tamizado vía húmeda.

\subsubsection{Método de separación vía seca}

Para la separación de las distintas fracciones granulométricas vía seca, se ha empleado una batería de tamices con luz de malla: 125, 300, 500 y $2000 \mu \mathrm{m}$ (Figura 3.1).

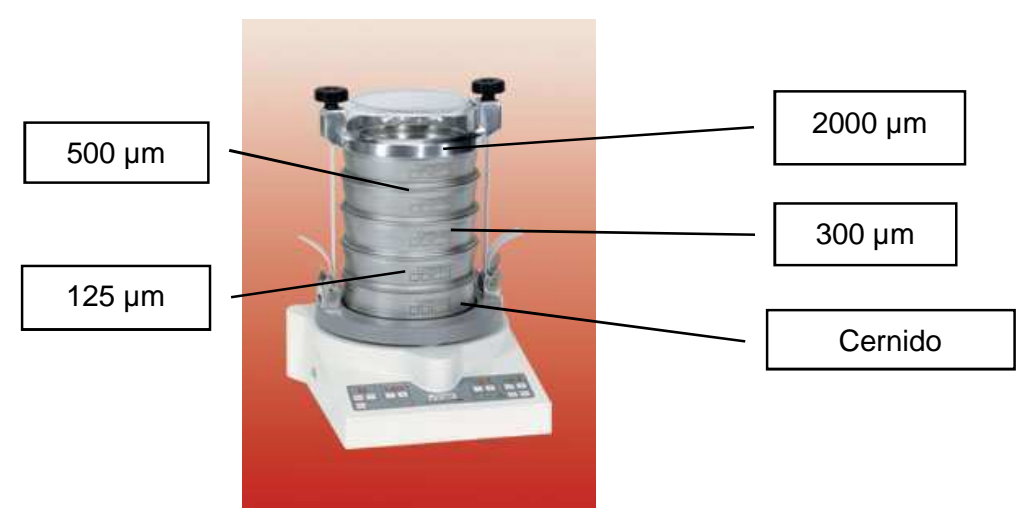

Figura 3.1 Batería de tamices 


\subsubsection{Métodos de separación vía húmeda.}

Se han empleado dos técnicas de separación vía húmeda en función de la distribución de tamaño de partícula de la materia prima y de las muestras a obtener: Sistemas de hidrociclones y tamizado vía húmeda.

\section{A) Sistemas de hidrociclones}

Para la obtención de fracciones granulométricas con tamaño medio de partícula inferior a $10 \mu \mathrm{m}$ se ha empleado el procedimiento que se describe a continuación (Figura 3.2):

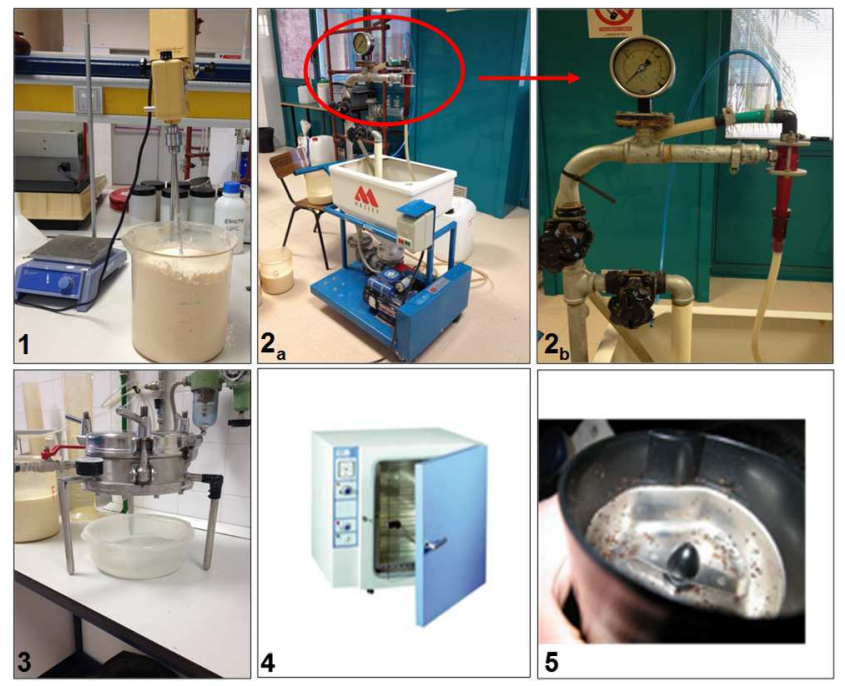

Figura 3.2. Obtención de fracciones granulométricas mediante hidrociclones

1. Preparación de la suspensión.

2. Separación de distintas fracciones granulométricas empleando un banco de hidrociclones. En este sistema, se introduce una suspensión (alimentación, Figura 3.3) y esta se separa en dos corrientes: las partículas finas pasan a través del vórtice o "vortex" hacia el derrame u "overflow" y las partículas gruesas caen a través del ápice o "apex" hacia la descarga o "underflow". El tamaño de corte de estos dispositivos se ajusta modificando la presión y el diámetro del vortex y del apex. En ese estudio, los componentes del ciclón se han mantenido fijos y se ha modificado la presión (Tabla 3.2).

Tabla 3.2 Tamaño de corte en función de la presión con el ciclón empleado

\begin{tabular}{|c|c|}
\hline Presión (bares) & Tamaño de corte $(\mu \mathrm{m})$ \\
\hline 0.5 & 5.0 \\
\hline 1.0 & 4.1 \\
\hline 1.5 & 3.7 \\
\hline 2.0 & 2.7 \\
\hline
\end{tabular}




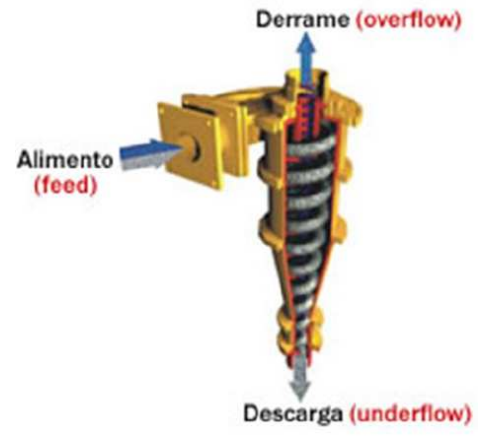

Figura 3.3 Esquema hidrociclón

3. A partir de las dos suspensiones obtenidas, preparación de las "tortas" mediante el uso de un filtro prensa.

4. Secado en estufa de las tortas.

5. Procesado de la torta para la obtención de las muestras en estado pulverulento.

B) Tamizado vía húmeda

Esta metodología ha sido empleada para la obtención de distintas fracciones granulométricas con tamaño medio de partícula superior a $25 \mu \mathrm{m}$ y consta de las siguientes etapas (Figura 3.4):

1. Preparación de la suspensión.

2. Alimentación de la suspensión a la batería de tamices: $25,45,63,75$ y $125 \mu \mathrm{m}$.

3. y 4. Obtención de las suspensiones de los distintos tamices.

5. Secado en estufa.

6. Obtención de la muestra objeto de estudio.
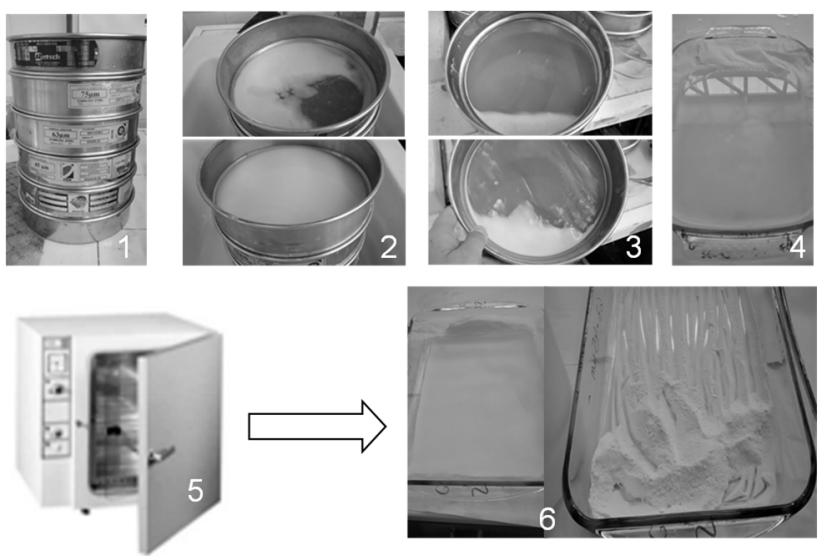

Figura 3.4 Obtención de fracciones granulométricas mediante tamizado vía húmeda 


\subsubsection{Obtención de muestras a distintas humedades}

Para obtener muestras a distintos porcentajes de humedad se ha llevado a cabo un proceso de humectación que consiste básicamente en los siguientes pasos:

1. Secado de la muestra.

2. Calculo de la masa de agua a añadir para obtener una muestra con la humedad deseada (Ecuación 3.1).

3. Humectación de la muestra mediante pulverización de agua hasta añadir la masa de agua requerida. Para la pulverización se ha empleado un aerógrafo que permite pulverizar el agua mediante aire a presión (Figura 3.5).

4. Tamizado de la muestra $(1000 \mu \mathrm{m})$ y homogeneización.

$$
\mathrm{m}_{\text {agua }}=\mathrm{m}_{\mathrm{ss}} \cdot \mathrm{M}
$$

Ecuación 3.1

magua: masa de agua a añadir $(\mathrm{kg})$; $\mathrm{m}_{\mathrm{ss}}$ : masa del sólido seco $(\mathrm{kg})$; M: Humedad en base seca ( $\mathrm{kg}$ agua / kg sólido seco)

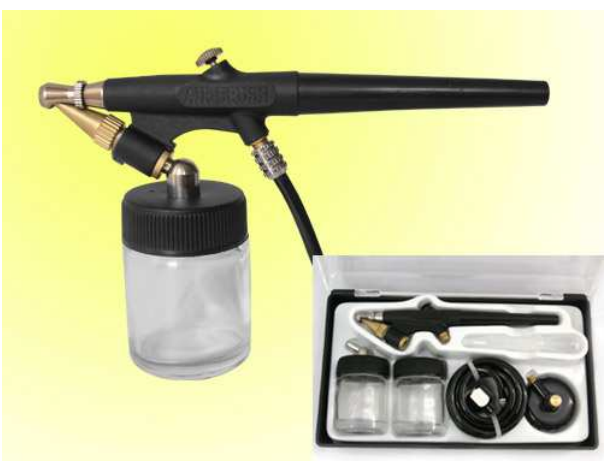

Figura 3.5 Aerógrafo empleado para llevar a cabo la pulverización de agua

\subsection{Caracterización de los materiales}

Para caracterizar los materiales empleados en este trabajo se han determinado las siguientes características físicas de las muestras: fluidez, humedad, densidad real del sólido, distribución de tamaño de las partículas o aglomerados, superficie específica, forma y poder de emisión de polvo. En este apartado se describen los ensayos empleados para llevar a cabo la caracterización de las materias primas objeto de estudio.

\subsubsection{Fluidez}

Existen diversas metodologías que permiten determinar parámetros indicadores del comportamiento reológico de los materiales pulverulentos (Amorós et al. 2011; Mallol et al. 2008; Mallol 2006). En base a una evaluación 
de las diferentes metodologías existentes, en el presente estudio se ha considerado oportuno determinar el Índice de Hausner. En este ensayo, a diferencia de lo que sucede empleando otras metodologías, el material no es sometido a tensiones normales y/o de cizalla, sino que es sometido a impactos que provocan que las partículas tiendan a reordenarse libremente como consecuencia de la modificación de la estructura inicial del lecho de polvo, que estaba soportada por las fuerzas cohesivas interparticulares o por fuerzas capilares. Por este motivo, se ha considerado que los resultados obtenidos en este ensayo serán representativos del comportamiento de los materiales pulverulentos en operaciones de almacenamiento, carga y descarga.

En este sentido, el índice de Hausner (Mallol et al., 2008) se define como el cociente entre la densidad aparente del lecho compactado y la densidad aparente aireada (Ecuación 3.2). Se denomina densidad aparente aireada a la densidad que se obtiene por simple vertido del polvo en un recipiente, sin agitación ni vibración. Por el contrario, para obtener la densidad aparente del lecho consolidado debe someterse el recipiente que contiene el material en forma de polvo a golpes sucesivos estandarizados (tapping), provocando una reordenación de las partículas e incrementando la compacidad del lecho. El incremento de compacidad es mayor cuanto más cohesivo sea el material.

$$
\mathrm{HR}=\frac{\rho_{\mathrm{v}}}{\rho_{\mathrm{a}}}
$$

Ecuación 3.2

HR: Hausner ratio; $\rho_{v}$ : densidad aparente del lecho compactado o vibrado $\left(\mathrm{kg} / \mathrm{m}^{3}\right)$; $\rho_{\mathrm{a}}$ : densidad aparente del lecho aireado $\left(\mathrm{kg} / \mathrm{m}^{3}\right)$

Este parámetro se emplea como indicador de la fluidez de los materiales puesto que materiales poco cohesivos, lisos, secos y de forma aproximadamente esférica darán lugar a un lecho de elevada compactación por caída libre y, por tanto, la diferencia entre la densidad aparente por caída y la densidad vibrada será reducida (HR próximo a 1); mientras que polvos húmedos o polvos muy finos (con elevadas fuerzas de atracción entre partículas) conducirán a índices de Hausner mayores. En la Tabla 3.3 se muestra la clasificación del comportamiento reológico de los materiales en función del Índice de Hausner.

Tabla 3.3 Clasificación del comportamiento reológico de los materiales pulverulentos en función de su índice de Hausner.

\begin{tabular}{|c|c|}
\hline Comportamiento del material & Índice de Hausner \\
\hline Flujo libre & $\mathrm{IH}<1.25$ \\
\hline Transición & $1.25<\mathrm{HH}<1.40$ \\
\hline Cohesivo & $\mathrm{IH}>1.40$ \\
\hline
\end{tabular}


El procedimiento experimental se basa en la siguiente secuencia:

\section{Llenado}

En los ensayos realizados el método de llenado del recipiente ha sido el de caída libre y agitado (Mallol., 2005). Consiste en dejar caer libremente el polvo en el interior del cilindro desde una bolsa de plástico. Previamente la bolsa se agita vigorosamente para conseguir una buena uniformidad del polvo. Cabe comentar que la altura mínima inicial del lecho debe de ser de $20 \mathrm{~cm}$ (Mallol., 2005).

Una vez vertido el material en el cilindro, se tapa y se somete manualmente a 2 o 3 rotaciones de $180^{\circ}$, provocando la rotura de las estructuras formadas durante el llenado, consiguiendo de este modo un lecho más homogéneo.

\section{Realización del ensayo}

Una vez llenado el cilindro, se determina la masa del lecho de polvo y se encaja el cilindro sobre el vástago del sistema de compactación (Figura 3.6). Desde el sistema de control se pone en funcionamiento el motor y se empiezan a aplicar los golpes de manera controlada sobre el cilindro. Cada cierto número de golpes se detiene el sistema y se mide la altura del lecho. De este modo puede seguirse la evolución de la altura del lecho y, por consiguiente, de su compacidad durante el ensayo.

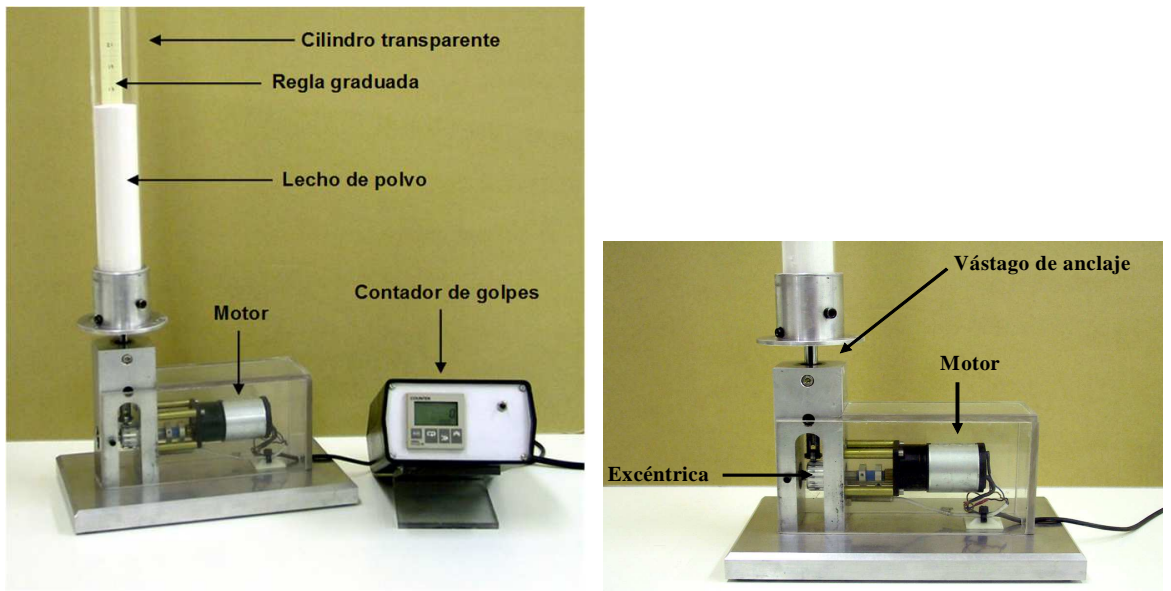

Figura 3.6 Dispositivo empleado para la determinación del Índice de Hausner

\subsubsection{Humedad}

Para la determinación del contenido en humedad la norma UNE EN 15051:2007 establece el siguiente procedimiento:

Se pesan seis placas Petri de vidrio, identificables, después de un periodo de almacenamiento de $2 \mathrm{~h}$ en las condiciones de la sala de balanzas. Se pesan 10 gramos aproximadamente del material a granel, tal como fue suministrado, en tres de las placas Petri y se anotan las masas. Se pesa con una exactitud de $0.1 \mathrm{mg}$ (se usa una balanza analítica de al menos cuatro cifras decimales). 
Se calientan las seis placas Petri a $100^{\circ} \mathrm{C}$ durante al menos $4 \mathrm{~h}$ y después se dejan enfriar en un desecador durante al menos $30 \mathrm{~min}$. Se sacan las placas Petri una tras otra del desecador y se vuelven a pesar, tomando la lectura de la balanza analítica $30 \mathrm{~s}$ después de que se hayan sacado del desecador 0 cuando la balanza analítica se haya estabilizado.

Las tres placas Petri de control se usan para corregir la masa final de las tres placas Petri de la muestra. La pérdida de masa registrada por el material a granel se utiliza para calcular el contenido en humedad, en porcentaje, por medio de la Ecuación 3.3.

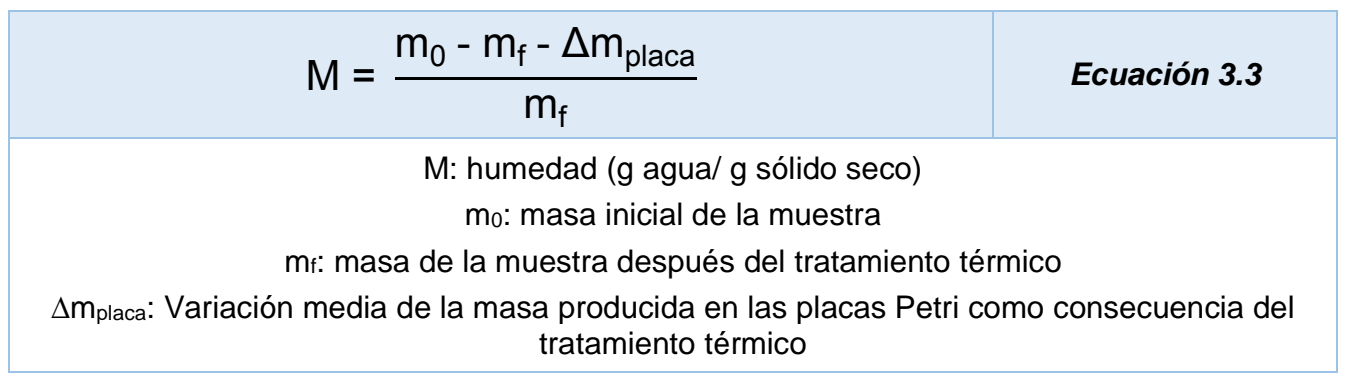

Finalmente, se calcula y registra la media y la desviación típica del contenido en humedad de las tres muestras.

\subsubsection{Densidad real del sólido}

Se ha determinado la densidad real del sólido con un picnómetro de helio (Figura 3.7). Las muestras se han secado en estufa a $110^{\circ} \mathrm{C}$ durante 24 horas y se ha dejado enfriar hasta temperatura ambiente en un desecador. Posteriormente se ha pesado una cantidad de cada muestra e introducido en la celda de medida del picnómetro. El volumen real que ocupa este sólido se mide a partir de la variación de presión que experimenta el helio al expandir desde la celda que contiene la muestra hasta otra celda sin muestra, con la que se conecta. La densidad real se calcula teniendo en cuenta la masa del polvo utilizado.

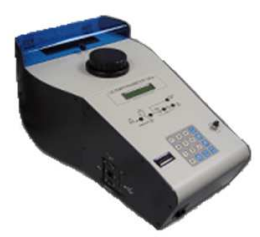

Figura 3.7 Picnómetro empleado para la medida de la densidad real del sólido 


\subsubsection{Distribución de tamaño de partícula y/o aglomerado}

Para la determinación de la distribución de tamaño de aglomerado se ha empleado la metodología de tamizado vía seca descrita anteriormente (ver apartado 3.2.1.1). Por otro lado, para la determinación del tamaño de partícula se han empleado dos técnicas vía húmeda: Difracción láser y sedimentación gravitacional controlada por absorción de rayos $\mathrm{X}$.

\subsubsection{Difracción láser vía húmeda}

Cuando un haz de luz interactúa con una partícula (Figura 3.8), puede ser absorbido, reflejado, difractado o transmitido. La importancia relativa de cada uno de estos fenómenos va a depender de varios parámetros:

- la relación entre el índice de refracción de la partícula y del medio dispersante $(\mathrm{m})$.

- la longitud de onda de la luz incidente $(\lambda)$.

- el coeficiente de absorción de las partículas a la longitud de onda del haz de luz.

- el tamaño de la partícula $\left(d_{i}\right)$.

Si se conocen los tres primeros parámetros, se dispone de una teoría capaz de predecir qué proporción del haz de luz va a extinguirse y qué cantidad va a ser dispersada. Por tanto, mediante un equipo capaz de medirla, podemos determinar cuál es el tamaño de la partícula que se está considerando.

La teoría que predice exactamente el camino que va a seguir la luz para cualquier tamaño de partícula, valor del coeficiente de absorción o del índice de refracción es la teoría de Lorenz-Mie. Un caso límite de esta teoría es la difracción de Fraunhofer, aplicable a partículas opacas, que no dejan pasar luz refractada. Para aplicar esta teoría no se necesitan las constantes ópticas del material. Si las partículas no son suficientemente grandes o absorbentes, empiezan a desarrollarse fenómenos de transmisión de luz a través de las partículas (refracción) que se han de tener en cuenta. Ha de utilizarse, por tanto, la teoría de Mie, teniendo en cuenta las propiedades ópticas de los materiales.

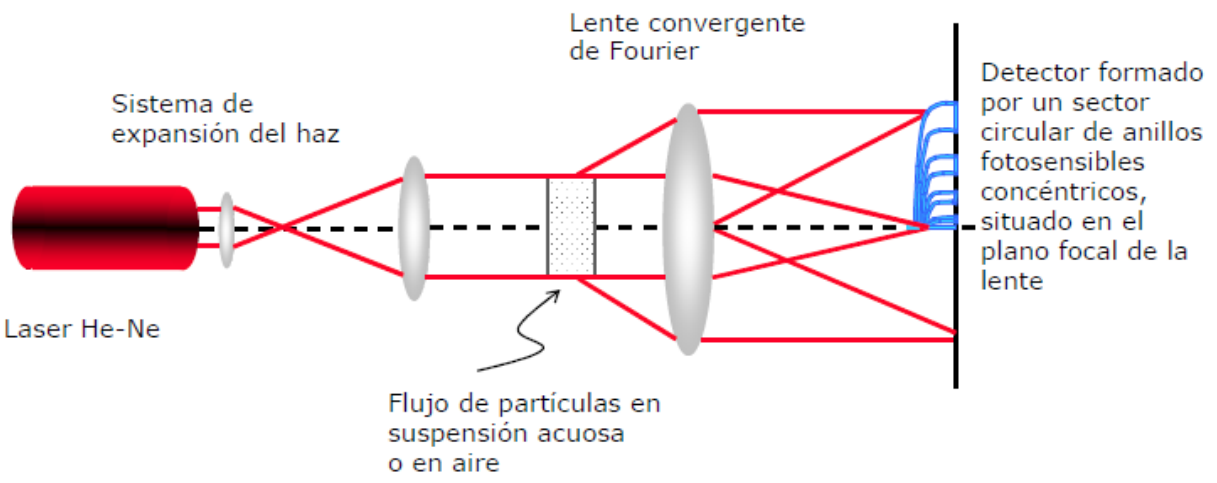

Figura 3.8 Esquema del principio de operación de la técnica de difracción láser 
El equipo empleado de difracción láser (Figura 3.9) opera con luz roja (longitud de onda de $632.8 \mathrm{~nm}$ ) y luz azul (longitud de luz de $470 \mathrm{~nm}$ ), analiza los datos, tanto por la teoría de Fraunhofer, como por la teoría Mie y detecta tamaños de partícula dentro del intervalo 0.02 a $2000 \mu \mathrm{m}$. La muestra se introduce con una espátula en la cubeta del equipo llena de agua, dejándola caer poco a poco hasta alcanzar la concentración óptima de medida, que indica el equipo. Cabe comentar que, en función del material, se lleva a cabo una preparación previa de la muestra (ultrasonidos, adición de desfloculante, etc.). La velocidad de agitación y bombeo en la cubeta ha de ser la máxima sin que se formen burbujas, para evitar la sedimentación de las partículas.

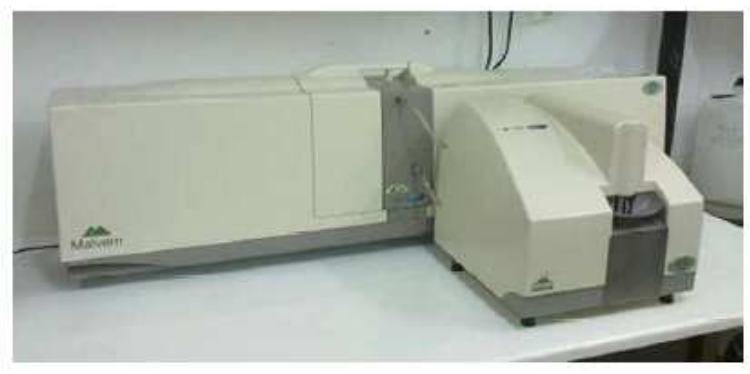

Figura 3.9 Mastersizer 2000

La luz que dispersan las partículas se recoge en detectores. La distribución de tamaños de partícula se ha calculado con el software que incorpora el equipo, utilizando la teoría de Mie para interpretar la señal de la luz dispersada y recogida por los detectores y utilizando como restricción en el proceso de deconvolución que el resultado siga una distribución logaritmo-normal. Se obtiene una distribución en volumen.

La luz recogida en los detectores se trata matemáticamente de acuerdo con la Ecuación 3.4 en la que:

$$
\begin{gathered}
\bar{L}=|A| \cdot \bar{q}+\varepsilon \\
\left(\begin{array}{c}
l_{1} \\
I_{2} \\
\ldots \\
\ldots \\
I_{n}
\end{array}\right)=\left(\begin{array}{cccc}
a_{11} & a_{11} & \ldots & a_{1 m} \\
a_{21} & a_{22} & \ldots & a_{2 m} \\
\ldots & \ldots & \ldots & \ldots \\
\ldots & \ldots & \ldots & \ldots \\
a_{n 1} & a_{n 2} & \ldots & a_{n m}
\end{array}\right) \cdot\left(\begin{array}{c}
q_{1} \\
q_{2} \\
\ldots \\
\ldots \\
q_{m}
\end{array}\right)+\left(\begin{array}{c}
\varepsilon_{1} \\
\varepsilon_{2} \\
\ldots \\
\ldots \\
\varepsilon_{m}
\end{array}\right)
\end{gathered}
$$

Ecuación 3.4

I: intensidad de luz recogida por cada anillo del detector, $\mathrm{n}$ es el número de anillos

$|A|$ : matriz de dispersión de luz. Intensidad de luz recogida por cada uno de los anillos del detector procedente de cada clase de tamaño de partícula

q: distribución de tamaños de partícula; proporción de partículas de cada clase de tamaño (m clases)

$\varepsilon$ : vector de error, intensidad de luz no explicada/ajustada en cada anillo del detector 
La distribución logaritmo-normal, impuesta como restricción en el proceso de cálculo, viene dada por la Ecuación 3.5.

$$
d p\left[d_{i}\right]=\frac{1}{\log s \sqrt{2 \pi}} \cdot e^{\left[-\frac{\left(\log d_{i}-\log d_{50}\right)^{2}}{2(\log s)^{2}}\right]} \cdot d\left(\log d_{i}\right)
$$

Ecuación 3.5

$$
\text { dp[di]: es la fracción de partículas de tamaño menor que di }
$$

$d_{50}$ : es la media de la distribución, o diámetro para el cual la mitad de las partículas de la distribución son más gruesas que dicho diámetro y la otra mitad más finas

s: es la desviación geométrica estándar

A partir de la distribución en volumen resultante se han obtenido los parámetros $d_{90}, d_{50} y_{10} d_{10}$, diámetros por debajo de los que hay un $90 \%$, un $50 \%$ y un $10 \%$ en volumen de las partículas totales, respectivamente.

\subsubsection{Sedimentación gravitacional}

La obtención de distribuciones de tamaño de partícula por sedimentación se basa en que sobre una partícula que se encuentra en el seno de un fluido actúan tres fuerzas (Figura 3.10): empuje $\left(F_{E}\right)$, rozamiento $\left(F_{R}\right)$ y gravedad $\left(F_{G}\right)$. Al aumentar la velocidad de la partícula, aumenta la fuerza de rozamiento hasta que $\mathrm{F}_{\mathrm{G}}=\mathrm{F}_{\mathrm{E}}+\mathrm{F}_{\mathrm{R}}$ y se alcanza la velocidad terminal (no hay aceleración).

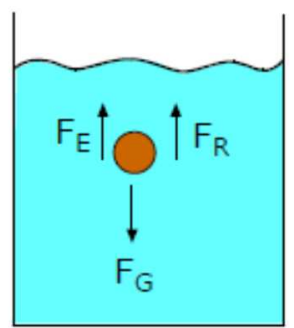

Figura 3.10. Fuerzas que actúan sobre una partícula en el seno de un fluido

En ese instante:

$$
F_{G}=F_{E}+F_{R}
$$




$$
\begin{gathered}
F_{G}=m_{p} \cdot g=\frac{\pi}{6} \cdot d^{3} \cdot \rho_{s} \cdot g \\
F_{E}=m_{f} \cdot g=\frac{\pi}{6} \cdot d^{3} \cdot \rho_{f} \cdot g \\
F_{R}=3 \cdot \pi \cdot \mu \cdot d \cdot v_{s t}
\end{gathered}
$$

Ecuación 3.7

Ecuación 3.8

Ecuación 3.9

A partir de las Ecuaciones 3.6 a 3.9:

$$
d=\sqrt{\frac{18 \cdot v_{s t} \cdot \mu}{g \cdot\left(\rho_{s}-\rho_{f}\right)}}
$$

Ecuación 3.10

$F_{G}$ : Fuerza de la gravedad (N); $F_{E}$ : Fuerza de empuje $(N)$; $F_{R}$ : Fuerza de rozamiento $(N)$; $\mathrm{g}$ : aceleración de la gravedad $\left(\mathrm{m} / \mathrm{s}^{2}\right) ; \mathrm{d}$ : diámetro de la partícula $(\mathrm{m})$;

$\rho_{s}$ : densidad del sólido $\left(\mathrm{kg} / \mathrm{m}^{3}\right)$; $\rho_{f}$ : densidad del fluido $\left(\mathrm{kg} / \mathrm{m}^{3}\right) ; \mu$ : viscosidad del fluido $(\mathrm{kg} / \mathrm{ms})$; $\mathrm{m}_{\mathrm{p}}$ : masa partícula $(\mathrm{kg})$; vst: velocidad terminal de sedimentación $(\mathrm{m} / \mathrm{s})$

La técnica empleada ha sido la de sedimentación gravitacional controlada por absorción de rayos X. En este ensayo la celda portamuestras (Figura 3.11) se llena del líquido dispersante y se mide su transmitancia, este valor se toma como blanco. Posteriormente, la celda portamuestras se llena con la suspensión perfectamente agitada y se mide su transmitancia. Finalmente, la celda se sitúa frente al detector, la celda se cierra, se para la bomba y se inicia el ensayo. La celda se desplaza hacia abajo respecto al haz de rayos $\mathrm{X}$, a una velocidad constante programada y se va midiendo la transmitancia (Figura 3.12).
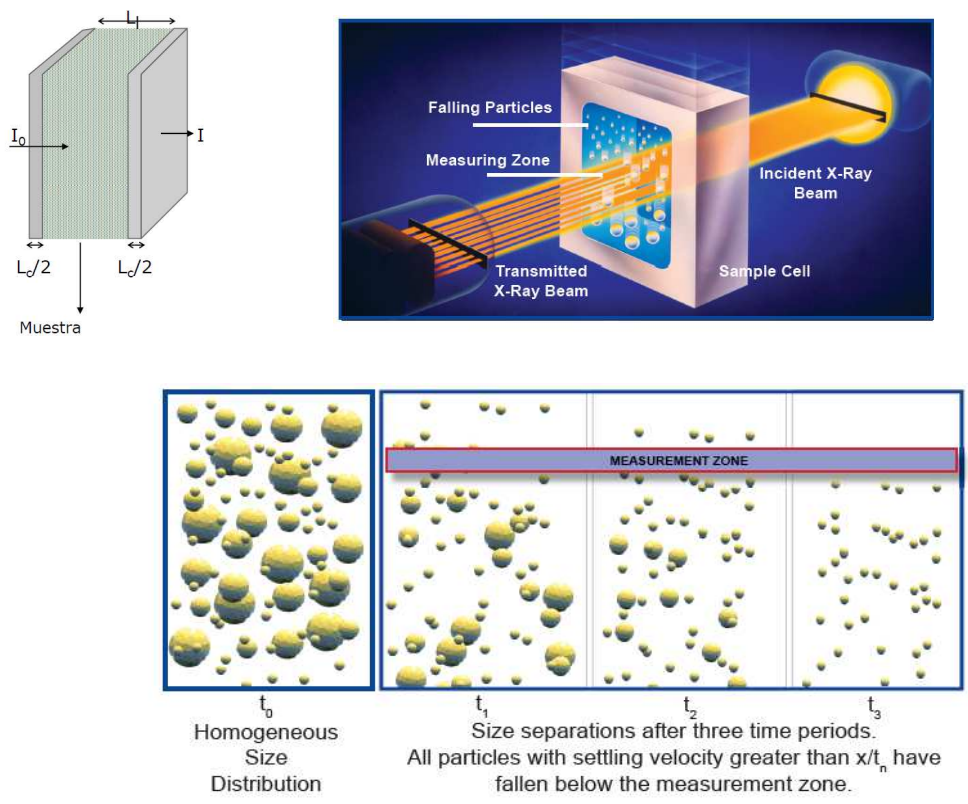

Figura 3.11 Celda de muestreo 


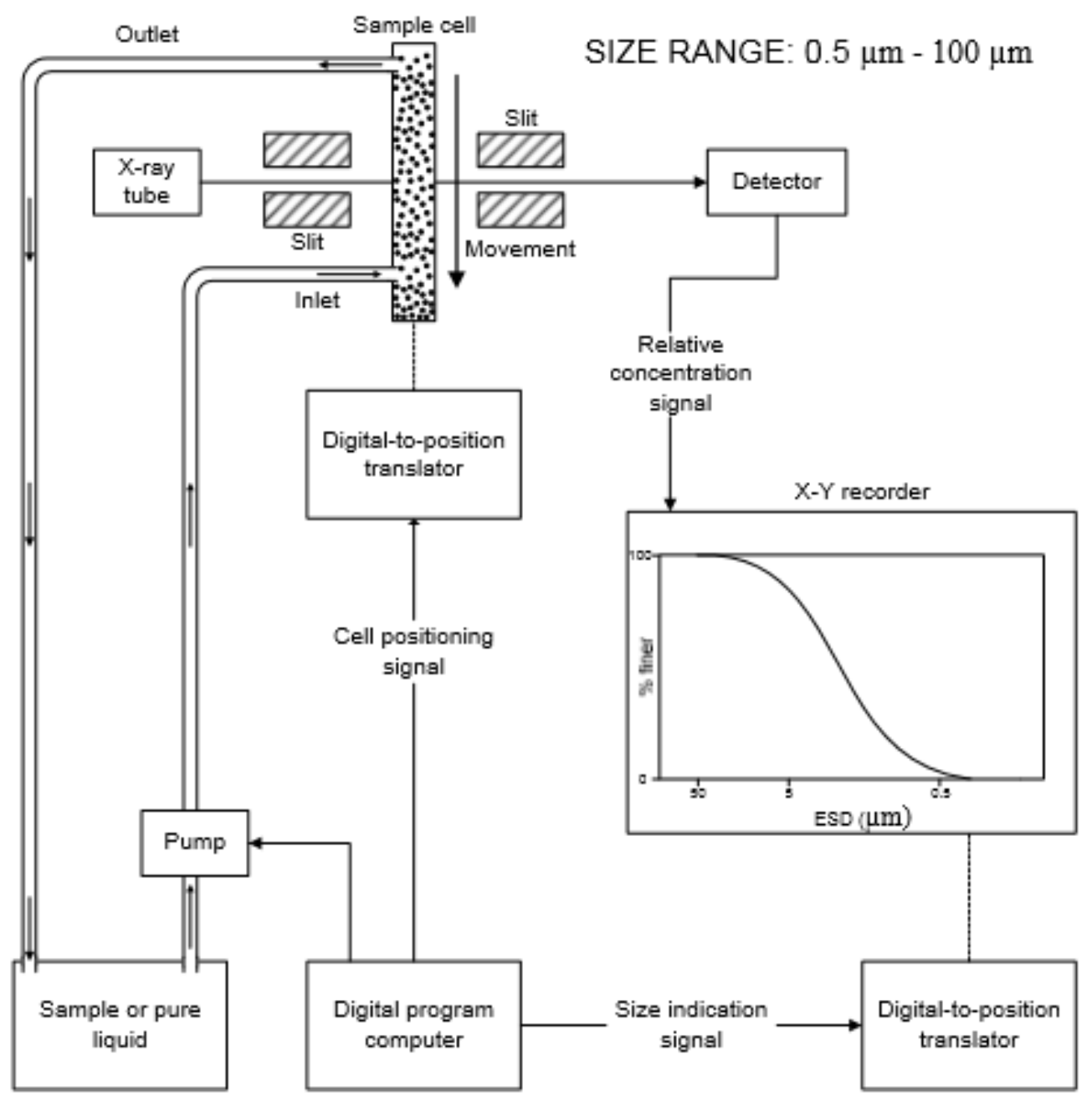

Figura 3.12. Esquema de funcionamiento de un sistema de sedimentación gravitacional controlada por rayos $X$ (Lobato, 2004)

Teniendo en cuenta la Ley de Lambert-Beer, la relación entre la intensidad inicial $\mathrm{I}_{0}$ y la intensidad de la radiación que abandona la celda (I) puede expresarse a través de la Ecuación 3.11. Además, definiendo $\mathrm{R}$ como el ratio entre la transmitancia de la celda con muestra y la celda conteniendo únicamente el medio dispersante (blanco), se obtiene la Ecuación 3.12. Por otro lado, teniendo en cuenta el valor inicial de transmitancia (muestra homogénea para $t=0$ ), puede obtenerse el porcentaje de partículas por debajo de un determinado tamaño i ( $p_{i}$, Ecuación 3.13 ) aplicando la Ecuación 3.14. Finalmente, ese porcentaje se asocia a un determinado tamaño, teniendo en cuenta la altura a la que se realiza la medida y el tiempo, mediante la Ecuación 3.15 . 


$$
\begin{gathered}
\mathrm{T}=\frac{\mathrm{I}}{\mathrm{I}_{\mathrm{o}}}=\mathrm{e}^{-\left[\left(\left(\mathrm{a}_{1} \varphi_{\mathrm{I}}+\mathrm{a}_{\mathrm{s}} \varphi_{\mathrm{s}}\right) \cdot \mathrm{L}_{\mathrm{l}}+\left(\mathrm{a}_{\mathrm{c}} \cdot \mathrm{L}_{\mathrm{c}}\right)\right)\right]} \\
\mathrm{R}=\frac{\mathrm{T}_{\text {muestra }}}{\mathrm{T}_{\text {blanco }}}=\frac{\left(\frac{I}{I_{0}}\right)_{\text {muestra }}}{\left(\frac{I}{I_{0}}\right)_{\text {blanco }}}=\mathrm{e}^{-\left[\left(\mathrm{a}_{\mathrm{s}}-\mathrm{al}\right) \cdot \varphi_{\mathrm{s}} \cdot \mathrm{L}_{l}\right]} \\
\ln \mathrm{R}=\mathrm{A} \cdot \varphi_{\mathrm{s}} \stackrel{\mathrm{A}=\text { cte }}{\longrightarrow} \mathrm{p}_{\mathrm{i}}=\frac{\ln \mathrm{R}_{\mathrm{i}}}{\ln \mathrm{R}_{0}} \\
\mathrm{~d}_{\mathrm{i}}=\sqrt{\frac{\ln \mathrm{R}_{\mathrm{i}}}{\ln \mathrm{R}_{\mathrm{o}}}=\frac{\left(\varphi_{\mathrm{s}}\right)_{\mathrm{i}}}{\left(\varphi_{\mathrm{s}}\right)_{100 \%}}} \\
\sqrt{\mathrm{g} \cdot\left(\rho_{\mathrm{s}}-\rho_{\mathrm{f}}\right)}=\mathrm{k}\left(\frac{\mathrm{h}_{0}-\mathrm{v}_{\mathrm{celda}} \cdot \mathrm{t}}{\mathrm{t}}\right)^{1 / 2}
\end{gathered}
$$

Io: Intensidad de la radiación incidente

I: Intensidad de la radiación qua abandona la celda

$\mathrm{L}$ : camino recorrido por la radiación $(\mathrm{cm})$

Lı y $L_{c}$ : camino que recorre la radiación en el medio líquido y la celda $(\mathrm{cm})$ a: coeficiente de absorción másica $(\mathrm{l} /(\mathrm{g} \cdot \mathrm{cm}))$

$a_{s}, a_{l}, a_{c}$ : coeficiente de absorción del sólido, del líquido y de la celda respectivamente. $(\mathrm{l} /(\mathrm{g} \cdot \mathrm{cm}))$

$$
\varphi \text { : fracción másica }(\mathrm{g} / \mathrm{l})
$$

$\varphi_{s}$ y $\varphi_{1}$ : fracción másica de sólido y líquido, respectivamente $(\mathrm{g} / \mathrm{l})$

$$
\mathrm{p}_{\mathrm{i}} \text { : Porcentaje de partículas por debajo del tamaño i }
$$

R: Ratio entre la transmitancia de la muestra (celda + muestra + dispersante) y la transmitancia del blanco (celda + dispersante)

$\mathrm{R}_{0}$ : Ratio entre la transmitancia de la muestra para $\mathrm{t}=0$ y la transmitancia del blanco. Medida al inicio, muestra en agitación

$R_{i}$ : Ratio entre la transmitancia de la muestra para $t=t_{i}$ y la transmitancia del blanco. Medida a un tiempo $t_{i}$

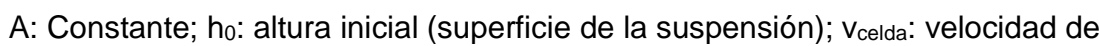
desplazamiento de la celda (m/s); t: tiempo (s)

\subsubsection{Determinación de la superficie especifica}

La superficie específica se determinó según el método BET a partir de la medida de las isotermas de adsorción (Figura 3.13), utilizándose como absorbente nitrógeno gas (ISO 9277: 1995), calculándose mediante el método multipunto (Ecuación 3.16). 


\begin{tabular}{|c|c|}
\hline $\mathrm{SSA}=\mathrm{n}_{\mathrm{m}} \cdot \mathrm{a}_{\text {nitrógeno }} \cdot \mathrm{N}_{\mathrm{A}}$ & Ecuación 3.16 \\
$\mathrm{SSA}:$ Superficie especifica $\left(\mathrm{m}^{2} / \mathrm{g}\right)$ & \\
\hline $\mathrm{n}$ : capacidad de gas en la monocapa que recubre toda la superficie del material (moles de \\
adsorbato en la monocapa $/ \mathrm{g}$ adsorbente) \\
anitrógeno: sección transversal de la molécula de nitrógeno $\left(0.162 \mathrm{~nm}^{2}\right)\left(\mathrm{m}^{2}\right)$ \\
$\mathrm{NA}$ : número de Avogadro
\end{tabular}

La capacidad de la monocapa $\left(\mathrm{n}_{\mathrm{m}}\right)$ se calculó por regresión lineal determinando la pendiente y la ordenada en el origen de la ecuación de BET en la que $n_{m}=(1 /(a+b))$, donde a es la pendiente y $b$ es la ordenada en el origen.

La cantidad de nitrógeno adsorbido se midió mediante un método volumétrico estático.

Antes de realizar el ensayo, las muestras se secaron en estufa a $110^{\circ} \mathrm{C}$ durante 2 horas y, a continuación, fueron sometidas a desgasificación por corriente de nitrógeno a $150{ }^{\circ} \mathrm{C}$.

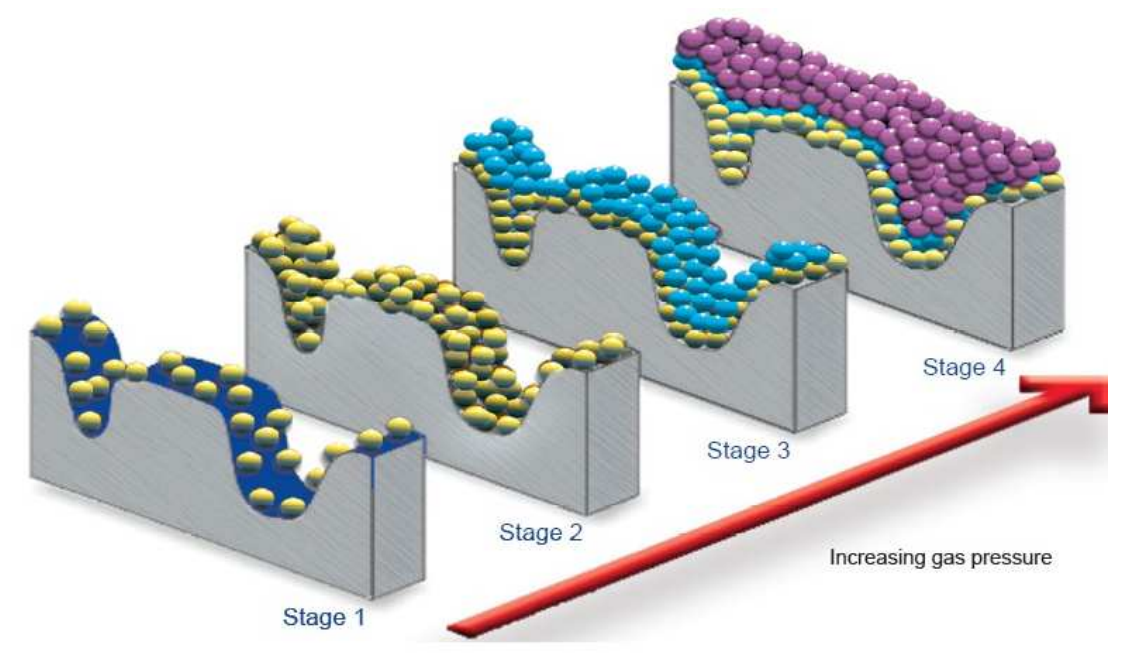

Figura 3.13 Teoría de adsorción (http://www.particletesting.com/)

\subsubsection{Forma de las partículas}

Para evaluar la forma de las partículas se ha determinado el "Aspect ratio" y se han realizado micrografías utilizando un microscopio electrónico de barrido (MEB).

\subsubsection{Determinación del "Aspect ratio" (AR)}

El factor de forma "Aspect ratio" (AR) se define para partículas anisotrópicas como la ratio entre el diámetro del plano basal más grande (a) y su espesor (b), (Ecuación 3.17). 


$$
A R=\frac{a}{b}
$$

Ecuación 3.17

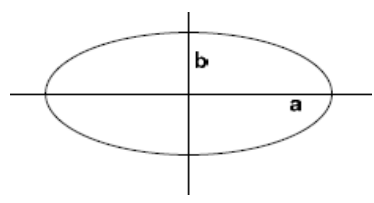

Este parámetro se ha determinado a partir de una metodología propuesta en la bibliografía (Parslow et al, 1986; Castro Lobato, 2004) que se fundamenta en la diferente relación que presentan con el AR los resultados obtenidos mediante dos metodologías de obtención de la distribución de tamaño de partícula: difracción láser y sedimentación. Mediante la aplicación de estas metodologías, en el caso ideal de partículas esféricas se obtendría el mismo resultado (Figura 3.14). A medida que las partículas se alejan de la esfericidad el resultado obtenido por ambas metodologías presentará una mayor diferencia (Figura 3.14).

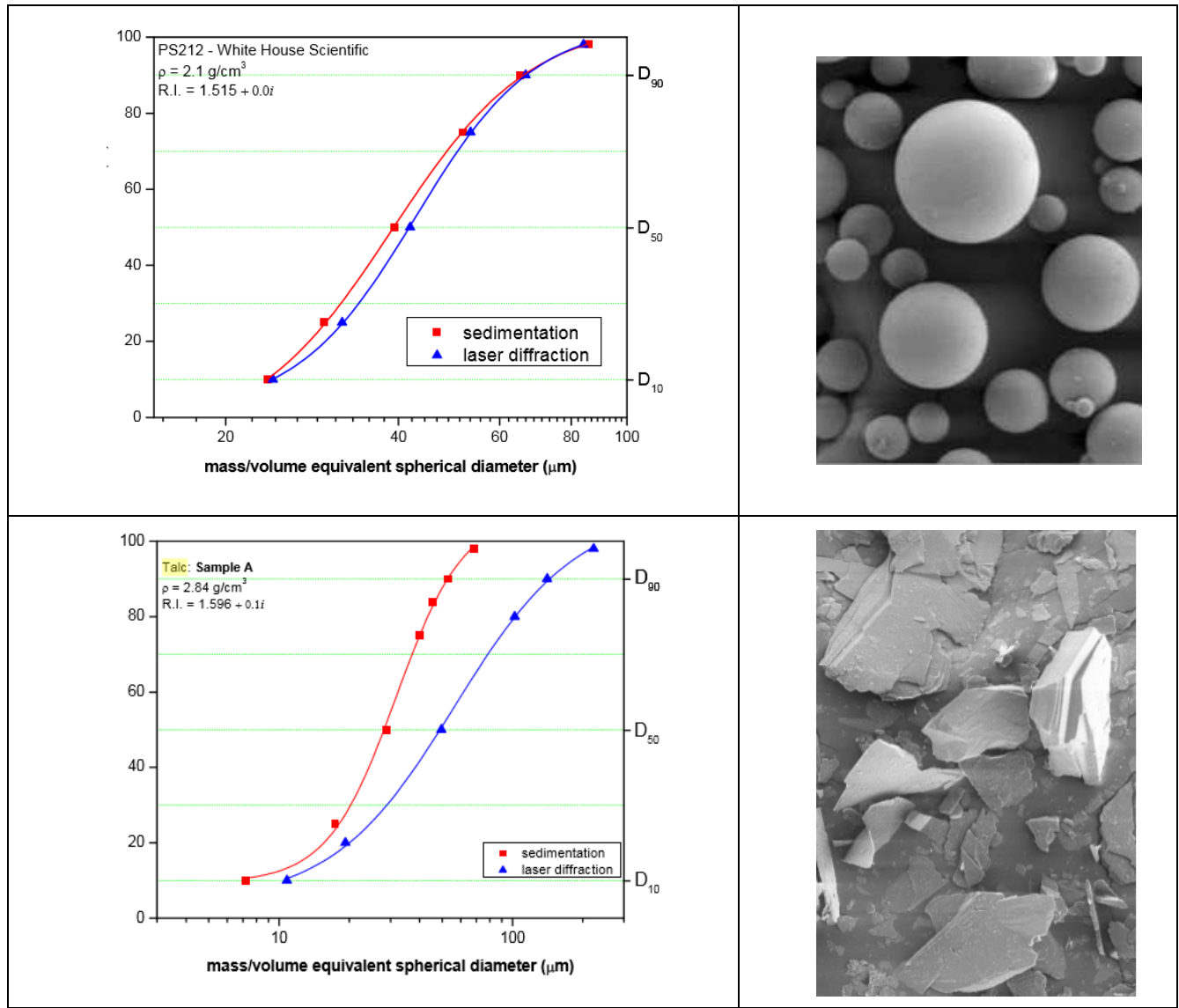

Figura 3.14 Resultados obtenidos con esferas de sílice (arriba) y con talco (abajo) Fuente: Castro Lobato, 2004 
En este sentido, de acuerdo a la metodología propuesta por Parslow-Jennings el diámetro obtenido por sedimentación y el diámetro obtenido por difracción láser están directamente relacionados con AR según la Ecuación 3.18 y la Ecuación 3.19, respectivamente (Castro Lobato, 2004). Por tanto, a partir del ratio entre ambos diámetros (Ecuación 3.20), se puede obtener AR mediante resolución numérica.

$$
\begin{gathered}
d_{\text {stokes }}=a \cdot \sqrt{\frac{\arctan ^{-1} \cdot \sqrt{A R^{2}-1}}{\sqrt{A R^{2}-1}}} \\
d_{\text {laser }}=\frac{a}{\sqrt{2}} \cdot \sqrt{1+\frac{\ln \left(A R-\sqrt{A R^{2}-1}\right)}{A R \cdot \sqrt{A R^{2}-1}}}
\end{gathered}
$$

Ecuación 3.18

Ecuación 3.19

Combinando las ecuaciones: 3.18 y 3.19 :

$$
\frac{d_{\text {stokes }}}{d_{\text {laser }}}=\sqrt{\frac{2 \cdot A R \cdot \arctan \cdot \sqrt{A R^{2}-1}}{A R \cdot \sqrt{A R^{2}-1}+\ln \left(A R+\sqrt{A R^{2}-1}\right)}}
$$

Ecuación 3.20

dstokes: diámetro obtenido por sedigraph, diámetro de una esfera con la misma densidad y velocidad de sedimentación que la partícula real

d laser: diámetro obtenido por difracción láser, diámetro de una esfera con la misma área proyectada que la partícula real (orientación aleatoria)

AR: "Aspect ratio"

\subsubsection{Obtención de imágenes MEB}

Para la obtención de micrografías se ha empleado un microscopio electrónico de barrido (Figura 3.15). En este equipo (Goldstein et al. 1983) se genera un haz de electrones que se acelera y se hace incidir sobre la muestra a examinar. Un generador de barrido se encarga de desplazar el haz sobre la superficie de la muestra. Como consecuencia de la interacción entre el haz de electrones y la muestra se producen una serie de señales que, convenientemente recogidas por los detectores, aportan diferente información. Entre las señales que se producen están las siguientes:

- Electrones secundarios: son electrones de baja energía, emitidos por la muestra como consecuencia de su interacción con el haz primario. El recorrido libre medio de estos electrones en el interior de la muestra es muy pequeño, por lo que solo salen los producidos en las inmediaciones de la superficie. La señal de electrones secundarios proporciona información sobre la morfología superficial de la muestra. 
- Electrones retrodispersados: son electrones de alta energía. Se producen como consecuencia de la interacción elástica entre los electrones del haz primario y los elementos de la muestra. Cuanto mayor el número atómico de la muestra, mayor es la probabilidad de que interaccionen, por lo que aportan información sobre la composición de la muestra. En una muestra plana las regiones con mayor número atómico se ven más brillantes (mayor emisión de electrones retrodispersados) y las de menor número atómico se ven más oscuras. Si la muestra es rugosa, la señal de electrones retrodispersados se ve afectada por la rugosidad y la información que aporta no es solo de su composición, sino que está mezclada con su topografía.

- Rayos X característicos: si lo electrones del haz incidente tienen suficiente energía pueden expulsar electrones de las capas internas de los átomos generando huecos que, cuando se rellenan, dan lugar a la emisión de rayos $X$ característicos. Los detectores de rayos $X$ por dispersión de energías (EDS) o de longitudes de onda (WDS) permiten obtener información sobre la composición elemental de la muestra.

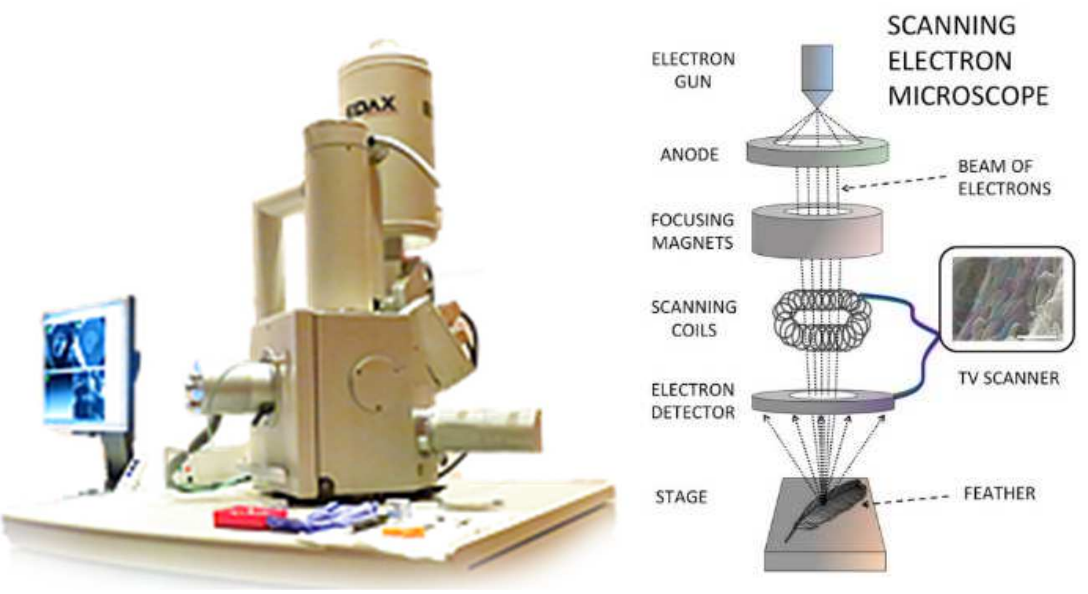

Figura 3.15 Microscopio electrónico de barrido

\subsubsection{Determinación del poder de emisión de polvo}

Para la determinación del poder de emisión de polvo se ha utilizado un equipo de caída continua.

En este apartado se describe, la puesta a punto del equipo de determinación de poder de emisión de polvo y las especificaciones a seguir en el desarrollo del ensayo.

El principio de operación del ensayo por caída continua consiste en dejar caer el material a ensayar desde una cierta altura sobre una corriente de aire ascendente. Cuanto mayor sea la cantidad de material que se incorpore a la corriente ascendente de gases mayor será la capacidad de dicho material para liberar polvo en suspensión. 
El equipo de muestreo (Figura 3.16) consiste, básicamente, en una conducción cilíndrica por la que circula una corriente de aire en sentido ascendente a una velocidad de $0.0500 \pm 0.0025 \mathrm{~m} / \mathrm{s}$. Desde la parte superior de dicha conducción se dosifica el material de ensayo con un caudal entre 6 y $10 \mathrm{~g} / \mathrm{min}$. El polvo se deja caer por un conducto interior, concéntrico al conducto por el que asciende el aire. La longitud de este tubo es menor que la del conducto exterior, de manera que el polvo se libera en el seno del flujo en contracorriente. Ligeramente por encima de la posición de descarga del material se ubican un par de cabezales de muestreo de fracciones granulométricas con relevancia en la salud. Concretamente, se emplea un muestreador de la fracción respirable (FSP-2, BGIA) y un diseño del Institut für Gefahrstoff-Forschung (IGF) para el muestreo de la fracción inhalable. Estos cabezales de muestreo posibilitan la determinación simultánea de la fracción inhalable y respirable de acuerdo a la norma EN 481:1995. La fracción inhalable representa las partículas en suspensión susceptibles de penetrar en el aparato respiratorio, mientras que la fracción respirable representa la fracción de estas partículas que puede penetrar en las vías respiratorias no ciliadas.

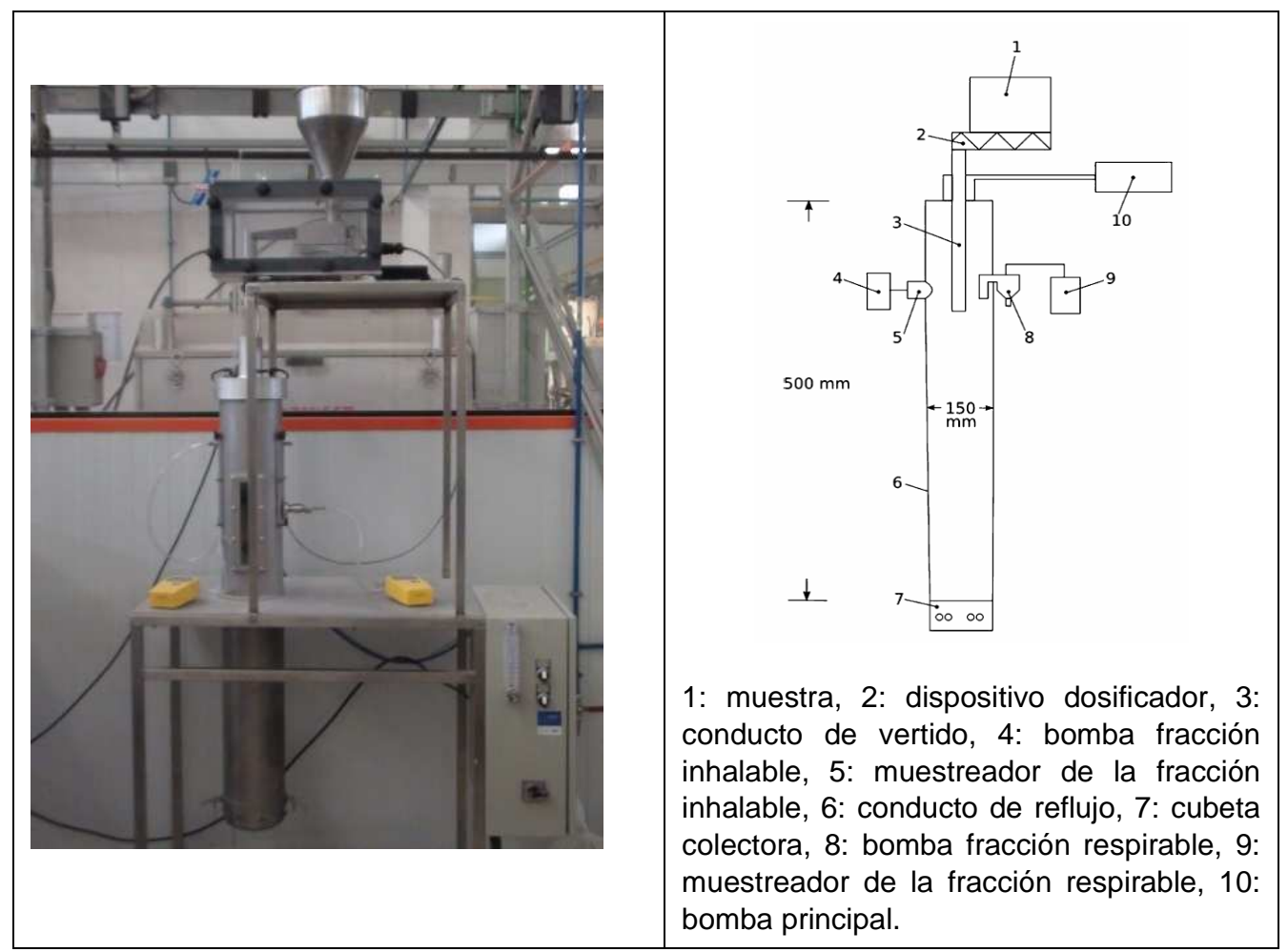

Figura 3.16 Equipo utilizado para la medida del poder de emisión de polvo

\section{Especificaciones del método}

Siguiendo la Norma UNE-EN 15051 al realizar el ensayo se deben cumplir las siguientes especificaciones: 
- Las muestras de ensayo deben obtenerse a partir de material a granel y deben ser representativas.

- Antes de la puesta en marcha del equipo debe limpiarse el conducto de reflujo, la cubeta colectora y los muestreadores.

- El conducto de reflujo debe ser redondo y con un diámetro interno de $150 \mathrm{~mm}$.

- La velocidad vertical de aire debe ser de $0.050 \mathrm{~m} / \mathrm{s}$.

- Los caudales de la bomba principal y las bombas de toma de muestras deben ser $49 \mathrm{l} / \mathrm{min}, 2 \mathrm{l} / \mathrm{min}$ y $2 \mathrm{l} / \mathrm{min}$ respectivamente.

- Ninguno de los caudales de toma de muestras debe ser superior a 3.5 I/min.

- La cubeta colectora debe poder anclarse y desanclarse del conducto de vertido, es la encargada de recoger el material y debe ser adecuada para la pesada. Por otro lado, el aire que genera el flujo de aire ascendente atraviesa la cubeta colectora.

- Antes del ensayo debe ajustarse el flujo másico de caída de material (debe estar entre 6 y $10 \mathrm{~g} / \mathrm{min}$ ). Este es uno de los parámetros más críticos del ensayo, sobre todo en materiales cohesivos.

A continuación, se describe brevemente el procedimiento experimental llevado a cabo:

\section{Ajuste de la bomba}

Se realiza el montaje del tren de muestreo a emplear, incluyendo en el cabezal de muestreo un filtro no muestreado al que se le denomina "blanco", de forma que las pérdidas de carga resulten similares a las que se tendrán durante el muestreo real. La bomba se conecta a la boca de succión (puerto inferior) del medidor de caudal mediante un tubo de diámetro adecuado y el tren de muestreo se conecta al puerto superior (Figura 3.17). Una vez realizado el montaje, se procede al ajuste de las bombas.

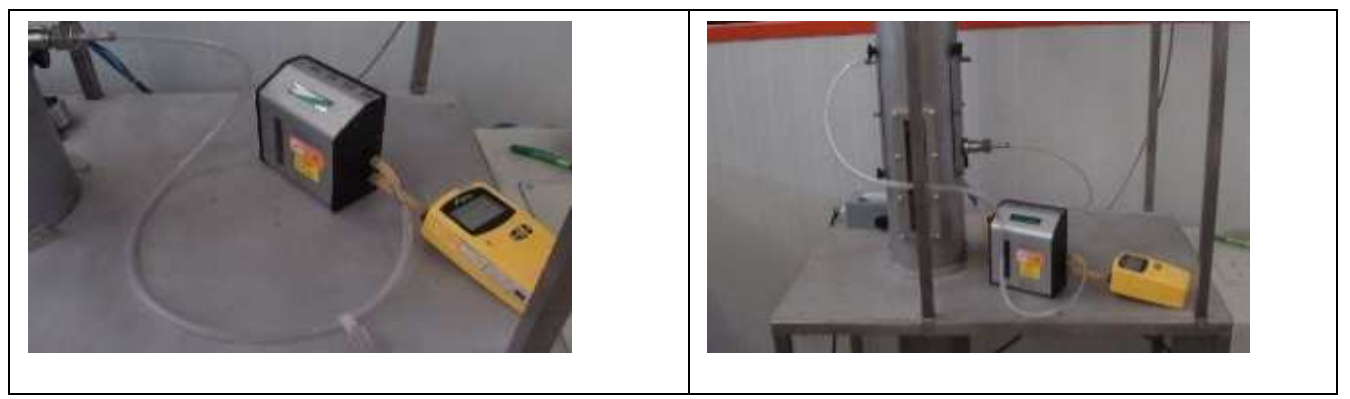

Figura 3.17 Ajuste de caudal, fracción inhalable (izq.) y fracción respirable (dcha.) 


\section{Preparación del equipo de ensayo}

Antes de realizar las medidas de la muestra, debe limpiarse cuidadosamente el conducto de reflujo, la cubeta colectora y los muestreadores, así como el filtro protector de la bomba principal.

Antes de comenzar los ensayos, debe ajustarse el flujo másico de caída al caudal deseado. Esta actividad preliminar se considera como la etapa de acondicionamiento del equipo de ensayo. Para ello se introduce el material en el dosificador, se conecta el dosificador y se regula la potencia del mismo hasta que la masa recogida en la cubeta en un minuto este comprendida entre 6 y 10 $\mathrm{g}$; también puede modificarse la altura del embudo en función del tipo de material a ensayar, ver Figura 3.18. Una vez alcanzado un caudal dentro del rango establecido por la norma, se repite la medida tres veces para asegurar que el caudal es constante. Si es así, puede procederse a realizar el ensayo.

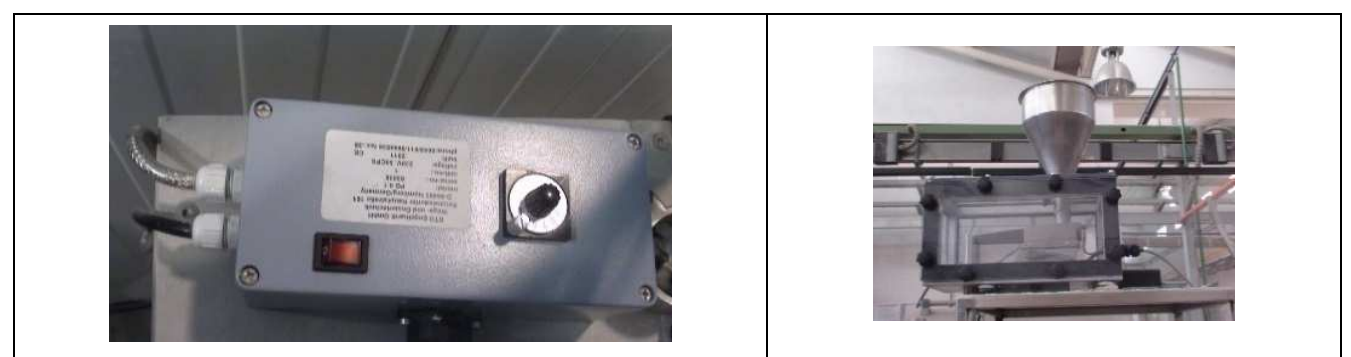

Figura 3.18 Regulador dosificador (izq.) y dosificador (dcha.)

Cabe comentar que el equipo debe limpiarse al iniciar el ensayo, pero no debe limpiarse nunca entre las distintas repeticiones, ni tampoco entre la etapa de acondicionamiento y el primer ensayo.

\section{$\underline{\text { Realización del ensayo }}$}

La muestra de material se carga en la cubeta en el estado en el que se recibió sin que se produzcan perdidas de polvo, en caso necesario con una cuchara 0 espátula, de modo que la cubeta de muestra esté convenientemente llena aún después de haber realizado los ensayos individuales planificados. En función del material a ensayar puede ser conveniente verter el material en el dosificador poco a poco, para evitar la formación de bóvedas, etc.

En los muestreadores (Figura 3.19 y Figura 3.20) se colocan los filtros pesados en una balanza analítica. La cubeta colectora, una vez limpia, se pesa y se fija en su lugar. Cabe comentar que para el primer ensayo se pueden usar los filtros empleados para el ajuste de caudal de las bombas, realizado previamente al ajuste de caudal de material. 


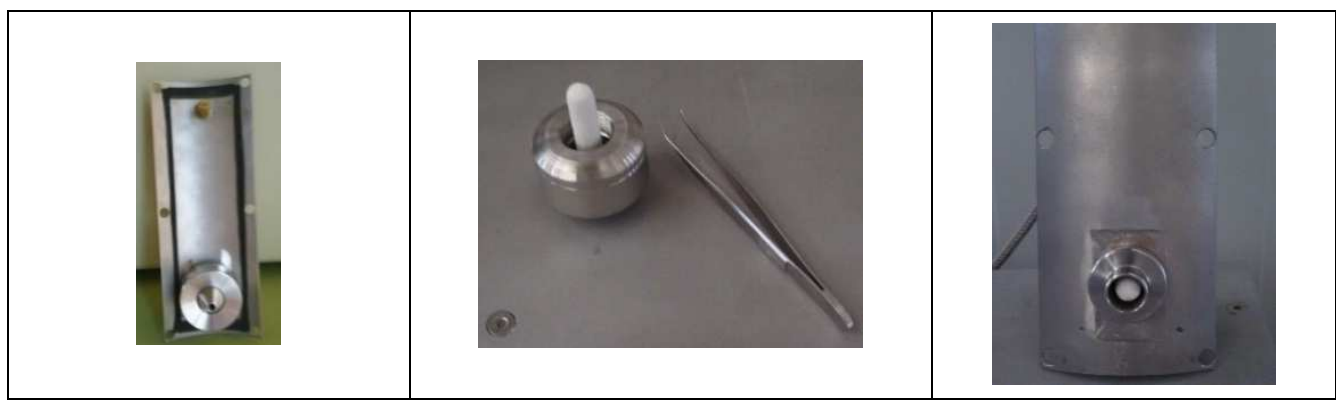

Figura 3.19: Cabezal de muestreo de la fracción inhalable y colocación de los cartuchos filtrantes o dedales de filtración

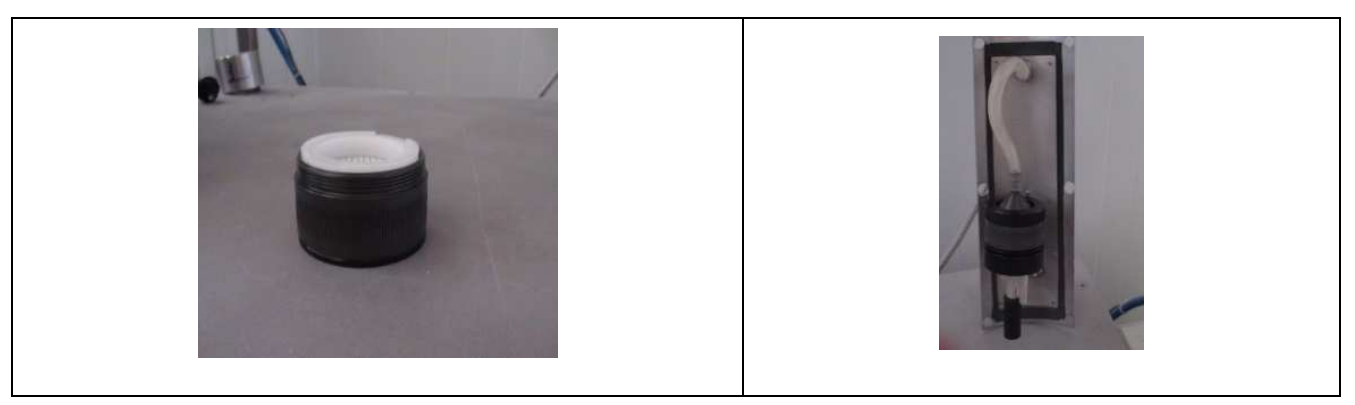

Figura 3.20 Colocación de los filtros en el cabezal de la fracción respirable

Una vez colocados los cabezales, se comienza la medición con la siguiente secuencia de arranque

1. Bomba del flujo principal. Se debe comprobar siempre, que al conectarla el caudal es de $49 \mathrm{l} / \mathrm{min}$. En caso contrario se debe ajustar, empleando el rotámetro.

2. Bomba de polvo respirable.

3. Bomba de polvo inhalable.

4. Dosificador.

La medida comienza con la puesta en marcha del dispositivo dosificador.

Al final de la medición (normalmente $10 \mathrm{~min}$ ), los equipos se paran simultáneamente.

La cubeta colectora llena se retira, se pesa, se vacía y se limpia. Los filtros cargados con el polvo respirable e inhalable se retiran de los muestreadores y se acondicionan para su posterior pesada en una balanza analítica. 


\section{$\underline{\text { Tratamiento de los datos }}$}

Como resultado del ensayo puede evaluarse la fracción másica de polvo inhalable $\left(w_{1}\right)$ y respirable $\left(w_{R}\right)$, del material pulverulento ensayado. Para el cálculo de las fracciones másicas deben pesarse los filtros previa y posteriormente a la toma de muestras siguiendo las indicaciones proporcionadas en la norma ISO 15767.

\section{$\underline{\text { Pesada de filtros }}$}

Cabe comentar que es necesario introducir en el desecador unos filtros testigo que se pesarán en cada sesión de pesada como medida de la diferencia de pesada obtenida por el cambio de condiciones de la sala (Ecuación 3.21).

$$
\begin{gathered}
\Delta \mathrm{m}=\left(\mathrm{m}_{\mathrm{f}}-\mathrm{m}_{0}\right)-\Delta \mathrm{m}_{\text {testigo }} \\
\Delta \mathrm{m}: \text { masa de polvo recogida en el ensayo }(\mathrm{mg}) \\
\mathrm{m}_{\mathrm{f}} \text { : masa final del cartucho filtrante/filtro plano }(\mathrm{mg}) \\
\mathrm{m}_{\mathrm{o}}: \text { masa inicial del cartucho filtrante/filtro plano }(\mathrm{mg})
\end{gathered}
$$

Ecuación 3.21

$\Delta \mathrm{m}_{\text {testigo: }}$ incremento de masa producido en el cartucho filtrante/filtro plano testigo $(\mathrm{mg})$

Una vez pesados los filtros se determinan las fracciones inhalable y respirable empleando las ecuaciones que se indican a continuación:

$$
\begin{gathered}
\mathrm{w}_{\mathrm{l}}=\frac{\Delta \mathrm{m}_{\mathrm{l}}}{\mathrm{m}_{\mathrm{c}}} \cdot \frac{\mathrm{Q}_{\mathrm{tot}}}{\mathrm{Q}_{\mathrm{l}}} \\
\mathrm{w}_{\mathrm{R}}=\frac{\Delta \mathrm{m}_{\mathrm{R}}}{\mathrm{m}_{\mathrm{c}}} \cdot \frac{\mathrm{Q}_{\mathrm{tot}}}{\mathrm{Q}_{\mathrm{R}}} \\
\mathrm{Q}_{\mathrm{tot}}=\mathrm{Q}_{\mathrm{R}}+\mathrm{Q}_{\mathrm{l}}+\mathrm{Q}_{\mathrm{m}}
\end{gathered}
$$

Ecuación 3.23

Ecuación 3.24

$\Delta \mathrm{m}_{\mathrm{I}}, \Delta \mathrm{m}_{\mathrm{R}}$ : masa recogida en el muestreador de polvo inhalable y respirable, respectivamente (mg)

mc: masa de material recogida en la cubeta colectora $(\mathrm{kg})$

Qtot: Es el caudal total (I/min), Qm: caudal de la bomba principal (I/min)

$Q_{l}, Q_{R}$ : caudal del muestreador de polvo inhalable y respirable, respectivamente $(\mathrm{l} / \mathrm{min})$

Los resultados obtenidos permiten clasificar los materiales a granel según su tendencia a emitir polvo (Tabla 3.4). 
Tabla 3.4: Clasificación según norma EN 15051

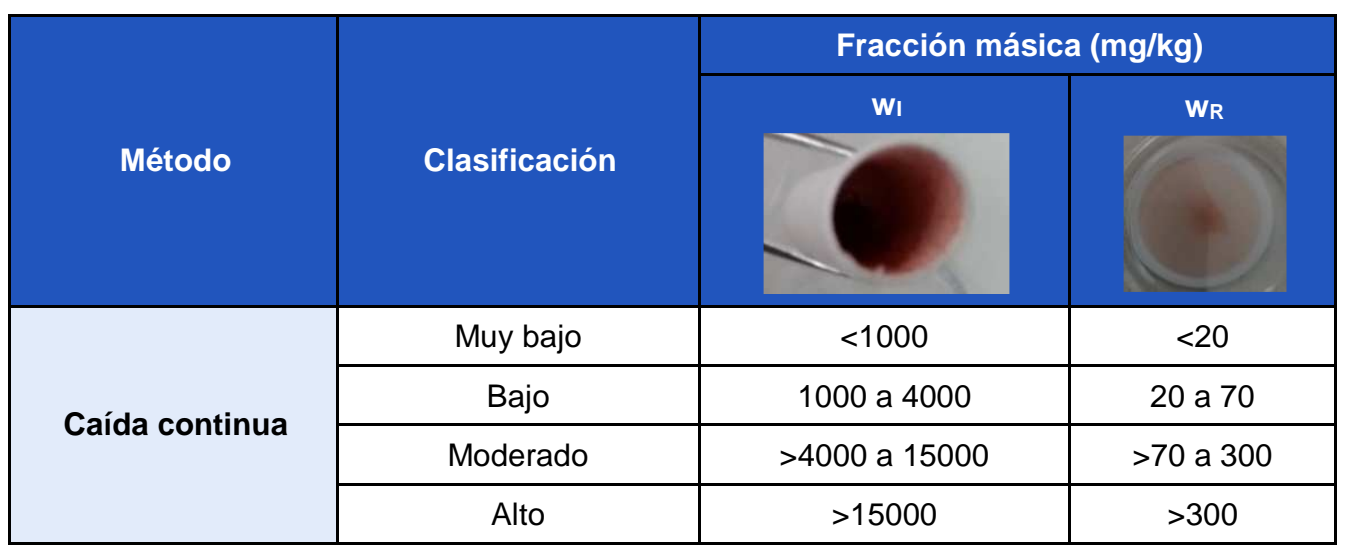




\section{BLOQUE III: RESULTADOS Y DISCUSIÓN}



4 RESULtAdOS Y DISCUSIÓN 

La difusión de los resultados obtenidos en la presente tesis se ha llevado a cabo mediante 6 publicaciones científicas y más de 10 comunicaciones en congresos (ver capítulo 7: Difusión de resultados). Los resultados publicados en dichos artículos serán expuestos de la siguiente forma:

Capítulo 4.1. Evaluación preliminar de la influencia de las variables del material sobre su poder de emisión de polvo.

Publicación no 1: "Determination of the dustiness of raw materials used in the ceramic sector". En este trabajo se seleccionaron más de 30 materias primas empleadas en la industria cerámica e industrias afines, incluyendo: carbonatos, cuarzos, silicatos de circonio, feldespatos, arcillas, etc. y se llevó a cabo una exhaustiva caracterización de las mismas, incluyendo la determinación de su poder de emisión de polvo. En base a los resultados obtenidos, se llevó a cabo un análisis preliminar de la influencia de distintas variables de los materiales pulverulentos sobre su poder de emisión de polvo.

Capítulo 4.2. Evaluación de la influencia del tamaño medio de partícula sobre el poder de emisión de polvo.

Publicación no 2: "Evaluation of the Dustiness of Different Kaolin Samples" Se llevó a cabo la preparación de varias muestras de caolín con distinto tamaño medio de partícula, empleando un sistema de separación vía húmeda mediante hidrociclones. Las muestras obtenidas permitieron evaluar el efecto del tamaño medio de partícula, el contenido en finos, la superficie específica y la fluidez sobre el poder de emisión de polvo.

Publicación no 3: "Quartz dustiness: A key factor in controlling exposure to crystalline silica in the workplace". Considerando la problemática asociada a la inhalación de sílice cristalina respirable, se seleccionaron un gran número de cuarzos, tanto comerciales como preparados a escala de laboratorio mediante tamizado vía húmeda, con la finalidad de cubrir un amplio rango de tamaños de partícula. Se evalúo el efecto del tamaño medio de partícula, el contenido en finos, la superficie específica y la fluidez sobre el poder de emisión de polvo de muestras de cuarzo.

\section{Capítulo 4.3. Evaluación de la influencia de la humedad sobre el poder de} emisión de polvo.

Publicación no 4: "Hydration mechanisms of clays and their effect on dustiness". Se seleccionaron tres arcillas y un caolín empleados en la industria cerámica y afines con diferente superficie especifica. Posteriormente, se llevó a cabo su humectación para obtener muestras que cubrieran un amplio rango de humedad (<0.05\% - 17\%). Se llevó a cabo la caracterización física de las muestras y se evalúo el efecto de la humedad sobre la fluidez y sobre el poder de emisión de polvo de las 
muestras objeto de estudio. Además, se desarrolló una metodología que permitió estimar los puntos críticos, en referencia al poder de emisión de polvo, a partir de las isotermas de adsorción de agua y el grado de saturación de la muestra.

Capítulo 4.4. Modelo de predicción del poder de emisión de polvo de los materiales pulverulentos

Publicación no 5: "Particle size distribution: a key factor in estimating powder dustiness". En base a los resultados obtenidos en los capítulos anteriores, se desarrolló un modelo que permite estimar el poder de emisión de polvo de los materiales pulverulentos. Este modelo se fundamenta en la hipótesis de que, al aumentar el tamaño de partícula, se incrementa la emisión relativa o la facilidad de liberación de polvo de los materiales pulverulentos.

Capítulo 4.5. Medidas de reducción del poder de emisión de polvo de los materiales pulverulentos

Publicación no 6: "Efecto del procesado de materias primas sobre su poder de emisión de polvo". Se determinó el poder de emisión de polvo de una composición cerámica (mezcla de materias primas empleada para la fabricación de los soportes de las baldosas cerámicas) durante las distintas etapas del proceso de fabricación, incluyendo: trituración, molienda, humectación, granulación y secado por atomización. En base a los resultados obtenidos, se identificó la forma de presentación óptima, desde el punto de vista de la generación de emisiones difusas de material particulado, así como las etapas del proceso en las que se requeriría la implantación de medidas correctoras (procesado de materiales con un elevado poder de emisión de polvo). 
4.1 Evaluación preliminar de la influencia de las variables del material sobre su poder de emisión de polvo

\title{
Determination of the dustiness of the raw materials used in the ceramic sector
}

\author{
${ }^{\mathrm{a} A}$. López-Lilao $\triangle$, aA. Escrig, ${ }^{\mathrm{a} V}$. Sanfelix, ${ }^{\mathrm{a}} \mathrm{E}$. Monfort, ${ }^{\mathrm{a}} \mathrm{G}$. Mallol \\ aInstituto de Tecnología Cerámica (ITC). Asociación de Investigación de las Industrias \\ Cerámicas (AICE) - Universitat Jaume I (UJI), Castellón, España
}
Publicación: Actas XI Congreso mundial de la calidad del azulejo y del pavimento cerámico (QUALICER 2014).

ISBN-13 978-84-95931-25-2

www.qualicer.org 

In this study, the dustiness of raw materials used in tile body compositions and frit and glaze compositions in the ceramic sector was determined. The tests were performed with the continuous drop method, one of the reference test methods according to standard UNE EN 15051:2007 "Workplace atmospheres - Measurement of the dustiness of bulk materials - Requirements and reference test methods".

On the other hand, with a view to relating the dustiness of the materials to their properties, the particle size distribution, Hausner ratio, flow factor, specific surface area, and moisture content of these materials were determined.

A database was drawn up of the dustiness of raw materials used in the ceramic sector, together with a classification of these materials according to the criteria established in the above standard. A preliminary evaluation was also made of the influence of certain parameters on the dustiness of particulate materials.

This information is deemed essential for establishing the most efficient preventive and/or corrective measures to reduce the generation of fugitive emissions of particulate matter (PM), both into the outside atmosphere (air pollution) and inside the facilities (occupational health).

Available from: www.qualicer.org 



\title{
4.2 Evaluación de la influencia del tamaño medio de partícula sobre el poder de emisión de polvo
}

\section{Evaluation of the Dustiness of Different Kaolin Samples}

\author{
${ }^{\mathrm{a}}$ A. López-Lilao $\triangle$, ${ }^{\mathrm{M}} \mathrm{M}$. Bruzi, a $\mathrm{V}$. Sanfélix \\ ${ }^{a} A$. Gozalbo, a G. Mallol, a E. Monfort \\ aInstituto de Tecnología Cerámica (ITC). Asociación de Investigación de las Industrias \\ Cerámicas (AICE) - Universitat Jaume I (UJI), Castellón, España

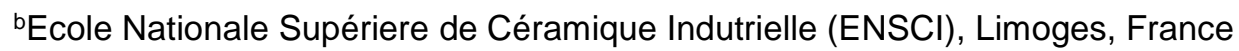

Journal of Occupational and Environmental Hygiene, 12: 547-554, 2015

ISSN: 1545-9624 (Print) 1545-9632 (Online)

http://www.tandfonline.com/doi/full/10.1080/15459624.2015.1019079 

Several samples of kaolin with different mean particle size were prepared and tested using the continuous drop method, one of the reference test methods according to standard EN 15051:2006 "Workplace atmospheres Measurement of the dustiness of bulk materials - Requirements and reference test methods." On the other hand, with a view to relating thedustiness of the materials to their properties, particle size distribution, specific surface area, and Hausner ratio of these samples were determined.

This article presents a characterization of these samples and an assessment of the influence of somematerial parameters on dustiness. The results show that dustiness may significantly be affected by mean particle size, specific surface area, and Hausner ratio.Moreover, it is highlighted that a detailed study of the influence of fine particles content on the dustiness was carried out. This information is deemed essential for establishing the most efficient preventive and/or corrective measures to reduce the generation of fugitive emissions of particulate matter during kaolin processing, both into the outside atmosphere (air pollution) and inside the facilities (occupational health).

Available from:

http://www.tandfonline.com/doi/full/10.1080/15459624.2015.1019079 



\title{
Quartz dustiness: A key factor in controlling exposure to crystalline silica in the workplace
}

\author{
${ }^{\mathrm{a} A}$. López-Lilao $\triangle$, a ${ }^{\mathrm{A}}$. Escrig, ${ }^{\mathrm{a} M . J .}$ Orts, ${ }^{\mathrm{a} G}$. Mallol, ${ }^{\mathrm{a}} \mathrm{E}$. Monfort \\ aInstituto de Tecnología Cerámica (ITC). Asociación de Investigación de las Industrias
} Cerámicas (AICE) - Universitat Jaume I (UJI), Castellón, España

Journal of Occupational and Environmental Hygiene, 13 (11), 817-828, 2016

ISSN: 1545-9624 (Print) 1545-9632 (Online)

http://www.tandfonline.com/doi/full/10.1080/15459624.2015.1019079 

The classification of Respirable Crystalline Silica (RCS) as carcinogenic for humans has drawn greater attention to crystalline silica exposure in the workplace in recent years, leading to recommendations by safety and health bodies in Europe and the U.S. for lower occupational exposure limits. In view of this new scenario, the present study examined quartz dustiness, as quartz handling is a major source of crystalline silica in theworkplace. The study was conducted on test samples with different mean particle sizes, prepared from several commercial quartzes. The quartz particle samples were characterized and the influence of certain quartz particle parameters on quartz dustiness was determined.

The results indicate that quartz dustiness may be significantly affected by mean particle size, specific surface area, the Hausner ratio, and fine particle content. The study shows that, in order to minimize the adverse health effects associated with the inhalation of crystalline silica, quartz dustiness may be deemed a key factor in controlling the generation of fugitive quartz emissions during quartz processing, both into the outside atmosphere (air pollution) and inside the facilities (occupational health).

Available from:

http://www.tandfonline.com/doi/full/10.1080/15459624.2015.1019079 

4.3 Evaluación de la influencia de la humedad sobre el poder de emisión de polvo

\section{Hydration mechanisms of clays and its effect on dustiness}

${ }^{\text {aA }}$. López-Lilao $\triangle$, aM.P. Gómez-Tena, a G. Mallol, a E. Monfort

aInstituto de Tecnología Cerámica (ITC). Asociación de Investigación de las Industrias Cerámicas (AICE) - Universitat Jaume I (UJI), Castellón, España

Applied Clay Science, 144, 157-164, 2017

ISSN: 0169-1317

https://doi.org/10.1016/j.clay.2017.05.003 

Clays are employed in a wide variety of industries such as ceramic industry, manufacture of paper, rubber, etc. In this sense, it is well known that at industrial processes in which clayey materials are used, such as ceramic industry, in order to carry out some specific stages, the wetting of clays is commonly required. Moreover, it is also long established that wetting is an appropriated measure to reduce particulate matter emissions during clays storage and handling.

The present study was undertaken to assess the influence of moisture on clay dustiness because, though the complex behaviour of the clay-water system has been known since antiquity, the mechanisms involved in clay hydration and their influence on dustiness are still not well understood. To encompass a wide range of specific surface areas, three clays and a kaolin were studied. Chemical and mineralogical analysis of these four raw materials was performed and their particle size distribution, flowability, true density, plastic limit, and specific surface area were determined. Raw materials dustiness was determined using the continuous drop method.

As against what might intuitively be expected, the results showed that the relationship between moisture and dustiness was quite complex and strongly related to the hydration mechanisms. In this regard, to better understand the phenomena involved in the clay hydration process, a specific methodology was developed to estimate the critical points of the clay hydration process (regarding dustiness). This methodology can be readily applied to other clays or even to materials of different nature to predict the optimum moisture and, therefore, it could be employed to propose specific measures which could entail an improvement of outdoor and indoor air quality.

Available from: https://doi.org/10.1016/j.clay.2017.05.003 

4.4 Modelo de predicción del poder de emisión de polvo de materiales pulverulentos

\title{
Particle size distribution: a key factor in estimating powders dustiness
}

\author{
${ }^{\mathrm{a}}$ A. López-Lilao $\triangle$, a V. Sanfelix, ${ }^{\mathrm{a}} \mathrm{G}$. Mallol, ${ }^{\mathrm{a}} \mathrm{E}$. Monfort
}

anstituto de Tecnología Cerámica (ITC). Asociación de Investigación de las Industrias Cerámicas (AICE) - Universitat Jaume I (UJI), Castellón, España

Journal of Occupational and Environmental Hygiene (article in press, 2017)

ISSN: 1545-9624 (Print) 1545-9632 (Online) 

A wide variety of raw materials, involving more than twenty samples of quartzes, feldspars, nephelines, carbonates, dolomites, sands, zircons, and alumina, were selected and characterised. Dustiness, i.e. a materials' tendency to generate dust on handling, was determined using the continuous drop method. These raw materials were selected to encompass a wide range of particle sizes $(1.6-294 \mu \mathrm{m})$ and true densities $(2650-4680 \mathrm{~kg} / \mathrm{m} 3)$.

The dustiness of the raw materials, i.e. their tendency to generate dust on handling, was determined using the continuous drop method. The influence of some key material parameters (particle size distribution, flowability and specific surface area) on dustiness was assessed. In this regard, dustiness was found to be significantly affected by particle size distribution. Data analysis enabled development of a model for predicting the dustiness of the studied materials, assuming that dustiness depended on the particle fraction susceptible to emission and on the bulk material's susceptibility to release these particles. On the one hand, the developed model allows the dustiness mechanisms to be better understood. In this regard, it may be noted that relative emission increased with mean particle size. However, this did not necessarily imply that dustiness did, because dustiness also depended on the fraction of particles susceptible to be emitted. On the other hand, the developed model enables dustiness to be estimated using just the particle size distribution data. The quality of the fits was quite good and the fact that only particle size distribution data are needed facilitates industrial application, since these data are usually known by raw materials managers, thus making additional tests unnecessary. 

4.5 Medidas de reducción del poder de emisión de polvo de los materiales pulverulentos

\title{
Efecto del procesado \\ de materias primas sobre \\ su poder de emisión de polvo
}

\author{
${ }^{\mathrm{a}}$ A. López-Lilao $\triangle$, bM. Juárez, ${ }^{\mathrm{a} V}$. Sanfélix, ${ }^{\mathrm{a}} \mathrm{G}$. Mallol, ${ }^{\mathrm{a}} \mathrm{E}$. Monfort \\ alnstituto de Tecnología Cerámica (ITC). Asociación de Investigación de las Industrias \\ Cerámicas (AICE) - Universitat Jaume I (UJI), Castellón, España \\ ${ }^{b}$ Ecole Nationale Supérieure d'Ingénieurs de Limoges (ENSIL), Limoges, France
}

Boletín de la Sociedad Española de Cerámica y Vidrio (article in press, 2016) ISSN: 0366-3175 (Print) 2173-0431(Online)

https://doi.org/10.1016/j.bsecv.2016.12.001 

During the handling and/or processing of powdered materials in the ceramic industry, one of the most important risks regarding the environmental and occupational health is the potential generation of dust. In this regard, a parameter of great interest is the dustiness of the processed materials; this parameter quantifies the tendency of the powdered materials to generate dust when handled.

In this study, to determine the dustiness of a ceramic raw material composition (mixture of the body raw materials), the continuous drop method has been used. This test apparatus was selected because it is considered to better simulate how ceramic materials are handled in the ceramic industry. The obtained results show that the dustiness of the same ceramic composition exhibits significant changes during the manufacturing process, depending on the presentation form. In this regard, the dry milling sample presents the highest dustiness, which can be significantly reduced (> 75\%) applying the moisturization and agglomeration. The obtained results also shown that the best presentation form, regarding the minimization of the dust generation, is achieved in the spraydrying process, where the dustiness is reduced by $95 \%$.

Available from: https://doi.org/10.1016/j.bsecv.2016.12.001 


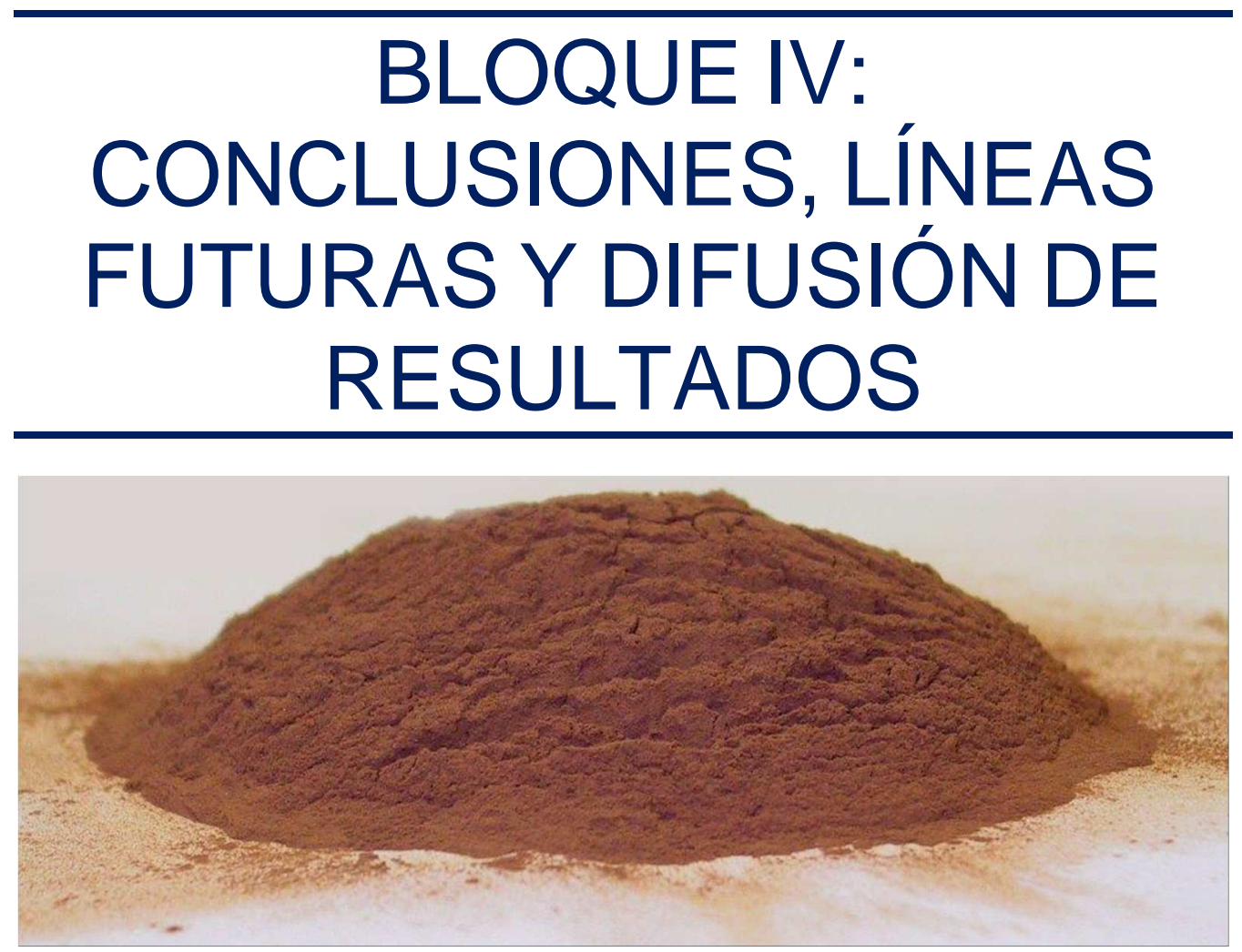

5 CONCLUSIONES 

El trabajo de investigación desarrollado pretende profundizar en el conocimiento científico relativo a los mecanismos de generación de PM, mediante el análisis de la influencia de las variables de los materiales pulverulentos sobre su poder de emisión de polvo.

Cabe comentar que, las conclusiones derivadas de cada uno de los artículos publicados se presentan en los mismos. No obstante, en el presente capítulo, se detallan y sintetizan las principales conclusiones globales que pueden extraerse del trabajo realizado.

\section{Sobre la influencia de las variables de los materiales pulverulentos sobre su poder de emisión de polvo, puede concluirse que:}

1) En la industria cerámica y afines, se emplean materias primas que cubren un amplio rango de poder de emisión de polvo. La caracterización física exhaustiva (forma, fluidez, distribución de tamaño de partícula, poder de emisión de polvo, etc.) de más de 70 materias primas ha permitido evaluar su comportamiento y concluir que una misma sustancia química presenta distinto poder de emisión de polvo en función de su forma de presentación (granulometría, fluidez, etc.).

2) El efecto del tamaño medio de partícula, fluidez y superficie específica sobre el poder de emisión de polvo depende del rango de tamaño evaluado. Concretamente, para las muestras con tamaño medio menor que $25 \mu \mathrm{m}$ se ha observado que incrementos en la fluidez y tamaño medio de partícula, así como descensos en la superficie especifica suponen un incremento en el poder de emisión de polvo mientras que en las muestras con tamaño medio superior a $25 \mu \mathrm{m}$ se ha observado el efecto contrario, incrementos en la fluidez y tamaño medio, así como descensos en la superficie especifica suponen una reducción en el poder de emisión de polvo.

3) Estos resultados pueden ser interpretados de acuerdo a los mecanismos involucrados en los procesos de emisión. Mientras que las partículas finas tienen una mayor relación de superficie a masa y por tanto un predominio de las fuerzas atractivas superficiales, las partículas gruesas presentan una menor superficie por unidad de masa, por lo que existe un predominio de las fuerzas gravitacionales o volumétricas. Estos dos efectos contrapuestos explican que se observe un máximo en el poder de emisión de polvo a tamaños intermedios. Por tanto, en contra de lo que intuitivamente cabría esperar, las muestras más finas no han resultado ser las muestras que presentan un mayor poder de emisión de polvo.

4) En este sentido, cabe destacar que la fracción inhalable disminuye al incrementar el contenido en finos (partículas de tamaño igual o inferior a $4 \mu \mathrm{m}$ ) de dichas muestras, mientras que la fracción respirable presenta un máximo para contenidos en finos intermedios 
(aproximadamente un 20\%). Por ello, las muestras con un tamaño medio entre 10 y $50 \mu \mathrm{m}$ y contenido en finos próximo al $20 \%$ son las que han presentado un mayor poder de emisión de polvo inhalable y respirable. En el trabajo se ha concluido que este comportamiento es especialmente relevante al abordar una problemática frecuente en las industrias cerámicas y afines, como es la exposición a sílice cristalina respirable (SCR), actualmente clasificada como agente cancerígeno para humanos. En efecto, se ha observado que, la manipulación de materiales con dichas características de tamaño medio y contenido en finos que sean susceptibles de liberar SCR al ambiente, debe realizarse tomando especiales medidas de protección. No obstante, cabe destacar que estos resultados no implican que la manipulación de materiales que puedan liberar SCR, pero que no presenten estas características de tamaño y contenido en finos, pueda ser realizada sin las medidas adecuadas de protección. Al contrario, evidencian que cualquier material que pueda liberar SCR deber ser correctamente manipulado, ya que se ha observado experimentalmente que, incluso los cuarzos más gruesos utilizados a nivel industrial, pueden dar lugar a altos niveles de exposición a SCR durante su manipulación.

Sobre los modelos desarrollados para la predicción y/o comprensión del poder de emisión de polvo de los materiales pulverulentos laminares e higroscópicos, puede concluirse que:

5) Un incremento en la humedad de las muestras de arcilla supone una reducción de su poder de emisión de polvo, excepto en las arcillas molturadas que muestran un comportamiento más complejo, presentando un máximo a humedades intermedias.

6) A partir de la caracterización física de las arcillas y de un exhaustivo análisis de los resultados obtenidos, se ha observado que el efecto del agua depende no sólo de las propiedades del material sino también de su interacción con las moléculas de agua (mecanismos de hidratación) que provocan que el agua pueda actuar alternativamente como ligante o como lubricante. Por tanto, el efecto de la humedad sobre el poder de emisión de polvo de los materiales higroscópicos presenta elevada complejidad. Para interpretar dichos resultados, en la presente tesis se postula que tienen lugar los siguientes fenómenos:

A) Durante la adsorción de capas monomoleculares de agua fuertemente atraídas a la superficie (2-3 capas) se produce un incremento en las fuerzas de unión entre partículas y, por tanto, en la cohesión. Esto implica una reducción del poder de emisión de polvo.

B) Durante la adsorción sucesiva de capas monomoleculares de agua, se produce un debilitamiento de la atracción agua-partícula y partícula-partícula. Esto da lugar a que esta película de agua 
tenga un efecto predominantemente lubricante, aumente la fluidez y, por tanto, el poder de emisión de polvo.

C) Cuando aumenta la humedad, la atracción agua-partícula no es significativa, el agua no tiene una posición preferente y, por tanto, no forma una película alrededor de la partícula, sino que actúa como ligante entre grupos de partículas (aumenta la cohesión y disminuye el poder de emisión de polvo).

D) Al incrementar el contenido en humedad, se favorece la granulación de la muestra lo que provoca un incremento en la fluidez y puede dar lugar a un incremento en el poder de emisión de polvo si existen finos libres (susceptibles de generar polvo) y/o si el granulo se desmenuza durante la manipulación (gránulos friables).

E) Finalmente, mayores contenidos en humedad provocan un incremento en la cohesión que se traduce en una disminución en el poder de emisión de polvo hasta alcanzar un poder de emisión de polvo que se ha considerado nulo en el límite plástico.

7) Atendiendo a estos mecanismos, se ha desarrollado una metodología que posibilita estimar los puntos críticos (en referencia al poder de emisión de polvo), basándose en la determinación de la isoterma de adsorción de agua y el grado de saturación de la muestra. Esta metodología puede ser empleada para comprender y/o predecir el efecto del agua sobre otras arcillas o incluso sobre materiales de distinta naturaleza.

Sobre los modelos desarrollados para la predicción y/o comprensión del poder de emisión de polvo de los materiales pulverulentos aproximadamente esféricos y secos, puede concluirse que:

8) La fracción fina de un material es un factor clave en referencia a la generación de polvo. No obstante, la facilidad de liberación de dichos finos o emisión relativa (relación entre la masa de polvo generado de tamaño i y masa de material ensayado con tamaño i) depende de la distribución de tamaño de partícula de la muestra completa.

9) La emisión relativa o facilidad de liberación de polvo de un material se incrementa al aumentar el tamaño medio de partícula y la fluidez, así como al disminuir la superficie especifica. Por este motivo, en contra de lo que cabría esperar, las muestras más finas no son las que presentan un mayor poder de emisión de polvo (como consecuencia de su baja facilidad de liberación de polvo). De hecho, las muestras con un tamaño medio elevado (alta facilidad de liberación de polvo) y contenido en finos intermedio parecen ser las más problemáticas, en referencia a la generación de polvo. 
10) Se ha desarrollado un modelo de predicción del poder de emisión de polvo que se fundamenta en la hipótesis de que el poder de emisión de polvo (relación entre la masa de polvo generado de tamaño i y la masa de material ensayado) depende del contenido en finos de la muestra y la facilidad de liberar dichos finos o emisión relativa. Dicho modelo permite estimar el poder de emisión de polvo a partir de la distribución de tamaño de partícula del material. Esto supone una gran ventaja, ya que esta información es generalmente conocida por las empresas que manipulan sólidos pulverulentos $\mathrm{y}$, por tanto, no son necesarios ensayos adicionales que pueden implicar más tiempo que el propio ensayo de determinación del poder de emisión de polvo.

11) La introducción del parámetro de emisión relativa ha permitido avanzar en el conocimiento de los mecanismos de generación de PM ya que justifica y posibilita la comprensión de los aparentemente contradictorios resultados obtenidos hasta el momento.

Sobre la viabilidad de la implantación de medidas preventivas, basadas en la modificación de la forma de presentación del material, se ha evaluado la modificación del poder de emisión de polvo de una composición de materias primas empleadas para la fabricación de los soportes de las baldosas cerámicas durante el proceso de preparación y acondicionado de materias primas. Concretamente, se han seleccionado y caracterizado muestras y fracciones granulométricas de las mismas, de composiciones industriales procedentes de las etapas de trituración y molienda, así como de las tres vías posibles para el acondicionado de la composición para su posterior prensado (en referencia a su granulometría y humedad): humectación (6.5\%), granulación y secado por atomización. A partir de los resultados obtenidos puede concluirse que:

12) La composición procedente de un proceso de molienda vía seca es la forma de presentación más desfavorable (en referencia a la generación de emisiones). Por otro lado, tanto la humectación (6.5\%) como la granulación de la muestra permiten reducir significativamente el poder de emisión de polvo (>75\%). Cabe comentar que estas conclusiones respaldan las obtenidas en el apartado referente al modelo de predicción del poder de emisión de polvo de materiales laminares e higroscópicos ya que para contenidos en humedad asociados a la etapa de granulación o superiores el poder de emisión de polvo resulta ser muy inferior al de la muestra seca (muestra procedente de la molienda vía seca). No obstante, en trabajos futuros sería recomendable evaluar la humedad óptima, es decir, determinar qué humedad supone un menor poder de emisión de polvo compatible con un comportamiento idóneo en la operación de prensado (buena fluidez).

13) La muestra procedente del proceso de secado por atomización supone una reducción del poder de emisión de polvo superior al $95 \%$ y, por tanto, en referencia al poder de emisión de polvo, parece la forma de 
presentación más favorable. Este comportamiento puede deberse a que el gránulo atomizado objeto de estudio presenta una proporción de finos $(<125 \mu \mathrm{m})$ muy inferior a la de las muestras humectada y granulada. Además, cabe destacar que el atomizado se forma a partir de una suspensión con un contenido en agua del orden del $35 \%$, lo que conlleva la formación de gránulos aproximadamente esféricos y con presencia de una costra superficial. Por ello, estos gránulos presentan una mayor resistencia al desmenuzamiento y menor tendencia a generar partículas finas que las muestras humectadas y granuladas.

14) Por este motivo, tanto la humectación como la granulación y sobre todo el secado por atomización pueden ser consideradas medidas eficaces para la reducción de PM. Por último, cabe comentar que, aunque el estudio se ha realizado para una composición de materias primas empleada para la fabricación de baldosas cerámicas, los resultados, al menos de forma cualitativa, deben ser extrapolables a distintas composiciones de materias primas e incluso a otros procesos cerámicos cuyas composiciones estén formuladas principalmente por arcillas. 

6 LÍNEAS FUTURAS 

A partir de los resultados obtenidos en la presente tesis, se han planteado una serie de recomendaciones para futuras líneas de investigación que complementarían dichos resultados y ampliarían el alcance del modelo desarrollado. A modo de ejemplo, pueden destacarse las siguientes:

- Realizar un estudio más exhaustivo del efecto de la humedad y la morfología de los materiales pulverulentos sobre su poder de emisión de polvo.

- Evaluar el efecto de las condiciones ambientales (temperatura y humedad del aire) sobre el poder de emisión de polvo.

- Caracterizar el polvo generado durante el ensayo de determinación del poder de emisión de polvo, incluyendo la determinación de la distribución de tamaño de partícula, composición química, etc.

- Incluir en el modelo de predicción del poder de emisión de polvo un factor de energía que posibilite simular diferentes procesos industriales y estimar el poder de emisión de polvo asociado al uso de otros dispositivos de laboratorio como el tambor rotatorio.

- Estudiar el poder de emisión de polvo de nanomateriales. El uso de estos materiales ha crecido exponencialmente en los últimos años y, por tanto, considerando el potencial riesgo por exposición asociado al uso de nanopartículas, se considera que se debería evaluar la aplicabilidad del modelo desarrollado para esta tipología de materiales.

- Evaluar la viabilidad técnica y económica de la implantación de medidas preventivas, basadas en la modificación de la forma de presentación de los materiales pulverulentos.

- Proponer, en base a los resultados obtenidos, las condiciones óptimas para la gestión de materiales pulverulentos.

- Evaluar la relación existente entre el poder de emisión de polvo de los materiales pulverulentos y las emisiones y/o niveles de exposición a PM asociados a su manipulación a escala industrial.

Por todo ello, se puede concluir que, en un futuro, el camino para el estudio del poder de emisión de polvo debe centrarse de forma simultánea en el estudio de nuevos materiales como las nanopartículas, así como en la evaluación de la relación existente entre dicho parámetro y las emisiones generadas a escala industrial. Esto permitiría subsanar los problemas actuales en cuanto a la predicción de las emisiones difusas y/o niveles de exposición a PM, así como establecer medidas para su control y minimización.

En este sentido, cabe comentar que la presente tesis actúa como nexo entre dos Proyectos de I+D+i: 1) Cuantificación y caracterización de emisiones difusas de partículas en la gestión y transporte de materiales pulverulentos 
(CGL 2009-14680-C02-01) y 2) Predicción de emisiones y exposición a partículas micro y nanométricas en ambientes industriales. Desarrollo de modelos de predicción (CGL2015-66777-C2-2-R). Es en el marco del último proyecto en el que se contempla la realización de gran parte de estas tareas adicionales. 
7 DIFUSIÓN DE RESULTADOS 

Dado el carácter aplicado del trabajo realizado, adicionalmente a las publicaciones citadas en el capítulo 4 , se ha llevado a cabo la difusión de los resultados obtenidos mediante la publicación de 1 artículo de divulgación, 1 archivo de prevención de riesgos laborales y la participación en numerosos congresos, tanto nacionales como internacionales. A continuación, se citan cada una de estas contribuciones:

\section{Publicaciones}

Título: Manejo seguro de los sólidos pulverulentos

Autores: $\underline{\text { A. López Lilao }}$

Interempresas Industria Alimentaria. pp. 58 - 59. 2015.

http://www.interempresas.net/FlipBooks/AL/

Tipo de producción: Artículo de divulgación

Grado de contribución: Coautora de artículo y autora de correspondencia

Título: Poder de emisión de polvo de materiales pulverulentos.

Autores: A. López Lilao, M.J. Ibáñez, A. Escrig, E. de la Cruz, D. Dahmann, E. Monfort

Archivos de Prevención de riesgos laborales. 17, pp. 22 - 22. 2014.

Tipo de producción: Archivos de Prevención de Riesgos Laborales

Grado de contribución: Coautora de artículo y autora de correspondencia

\section{Congresos y Jornadas}

Título del trabajo: Poder de emisión de polvo: un parámetro clave en el control de las emisiones de material particulado asociadas a la gestión de materiales pulverulentos

\section{Autores: A. López Lilao}

Nombre del congreso: Exposólidos 2017. Salón internacional de la Tecnología y el procesamiento de Sólidos

Lugar de celebración: L’Hospitalet, España

Fecha de celebración: 14/02/2017-17/02/2017

Tipo de participación: Ponencia oral (ponente) 
Título del trabajo: Modelo de predicción del poder de emisión de polvo de materias primas empleadas en la industria cerámica

Autores: A. López Lilao, V. Sanfelix, M.J. Orts, E. Monfort, G. Mallol

Nombre del congreso: LV Congreso de la Sociedad Española de Cerámica y Vidrio

Lugar de celebración: Sevilla, España

Fecha de celebración: 05/10/2016-07/10/2016

Tipo de participación: Póster

Título del trabajo: Influencia de la forma de presentación de una composición cerámica sobre su capacidad de emisión de polvo

Autores: A. López-Lilao, M.J. Ibáñez, V. Sanfélix, E. Monfort, G. Mallol

Nombre del congreso: Congreso Mundial de la Calidad del Azulejo y del Pavimento Cerámico (QUALICER 2016)

Lugar de celebración: Castellón, España

Fecha de celebración: 08/02/2016-09/02/2016

Tipo de participación: Póster

Título del trabajo: Medidas de eliminación de la polución derivada del manejo de los sólidos pulverulentos en el sector FOOD

Autores: A. López-Lilao

Nombre del evento: Jornada Techsolids sobre "Gestión y control de sólidos en la industria alimentaria"

Ciudad de celebración: Paterna, España

Fecha de celebración: 19/11/2015

Tipo de participación: Ponencia oral (ponente) 
Título del trabajo: Influence of certain parameters of China clay on its dustiness

Autores: A. López-Lilao, M. Bruzi, V. Sanfélix, A. Gozalbo, G. Mallol, E. Monfort Nombre del congreso: 13th Mediterranean Congress of Chemical Engineering Lugar de celebración: Barcelona, España

Fecha de celebración: 30/09/2014-03/10/2014

Tipo de participación: Póster

Título del trabajo: Poder de emisión de polvo de materiales pulverulentos

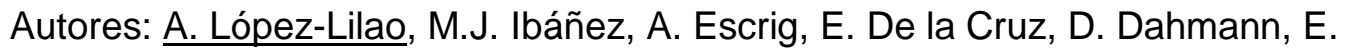
Monfort

Nombre del congreso: XII International Conference on Occupational Risk Prevention (ORP2014)

Lugar de celebración: Zaragoza, España

Fecha de celebración: 21/05/2014

Tipo de participación: Ponencia oral (ponente)

Título del trabajo: Determinación del poder de emisión de polvo de materias primas empleadas en el sector cerámico

Autores: A. López-Lilao, A. Escrig, V. Sanfélix, E. Monfort, G. Mallol

Nombre del congreso: XI Congreso Mundial de la Calidad del Azulejo y del Pavimento Cerámico (QUALICER 2014)

Ciudad de celebración: Castellón, España

Fecha de celebración: 17/02/2014-18/02/2014

Tipo de participación: Ponencia oral (ponente) 
Título del trabajo: Variables que influyen sobre el poder de emisión de polvo de materias primas cerámicas

Autores: A. López-Lilao, M. Lavall, A. Escrig, V. Sanfelix, E. Monfort, G. Mallol, D. Dahmann

Nombre del congreso: LIII Congreso de la Sociedad Española de Cerámica y Vidrio (SECV) y XII Congreso del Técnico Cerámico (ATC)

Lugar de celebración: Alcora, España

Fecha de celebración: 23/10/2013

Tipo de participación: Ponencia oral (ponente)

Título del trabajo: Quantification and assessment of bulk ceramic materials dustiness

Autores: A. López-Lilao, V. Sanfélix, A. Escrig, I. Celades, G. Mallol, E. Monfort Nombre del congreso: 13th Conference and exhibition of the European Ceramic Society

Lugar de celebración: Limoges, Francia

Fecha de celebración: 23/06/2013-27/06/2013

Tipo de participación: Póster

Título del trabajo: Dustiness of bulk materials used in the ceramic industry Autores: A. López-Lilao, V. Sanfelix, A. Escrig, I. Celades, G. Mallol,3 E. Monfort Nombre del congreso: LII Congreso anual Sociedad Española de Cerámica y Vidrio.

Lugar de celebración: Burgos, España

Fecha de celebración: 03/10/2012-06/10/2012

Tipo de participación: Ponencia oral (ponente) 


\section{BLOQUE V: REFERENCIAS Y ANEXOS}

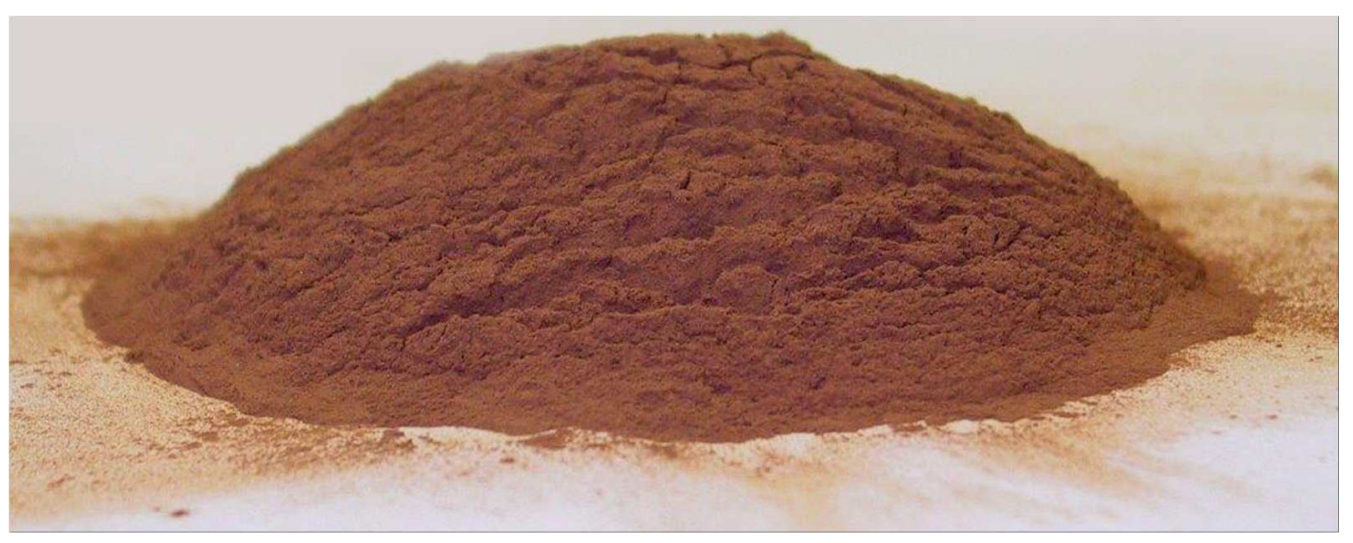



8 REFERENCIAS 

Adedokun, J.A., Emofurieta, W.O. \& Adedeji, O.A., 1989. Physical, mineralogical and chemical properties of harmattan dust at Ile-Ife, Nigeria. Theoretical and Applied Climatology, 40(3), pp.161-169.

Alwis, U. et al., 1999. Dust Exposures in the Wood Processing Industry. American Industrial Hygiene Association Journal, 60(5), pp.641-646.

Amato, F., 2010. Particulate Matter Resuspension from Urban Paved Roads: Impact on Air Quality and Abatement Strategies (Doctoral dissertation).

Amorós, J.L. et al., 2011. Study of the rheological behaviour of monomodal quartz particle beds under stress. A model for the shear yield functions of powders. Chemical Engineering Science, 66(18), pp.4070-4077.

Andreasen, A.H.M., Hofman-Bang, N. \& Rasmussen, N.H., 1939. Über das Stäubungsvermögen der Stoffe. Kolloid-Zeitschrift, 86(1), pp.70-77.

AS 4156.6, 2000. Coal preparation Part 6: Determination of dust/moisture relationship for coal.

ASTM D547-41, 1980. Test Method for Index of Dustiness of Coal and Coke.

Atkinson, R.W. et al., 2001. Acute Effects of Particulate Air Pollution on Respiratory Admissions. American Journal of Respiratory and Critical Care Medicine, 164(10), pp.1860-1866.

Authier-Martin, M., 1987. Alumina Handling Dustiness. In Essential Readings in Light Metals. Cham: Springer International Publishing, pp. 103-111.

Avila, A., Queralt-Mitjans, I. \& Alarcón, M., 1997. Mineralogical composition of African dust delivered by red rains over northeastern Spain. Journal of Geophysical Research: Atmospheres, 102(D18), pp.21977-21996.

Baron, P. \& Willeke, K., 2001. Aerosol fundamentals. In Aerosol measurement: principles, techniques, and applications, 2 ,

Bascom, R., 1996. Environmental factors and respiratory hyper sensitivity: the Americas. Toxicology Letters, 86(2-3), pp.115-130.

Biggeri, A., Bellini, P. \& Terracini, B., 2001. Metanalisi italiana degli studi sugli effetti a breve termine dell'inquinamento atmosferico. Epidemiologia e prevenzione, 25(2), pp.1-72.

Boundy, M., Leith, D. \& Polton, T., 2006. Method to evaluate the dustiness of pharmaceutical powders. Annals of Occupational Hygiene, 26A(5), p.1453.

Bozlaker, A. et al., 2013. Quantifying the Contribution of Long-Range Saharan Dust Transport on Particulate Matter Concentrations in Houston, Texas, Using Detailed Elemental Analysis. Environmental Science \& Technology, 47(18), pp.1017910187.

Brauer, M., Avila-Casado, C., et al., 2001. Air pollution and retained particles in the lung. Environmental Health, 109(10), pp.1039-1043.

Brauer, M., Ebelt, S.T., et al., 2001. Exposure of chronic obstructive pulmonary disease patients to particles: respiratory and cardiovascular health effects. Journal of Exposure Science and Environmental Epidemiology, 11, pp.490-500.

Brunekreef, B. et al., 1997. Air pollution from truck traffic and lung function in children 
living near motorways. Epidemiology, 8(3), pp.298-303.

Brunekreef, B., 1997. Air pollution and life expectancy: is there a relation? Occupational and environmental medicine, 54(11), pp.781-794.

Burdett, G. et al., 2000. Development of a method for dustiness testing. EU contract SMT4-CT96-2074,

Caquineau, S. et al., 1998. Saharan dust: Clay ratio as a relevant tracer to assess the origin of soil-derived aerosols. Geophysical Research Letters, 25(7), pp.983-986.

Castranova, V., Walker, W. \& Vallyathan, V., 1995. Silica and silica-induced lung diseases. CRC Press,

Cawley, B. \& Leith, D., 1993. Bench-Top Apparatus to Examine Factors that Affect Dust Generation. Applied Occupational and Environmental Hygiene, 8(7), pp.624-631.

Celades, I., 2013. Caracterización física, química, mineralógica y morfológica del material particulado emitido por focos canalizados de la industria de baldosas y fritas (Tesis Doctoral).

CEPROSS, 2015. Observatorio de enfermedades profesionales (CEPROSS) y de enfermedades causadas o agravadas por el trabajo. Informe anual 2015 Secretaria de Estado de la Seguridad Social-Dirección General de Ordenación de la Seguridad Social.

Chambers, A.J., 1992. Assessment of alumina dustiness. Powder Handling \& Processing(Germany), 4(1), pp.47-52.

Charron, A. \& Harrison, R.M., 2003. Primary particle formation from vehicle emissions during exhaust dilution in the roadside atmosphere. Atmospheric Environment, 37(29), pp.4109-4119.

Chuang, C.C. et al., 1997. An assessment of the radiative effects of anthropogenic sulfate. Journal of Geophysical Research: Atmospheres, 102(D3), pp.3761-3778.

Churg, A. \& Brauer, M., 1997. Human lung parenchyma retains PM2.5. American journal of respiratory and critical care medicine, 155(6), pp.2109-2111.

Clouter, A. et al., 2001. Inflammatory Effects of Respirable Quartz Collected in Workplaces versus Standard DQ12 Quartz: Particle Surface Correlates. Toxicological Sciences, 63(1), pp.90-98.

Cowherd, C., Grelinger, M.A. \& Wong, K.F., 1989. Dust Inhalation Exposures from the Handling of Small Volumes of Powders. American Industrial Hygiene Association Journal, 50(3), pp.131-138.

DIN 33897, 2002. Workplace atmospheres - Routine methods for the determination of the dustiness of bulk materials.

DIN 55992-1, 1999. Determination of a parameter for the dust formation of pigments and extenders - Part 1: Rotation method.

DIN 55992-2, 1999. Determination of a parameter for the dust formation of pigments and extenders - Part 2: Dropmethod.

Dockery, D. \& Pope, A., 1996. Epidemiology of acute health effects: summary of timeseries studies. Particles in our air: Concentrations and health effects, pp.123-147.

Dockery, D.W. et al., 1993. An Association between Air Pollution and Mortality in Six U.S. Cities. New England Journal of Medicine, 329(24), pp.1753-1759. 
Dominici, F., McDermott, A. \& Zeger, S.L., 2002. On the Use of Generalized Additive Models in Time-Series Studies of Air Pollution and Health. American Journal of Epidemiology, 156(3), pp.193-203.

Donaldson, K.E.N. \& Borm, P.J., 1998. The Quartz Hazard: A Variable Entity. The Annals of Occupational Hygiene, 42(5), pp.287-294.

Duce, R.A., 1995. Sources, distributions, and fluxes of mineral aerosols and their relationship to climate. Aerosol forcing of climate, 6, pp.43-72.

Ehrlich, C. et al., 2007. PM10, PM2.5 and PM1.0-Emissions from industrial plantsResults from measurement programmes in Germany. Atmospheric Environment, $41(29)$, pp.6236-6254.

Enviroment Australia, 1999. National Pollutant Inventory Emission estimation technique manual for Fugitive Emissions Version 2.0,

Environmental Australia, 2012. Emission estimation technique manual for mining version 3.1,

EPA, 1996. Air Quality Criteria for Particulate Matter (Final Report, 1996),

Escrig, A. et al., 2011. Simple estimates of vehicle-induced resuspension rates. Journal of Environmental Management, 92(10), pp.2855-2859.

Fang, S.C., Cassidy, A. \& Christiani, D.C., 2010. A Systematic Review of Occupational Exposure to Particulate Matter and Cardiovascular Disease. International Journal of Environmental Research and Public Health, 7(4), pp.1773-1806.

Farrugia, T.R., Ahmed, N. \& Jameson, G.J., 1989. A new technique for measuring dustiness of coal. Journal of Coal Quality, 8(2), p.51.

Fransman, W. et al., 2009. Development of a mechanistic model for the Advanced REACH Tool (ART), Version 1.5-(Updates previous version 1.0, June 2010), TNO report V9009.,

Gautam, S., Kumar, P. \& Patra, A.K., 2016. Occupational exposure to particulate matter in three Indian opencast mines. Air Quality, Atmosphere \& Health, 9(2), pp.143158.

Generalitat de Catalunya. Direcció General de Qualitat Ambiental, 2004. Càlcul d'emissions fugitives de partícules en activitats extractives amb o sense planta de tractament de productes minerals associada i operacions similars. $1^{\text {a }}$ Edició Maig 2004.

Gieré, R. \& Querol, X., 2010. Solid Particulate Matter in the Atmosphere. Elements, 6(4).

Glaccum, R.A. \& Prospero, J.M., 1980. Saharan aerosols over the tropical North Atlantic - Mineralogy. Marine Geology, 37(3-4), pp.295-321.

Godinho da Fonseca, A.S., 2016. Exposure characterisation and sources of nanoparticles in workplace environments. Universitat de Barcelona.

Goldsmith, D.F., Gift, J.S. \& Grant, L.D., 1997. Silica risk assessments. J Expo Anal Environ Epidemiol, 7, pp.265-295.

Goldstein, J.I. et al., 1983. Scanning electron-microscopy and X-Ray-Microanalysis. Plenum Press. New York.

Guía aireaAIRE, 2012. Guía para la prevención de emisiones difusas de partículas. Gobierno Vasco. Departamento de Medio Ambiente, Planificación Territorial, 
Agricultura y Pesca. Dirección de Planificación Ambiental.

Hamelmann, F. et al., 2003. Methods of Estimating the Dustiness of Industrial Powders - A Review. KONA Powder and Particle Journal, 21(0), pp.7-18.

Hashim, D., 2014. Occupational and Environmental Exposures and Cancers in Developing Countries. Annals of Global Health, 80(5), pp.393-411.

Healy, C.B. et al., 2013. Determinants of Respirable Crystalline Silica Exposure Among Stoneworkers Involved in Stone Restoration Work. The Annals of Occupational Hygiene, 58(1), pp.6-18.

Higman, R.W., 1986. Dustiness testing: a useful tool. Ventilation'85.

Hinds, W.C., 1999. Aerosol Technology: Properties, Behavior, and Measurement of airborne Particles,

Hjemsted, K. \& Schneider, T., 1996. Dustiness from powder materials. Journal of Aerosol Science, 27, pp.S485-S486.

Hsieh, H.P., 1987. Measurement of flowability and dustiness of alumina. Light Metals 1987.

IARC, 2012. Arsenic, Metals, Fibres and Dusts Volume $100 \mathrm{C}$ A review of human carcinogens.

IARC, 1997. Silica, Some Silicates, Coal Dust and para-Aramid Fibrils,

IARC, 1987. Silica and Some Silicates,

INSHT, Definición técnica de enfermedad profesional. http://www.insht.es/InshtWeb/Contenidos/Documentacion/TextosOnline/GuiasMon itor/CondicionesTrabajo/I/Ficheros/ctsi21.pdf.

INSHT, 2016. Límites de exposición profesional para agentes químicos en España 2016,

INSHT, 2012. Nota técnica de prevención - NTP 937.

IPCC, 1996. Climate Change 1995 The Science of Climate Change,

IPCC, 2001. Climate Change 2001: The scientific basis,

IPCC, 2007. Climate Change 2007 The Physical Science Basis,

IPTS, 2013. Best Available Techniques (BAT) Reference Document for the Manufacture of Glass,

IPTS, 2007. Ceramic Manufacturing Industry,

IPTS, 2006. Emissions from Storage,

ISO 9277:, 1995. Determination of the specific surface area of solids by gas adsorption using the BET method.

Karagulian, F. et al., 2015. Contributions to cities' ambient particulate matter (PM): A systematic review of local source contributions at global level. Atmospheric Environment, 120, pp.475-483.

Katsouyanni, K. et al., 2001. Confounding and effect modification in the short-term effects of ambient particles on total mortality: results from 29 European cities within the APHEA2 project. Epidemiology, 12(5), pp.521-531.

Kauppinen, T. et al., 2000. Occupational exposure to carcinogens in the European 
Union. Occupational and environmental medicine, 57(1), pp.10-18.

Kerminen, V.M. et al., 2007. Development of particle number size distribution near a major road in Helsinki during an episodic inversion situation. Atmospheric Environment, 41(8), pp.1759-1767.

Kittelson, D.B., 1998. Engines and nanoparticles: a review. Journal of Aerosol Science, 29(5), pp.575-588.

Koivisto, A.J., 2013. Source Specific Risk Assessment of Indoor Aerosol Particles. Doctoral dissertation.

Künzli, N. et al., 1997. Air pollution and health-causal criteria in environmental epidemiology. Schweizerische medizinische Wochenschrift, 127(33), pp.13341344.

Künzli, N. et al., 2000. Public-health impact of outdoor and traffic-related air pollution: a European assessment. The Lancet, 356(9232), pp.795-801.

Leith, D., 1991. Fundamental factors that affect dust generation. Final report (No. PB92-109255/XAB). North Carolina Univ., Chapel Hill, NC (United States). Dept. of Environmental Sciences and Engineering.,

Leopold, J. \& Gough, J., 1957. The centrilobular form of hypertrophic emphysema and its relation to chronic bronchitis. Thorax, 12, p.219.

Leung, C.C., Yu, I.T.S. \& Chen, W., 2012. Silicosis. The Lancet, 379(9830), pp.20082018.

Lingard, J.J.N. et al., 2006. Observations of urban airborne particle number concentrations during rush-hour conditions: analysis of the number based size distributions and modal parameters. Journal of Environmental Monitoring, 8(12), p.1203.

Lobato, E.M. de C., 2004. Determination of Surface Free Energies and Aspect Ratio of Talc (Doctoral dissertation). Virginia Tech.

Lyons, C. \& Mark, D., 1992. An evaluation of the Roaches' Dust Particle Apparatus' dustiness testing equipment. Great Britain, Health and Safety Executive.,

Mallol, G. et al., 2008. Densification of monomodal quartz particle beds by tapping. Chemical Engineering Science, 63(22), pp.5447-5456.

Mallol, J.G., 2006. Densificación y flujo de lechos de partículas de cuarzo, Universitat Jaume I.

Marticorena, B. et al., 1997. Modeling the atmospheric dust cycle: 2. Simulation of Saharan dust sources. Journal of Geophysical Research: Atmospheres, 102(D4), pp.4387-4404.

McKenna, J.., Turner, J.H. \& McKenna, J.P., 2008. Fine particle (2.5 microns) emissions : regulation, measurement, and control, John Wiley \& Sons.

Mészáros, E., 1999. Fundamentals of atmospheric aerosol chemistry. Budapest: Acad. Kiado.,

Mikula, R.J. \& Parsons, I.S., 1991. Coal Dustiness: Characterization and Control. Coal Preparation, 9(3-4), pp.199-212.

Minguillón, M.. et al., 2009. Effect of ceramic industrial particulate emission control on key components of ambient PM10. Journal of Environmental Management, 90(8), 
pp.2558-2567.

Minguillón, M.C., 2007. Composición y fuentes del material particulado atmosférico en la zona cerámica de Castellón. Impacto de la introducción de las Mejores Técnicas Disponibles (Tesis Doctoral).

Mirabelli, D. \& Kauppinen, T., 2005. Occupational Exposures to Carcinogens in Italy: An Update of CAREX Database. International journal of occupational and environmental health, 11(1), pp.53-63.

Monfort, E. et al., 2011. Diffuse PM10 emission factors associated with dust abatement technologies in the ceramic industry. Atmospheric Environment, 45(39), pp.72867292.

Monfort, E. et al., 2009. Estimación de emisiones difusas de PM10 y rendimiento de MTD's en el sector cerámico. Boletín de la Sociedad Española de Cerámica y Vidrio, 48(1), pp.15-24.

Monfort, E. et al., 2014. Libro blanco sobre emisiones difusas de material particulado: Cuantificación, control y minimización,

Monfort, E. et al., 2004. PMx Data Processing in Ceramic Tile Manufacturing Emissions. Key Engineering Materials, 264-268, pp.2453-2456.

Monfort, E., Ibanez, M. \& Escrig, A., 2008. Respirable crystalline silica in the ceramics industries sampling, exposure and toxicology, Göller.

Moran, R.E. et al., 2014. Occupational exposure to particulate matter from three agricultural crops in California. International journal of hygiene and environmental health, 217(2-3), pp.226-30.

Morawska, L. et al., 1998. Submicrometer and Supermicrometer Particles from Diesel Vehicle Emissions. Environ. Sci. Technol., 32(14), pp.2033-2042.

Pensis, I. et al., 2009. Comparative Evaluation of the Dustiness of Industrial Minerals According to European Standard EN 15051, 2006. The Annals of Occupational Hygiene, 53(2), pp.325-30.

Perra, S., 1984. Measurement of Sandy Alumina Dustiness. In Essential Readings in Light Metals. Cham: Springer International Publishing, pp. 765-773.

Plinke, M.A.E. et al., 1995. Dust Generation from Handling Powders in Industry. American Industrial Hygiene Association Journal, 56(3), pp.251-257.

Plinke, M.A.E. et al., 1991. Expermiental examination of factors that affect dust generation. American Industrial Hygiene Association Journal, 52(12), pp.521-528.

Plinke, M.A.E., Maus, R. \& Leith, D., 1992. Experimental examination of factors that affect dust generation by using Heubach and MRI testers. American Industrial Hygiene Association Journal, 53(5), pp.325-330.

PMCA-AL, 2010. Plan de Mejora de la Calidad del Aire de L'Alacantí Occidental. Conselleria de Medio Ambiente, Agua, Urbanismo y Vivienda; Fundación Centro de Estudios Ambientales del Mediterráneo; Instituto de Diagnóstico Ambiental y Estudios del Agua, CSIC; Instituto d.

PMCA-CS, 2008. Plan de Mejora de la Calidad del aire de la zona ES1003: MijaresPenyagolosa (A. Costera) y aglomeración ES 1015: Castelló. Instituto de Ciencias de la Tierra "Jaume Almera", CSIC; Instituto de Tecnología Cerámica, Universitat Jaume I; Fundación Centro de. 
PNMCA, 2013. PLAN NACIONAL DE CALIDAD DEL AIRE Y PROTECCIÓN DE LA ATMÓSFERA 2013-2016 Dirección General de Calidad y Evaluación Ambiental y Medio Natural Subdirección General de Calidad del Aire y Medio Ambiente Industrial.

Pope, C.A. et al., 2002. Lung cancer, cardiopulmonary mortality, and long-term exposure to fine particulate air pollution. JAMA, 287(9)(9), pp.1132-1141.

Pope, C.A. \& Dockery, D.W., 2006. Health Effects of Fine Particulate Air Pollution: Lines that Connect. Journal of the Air \& Waste Management Association, 56(6), pp.709742.

Powell, A. \& Russell, C., 1933. Method for Determining the Dustiness of Coal and Coke. Industrial \& Engineering Chemistry Analytical Edition, 5(5), pp.340-341.

Pujara, C., 1997. Determination of factors that affect the generation of airborne particles from bulk pharmaceutical powders (Doctoral Dissertation).

Putaud, J.P. et al., 2004. A European aerosol phenomenology-2: chemical characteristics of particulate matter at kerbside, urban, rural and background sites in Europe. Atmospheric Environment, 38(16), pp.2579-2595.

Putaud, J.P. et al., 2010. A European aerosol phenomenology - 3: Physical and chemical characteristics of particulate matter from 60 rural, urban, and kerbside sites across Europe. Atmospheric Environment, 44(10), pp.1308-1320.

Querol, X. et al., 2012. Bases científico-técnicas para un Plan Nacional de Mejora de la Calidad del Aire.

Querol, X., Alastuey, A., Rodríguez, S., et al., 2004. Levels of particulate matter in rural, urban and industrial sites in Spain. Science of The Total Environment, 334, pp.359376.

Querol, X. et al., 2008. Spatial and temporal variations in airborne particulate matter (PM 10 and PM 2.5) across Spain 1999-2005. Atmospheric.

Querol, X., Alastuey, A., Viana, M.M., et al., 2004. Speciation and origin of PM10 and PM2.5 in Spain. Journal of Aerosol Science, 35(9), pp.1151-1172.

Radnoff, D.L. \& Kutz, M.K., 2013. Exposure to Crystalline Silica in Abrasive Blasting Operations Where Silica and Non-Silica Abrasives Are Used. The Annals of Occupational Hygiene, 36(1), pp.140-8.

Rodríguez, S. et al., 2005. Nucleation and growth of new particles in the rural atmosphere of Northern Italy-relationship to air quality monitoring. Atmospheric Environment, 39(36), pp.6734-6746.

Samet, J.M. et al., 2000. The national morbidity, mortality, and air pollution study. Part II: morbidity and mortality from air pollution in the United States. Cambridge, MA: Health Effects Institute, 2000 (No. 94). Report.,

Samoli, E. et al., 2008. Acute Effects of Ambient Particulate Matter on Mortality in Europe and North America: Results from the APHENA Study. Environmental Health Perspectives, 116(11), pp.1480-1486.

Scarselli, A., Binazzi, A. \& Marinaccio, A., 2008. Occupational exposure to crystalline silica: Estimating the number of workers potentially at high risk in Italy. American Journal of Industrial Medicine, 51(12), pp.941-949.

Schofield, C., 1981. Dust generation and control in materials handling. Bulk solids handling, 1(3), pp.419-427. 
Schofield, C., Sutton, H. \& Waters, K., 1979. The generation of dust by materials handling operations. J. Powder Bulk Solids Technol., 3(1), p.40.

Schütz, L. \& Sebert, M., 1987. Mineral aerosols and source identification. Journal of Aerosol Science, 18(1), pp.1-10.

Schwartz, J. et al., 1994. Acute effects of summer air pollution on respiratory symptom reporting in children. American journal of respiratory and critical care medicine, 150(5 Pt 1), pp.1234-42.

Schwartz, J., 1994. Air Pollution and Daily Mortality: A Review and Meta Analysis. Environmental Research, 64(1), pp.36-52.

Schwartz, J., 1996. Air pollution and hospital admissions for respiratory disease. Epidemiology, 7(1), pp.20-28.

Schwartz, J., 1994. Total suspended particulate matter and daily mortality in Cincinnati, Ohio. Environmental health perspectives, 102(2), pp.186-9.

Schwartz, J., Dockery, D.W. \& Neas, L.M., 1996. Is Daily Mortality Associated Specifically with Fine Particles? Journal of the Air \& Waste Management Association, 46(10), pp.927-939.

SCOEL/SUM/94, 2003. Recommendation from the Scientific Committee on Occupational Exposure Limits for Silica, Crystalline (respirable dust),

Seinfeld, J., Pandis, S. \& Noone, K., 1998. Atmospheric chemistry and physics: from air pollution to climate change,

Sethi, S.A., 1997. Generation of small particles by gas fluidization. Journal of Aerosol Science, 1001(28), pp.S539-S540.

Sethi, S. \& Schneider, T., 1996. A gas fluidization dustiness tester. Journal of Aerosol Science, 27, pp.S305-S306.

Soutar, C.A. et al., 2000. Epidemiological Evidence on the Carcinogenicity of Silica: Factors in Scientific Judgement. The Annals of Occupational Hygiene, 44(1), pp.314.

Stieb, D.M.D., Judek, S. \& Burnett, R.R.T., 2002. Meta-Analysis of Time-Series Studies of Air Pollution and Mortality: Effects of Gases and Particles and the Influence of Cause of Death, Age, and Season. Journal of the Air \& Waste Management Association, 52(4), pp.470-484.

Streets, D.G. et al., 2011. All-time releases of mercury to the atmosphere from human activities. Environmental science \& technology, 45(24), pp.10485-91.

Takai, H. \& Dahl, P.J., 2008. Estimation of dustiness of straws and dust exposure. In Agricultural and biosystems engineering for a sustainable world. International Conference on Agricultural Engineering, Hersonissos, Crete, Greece, 23-25 June, 2008. European Society of Agricultural Engineers (AgEng).

Tertre, A. Le et al., 2002. Short-term effects of particulate air pollution on cardiovascular diseases in eight European cities. Journal of Epidemiology \& Community Health, 56(10), pp.773-779.

Teschke, K. et al., 1999. Determinants of Exposure to Inhalable Particulate, Wood Dust, Resin Acids, and Monoterpenes in a Lumber Mill Environment. The Annals of Occupational Hygiene, 43(4), pp.247-255.

UNE EN 12341, 2015. Aire ambiente. Método de medición gravimétrico normalizado 
para la determinación de la concentración másica PM10 o PM2,5 de la materia particulada en suspensión. http://www.aenor.es/.

UNE EN 15051, 2007. Atmósferas en los lugares de trabajo. Medición del estado pulverulento de los materiales a granel. Requisitos y métodos de ensayo de referencia. http://www.aenor.es/.

UNE EN 15051, 2014. Exposición en el lugar de trabajo. Medición de la capacidad de emisión de polvo de los materiales a granel. http://www.aenor.es/.

UNE EN 481, 1995. Atmósferas en los puestos de trabajo. Definición de las fracciones por el tamaño de las partículas para la medición de aerosoles. http://www.aenor.es/.

Upton, S., Hall, D. \& Marsland, G., 1990. Some experiments on material dustiness. In Aeorosol Society Annual Conference, University of Surrey, Guildford, Surrey, UK.

Visser, G.G.T. \& Cleijne, J.W.J., 1994. Wind comfort predictions by wind tunnel tests: comparison with full-scale data. Journal of Wind Engineering and Industrial Aerodynamics, 52, pp.385-402.

Visser, G.T., 1992. A wind-tunnel study of the dust emissions from the continuous dumping of coal. Atmospheric Environment. Part A. General Topics, 26(8), pp.1453-1460.

Wagstrom, K.M. \& Pandis, S.N., 2011. Contribution of long range transport to local fine particulate matter concerns. Atmospheric Environment, 45(16), pp.2730-2735.

Warneck, P., 1988. Chemistry of the natural atmosphere, Academic Press.

Watson, J.G. et al., 2002. Receptor modeling application framework for particle source apportionment. Chemosphere, 49(9), pp.1093-1136.

Watson, J.G., Chow, J.C. \& Fujita, E.M., 2001. Review of volatile organic compound source apportionment by chemical mass balance. Atmospheric Environment, 35(9), pp.1567-1584.

Watson, J.G., Chow, J.C. \& Houck, J.E., 2001. PM2.5 chemical source profiles for vehicle exhaust, vegetative burning, geological material, and coal burning in Northwestern Colorado during 1995. Chemosphere, 43(8), pp.1141-1151.

Wehner, B. et al., 2002. Particle number size distributions in a street canyon and their transformation into the urban-air background: measurements and a simple model study. Atmospheric Environment, 36(13), pp.2215-2223.

Wells, A. \& Alexander, D., 1978. A method for estimating the dust yield of powders. Powder technology, 19(2), pp.271-277.

Westborg, S. \& Cortson, C., 1990. Determination of Dustiness of Coal by the Rotating Drum Method. Journal of Coal Quality, 9(3), p.77.

WHO, 2005. Air quality guidelines. Global update 2005. Particulate matter, ozone, nitrogen dioxide and sulfur dioxide, World Health Organization.

WHO/SDE/OEH/99.14, 1999. Hazard prevention and control in the work environment: Airborne dust.

Wichmann, H.E. \& Peters, A., 2000. Epidemiological evidence of the effects of ultrafine particle exposure. Philosophical Transactions of the Royal Society of London A: Mathematical, Physical and Engineering Sciences, 358(1775). 
Wypych, P. \& Mar, L., 2013. Investigations into the dustiness of bulk materials. Faculty of Engineering and Information Sciences - Papers: Part A, 18(1), pp.64-67.

Zhang, K.M. \& Wexler, A.S., 2002. A hypothesis for growth of fresh atmospheric nuclei. Journal of Geophysical Research: Atmospheres, 107(D21), p.AAC 15-1-AAC 15-6.

Zhu, Y. et al., 2002. Study of ultrafine particles near a major highway with heavy-duty diesel traffic. Atmospheric Environment, 36(27), pp.4323-4335. 
ANEXO I: GLOSARIO DE TÉRMINOS 

Para facilitar la lectura de la memoria se incluyen en este apéndice algunos de los términos de ingeniería ambiental y salud laboral que aparecen con frecuencia en el texto o que se considera que pueden ser de utilidad para el lector.

\section{Atomización (secaderos por atomización):}

Este tipo de secaderos se utilizan en el proceso de fabricación de baldosas cerámicas para el secado de la suspensión de materias primas del soporte obtenida tras la molienda vía húmeda. El secado se realiza pulverizando la suspensión en una cámara en la que se introduce una corriente de gases a temperaturas del orden de 550 - 650 -C. El producto obtenido en esta etapa se encuentra en forma de aglomerados esféricos huecos de partículas con una humedad controlada que resultan adecuados para el prensado.

\section{Autorización Ambiental Integrada (AAl):}

Documento que agrupa los permisos medioambientales de una instalación industrial en uno solo. Es la resolución del órgano competente de la Comunidad Autónoma en la que se ubique la instalación industrial. El permiso incluirá todas las medidas necesarias para conseguir un alto nivel de protección del medio ambiente en su conjunto y para asegurar que la explotación de la instalación se efectúe de acuerdo con los principios generales aplicables a las obligaciones fundamentales del titular. El permiso también incluirá valores límite de emisión para las sustancias contaminantes, o parámetros equivalentes o medidas técnicas, requisitos adecuados para la protección del suelo y las aguas subterráneas y requisitos para el control.

Las condiciones del permiso se fijarán basándose en las mejores técnicas disponibles publicadas en los Documentos de Conclusiones.

BAT: (ver MTD)

\section{BREF (BAT Reference Document):}

Documento elaborado para determinadas actividades, en el que se describen, en particular, las técnicas aplicadas, las emisiones actuales, los niveles de consumo, las consideraciones que se tienen en cuenta para determinar las MTD, así como las conclusiones sobre las MTD y las técnicas emergentes, tomando especialmente en consideración los criterios que se enumeran en el anexo III de la Directiva 2010/75/UE.

\section{Contaminación atmosférica:}

La introducción directa o indirecta, mediante la actividad humana, de sustancias, vibraciones, calor o ruido en la atmósfera, que puedan tener efectos perjudiciales para la salud humana o la calidad del medio ambiente, o que puedan causar daños a los bienes materiales o deteriorar o perjudicar el disfrute $u$ otras utilizaciones legítimas del medio ambiente.

\section{Diámetro aerodinámico:}

Diámetro de una partícula ficticia esférica de densidad $1 \mathrm{~g} / \mathrm{cm}^{3}$ que tiene el mismo comportamiento aerodinámico (misma velocidad terminal en régimen estacionario en el aire) que la partícula real. 


\section{Diámetro de Stokes:}

Diámetro de una partícula ficticia esférica de igual densidad que la partícula real que tiene la misma velocidad terminal en régimen estacionario en el aire que la partícula real.

\section{Emisión:}

La expulsión a la atmósfera, al agua o al suelo de sustancias, vibraciones, calor o ruido procedentes de forma directa o indirecta de fuentes puntuales o difusas de la instalación.

\section{Emisión canalizada:}

Corriente vertida a la atmósfera a través de una conducción, bien sea fija o móvil.

\section{Emisión difusa o fugitiva:}

Emisión no canalizada, sino vertida a la atmósfera desde una superficie o volumen.

\section{Enfermedad profesional:}

Deterioro lento y paulatino de la salud del trabajador, producido por una exposición crónica a situaciones adversas, sean éstas producidas por el ambiente en el que se desarrolla el trabajo o por la forma en que éste está organizado.

\section{Fracción inhalable:}

Fracción másica de partículas que es inhalada a través de la nariz y la boca. En el caso de los resultados del ensayo de determinación del poder de emisión de polvo, dicha fracción hace referencia al ratio de polvo inhalable producido en el procedimiento de ensayo, en miligramos, respecto a la masa del material utilizado en el ensayo, en kilogramos.

\section{Fracción torácica:}

Fracción másica de partículas inhaladas que penetra más allá de la laringe. En el caso de los resultados del ensayo de determinación del poder de emisión de polvo, dicha fracción hace referencia al ratio de polvo torácico producido en el procedimiento de ensayo, en miligramos, respecto a la masa del material utilizado en el ensayo, en kilogramos.

\section{Fracción respirable:}

Fracción másica de partículas inhaladas que penetra en las vías respiratorias no ciliadas. En el caso de los resultados del ensayo de determinación del poder de emisión de polvo, dicha fracción hace referencia al ratio de polvo respirable producido en el procedimiento de ensayo, en miligramos, respecto a la masa del material utilizado en el ensayo, en kilogramos. 


\section{Granulación:}

Proceso en el que la composición, previamente molida vía seca, es sometida a la acción de una granuladora con el doble objetivo de acondicionar la humedad y la granulometría del polvo para el prensado. En esta operación el polvo se humecta inicialmente a una humedad superior a la requerida para su prensado con el objeto de favorecer su granulación, y posteriormente se somete a un secado para ajustar la humedad final. Esta metodología de preparación del polvo es la más utilizada actualmente en los procesos de fabricación de baldosas por molienda vía seca.

\section{Humectación industrial:}

Proceso en el que la composición, previamente molida vía seca, es sometida a la acción de una humectadora o bañadora, cuyo objetivo fundamentalmente es ajustar la humedad del polvo para el proceso de prensado. Esta forma de preparación del polvo es conocida en el argot industrial como «vía seca tradicional», y actualmente su uso es minoritario en Europa.

\section{Inmisión o calidad de aire:}

Nivel de contaminación en el ambiente gaseoso, en puntos suficientemente alejados de las fuentes, como para no poder discernir cuál de ellas es la causante de los niveles de contaminación alcanzados, a los que van a estar expuestos los receptores.

IPPC:

Siglas en inglés de Prevención y Control Integrados de la Contaminación (Integrated Prevention Pollution Control), término que se aplica a la Directiva 1996/61/CE y a las leyes nacionales de transposición de dicha Directiva.

\section{Material particulado atmosférico (PM):}

Conjunto de partículas sólidas y/o líquidas, a excepción del agua pura, presentes en la atmósfera.

\section{Material crustal o mineral:}

Material de composición similar a la de la corteza terrestre.

\section{Molienda vía seca:}

En el sector cerámico, proceso de molienda llevado a cabo mediante molino de martillos o molino pendular ( $d_{90}$ aproximadamente $500 \mu \mathrm{m}$ ). Por tanto, el producto obtenido es un material intermedio en el proceso de fabricación, puesto que tiene que someterse a una humectación o granulación posterior para posibilitar la realización idónea de la operación de prensado.

MTD:

Mejor Técnica Disponible, término utilizado en inglés como BAT: best available technique. Se entiende por la técnica más eficaz para proteger al medio ambiente en su conjunto, donde la tecnología empleada, incluye el diseño, la construcción, el mantenimiento y la explotación, y debe ser viable técnica y económicamente. 
PMx:

Material particulado en suspensión que atraviesa un cabezal de tamaño selectivo para un diámetro aerodinámico de $x \mu \mathrm{m}$ con una eficiencia de corte del $50 \%$. Los parámetros más habituales son $\mathrm{PM}_{10}, \mathrm{PM}_{2.5}$ y $\mathrm{PM}_{1}$. Las siglas $\mathrm{PM}$ vienen del inglés particulate matter (material particulado o materia particulada).

\section{Partículas totales en suspensión (PST):}

Acumulación de gotas de un sólido o líquido en la atmósfera ambiental generada a partir de alguna actividad antropogénica o natural.

\section{Partículas sedimentables (PSD):}

Aquellas partículas presentes en la atmósfera que son susceptibles de ser depositadas por gravedad o arrastradas por la lluvia.

\section{Poder de emisión de polvo:}

Tendencia de los materiales a producir polvo suspendido en el aire cuando se manipulan.

\section{Poder de emisión de polvo inhalable:}

Clasificación correspondiente al poder de generar polvo de la fracción inhalable (EN 15051).

\section{Poder de emisión de polvo torácico:}

Clasificación correspondiente al poder de generar polvo de la fracción torácica (EN 15051).

\section{Poder de emisión de polvo respirable:}

Clasificación correspondiente al poder de generar polvo de la fracción respirable (EN15051).

\section{Silicosis:}

Enfermedad pulmonar profesional atribuible a la inhalación de sílice cristalina respirable, generalmente como cuarzo, pero también como cristobalita y tridimita.

\section{Trituración:}

En el sector cerámico, proceso preliminar de molienda ( $d_{90}$ aproximadamente $10 \mathrm{~mm}$ ).

\section{Valor Límite Ambiental-Exposición Diaria (VLA-ED):}

Valor que representa las condiciones a las cuales se cree, basándose en los conocimientos actuales, que la mayoría de los trabajadores pueden estar expuestos 8 h/día y $40 \mathrm{~h} /$ semana durante toda su vida laboral, sin sufrir efectos adversos para su salud. 


\section{Valor Límite Ambiental-Exposición de Corta Duración (VLA-EC):}

Valor que no debe ser superado por ninguna exposición de corta duración a lo largo de la jornada laboral (cualquier periodo de $15 \mathrm{~min}$ a lo largo de la jornada laboral, excepto para aquellos agentes químicos para los que se especifique un periodo de referencia inferior). 

ANEXO II: NOMENCLATURA 



\begin{tabular}{|c|c|c|}
\hline Símbolo & Nombre & Unidades \\
\hline$\Delta \mathrm{m}$ & Incremento de masa & $g$ \\
\hline A & Área & $\mathrm{m}^{2}$ \\
\hline$|A|$ & $\begin{array}{l}\text { Matriz de dispersión de luz. } \\
\text { Intensidad de luz recogida por } \\
\text { cada uno de los anillos del } \\
\text { detector procedente de cada clase } \\
\text { de tamaño de partícula }\end{array}$ & \\
\hline anitrógeno & $\begin{array}{c}\text { Sección transversal de la molécula } \\
\text { de nitrógeno }\end{array}$ & $\mathrm{nm}^{2}$ \\
\hline AR & Aspect ratio & - \\
\hline a & Coeficiente de absorción másica & $\mathrm{l} /(\mathrm{g} \cdot \mathrm{cm})$ \\
\hline$a_{s}, a_{1}, a_{c}$ & $\begin{array}{l}\text { Coeficiente de absorción del } \\
\text { sólido, del líquido y de la celda } \\
\text { respectivamente }\end{array}$ & $\mathrm{I} /(\mathrm{g} \cdot \mathrm{cm})$ \\
\hline $\mathrm{BQ}$ & Contenido en cuarzo & $\%$ \\
\hline C & Concentración de $\mathrm{PM}_{10}$ & $\mu \mathrm{g} \mathrm{PM} M_{10} / \mathrm{m}^{3}$ \\
\hline Cohesión & $\begin{array}{l}\text { Cohesión medida con una célula } \\
\text { rotacional de Pesch }\end{array}$ & $\mathrm{kPa}$ \\
\hline$d_{50}$ & $\begin{array}{l}\text { Tamaño medio de partícula. Es la } \\
\text { media de la distribución, o } \\
\text { diámetro para el cual la mitad de } \\
\text { las partículas de la distribución } \\
\text { son más gruesas que dicho } \\
\text { diámetro y la otra mitad más finas }\end{array}$ & $\mu \mathrm{m}$ \\
\hline $\mathrm{d}_{97} / \mathrm{d}_{10}$ & $\begin{array}{l}\text { Ratio que representa la amplitud } \\
\text { de la distribución de tamaño de } \\
\text { partícula }\end{array}$ & - \\
\hline $\mathrm{d}_{\text {aerodinámico }}$ & Diámetro aerodinámico & $\mu \mathrm{m}$ \\
\hline$d_{i}$ & $\begin{array}{c}\text { Diámetro de corte de cada } \\
\text { impactador (diámetro medio } \\
\text { aerodinámico colectado en cada } \\
\text { etapa del impactador) }\end{array}$ & $\mu \mathrm{m}$ \\
\hline$d_{\text {laser }}$ & $\begin{array}{c}\text { Diámetro obtenido por difracción } \\
\text { láser }\end{array}$ & $\mu \mathrm{m}$ \\
\hline$\Delta \mathrm{m}_{\mathrm{c}}$ & $\begin{array}{c}\text { Masa de muestra recogida en la } \\
\text { cubeta colectora }\end{array}$ & $g$ \\
\hline $\mathrm{d}_{\text {stokes }}$ & Diámetro de Stokes & $\mu \mathrm{m}$ \\
\hline$d_{\mathrm{sv}}$ & $\begin{array}{l}\text { Diámetro medio superficie- } \\
\text { volumen, es el tamaño medio } \\
\text { basado en la superficie especifica } \\
\text { por unidad de volumen }\end{array}$ & $\mu \mathrm{m}$ \\
\hline$E$ & Emisión & $\mathrm{g} / \mathrm{s}$ \\
\hline$\varepsilon$ & $\begin{array}{c}\text { Vector de error, intensidad de luz } \\
\text { no explicada/ajustada en cada } \\
\text { anillo del detector }\end{array}$ & \\
\hline ER & $\begin{array}{l}\text { Ratio de elongación, es el ratio } \\
\text { entre el máximo diámetro y el } \\
\text { mínimo diámetro de la partícula }\end{array}$ & - \\
\hline $\mathrm{F}$ & Flujo másico de material & $\mathrm{kg} / \mathrm{s}$ \\
\hline
\end{tabular}




\begin{tabular}{|c|c|c|}
\hline Símbolo & Nombre & Unidades \\
\hline$F_{E}$ & Fuerza de empuje & $\mathrm{N}$ \\
\hline $\mathrm{F}_{\mathrm{G}}$ & Fuerza de la gravedad & $\mathrm{N}$ \\
\hline$F_{R}$ & Fuerza de rozamiento & $\mathrm{N}$ \\
\hline g & Aceleración de la gravedad & $\mathrm{m}^{2} / \mathrm{s}$ \\
\hline $\mathrm{H}$ & Altura de caída & $\mathrm{m}$ \\
\hline$\eta$ & Viscosidad del fluido & $(\mathrm{kg} / \mathrm{ms})$ \\
\hline $\mathrm{h}$ & $\begin{array}{l}\text { Distancia recorrida desde la } \\
\text { superficie de la suspensión }\end{array}$ & $\mathrm{m}$ \\
\hline $\mathrm{HR}$ & Hausner ratio & - \\
\hline I & $\begin{array}{c}\text { Intensidad de la radiación que } \\
\text { abandona la celda }\end{array}$ & \\
\hline $\mathrm{I}_{0}$ & $\begin{array}{l}\text { Intensidad de la radiación } \\
\text { incidente }\end{array}$ & \\
\hline Impaction & $\begin{array}{c}\text { Ratio entre la fuerza de impacto y } \\
\text { el flujo de material }\end{array}$ & $\mathrm{m} / \mathrm{s}$ \\
\hline$\varphi$ & Fracción másica & $g / l$ \\
\hline$\varphi_{\mathrm{S},}, \varphi_{\mathrm{L}}$ & $\begin{array}{l}\text { Fracción másica de sólido y } \\
\text { líquido, respectivamente }\end{array}$ & $g / l$ \\
\hline$k_{p}$ & $\begin{array}{c}\text { Factor de forma Superficie- } \\
\text { Volumen }\end{array}$ & - \\
\hline $\bar{L}$ & $\begin{array}{l}\text { Intensidad de luz recogida por } \\
\text { cada anillo del detector }\end{array}$ & \\
\hline $\mathrm{L}$ & Camino recorrido por la radiación & $\mathrm{cm}$ \\
\hline$L_{1} y L_{c}$ & $\begin{array}{l}\text { Camino que recorre la radiación } \\
\text { en el medio líquido y la celda }\end{array}$ & $\mathrm{cm}$ \\
\hline M & Humedad & $\%$ \\
\hline $\mathrm{m}_{0}$ & Masa inicial de la muestra & g \\
\hline$m_{f}$ & Masa final de la muestra & g \\
\hline$M F_{i}:$ & $\begin{array}{c}\text { Factor del material, indicador de la } \\
\text { facilidad de liberación de polvo de } \\
\text { tamaño i (dependiente de } \\
\text { parámetros del material) }\end{array}$ & - \\
\hline$m_{p}$ & Masa partícula & $\mathrm{kg}$ \\
\hline $\mathrm{N}_{\mathrm{A}}$ & Número de Avogadro & - \\
\hline $\mathrm{n}_{\mathrm{m}}$ & $\begin{array}{c}\text { Capacidad de gas en la monocapa } \\
\text { que recubre toda la superficie del } \\
\text { material }\end{array}$ & $\begin{array}{l}\text { Moles adsorbato } / \mathrm{g} \\
\text { adsorbente }\end{array}$ \\
\hline $\mathrm{p}[\mathrm{di}]$ & $\begin{array}{l}\text { Fracción de partículas de tamaño } \\
\text { menor que di }\end{array}$ & $\%$ \\
\hline PF & $\begin{array}{l}\text { Factor de proceso, indicador del } \\
\text { tipo y cantidad de energía } \\
\text { aplicada (depende del ensayo) }\end{array}$ & - \\
\hline $\bar{q}$ & $\begin{array}{l}\text { Distribución de tamaños de } \\
\text { partícula }\end{array}$ & - \\
\hline
\end{tabular}




\begin{tabular}{|c|c|c|}
\hline Símbolo & Nombre & Unidades \\
\hline$Q_{1}, Q_{R}$ & $\begin{array}{l}\text { Caudal del muestreador de polvo } \\
\text { inhalable y respirable }\end{array}$ & $(\mathrm{l} / \mathrm{min})$ \\
\hline$Q_{m}$ & Caudal de la bomba principal & $(\mathrm{l} / \mathrm{min})$ \\
\hline$Q_{\text {tot }}$ & $\begin{array}{l}\text { Caudal total de aire } \\
\qquad Q_{1}+Q_{R}+Q_{m}\end{array}$ & $(\mathrm{l} / \mathrm{min})$ \\
\hline $\mathrm{R}$ & $\begin{array}{l}\text { Ratio entre la transmitancia de la } \\
\text { muestra (celda + muestra }+ \\
\text { dispersante) y la transmitancia del } \\
\text { blanco (celda + dispersante) }\end{array}$ & - \\
\hline $\mathrm{R}_{0}$ & $\begin{array}{l}\text { Ratio entre la transmitancia de la } \\
\text { muestra para } \mathrm{t}=0 \text { y la } \\
\text { transmitancia del blanco. Medida } \\
\text { al inicio, muestra en agitación }\end{array}$ & - \\
\hline $\mathrm{R}_{\mathrm{i}}$ & $\begin{array}{c}\text { Ratio entre la transmitancia de la } \\
\text { muestra para } t=t_{i} \text { y la } \\
\text { transmitancia del blanco. Medida a } \\
\text { un tiempo } t_{i}\end{array}$ & - \\
\hline $\mathrm{RE}_{\mathrm{i}}$ & $\begin{array}{c}\text { Emisión relativa, ratio entre la } \\
\text { masa de polvo de tamaño i } \\
\text { (colectada en los cabezales de } \\
\text { muestreo) y la masa de partículas } \\
\text { de ese tamaño en el material }\end{array}$ & $g / g \circ \%$ \\
\hline$\rho_{\mathrm{s}, \mathrm{f}}$ & $\begin{array}{c}\text { Densidad del sólido y del fluido, } \\
\text { respectivamente }\end{array}$ & $\mathrm{kg} / \mathrm{m}^{3}$ \\
\hline S & $\begin{array}{l}\text { Factor asociado al equipo } \\
\text { empleado, } 1 \mathrm{MRI} \text { y } 2 \text { Heubach }\end{array}$ & - \\
\hline $\mathrm{S}_{\mathrm{g}}$ & $\begin{array}{l}\text { Desviación geométrica estándar } \\
\text { de la distribución de tamaño de } \\
\text { partícula }\end{array}$ & - \\
\hline SSA & Superficie especifica & $\mathrm{m}^{2} / \mathrm{g}$ \\
\hline $\mathrm{t}$ & Tiempo & $\mathrm{s}$ \\
\hline $\mathrm{V}$ & Velocidad media del viento & $\mathrm{m} / \mathrm{s}$ \\
\hline $\mathrm{V}_{\mathrm{st}}$ & $\begin{array}{l}\text { Velocidad terminal de } \\
\text { sedimentación }\end{array}$ & $\mathrm{m} / \mathrm{s}$ \\
\hline $\mathrm{W}_{\mathrm{l}}, \mathrm{W}_{\mathrm{R}}$ & $\begin{array}{c}\text { Fracción másica de polvo } \\
\text { inhalable y respirable, } \\
\text { respectivamente, expresada como } \\
\text { el ratio entre la masa de polvo } \\
\text { (colectada en los cabezales de } \\
\text { muestreo) y la masa de material } \\
\text { ensayado }\end{array}$ & $\mathrm{mg} / \mathrm{kg}$ \\
\hline$X_{i}$ & $\begin{array}{l}\text { Fracción másica de partículas (en } \\
\text { el material) con tamaño i }\end{array}$ & $g / g$ \\
\hline$\rho_{a}$ & Densidad del lecho aireado & $\mathrm{g} / \mathrm{cm}^{3}$ \\
\hline$\rho_{\mathrm{t}}$ & Densidad real & $\mathrm{g} / \mathrm{cm}^{3}$ \\
\hline$\rho_{v}$ & $\begin{array}{l}\text { Densidad aparente del lecho } \\
\text { compactado o vibrado }\end{array}$ & $\mathrm{g} / \mathrm{cm}^{3}$ \\
\hline
\end{tabular}



ANEXO III: CONVENIO DE MUESTREO 

Tabla 8.1 Valores numéricos de los convenios inhalable, torácico y respirable, expresados como porcentaje del aerosol total (EN 481: 1995)

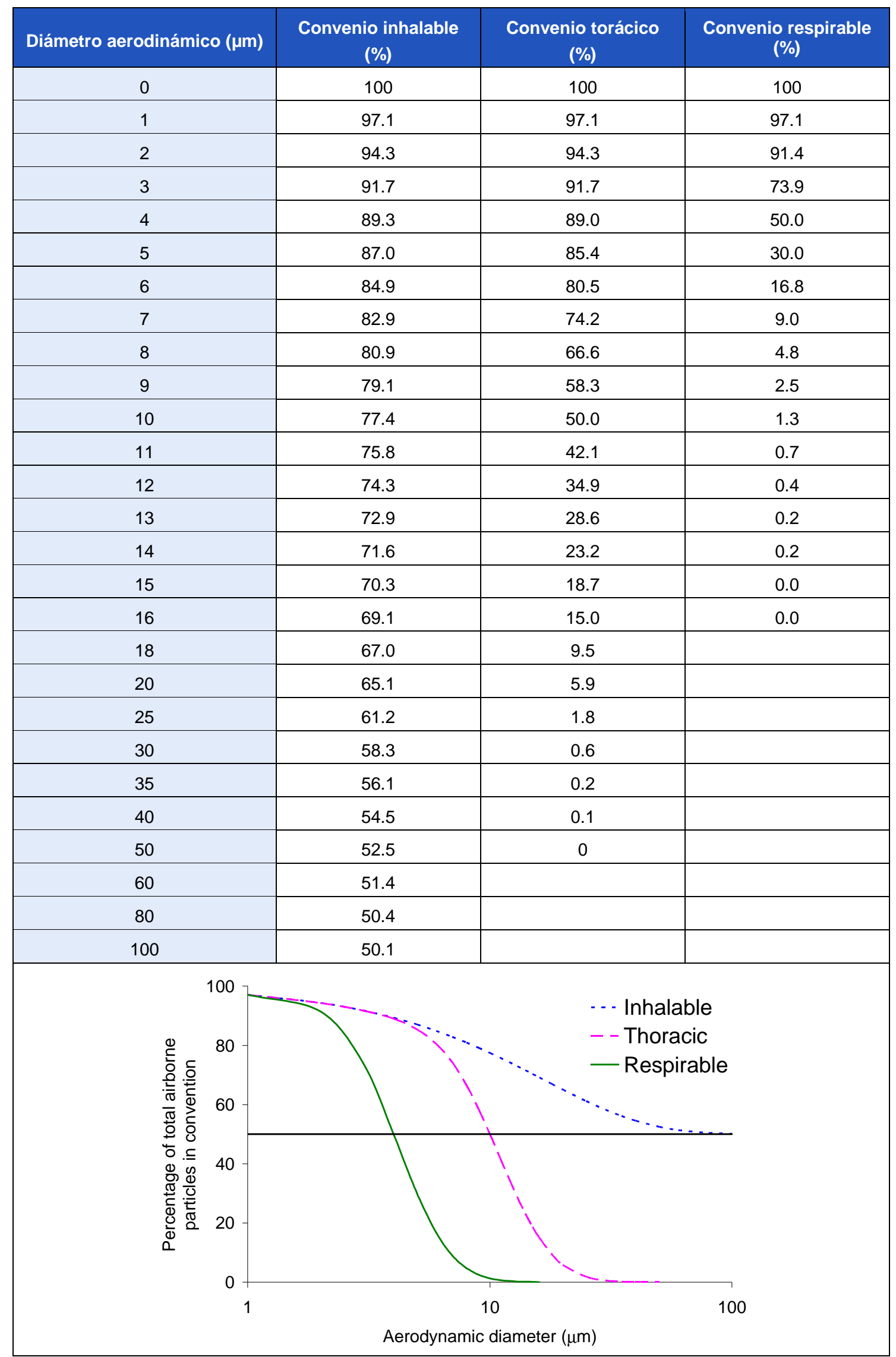



ANEXO IV: CARACTERIZACIÓN FÍSICA DE LOS MATERIALES 



\section{Tabla 8.2 Caracterización física de las muestras de caolín (K)}

\begin{tabular}{|c|c|c|c|c|c|c|c|c|c|c|}
\hline \multirow[t]{2}{*}{ Referencia } & \multirow[t]{2}{*}{ Muestra } & \multirow{2}{*}{$\begin{array}{l}\text { Humedad } \\
\qquad \%)\end{array}$} & \multicolumn{4}{|c|}{ DTP } & \multirow{2}{*}{$\begin{array}{l}\text { Superficie específica } \\
\qquad\left(\mathrm{m}^{2} / \mathrm{g}\right)\end{array}$} & \multirow{2}{*}{$\begin{array}{l}\text { Índice de Hausner } \\
\text { (HR) }\end{array}$} & \multicolumn{2}{|c|}{$\begin{array}{c}\text { Fracción másica de polvo (mg/kg) } \\
\text { Clasificación EN } 15051\end{array}$} \\
\hline & & & $d_{10}$ & $d_{50}$ & $d_{90}$ & $\mathbf{d}_{90} / \mathbf{d}_{10}$ & & & Inhalable $\left(w_{1}\right)$ & Respirable $\left(W_{R}\right)$ \\
\hline K1 & Caolín & 0.4 & 1.38 & 5.72 & 15.72 & 11.39 & 10.0 & 1.8 & $\begin{array}{l}10600 \\
\text { Moderado }\end{array}$ & $\begin{array}{c}80 \\
\text { Moderado }\end{array}$ \\
\hline K2 & $\begin{array}{l}\text { Finos } \\
\text { procedentes de } \\
\text { la separación } \\
\text { mediante } \\
\text { hidrociclones de } \\
\text { K1 (Presión=0.5) }\end{array}$ & 0.3 & 1.23 & 4.67 & 11.09 & 9.02 & 10.8 & 2.3 & $\begin{array}{l}5100 \\
\text { Moderado }\end{array}$ & $\begin{array}{c}40 \\
\text { Bajo }\end{array}$ \\
\hline K3 & K2 humectada & 1.0 & 1.23 & 4.67 & 11.09 & 9.02 & 10.8 & 2.0 & $\begin{array}{c}7135 \\
\text { Moderado }\end{array}$ & $\begin{array}{c}46 \\
\text { Bajo }\end{array}$ \\
\hline K4 & K2 humectada & 2.2 & 1.23 & 4.67 & 11.09 & 9.02 & 10.8 & 1.9 & $\begin{array}{c}8090 \\
\text { Moderado }\end{array}$ & $\begin{array}{c}27 \\
\text { Bajo }\end{array}$ \\
\hline K5 & $\begin{array}{c}\text { Gruesos } \\
\text { procedentes de } \\
\text { la separación } \\
\text { mediante } \\
\text { hidrociclones de } \\
\text { K1 (Presión=0.5) }\end{array}$ & 0.2 & 1.77 & 7.71 & 20.11 & 11.36 & 7.3 & 1.8 & $\begin{array}{l}12000 \\
\text { Moderado }\end{array}$ & $\begin{array}{c}80 \\
\text { Moderado }\end{array}$ \\
\hline K6 & K5 humectada & 2.1 & 1.77 & 7.71 & 20.11 & 11.36 & 7.3 & 1.5 & $\begin{array}{l}22425 \\
\text { Alto }\end{array}$ & $\begin{array}{c}148 \\
\text { Moderado }\end{array}$ \\
\hline K7 & $\begin{array}{c}\text { Finos } \\
\text { procedentes de } \\
\text { la separación } \\
\text { mediante } \\
\text { hidrociclones de } \\
\text { K1 (Presión=2) }\end{array}$ & 0.2 & 1.13 & 3.87 & 8.68 & 7.68 & 11.8 & 2.4 & $\begin{array}{c}5600 \\
\text { Moderado }\end{array}$ & $\begin{array}{c}40 \\
\text { Bajo }\end{array}$ \\
\hline
\end{tabular}




\begin{tabular}{|c|c|c|c|c|c|c|c|c|c|c|}
\hline \multirow{2}{*}{ Referencia } & \multirow{2}{*}{ Muestra } & \multirow{2}{*}{$\begin{array}{l}\text { Humedad } \\
(\%)\end{array}$} & \multicolumn{4}{|c|}{ DTP } & \multirow{2}{*}{$\begin{array}{l}\text { Superficie específica } \\
\left(\mathrm{m}^{2} / \mathrm{g}\right)\end{array}$} & \multirow{2}{*}{$\begin{array}{c}\text { Índice de Hausner } \\
\text { (HR) }\end{array}$} & \multicolumn{2}{|c|}{$\begin{array}{c}\text { Fracción másica de polvo (mg/kg) } \\
\text { Clasificación EN } 15051\end{array}$} \\
\hline & & & $d_{10}$ & $d_{50}$ & $d_{90}$ & $\mathbf{d}_{90} / \mathbf{d}_{10}$ & & & Inhalable ( $\left.w_{1}\right)$ & Respirable $\left(W_{R}\right)$ \\
\hline K8 & $\begin{array}{c}\text { Gruesos } \\
\text { procedentes de } \\
\text { la separación } \\
\text { mediante } \\
\text { hidrociclones de } \\
\text { K1 (Presión=2) }\end{array}$ & 0.5 & 2.51 & 9.06 & 21.40 & 8.53 & 6.3 & 1.7 & $\begin{array}{c}14100 \\
\text { Alto }\end{array}$ & $\begin{array}{c}70 \\
\text { Bajo }\end{array}$ \\
\hline K9 & Caolín & 0.3 & 2.80 & 8.01 & 25.82 & 9.22 & 12.0 & 1.9 & $\begin{array}{c}17348 \\
\text { Alto }\end{array}$ & $\begin{array}{c}186 \\
\text { Moderado }\end{array}$ \\
\hline K10 & K10 humectada & 1.1 & 2.80 & 8.01 & 25.82 & 9.22 & 12.0 & 1.9 & $\begin{array}{c}13390 \\
\text { Moderado }\end{array}$ & $\begin{array}{c}75 \\
\text { Moderado }\end{array}$ \\
\hline K11 & K10 humectada & 2.4 & 2.80 & 8.01 & 25.82 & 9.22 & 12.0 & 1.8 & $\begin{array}{c}21985 \\
\text { Alto }\end{array}$ & $\begin{array}{c}231 \\
\text { Moderado }\end{array}$ \\
\hline K12 & K10 humectada & 5.8 & 2.80 & 8.01 & 25.82 & 9.22 & 12.0 & 1.7 & $\begin{array}{l}17211 \\
\text { Alto }\end{array}$ & $\begin{array}{c}116 \\
\text { Moderado }\end{array}$ \\
\hline K13 & K10 humectada & 7.9 & 2.80 & 8.01 & 25.82 & 9.22 & 12.0 & 1.7 & $\begin{array}{c}18315 \\
\text { Alto }\end{array}$ & $\begin{array}{c}130 \\
\text { Moderado }\end{array}$ \\
\hline K14 & K10 humectada & 10.6 & 2.80 & 8.01 & 25.82 & 9.22 & 12.0 & 1.6 & $\begin{array}{c}14288 \\
\text { Moderado }\end{array}$ & $\begin{array}{c}69 \\
\text { Bajo }\end{array}$ \\
\hline
\end{tabular}




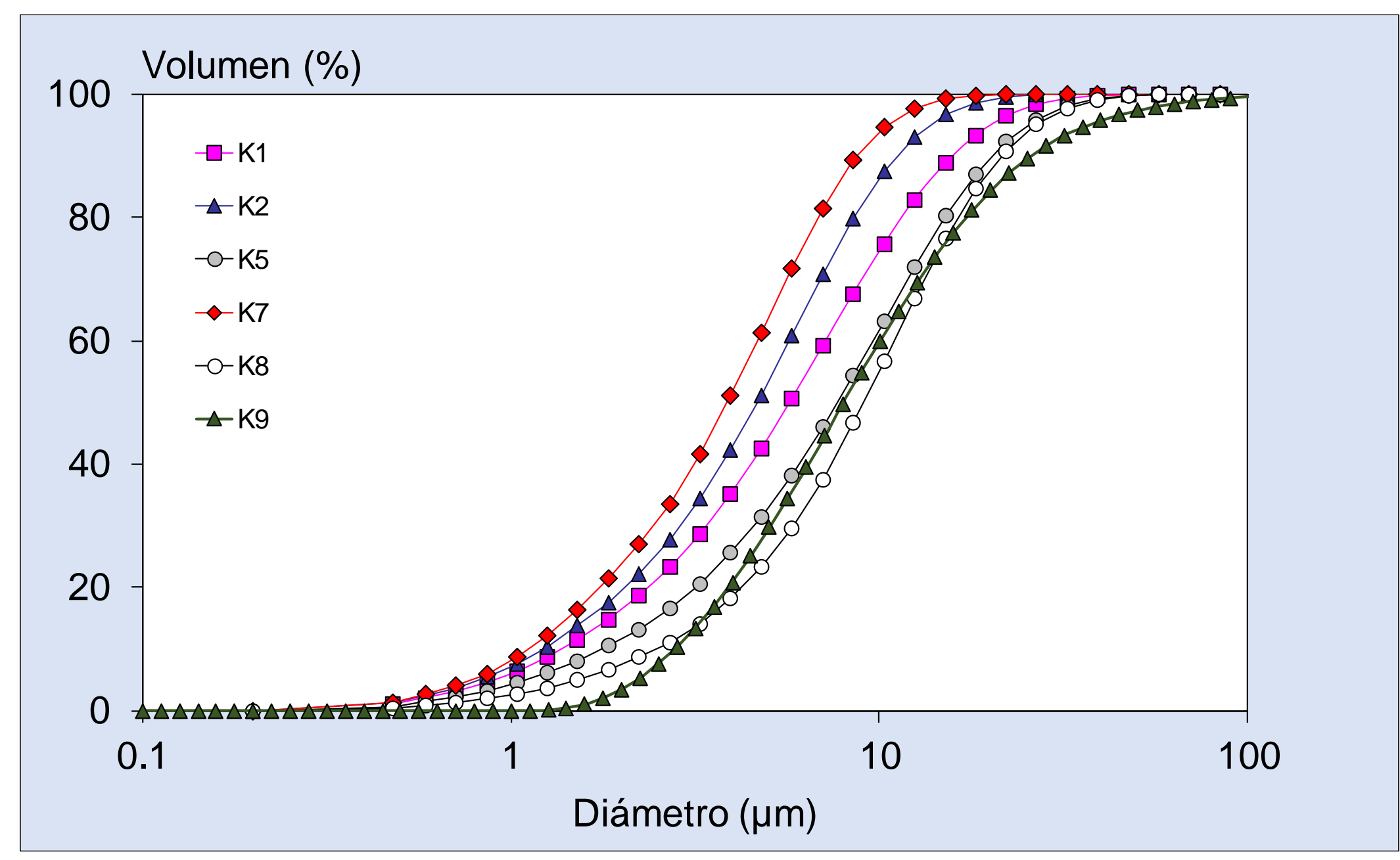

Figura 8.1 DTP de las muestras de caolín (K) 
Tabla 8.3 Caracterización física de las muestras de cuarzo (Q)

\begin{tabular}{|c|c|c|c|c|c|c|c|c|c|c|}
\hline \multirow{2}{*}{ Referencia } & \multirow{2}{*}{ Muestra } & \multirow{2}{*}{$\begin{array}{l}\text { Humedad } \\
(\%)\end{array}$} & \multicolumn{4}{|c|}{ DTP } & \multirow{2}{*}{$\begin{array}{l}\text { Superficie específica } \\
\qquad\left(\mathrm{m}^{2} / \mathrm{g}\right)\end{array}$} & \multirow{2}{*}{$\begin{array}{l}\text { Índice de Hausner } \\
\text { (HR) }\end{array}$} & \multicolumn{2}{|c|}{$\begin{array}{c}\text { Fracción másica de polvo (mg/kg) } \\
\text { Clasificación EN } 15051\end{array}$} \\
\hline & & & $d_{10}$ & $d_{50}$ & dgo $_{90}$ & $\mathbf{d}_{90} / \mathbf{d}_{10}$ & & & Inhalable ( $\left.w_{1}\right)$ & Respirable $\left(W_{R}\right)$ \\
\hline Q1 & \multirow{3}{*}{ Cuarzo } & \multirow{11}{*}{$<0.5 \%$} & 0.59 & 2.20 & 5.82 & 9.86 & 4.3 & 2.8 & $\begin{array}{l}1420 \\
\text { Bajo }\end{array}$ & $\begin{array}{c}24 \\
\text { Bajo }\end{array}$ \\
\hline Q2 & & & 0.99 & 3.39 & 8.42 & 8.54 & 4.4 & 2.0 & $\begin{array}{l}1908 \\
\text { Bajo }\end{array}$ & $\begin{array}{c}<\mathrm{DL} \\
\text { Muy bajo }\end{array}$ \\
\hline Q3 & & & 1.20 & 3.61 & 11.80 & 9.83 & 3.8 & 2.0 & $\begin{array}{l}1552 \\
\text { Bajo }\end{array}$ & $\begin{array}{c}32 \\
\text { Bajo }\end{array}$ \\
\hline Q4 & $\begin{array}{l}\text { Mezcla Q3 } \\
\quad \text { y Q9 }\end{array}$ & & 0.83 & 3.94 & 27.96 & 33.69 & 3.0 & 2.7 & $\begin{array}{l}1962 \\
\text { Bajo }\end{array}$ & $\begin{array}{c}25 \\
\text { Bajo }\end{array}$ \\
\hline Q5 & $\begin{array}{l}\text { Mezcla Q3 } \\
\text { y Q9 }\end{array}$ & & 1.04 & 5.42 & 32.47 & 31.22 & 2.5 & 2.3 & $\begin{array}{l}1687 \\
\text { Bajo }\end{array}$ & $\begin{array}{c}28 \\
\text { Bajo }\end{array}$ \\
\hline Q6 & Cuarzo & & 1.13 & 5.76 & 18.80 & 16.64 & 2.7 & 1.8 & $\begin{array}{l}3370 \\
\text { Bajo }\end{array}$ & $\begin{array}{c}43 \\
\text { Bajo }\end{array}$ \\
\hline Q7 & $\begin{array}{l}\text { Mezcla Q3 } \\
\quad \text { y Q9 }\end{array}$ & & 1.61 & 9.83 & 37.37 & 23.21 & 1.7 & 1.8 & $\begin{array}{c}5174 \\
\text { Moderado }\end{array}$ & $\begin{array}{c}40 \\
\text { Bajo }\end{array}$ \\
\hline Q8 & \multirow{4}{*}{ Cuarzo } & & 2.77 & 10.03 & 24.45 & 8.83 & 1.8 & 1.6 & $\begin{array}{c}4053 \\
\text { Moderado }\end{array}$ & $\begin{array}{c}42 \\
\text { Bajo }\end{array}$ \\
\hline Q9 & & & 1.44 & 12.13 & 37.03 & 25.66 & 1.4 & 1.6 & $\begin{array}{c}8045 \\
\text { Moderado }\end{array}$ & $\begin{array}{c}130 \\
\text { Moderado }\end{array}$ \\
\hline Q10 & & & 2.01 & 17.17 & 51.99 & 25.82 & 0.9 & 1.6 & $\begin{array}{c}6873 \\
\text { Moderado }\end{array}$ & $\begin{array}{c}53 \\
\text { Bajo }\end{array}$ \\
\hline Q11 & & & 2.24 & 20.52 & 64.96 & 28.95 & 0.8 & 1.5 & $\begin{array}{c}9396 \\
\text { Moderado }\end{array}$ & $\begin{array}{c}132 \\
\text { Moderado }\end{array}$ \\
\hline
\end{tabular}




\begin{tabular}{|c|c|c|c|c|c|c|c|c|c|c|}
\hline \multirow[t]{2}{*}{ Referencia } & \multirow[t]{2}{*}{ Muestra } & \multirow{2}{*}{$\begin{array}{c}\text { Humedad } \\
(\%)\end{array}$} & \multicolumn{4}{|c|}{$\begin{array}{r}\text { DTP } \\
d_{i}(\text { um) }\end{array}$} & \multirow{2}{*}{$\begin{array}{l}\text { Superficie específica } \\
\qquad\left(\mathrm{m}^{2} / \mathrm{g}\right)\end{array}$} & \multirow{2}{*}{$\begin{array}{l}\text { Índice de Hausner } \\
\text { (HR) }\end{array}$} & \multicolumn{2}{|c|}{$\begin{array}{c}\text { Fracción másica de polvo (mg/kg) } \\
\text { Clasificación EN } 15051\end{array}$} \\
\hline & & & $d_{10}$ & $d_{50}$ & $d_{90}$ & d90//d10 & & & Inhalable $\left(w_{1}\right)$ & Respirable $\left(W_{R}\right)$ \\
\hline Q12 & \multirow{3}{*}{ Cuarzo } & & 2.54 & 26.47 & 94.24 & 37.04 & 0.7 & 1.5 & $\begin{array}{c}10080 \\
\text { Moderado }\end{array}$ & $\begin{array}{c}119 \\
\text { Moderado }\end{array}$ \\
\hline Q13 & & & 3.38 & 31.29 & 109.09 & 32.28 & 0.6 & 1.5 & $\begin{array}{c}12500 \\
\text { Moderado }\end{array}$ & $\begin{array}{c}87 \\
\text { Moderado } \\
\end{array}$ \\
\hline Q14 & & & 8.56 & 35.00 & 113.00 & 13.20 & 0.6 & 1.5 & $\begin{array}{c}10417 \\
\text { Moderado }\end{array}$ & $\begin{array}{c}70 \\
\text { Bajo-Moderado }\end{array}$ \\
\hline Q15 & \multirow{3}{*}{$\begin{array}{c}\text { Obtenida } \\
\text { por } \\
\text { tamizado } \\
\text { vía } \\
\text { húmeda de } \\
\text { Q13 }\end{array}$} & & 42.60 & 58.18 & 80.69 & 1.89 & 0.1 & 1.3 & $\begin{array}{l}3542 \\
\text { Bajo }\end{array}$ & $\begin{array}{c}<\mathrm{LL} \\
\text { Muy bajo }\end{array}$ \\
\hline Q16 & & & 52.51 & 75.36 & 107.96 & 2.06 & 0.1 & 1.5 & $\begin{array}{c}725 \\
\text { Muy bajo } \\
\end{array}$ & $\begin{array}{c}<D L \\
\text { Muy bajo }\end{array}$ \\
\hline Q17 & & & 73.94 & 107.56 & 157.40 & 2.13 & 0.1 & 1.2 & $\begin{array}{c}473 \\
\text { Muy bajo }\end{array}$ & $\begin{array}{c}4 \\
\text { Muy bajo }\end{array}$ \\
\hline Q18 & Cuarzo & & 157.00 & 294.00 & 294.00 & 1.87 & 0.2 & 1.1 & $\begin{array}{l}1471 \\
\text { Bajo }\end{array}$ & $\begin{array}{c}18 \\
\text { Muy bajo }\end{array}$ \\
\hline
\end{tabular}




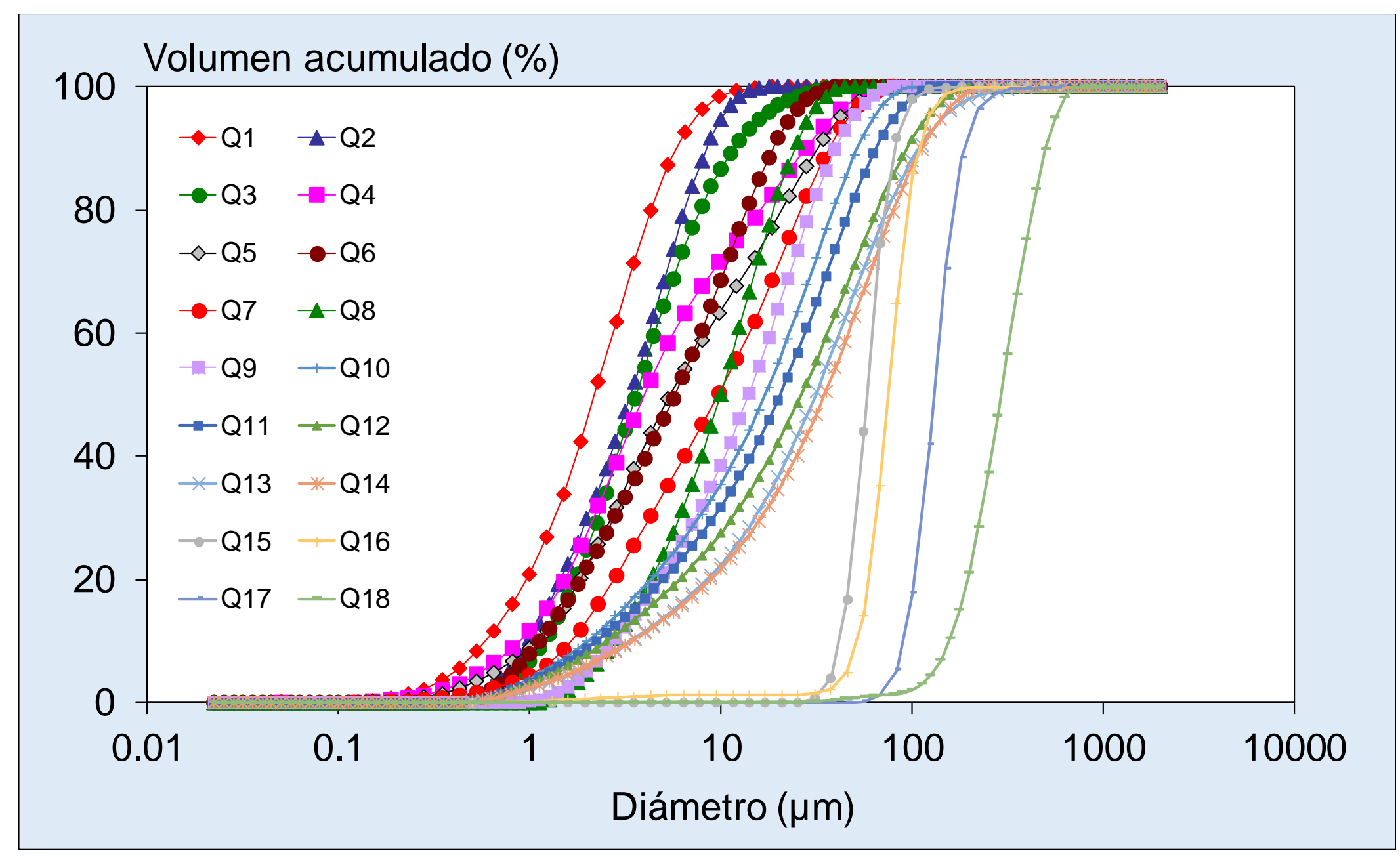

Figura 8.2 DTP de las muestras de cuarzo 
Tabla 8.4 Caracterización física de las muestras de silicato de circonio (Z), Alúmina (A), feldespatos y feldespatoides (F), arenas feldespáticas (S) y carbonatos (C)

\begin{tabular}{|c|c|c|c|c|c|c|c|c|c|c|}
\hline \multirow{2}{*}{ Referencia } & \multirow{2}{*}{ Muestra } & \multirow{2}{*}{$\begin{array}{l}\text { Humedad } \\
(\%)\end{array}$} & \multicolumn{4}{|c|}{ DTP } & \multirow{2}{*}{$\begin{array}{l}\text { Superficie } \\
\text { especifica } \\
\left(\mathrm{m}^{2} / \mathrm{g}\right)\end{array}$} & \multirow{2}{*}{$\begin{array}{l}\text { Índice de } \\
\text { Hausner } \\
\text { (HR) }\end{array}$} & \multicolumn{2}{|c|}{$\begin{array}{c}\text { Fracción másica de polvo (mg/kg) } \\
\text { Clasificación EN } 15051\end{array}$} \\
\hline & & & $d_{10}$ & $d_{50}$ & d90 & $\mathbf{d}_{90} / \mathbf{d}_{10}$ & & & Inhalable ( $\left.w_{1}\right)$ & Respirable (WR) \\
\hline Z1 & Silicato de Circonio & \multirow{10}{*}{$<0.5 \%$} & 0.47 & 1.60 & 3.99 & 8.45 & 4.5 & 2.6 & $\begin{array}{l}1847 \\
\text { Bajo }\end{array}$ & $\begin{array}{c}18 \\
\text { Muy bajo }\end{array}$ \\
\hline A1 & Alúmina & & 1.65 & 10.14 & 23.96 & 14.52 & 4.9 & 1.8 & $\begin{array}{l}2357 \\
\text { Bajo }\end{array}$ & $\begin{array}{c}<D L \\
\text { Muy bajo }\end{array}$ \\
\hline $\mathbf{F} 1$ & Nefelina & & 2.08 & 10.90 & 31.80 & 15.29 & 1.6 & 1.8 & $\begin{array}{l}3892 \\
\text { Bajo }\end{array}$ & $\begin{array}{c}30 \\
\text { Bajo }\end{array}$ \\
\hline C1 & Calcita & & 3.62 & 11.30 & 24.9 & 6.88 & 1.6 & 1.6 & $\begin{array}{c}8187 \\
\text { Moderado }\end{array}$ & $\begin{array}{c}48 \\
\text { Bajo }\end{array}$ \\
\hline F2 & Feldespato sódico & & 1.90 & 13.47 & 37.43 & 19.70 & 1.1 & 1.6 & $\begin{array}{c}6122 \\
\text { Moderado }\end{array}$ & $\begin{array}{c}76 \\
\text { Moderado }\end{array}$ \\
\hline $\mathbf{Z 2}$ & Silicato de Circonio & & 2.24 & 15.70 & 58.39 & 26.08 & 1.1 & 1.5 & $\begin{array}{c}12160 \\
\text { Moderado }\end{array}$ & $\begin{array}{c}121 \\
\text { Moderado }\end{array}$ \\
\hline C2 & Dolomita & & 4.80 & 22.00 & 50.50 & 10.52 & 1.1 & 1.5 & $\begin{array}{c}15181 \\
\text { Alto }\end{array}$ & $\begin{array}{c}71 \\
\text { Moderado }\end{array}$ \\
\hline F3 & Feldespato potásico & & 2.36 & 27.98 & 91.34 & 38.70 & 1.1 & 1.4 & $\begin{array}{c}31900 \\
\text { Alto }\end{array}$ & $\begin{array}{l}369 \\
\text { Alto }\end{array}$ \\
\hline S1 & Arena feldespática & & 5.62 & 39.08 & 109.9 & 19.56 & 0.9 & 1.5 & $\begin{array}{c}9942 \\
\text { Moderado }\end{array}$ & $\begin{array}{c}71 \\
\text { Moderado }\end{array}$ \\
\hline S2 & Arena feldespática & & 32.50 & 83.6 & 183.0 & 5.60 & 0.5 & 1.3 & $\begin{array}{c}26192 \\
\text { Alto }\end{array}$ & $\begin{array}{c}60 \\
\text { Bajo }\end{array}$ \\
\hline
\end{tabular}




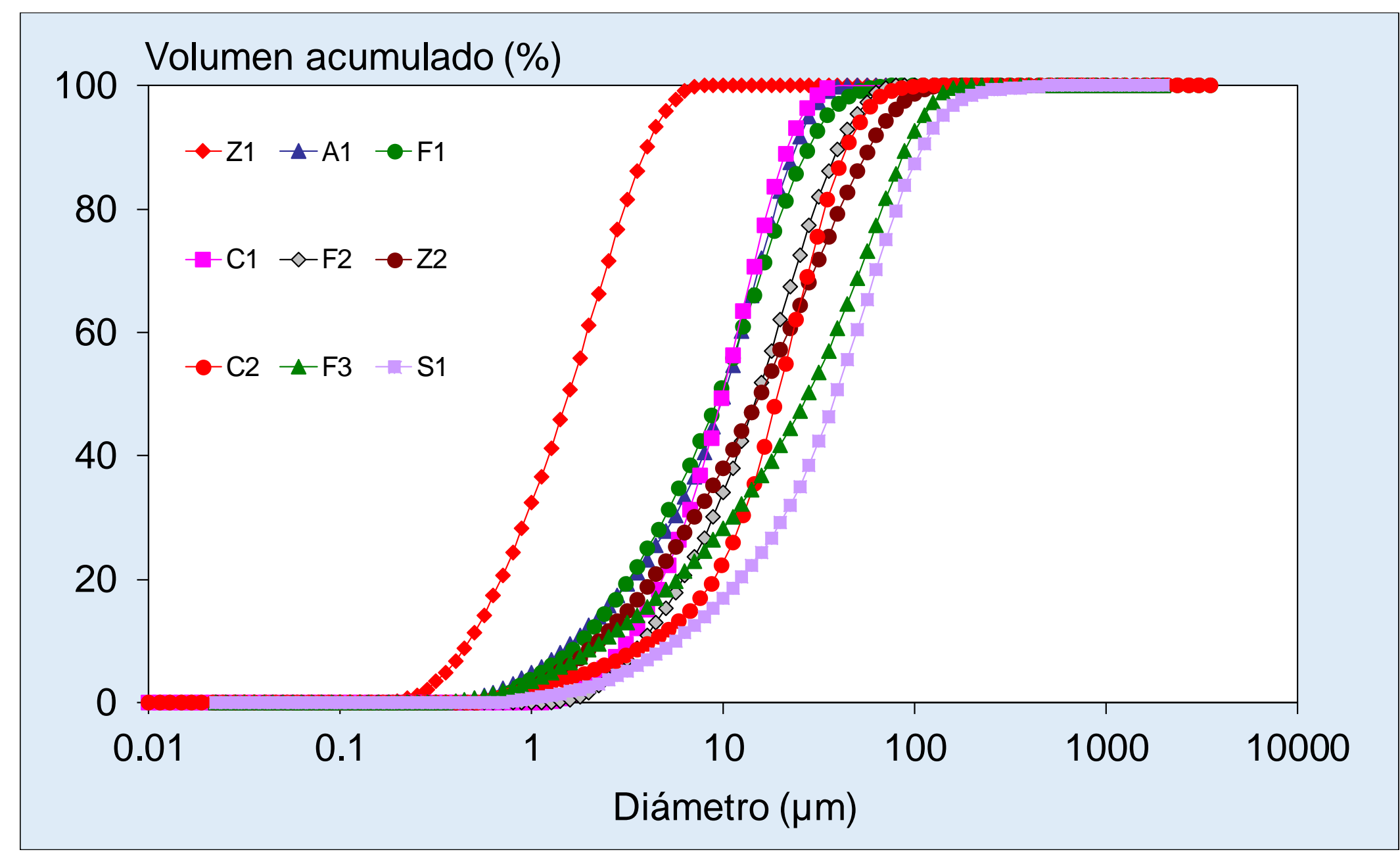

Figura 8.3 DTP de las muestras de silicato de circonio (Z), Alúmina (A), feldespatos y feldespatoides (F), arenas feldespáticas (S) y carbonatos (C) 
Tabla 8.5 Caracterización física de las muestras de las arcillas rojas: Arcilla Moro (AM) y arcilla Villar (AV)

\begin{tabular}{|c|c|c|c|c|c|c|c|c|c|c|}
\hline \multirow{3}{*}{ Referencia } & \multirow{3}{*}{ Muestra } & \multirow{3}{*}{$\begin{array}{l}\text { Humedad } \\
(\%)\end{array}$} & \multicolumn{4}{|c|}{ DTP } & \multirow{3}{*}{$\begin{array}{l}\text { Superficie especifica } \\
\qquad\left(\mathrm{m}^{2} / \mathrm{g}\right)\end{array}$} & \multirow{3}{*}{$\begin{array}{l}\text { Índice de Hausner } \\
\text { (HR) }\end{array}$} & \multirow{2}{*}{\multicolumn{2}{|c|}{$\begin{array}{l}\text { Fracción másica de polvo (mg/kg) } \\
\text { Clasificación EN } 15051\end{array}$}} \\
\hline & & & \multicolumn{3}{|c|}{$d_{i}(\mu m)$} & \multirow{2}{*}{$\mathbf{d}_{90} / \mathbf{d}_{10}$} & & & & \\
\hline & & & $d_{10}$ & $d_{50}$ & $d_{90}$ & & & & Inhalable ( $\left.w_{1}\right)$ & Respirable ( $\left.W_{R}\right)$ \\
\hline AM1 & $\begin{array}{c}\text { Arcilla Moro } \\
\text { (molturada en } \\
\text { molino pendular) }\end{array}$ & 0.1 & & & & & & 1.6 & $\begin{array}{c}19185 \\
\text { Alto }\end{array}$ & $\begin{array}{c}194 \\
\text { Moderado }\end{array}$ \\
\hline AM2 & & 1.8 & & & & & & 1.7 & $\begin{array}{c}11986 \\
\text { Moderado }\end{array}$ & $\begin{array}{c}107 \\
\text { Moderado }\end{array}$ \\
\hline AM3 & & 2.4 & & & & & & 1.7 & $\begin{array}{c}13667 \\
\text { Moderado }\end{array}$ & $\begin{array}{c}147 \\
\text { Moderado }\end{array}$ \\
\hline AM4 & & 4.5 & 0.92 & 4.89 & 14.52 & 15.78 & 13.7 & 1.9 & $\begin{array}{c}11635 \\
\text { Moderado }\end{array}$ & $\begin{array}{c}80 \\
\text { Moderado }\end{array}$ \\
\hline AM5 & $\begin{array}{c}\text { Obtenida por } \\
\text { humectación de } \\
\text { AM1 }\end{array}$ & 5.5 & & & & & & 1.7 & $\begin{array}{c}15040 \\
\text { Moderado-Alto } \\
\end{array}$ & $\begin{array}{c}97 \\
\text { Moderado } \\
\end{array}$ \\
\hline AM6 & & 6.5 & & & & & & 1.6 & $\begin{array}{c}16258 \\
\text { Alto }\end{array}$ & $\begin{array}{c}87 \\
\text { Moderado } \\
\end{array}$ \\
\hline AM7 & & 7.4 & & & & & & 1.6 & $\begin{array}{c}10060 \\
\text { Moderado }\end{array}$ & $\begin{array}{c}41 \\
\text { Bajo }\end{array}$ \\
\hline AM8 & & 8.5 & & & & & & 1.8 & $\begin{array}{c}4266 \\
\text { Moderado }\end{array}$ & $\begin{array}{c}3 \\
\text { Muy bajo }\end{array}$ \\
\hline
\end{tabular}




\begin{tabular}{|c|c|c|c|c|c|c|c|c|c|c|}
\hline \multirow{3}{*}{ Referencia } & \multirow{3}{*}{ Muestra } & \multirow{3}{*}{$\begin{array}{l}\text { Humedad } \\
(\%)\end{array}$} & \multicolumn{4}{|c|}{ DTP } & \multirow{3}{*}{$\begin{array}{l}\text { Superficie específica } \\
\qquad\left(\mathrm{m}^{2} / \mathrm{g}\right)\end{array}$} & \multirow{3}{*}{$\begin{array}{l}\text { Índice de Hausner } \\
\text { (HR) }\end{array}$} & \multirow{2}{*}{\multicolumn{2}{|c|}{$\begin{array}{c}\text { Fracción másica de polvo (mg/kg) } \\
\text { Clasificación EN } 15051\end{array}$}} \\
\hline & & & \multicolumn{3}{|c|}{$d_{i}(\mu m)$} & \multirow{2}{*}{$\mathbf{d}_{90} / \mathbf{d}_{10}$} & & & & \\
\hline & & & $d_{10}$ & $d_{50}$ & $d_{90}$ & & & & Inhalable ( $\left.w_{1}\right)$ & Respirable (WR) \\
\hline AV1 & $\begin{array}{c}\text { Arcilla Villar } \\
\text { (molturada en } \\
\text { molino pendular) }\end{array}$ & 1.4 & & & & & & 1.4 & $\begin{array}{l}41433 \\
\text { Alto }\end{array}$ & $\begin{array}{l}445 \\
\text { Alto }\end{array}$ \\
\hline AV2 & & 3.0 & & & & & & 1.6 & $\begin{array}{l}34676 \\
\text { Alto }\end{array}$ & $\begin{array}{l}381 \\
\text { Alto }\end{array}$ \\
\hline AV3 & & 4.1 & & & & & & 1.6 & $\begin{array}{c}24352 \\
\text { Alto }\end{array}$ & $\begin{array}{l}353 \\
\text { Alto }\end{array}$ \\
\hline AV4 & & 4.9 & 1.04 & 5.80 & 19.19 & 18.45 & 33.0 & 1.6 & $\begin{array}{c}29471 \\
\text { Alto }\end{array}$ & $\begin{array}{l}508 \\
\text { Alto }\end{array}$ \\
\hline AV5 & $\begin{array}{c}\text { Obtenida por } \\
\text { humectación de } \\
\text { AV1 }\end{array}$ & 6.4 & & & & & & 1.6 & $\begin{array}{c}17766 \\
\text { Alto }\end{array}$ & $\begin{array}{c}164 \\
\text { Moderado }\end{array}$ \\
\hline AV6 & & 7.6 & & & & & & 1.6 & $\begin{array}{c}27780 \\
\text { Alto }\end{array}$ & $\begin{array}{c}196 \\
\text { Moderado }\end{array}$ \\
\hline AV7 & & 9.0 & & & & & & 1.6 & $\begin{array}{c}15147 \\
\text { Moderado-Alto }\end{array}$ & $\begin{array}{c}19 \\
\text { Muy bajo }\end{array}$ \\
\hline AV8 & & 9.6 & & & & & & 1.7 & $\begin{array}{c}5506 \\
\text { Moderado }\end{array}$ & $\begin{array}{c}17 \\
\text { Muy bajo }\end{array}$ \\
\hline
\end{tabular}




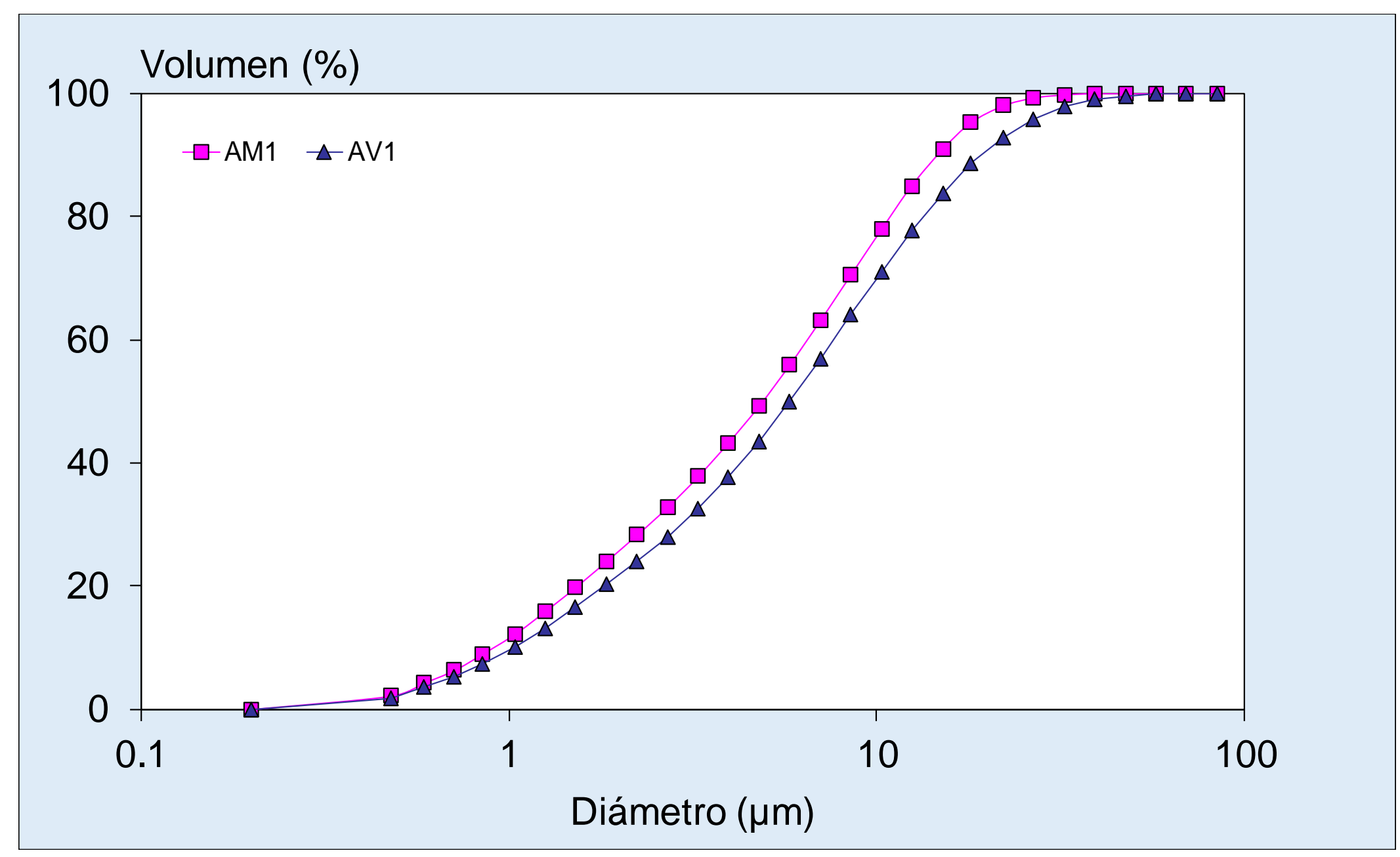

Figura 8.4 DTP de las muestras de las arcillas rojas: Arcilla Moro (AM) y arcilla Villar (AV) 
Tabla 8.6 Caracterización física de las muestras de la arcilla blanca: Arcilla Ucrania (AU)

\begin{tabular}{|c|c|c|c|c|c|c|c|c|c|c|}
\hline \multirow[t]{2}{*}{ Referencia } & \multirow[t]{2}{*}{ Muestra } & \multirow{2}{*}{$\begin{array}{l}\text { Humedad } \\
\qquad \%)\end{array}$} & \multicolumn{4}{|c|}{ DTP } & \multirow{2}{*}{$\begin{array}{l}\text { Superficie específica } \\
\qquad\left(\mathrm{m}^{2} / \mathrm{g}\right)\end{array}$} & \multirow{2}{*}{$\begin{array}{l}\text { Índice de Hausner } \\
\text { (HR) }\end{array}$} & \multicolumn{2}{|c|}{$\begin{array}{l}\text { Fracción másica de polvo (mg/kg) } \\
\text { Clasificación EN } 15051\end{array}$} \\
\hline & & & $d_{10}$ & $d_{50}$ & d9o & $\mathbf{d}_{90} / \mathbf{d}_{10}$ & & & Inhalable ( $\left.w_{1}\right)$ & Respirable ( $\left.W_{R}\right)$ \\
\hline AU1 & $\begin{array}{l}\text { Arcilla Ucrania } \\
\text { (molturada en } \\
\text { molino pendular) }\end{array}$ & 0.3 & \multirow{9}{*}{0.68} & \multirow{9}{*}{2.72} & \multirow{9}{*}{10.07} & \multirow{9}{*}{14.81} & \multirow{9}{*}{29.7} & 2.0 & $\begin{array}{c}30622 \\
\text { Alto }\end{array}$ & $\begin{array}{l}498 \\
\text { Alto }\end{array}$ \\
\hline AU2 & \multirow{8}{*}{$\begin{array}{c}\text { Obtenida por } \\
\text { humectación de } \\
\text { AM1 }\end{array}$} & 0.7 & & & & & & 2.0 & $\begin{array}{c}14995 \\
\text { Moderado-Alto }\end{array}$ & $\begin{array}{c}140 \\
\text { Moderado }\end{array}$ \\
\hline AU3 & & 1.8 & & & & & & 2.2 & $\begin{array}{c}14312 \\
\text { Moderado }\end{array}$ & $\begin{array}{c}127 \\
\text { Moderado }\end{array}$ \\
\hline AU4 & & 3.3 & & & & & & 2.2 & $\begin{array}{c}13832 \\
\text { Moderado }\end{array}$ & $\begin{array}{c}83 \\
\text { Moderado }\end{array}$ \\
\hline AU5 & & 4.7 & & & & & & 2.2 & $\begin{array}{c}15524 \\
\text { Alto }\end{array}$ & $\begin{array}{c}110 \\
\text { Moderado }\end{array}$ \\
\hline AU6 & & 6.1 & & & & & & 2.1 & $\begin{array}{c}14573 \\
\text { Moderado }\end{array}$ & $\begin{array}{c}94 \\
\text { Moderado }\end{array}$ \\
\hline AU7 & & 7.8 & & & & & & 1.8 & $\begin{array}{c}12978 \\
\text { Moderado }\end{array}$ & $\begin{array}{c}58 \\
\text { Bajo }\end{array}$ \\
\hline AU8 & & 9.4 & & & & & & 1.5 & $\begin{array}{c}11997 \\
\text { Moderado }\end{array}$ & $\begin{array}{c}53 \\
\text { Bajo }\end{array}$ \\
\hline AU9 & & 14.0 & & & & & & 1.4 & $\begin{array}{c}6918 \\
\text { Moderado }\end{array}$ & $\begin{array}{c}20 \\
\text { Bajo-Muy bajo }\end{array}$ \\
\hline
\end{tabular}




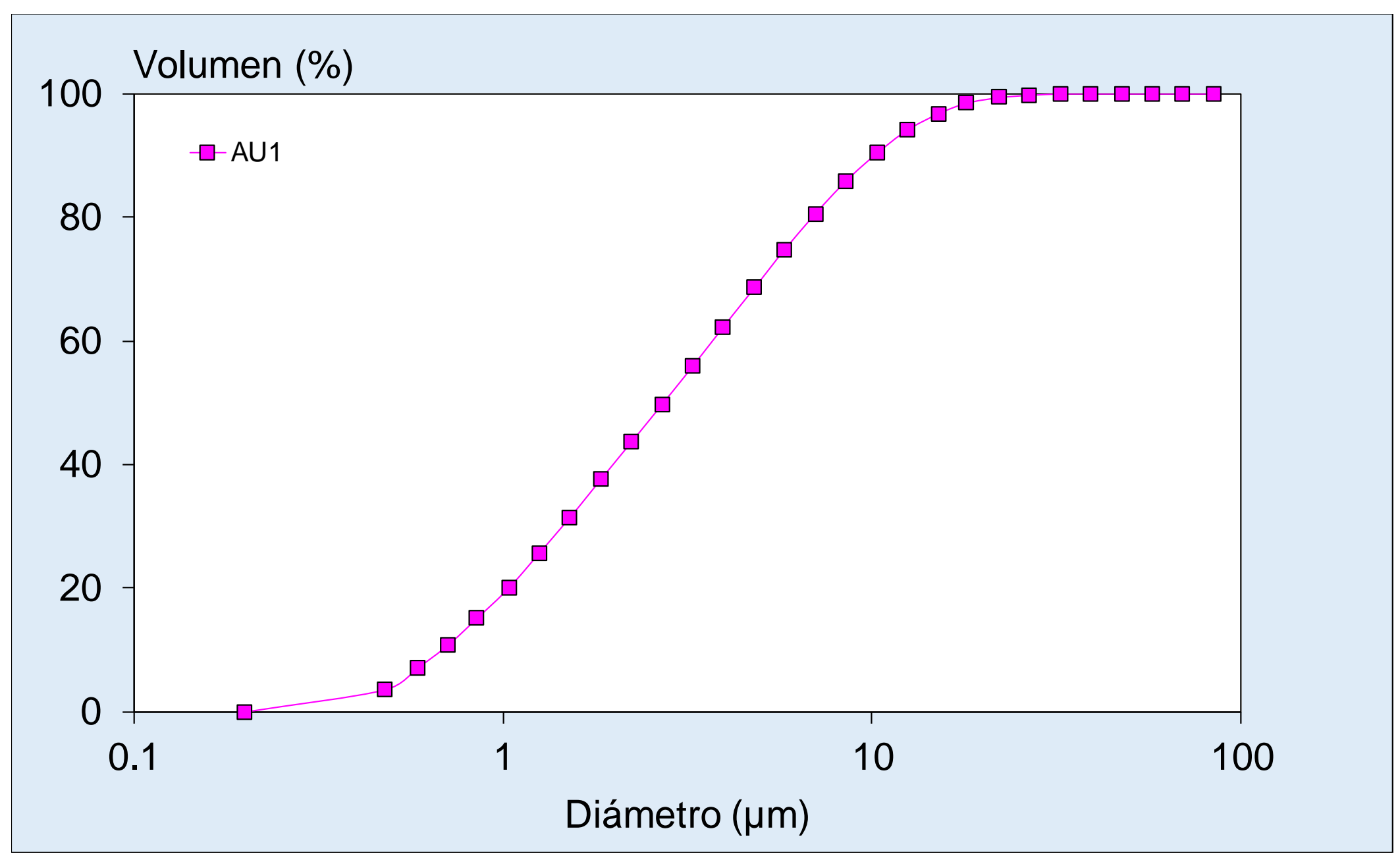

Figura 8.5 DTP de las muestras de la arcilla blanca: Arcilla Ucrania (AU) 
Tabla 8.7 Caracterización física de una composición de materias primas empleada para la fabricación de los soportes de las baldosas cerámicas durante las distintas etapas del proceso de acondicionado y preparación de las materias primas

\begin{tabular}{|c|c|c|c|c|c|c|}
\hline \multirow[t]{2}{*}{ Referencia } & \multirow[t]{2}{*}{ Muestra } & \multirow{2}{*}{$\begin{array}{l}\text { Humedad } \\
(\%)\end{array}$} & \multirow{2}{*}{$\begin{array}{c}\text { Distribución de tamaño } \\
\text { de aglomerado } \\
\text { (tamizado vía seca) }\end{array}$} & \multirow{2}{*}{$\begin{array}{c}\text { Índice de Hausner } \\
\text { (HR) }\end{array}$} & \multicolumn{2}{|c|}{$\begin{array}{c}\text { Fracción másica de polvo (mg/kg) } \\
\text { Clasificación EN } 15051\end{array}$} \\
\hline & & & & & Inhalable ( $\left.w_{1}\right)$ & Respirable ( $\left.W_{R}\right)$ \\
\hline $\mathbf{T}$ & $\begin{array}{c}\text { Muestra procedente de la etapa de } \\
\text { trituración }\end{array}$ & 3.0 & $d_{50}=1500 \mu \mathrm{m}$ & 1.2 a) & $\begin{array}{c}8342 \\
\text { Moderado }\end{array}$ & $\begin{array}{c}45 \\
\text { Bajo }\end{array}$ \\
\hline T125 & \multirow{2}{*}{ Obtenida por tamizado de $\mathrm{T}$} & 2.0 & $<125 \mu \mathrm{m}$ & 1.4 & $\begin{array}{c}12474 \\
\text { Moderado }\end{array}$ & $\begin{array}{c}52 \\
\text { Bajo }\end{array}$ \\
\hline $\mathrm{T} 125-500$ & & 3.0 & $125-500 \mu \mathrm{m}$ & 1.2 & $\begin{array}{c}18796 \\
\text { Alto }\end{array}$ & $\begin{array}{c}146 \\
\text { Moderado }\end{array}$ \\
\hline $\mathbf{M}$ & $\begin{array}{l}\text { Muestra procedente de la etapa de } \\
\text { molienda vía seca }\end{array}$ & 0.5 & $\mathrm{~d}_{50}=254 \mu \mathrm{m}$ & 1.2 & $\begin{array}{l}60300 \\
\text { Alto }\end{array}$ & $\begin{array}{l}882 \\
\text { Alto }\end{array}$ \\
\hline M125 & \multirow{2}{*}{ Obtenida por tamizado de M } & 0.5 & $<125 \mu \mathrm{m}$ & 1.3 & $\begin{array}{c}81769 \\
\text { Alto }\end{array}$ & $\begin{array}{l}1212 \\
\text { Alto }\end{array}$ \\
\hline M125-500 & & 1.0 & $125-500 \mu \mathrm{m}$ & 1.1 & $\begin{array}{c}7929 \\
\text { Moderado }\end{array}$ & $\begin{array}{c}78 \\
\text { Moderado }\end{array}$ \\
\hline $\mathbf{H}$ & Humectación de M & 6.5 & $d_{50}=214$ & 1.3 & $\begin{array}{c}9532 \\
\text { Moderado }\end{array}$ & $\begin{array}{c}14 \\
\text { Muy bajo }\end{array}$ \\
\hline H125 & Humectación de M125 & 6.5 & $<125 \mu \mathrm{m}$ & 1.5 & $\begin{array}{c}8270 \\
\text { Moderado }\end{array}$ & $\begin{array}{c}<\text { LD } \\
\text { Muy bajo }\end{array}$ \\
\hline $\mathrm{H} 125-500$ & Humectación de M125-500 & 6.5 & $125-500 \mu \mathrm{m}$ & 1.2 & $\begin{array}{l}945 \\
\text { Bajo }\end{array}$ & $\begin{array}{c}15 \\
\text { Muy bajo }\end{array}$ \\
\hline
\end{tabular}

a) El IH se ha determinado con la fracción inferior a $2 \mathrm{~mm}$ 


\begin{tabular}{|c|c|c|c|c|c|c|}
\hline \multirow[t]{2}{*}{ Referencia } & \multirow[t]{2}{*}{ Muestra } & \multirow{2}{*}{$\begin{array}{l}\text { Humedad } \\
(\%)\end{array}$} & \multirow{2}{*}{$\begin{array}{l}\text { Distribución de tamaño } \\
\text { de aglomerado } \\
\text { (tamizado vía seca) }\end{array}$} & \multirow{2}{*}{$\begin{array}{l}\text { Índice de Hausner } \\
\text { (HR) }\end{array}$} & \multicolumn{2}{|c|}{$\begin{array}{l}\text { Fracción másica de polvo (mg/kg) } \\
\text { Clasificación EN } 15051\end{array}$} \\
\hline & & & & & Inhalable $\left(w_{1}\right)$ & Respirable $\left(W_{R}\right)$ \\
\hline $\mathbf{A G}$ & $\begin{array}{l}\text { Muestra aglomerada procedente de la } \\
\text { etapa de granulación }\end{array}$ & 6.0 & $\mathrm{~d}_{50}=355 \mu \mathrm{m}$ & 1.2 & $\begin{array}{c}13612 \\
\text { Moderado }\end{array}$ & $\begin{array}{c}31 \\
\text { Bajo }\end{array}$ \\
\hline AG125 & \multirow{2}{*}{ Obtenida por tamizado de AG } & 4.0 & $<125 \mu \mathrm{m}$ & 1.4 & $\begin{array}{l}22611 \\
\text { Alto }\end{array}$ & $\begin{array}{l}29 \\
\text { Bajo }\end{array}$ \\
\hline AG125-500 & & 5.0 & $125-500 \mu \mathrm{m}$ & 1.1 & $\begin{array}{c}4459 \\
\text { Bajo-Moderado }\end{array}$ & $\begin{array}{c}22 \\
\text { Bajo }\end{array}$ \\
\hline AA & $\begin{array}{l}\text { Muestra aglomerada procedente de la } \\
\text { etapa de atomización }\end{array}$ & 6.0 & $d_{50}=268 \mu \mathrm{m}$ & 1.1 & $\begin{array}{c}950 \\
\text { Muy bajo }\end{array}$ & $\begin{array}{c}<\text { LD } \\
\text { Muy bajo }\end{array}$ \\
\hline AA125 & \multirow{2}{*}{ Obtenida por tamizado de AA } & 4.0 & $<125 \mu \mathrm{m}$ & 1.1 & $\begin{array}{c}6353 \\
\text { Moderado }\end{array}$ & $\begin{array}{c}<\text { LD } \\
\text { Muy bajo }\end{array}$ \\
\hline AA125-500 & & 5.0 & $125-500 \mu \mathrm{m}$ & 1.1 & $\begin{array}{c}353 \\
\text { Muy bajo }\end{array}$ & $\begin{array}{c}<L D \\
\text { Muy bajo }\end{array}$ \\
\hline
\end{tabular}




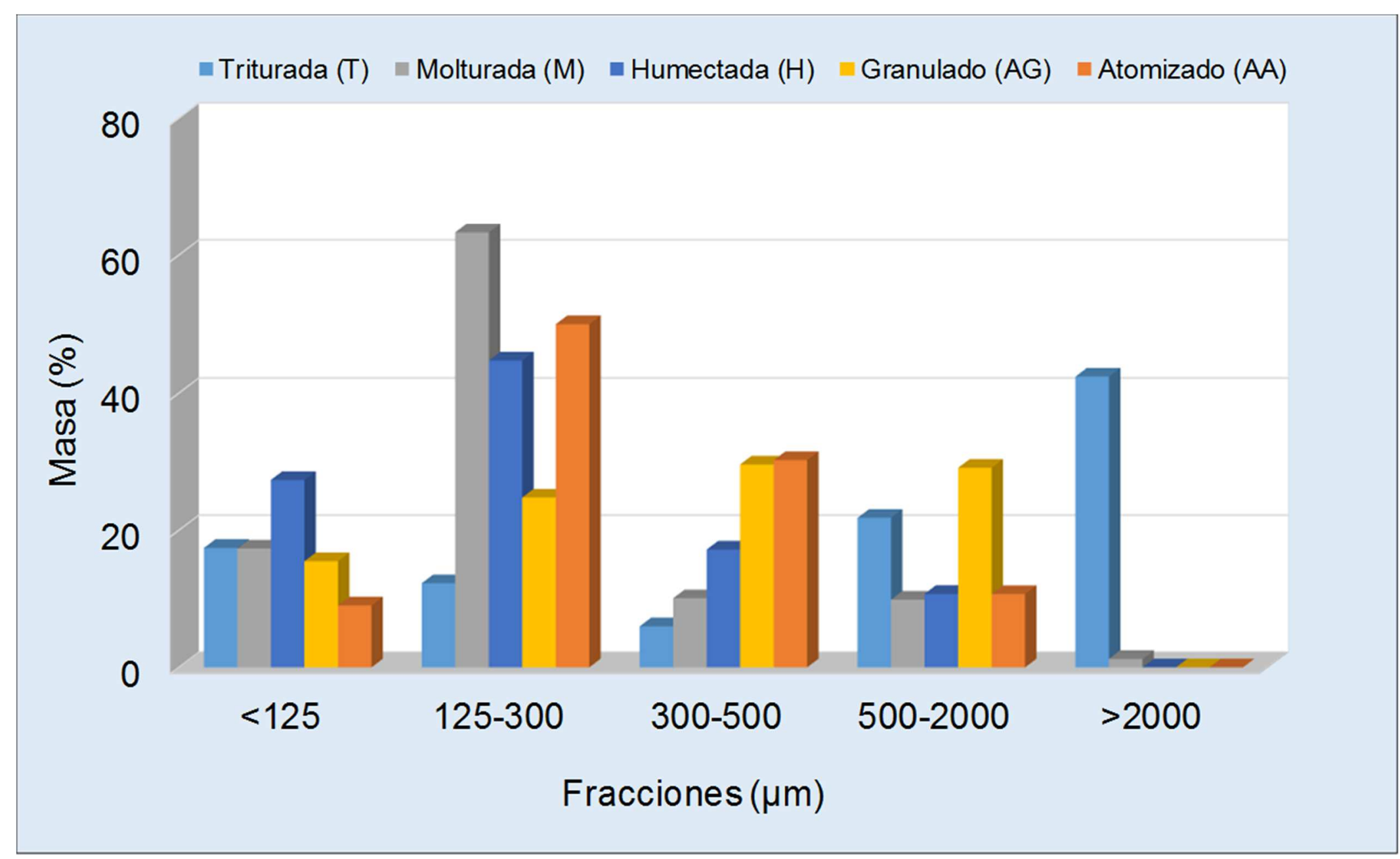

Figura 8.6 Distribución de tamaño de aglomerado de una composición de materias primas empleada para la fabricación de los soportes de las baldosas cerámicas durante las distintas etapas del proceso de acondicionado y preparación de las materias primas 


\section{ANEXO V: ACEPTACIÓN DE LOS COAUTORES}

Autorización de los coautores para que la doctoranda presente el trabajo como tesis y renuncia expresa de estos a presentarlo como parte de otra tesis doctoral. 

La doctoranda Ana López Lilao, dispone de la autorización de los coautores para presentar los artículos que se detallan a continuación. Asimismo, dichos coautores han manifestado su renuncia a poder utilizar dichos artículos como parte de otra tesis doctoral.

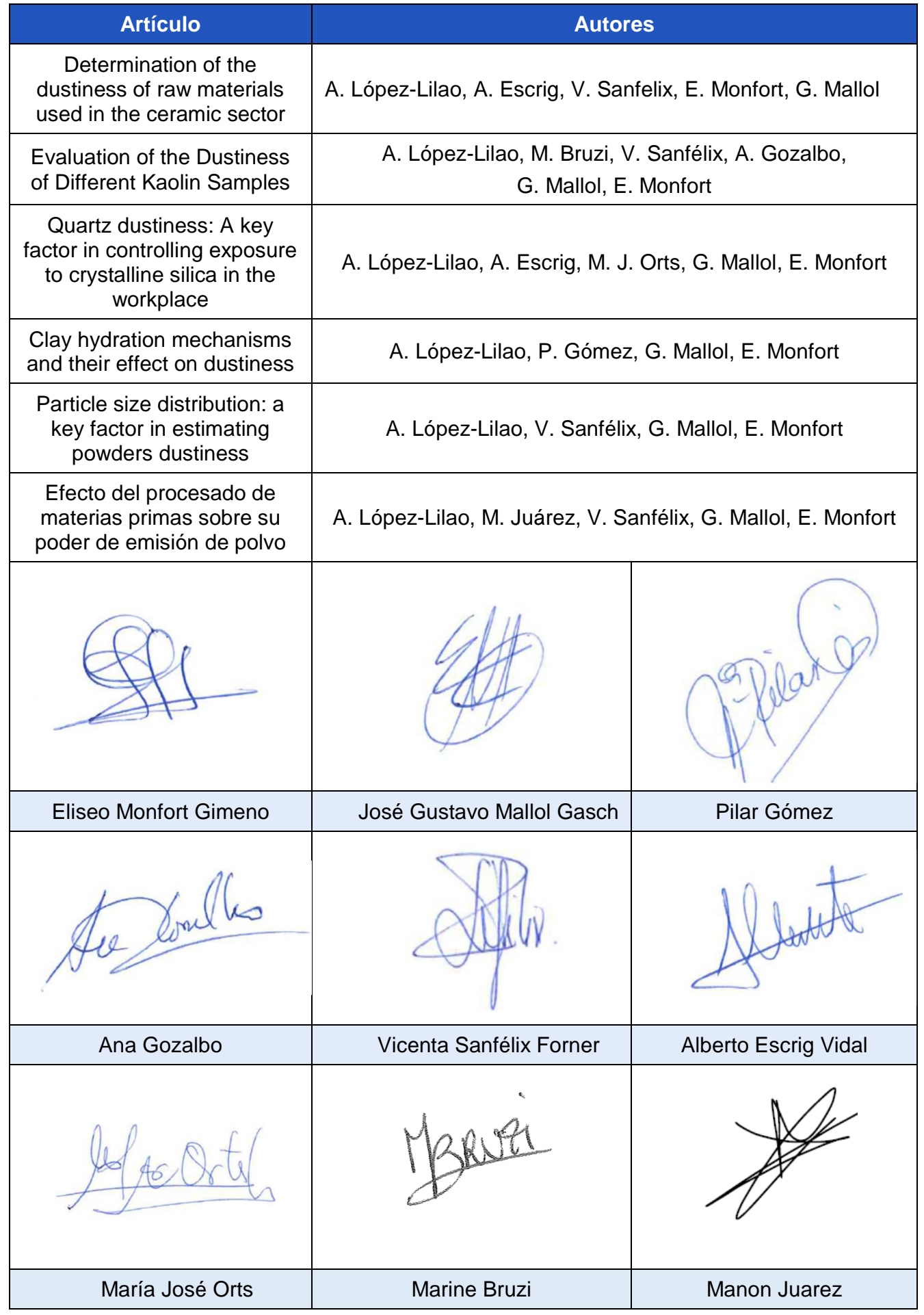



